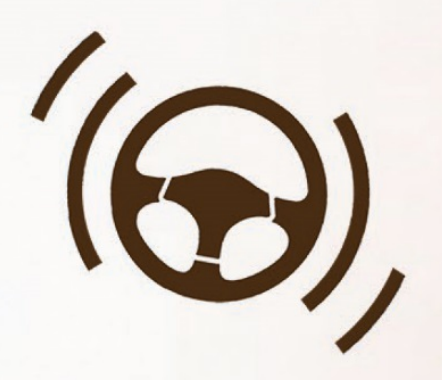

Driving automation interface design Supporting drivers' changing role

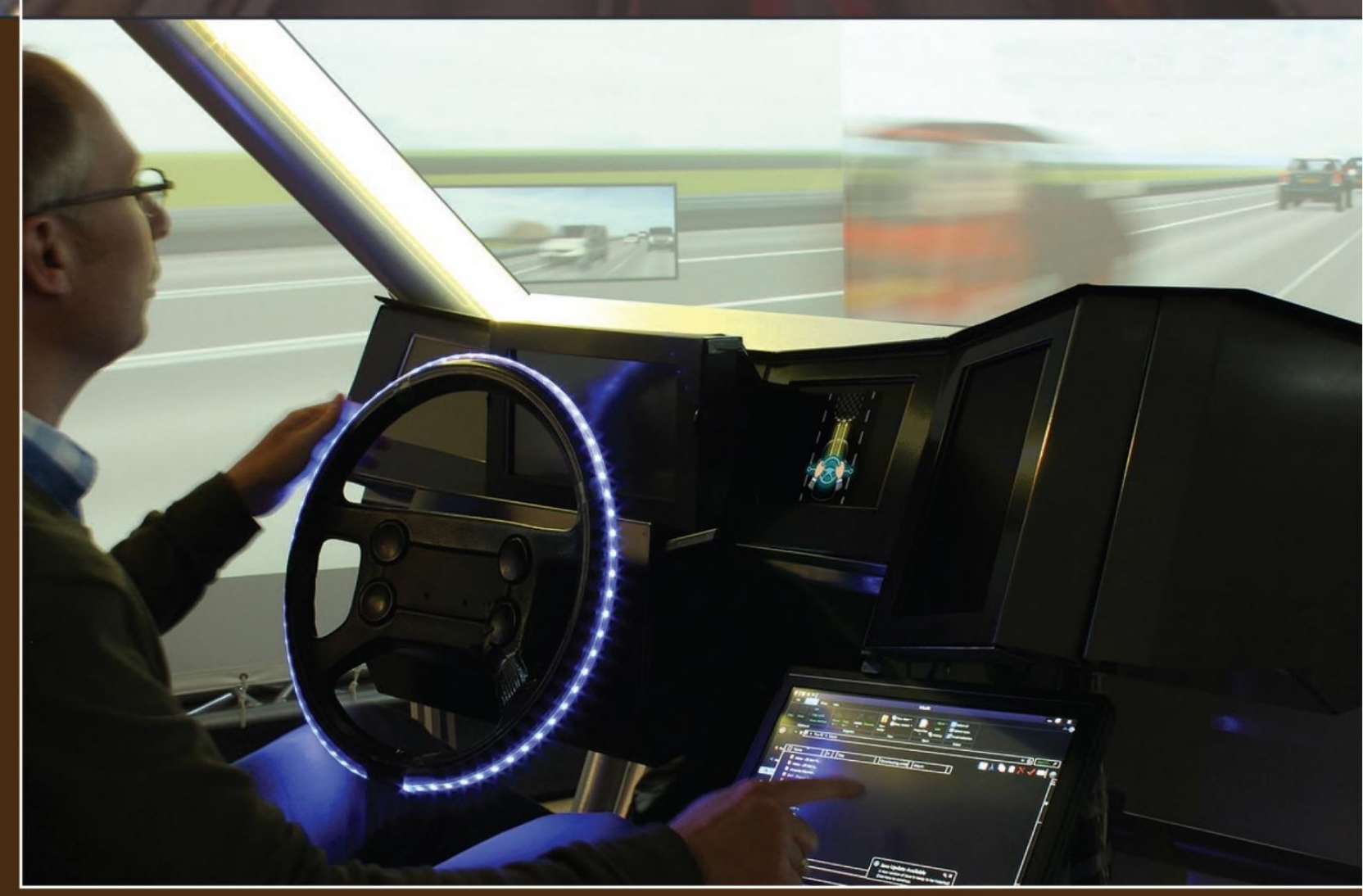

Arie Paul van den Beukel 


\title{
Driving automation interface design supporting drivers' changing role
}

\author{
PROEFSCHRIFT
}

ter verkrijging van

de graad van doctor aan de Universiteit Twente, op gezag van de rector magnificus,

prof. dr. H. Brinksma

volgens besluit van het College voor Promoties

in het openbaar te verdedigen

op donderdag 10 november 2016 om 14:45 uur

door

ARIE PAUL VAN DEN BEUKEL

geboren op 23 juni 1975

te Rotterdam 
Dit proefschrift is goedgekeurd door de promotoren:

prof.dr.ir. M.C. van der Voort

prof.dr.ir. A.O. Eger 


\title{
Driving automation interface design supporting drivers' changing role
}

\author{
Arie Paul van den Beukel
}

PhD Thesis

Faculty of Engineering Technology (CTW)

University of Twente, Enschede, the Netherlands.

Enschede, 10 ${ }^{\text {th }}$ November 2016 


\section{Dissertation Committee:}

Prof. dr. G.P.M.R Dewulf

Prof. dr. ir. M.C. van der Voort

Prof. dr. ir. A.O. Eger

Prof. dr. K. Bengler

Dr. S. Becker

Prof. dr. A.P. Morris

Prof. dr. M.H. Martens

Prof. dr. V. Evers
University of Twente (Chairman and Secretary)

University of Twente (Promotor)

University of Twente (Promotor)

Technical University Munich

Ford Motor Company

Loughborough University

University of Twente, TNO

University of Twente

This research was initiated and conducted at University of Twente. Support from Ford Motor Company by means of University Research Project (URP) funding is gratefully acknowledged.

ISBN 978-90-365-4239-5

doi 10.3990/1.9789036542395

Copyright (C) A.P. van den Beukel, 2016

Photo references: Page xxvi, Mobiliteits visie Utrecht. Photo publically released at https://beeldbank.rws.nl/. Page 10, adapted picture from Stadtpilot project TU Braunschweig. Original picture was publically released at www.tu-braunschweig.de/presse/medien on 8th October 2010. Page 156, photo retrieved from www.wordpress.com and edited by author.

All other images (C) author.

Cover design (C) by A.P. van den Beukel, 2016

Printed by Gildeprint, Enschede

All rights reserved. 


\section{Publications}

Beukel A.P. van den, Voort M.C. van der, Eger A.O. (2016). Supporting the changing driver's task: Exploration of interface designs for supervision and intervention in automated driving. Transportation Research Part F: Traffic Psychology and Behaviour. Published online: $28^{\text {th }}$ September 2016. DOI: 10.1016/j.trf.2016.09.009

Van den Beukel, A. P. \& Van der Voort, M. C. (2016). Drivers and automation - Does directional illumination support mode awareness and understanding of driver's role? IET Intelligent Transport Systems. [Paper conditionally accepted on $25^{\text {th }}$ September 2016.]

Beukel A.P. van den, Voort M.C. van der (2016). How to Assess Driver's Interaction with Partially Automated Driving Systems - a Framework for Early Concept Assessment. Applied Ergonomics (2017), pp. 302-312. Published online: 24th September 2016. DOI: 10.1016/j.apergo. 2016.09.005.

Beukel A.P. van den, Voort M.C. van der. (2016). Comparing driver's support for supervision and intervention during partially automated driving. In: Proceedings of the Fifth European Conference on Human Centred Design for Intelligent Transport Systems. HUMANIST, Loughborough, June 30 $30^{\text {th }}+$ July $1^{\text {st }}, 2016$.

Beukel A.P. van den, Voort M.C. van der. (2016). Driving Automation \& Changed Driving TaskEffect of Driver-interfaces on Intervention. In: 2016 IEEE International Conference on Intelligent Vehicles. IEEE, Gothenburg, $20^{\text {th }}-22^{\text {nd }}$ June 2016. pp. 1327-1332. ISBN 978-1-5090-1820-8.

Beukel A.P. van den, Voort M.C. van der, Eger A.O. (2015). Towards a Framework for Testing Drivers' Interaction with Partially Automated Driving. In: 2015 IEEE 18th International Conference on Intelligent Transportation Systems (ITSC). IEEE, Las Palmas, $15^{\text {th }}-18^{\text {th }}$ September 2015. pp. 1902-1907. ISBN 1467365955.

Beukel A.P. van den, Voort M.C. van der. (2014). Design Considerations on User-Interaction For Semi-Automated Driving. In: J. Wismans, Proceedings of the FISITA 2014 World Automotive Congress, Maastricht, $2^{\text {nd }}-6^{\text {th }}$ June 2014.

Beukel A.P. van den, Voort M.C. van der. (2014). Driver's Situation Awareness during Supervision of Automated Control - Comparison Between SART and SAGAT Measurement Techniques. In: R. Risser, Proceedings of the Fourth European Conference on Human Centred Design for Intelligent Transport Systems. HUMANIST, Vienna, $5^{\text {th }}-6^{\text {th }}$ June 2014. 
Beukel A.P. van den, Voort M.C. van der. (2013). Retrieving human control after situations of automated driving: How to measure Situation Awareness. In: G. Meyer, J. Fischer-Wolfarth (Eds.), Advanced Microsystems for Automotive Applications 2013, Springer-Verlag Berlin, pp. $43-53$.

Beukel A.P. van den, Voort M.C. van der. (2013).The Influence of Time-criticality on Situation Awareness when Retrieving Human Control after Automated Driving. In: Proceedings of the 16th International IEEE Annual Conference on Intelligent Transportation Systems (ITSC 2013), The Hague, pp. 2000-2005.

Martens, M., Beukel A.P. van den. (2013). The road to automated driving: dual mode and human factors considerations. In: Proceedings of the 16th International IEEE Annual Conference on Intelligent Transportation Systems (ITSC 2013), The Hague, pp. 2262-2267.

Beukel A.P. van den, Voort M.C. van der. (2012). Making automated driving support-Method for Driver-Vehicle task allocation. In: H. Reiterer, O. Deussen (Eds.), Workshopband Mensch \& Computer 2012. Oldenbourg-Verlag München, 2012, pp. 355-362.

Beukel A.P. van den. (2011). Mens vs. machine; wie rijdt er beter? Mogelijkheden én ergonomische uitdagingen van automatisch rijden. Tijdschrift voor Ergonomie, 2011, 3

Beukel A.P. van den, Voort M.C. van der. (2011). Human-centered challenges and contributions for the implementation of automated driving. In: G. Meyer, J. Valldorf (Eds.), Advanced Microsystems for Automotive Applications 2011. Springer-Verlag Berlin, 2011, pp. 225-235.

Beukel A.P. van den. (2011). Komt de automatische snelweg er nu wel? Product, 2011, 1.

Beukel A.P. van den, Voort M.C. van der. (2010). An assisted driver model - Towards developing driver assistance systems by allocating support dependent on driving situations. In: J. Krems, T. Petzold, M. Henning (Eds.), Proceedings of the Second European Conference on Human Centred Design for Intelligent Transport Systems. HUMANIST, Berlin, 2010, pp. 175-188.

Beukel A.P. van den, Voort M.C. van der. (2009). Evaluation of ADAS with a supported-driver model for desired allocation of tasks between human and technology performance. In: G. Meyer, J. Valldorf (Eds.), Advanced Microsystems for Automotive Applications 2009, SpringerVerlag Berlin, 2009, pp. 187-208. 


\section{About the author}

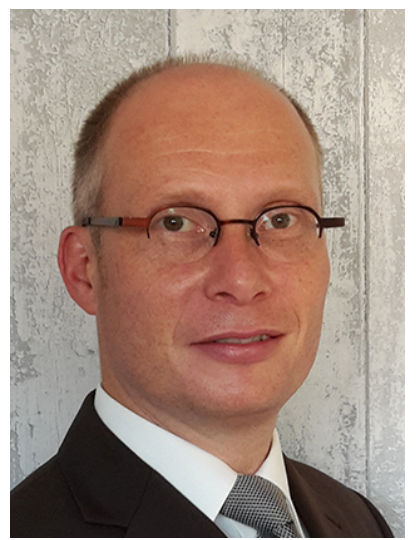

Arie Paul van den Beukel (1975) received his Master degrees in Industrial Design Engineering (IDE) and Technology Design (MTD) from Delft University of Technology. His IDE Master assignment considered the ergonomic design of a workbench for healthcare in hospitals. While developing a strong interest in human-centred aspects of product design, rousing interests in automotive design made his MTD assignment a perfect match: Developing interaction solutions for an in-vehicle infotainment system. The result was successfully demonstrated in a showcar at the international automotive exhibition IAA in Frankfurt. Then, Arie Paul continued his professional career at his internship's company: automotive supplier Johnson Controls where he was appointed Interaction Designer and later Senior Interaction Designer at the Design department. While cooperating in a broad range of HMI-projects for international customers, he contributed to the implementation of an HMI design discipline as part of the company's strategic product development plan. In 2005, Arie Paul continued his career at Ford Motor Company where he worked on a cross car-line HMI product strategy at Ford's European Electrical and Electronic Systems Engineering (EESE) department. His focus included driver's interaction with driving assistance systems. In this position, his curiosity about the influence of driver-vehicle interfaces on drivers' behavioural aspects and system performance grew. In 2008, Arie Paul received the opportunity to start at the University of Twente as Assistant Professor. Here, Arie Paul combines his interests in product design - and specifically automotive design - with research and education on human-centred product development. His research focusses on improving driver's interaction with assistance systems - especially systems concerning driving automation. As a university lecturer, Arie Paul supervises students' assignments, lectures Human Factors, coordinates courses and is responsible for the BSc final assignments in Industrial Design Engineering.

During his stay abroad Arie Paul met his wife. Together they have two children and live in Twente. 


\section{Abbreviations}

ACC

Adaptive Cruise Control

ADAS Advanced Driver Assistance Systems

AEB VRU Autonomous Emergency Braking (specifically for) Vulnerable Road Users

CA

Congestion Assistant (i.e. driving automation during congestion on motorways)

EU

European Commission

Euro NCAP European New Car Assessment Program

FCA Frontal Collision Warning

HMI Human-Machine Interface or Human-Machine Interaction

LDW $\quad$ Lane Departure Warning

LKA Lane Keeping Assist

NHTSA National Highway Traffic Safety Administration of the United States

OOTL Out-of-the-loop, i.e. human operator placed outside the control-loop

RSME Rating Scale Mental Effort

SA Situation or Situational Awareness

TJA Traffic Jam Assist (i.e. driving automation during congestion on motorways)

TTC Time-to-Collision

V21 Vehicle-to-Infrastructure communication (and vice versa)

V2V Vehicle-to-Vehicle communication 


\section{Summary}

Car manufacturers are introducing automated driving to enhance comfort. This is in line with the ongoing pursuit of effort-less operation of vehicles. This technology is also expected to increase road safety and road use efficiency, since automated cars will be more precise and faster in detecting relevant elements within the vehicle's surroundings. But despite technological advances, the driver remains ultimately responsible for the safe operation of the vehicle on public roads. This is because, along legal reasons, the reliability of the automation is (for now) restricted to boundary conditions, like for example detection of lane markings and gap distances.

An abundance of possible road-traffic circumstances influences whether boundary conditions are met, making it very challenging to take reliable driving control decisions. As a consequence, driving automation changes the driver's role from actively operating the vehicle to supervising the system with the occasional necessity to intervene. For instance, if the system reaches its limits, or if it is not able to detect relevant information, the driver is required to act and should retake control. Because intervention often occurs unexpectedly and requires fast responses, this task is difficult and causes a high workload.

Supervision is not something humans are particularly good at, due to low vigilance and behavioural adaptation. Therefore, the driver's changing role and responsibility to supervise automation is not merely a legal requirement, but for most a demanding task. This notion does not only mark an unfortunate irony of automation, it is also why carefully designed driverinterfaces are needed to support drivers. These driver-interfaces facilitate additional supervisory tasks and support the driver regaining control safely and adequately.

To help the development of such interfaces, this thesis has two objectives: (a) to design efficient means to evaluate potential improvements in driver support, and (b) to recommend interface-features that support drivers in performing their changing task.

\section{Assessment framework}

In order to design efficient means to evaluate potential improvements in driver support, an assessment framework is defined. This framework aims at assessing the following three aspects: (1) Situation Awareness (SA) to evaluate driver's cognitive understanding of how a system reacts to different situations, (2) Accident Avoidance (AA): evaluating operational capabilities for reacting fast and adequately to solve a critical situation, and (3) Concept Acceptance (CA): evaluating how drivers perceive new interface-features intended to support them in their changing role.

The framework is designed for application within a driving simulator. Because assessment of $S A, A A$ and $C A$ require relevant testing situations, driving scenarios representative for 
automated driving are inseparable from the framework. In line with the driver's changing demand to supervise the automation and occasionally intervene, these driving scenarios are divided in two categories: 'Hazardous' scenarios with a need for driver's attention (but without an immediate necessity for intervention), 'Critical' scenarios requiring driver's intervention in order to avoid an accident.

\section{Validation of the framework}

The framework and driving scenarios have been validated within a preliminary test using predefined interface-concepts. Analysis of driving performance and participants' mental effort per driving scenario show differences in the required scope, urgency and difficulty to execute the driving task. These differences confirm that the driving scenarios conceive of the two intended categories. It is therefore concluded that the driving scenarios are representative for supervision and intervention tasks as introduced by automated driving.

The predefined interface-concepts are purposely designed to offer different levels of support ranging from: (A) audible alerts only, (B) alerts including a textual instruction to the driver (e.g. words displaying "attention" or "take over"), to (C) alerts in combination with graphical explanation of automation mode. Conformity between the concepts' performance (i.e. results in $\mathrm{AA}$ and $\mathrm{SA}$ ) and their purposely designed differences in level of support, demonstrates the framework's validity to identify meaningful differences between potential interface-solutions.

Although the framework can't identify the most optimal support for the intervention-task, it succeeds in identifying inadequate interface-support. Along with the recommendation to use the framework's results for expert judgement, it is concluded that the framework shows predictive power to fast fail inadequate interface-support early in the design process. Therewith, the developed assessment framework provides an important contribution to an efficient development of adequate interface-solutions.

\section{Concepts}

With regard to this thesis' second objective (i.e. recommending interface-features that support drivers in performing their changing task), the assessment framework is used to evaluate a total of five potential interface concepts. Due to the demand for supervision and occasional intervention, all concepts are designed to provide signals of two kinds: (1) 'soft' warnings asking for attention, and (2) 'hard' warnings urging for intervention. Concepts A, B and C are introduced above. Concept $\mathrm{A}$ is intended as a reference and includes only audible soft and hard warnings. All other concepts include the same audible warnings with other added features. Concept $B$ enhances hard warnings by instructing the driver upon required intervention. Concept $C$ enhances soft warnings by graphically explaining why automation mode changes. $A$ fourth concept (D) enhances both soft and hard warnings by providing mode information in combination with instruction on the driver's role with depiction of an avatar-like icon. 
The graphical information of concepts $B, C$ and $D$ is presented inside the vehicle (behind the steering wheel). Because changes in automation mode dominantly originate from external road-traffic situations, supervision support that conveys information about the location of an event (outside the vehicle) and its criticality was expected to improve driver's attention. Therefore, a fifth (and advanced) concept is introduced: (E) 'Illumination'. During relevant situations this concept illuminates edges of the windscreen and side windows to help identify potentially dangerous or critical events. Through variation of location, length and colour of the illumination, concept E differentiates between soft- and hard-warnings and, more importantly, tries to steer the driver's notice to the location outside the vehicle that requires attention. Furthermore, the hard warning of this concept includes a vibro-tactile signal in the front end of the seat as a cue for intervention.

The concepts are tested in two series of driving simulator experiments and an intermediate internet-survey. The driving simulator experiments involved twenty-four participants for the first experiment and thirty-seven participants for the second experiment. The survey conducted in between the two simulator experiments received a hundred responses.

\section{Illumination vs. graphical information}

The 'Illumination' concept (E) is expected to support especially intervention. In contrast to concepts $C$ and $D$, this concept does not provide explanatory information. To assess whether drivers nonetheless understand the automation mode and why mode changes occur, concept E was tested in an internet-survey on Situation Awareness (SA). The survey presented driving scenarios and measured SA, in line with afore designed assessment framework. The results reveal that illumination in the windscreen raises driver's awareness of the automation mode and therewith contributes to support for supervision.

Within subsequent driving simulator tests, support for supervision and intervention is compared between the reference case (A), the graphical icon-based concept (D) and Illumination (E).

\section{Support for supervision}

Based on these extensive tests, this research shows that alerting for potentially hazardous traffic situations by means of illumination in the windscreen raises driver's SA compared to traditional icon-based (on-screen) interfaces. It shows that directing driver's alertness (i.e. conscious perception) outside the vehicle to the location where attention is needed provides better SA, despite the lack of explanatory (icon-based) information. A plausible and favourable explanation is that providing information where attention is needed, compensates for reduced information why attention is needed. Illumination in the windscreen also reveals to significantly improve detection of potentially hazardous traffic situations within the driver's peripheral field of view, compared to icon-based warning. 
Both outcomes with respect to directing driver's alertness and improved hazard-detection, confirm that there is in general a favourable relation between illumination and support for supervision. Moreover, Illumination shows to be favourable based on subjective rating of Concept Acceptance. Furthermore, illumination provides a relatively generic and regular means to guide attention. This is an especially important benefit, because the change in task for the driver is being dominated by a rather unremitting demand for supervision.

\section{Support for intervention}

With respect to support for intervention, neither the graphical interface concept (D) that includes instruction for action, nor the illumination concept (E), show significant improvements compared to the baseline concept (A). This is despite the fact that; (i) the illumination concept yields stronger stimuli (e.g. an additional vibro-tactile cue) intending to enhance intervention, and (ii) the illumination original intent is to be especially supportive in critical situations. Furthermore, the graphical interface-concept (D) with its combination of explanatory information and instruction performs worse than the baseline concept. Extensive review of possible explanations for these counter-productive effects, provide valuable recommendations for further development of interface-features that support the driver's intervention task. The recommendations are summarized as follows:

* Avoid explanatory-rich and graphically loaded features during critical situations because such contents causes distraction and reduces performance when intervention is needed.

* Use sensorial cues that users are familiar with. Because an unexpected stimulus may cause inappropriate levels of perceived urgency which then deteriorates intervention.

* Be careful with sensorial redundancy to avoid the combination of sensorial stimuli conveying mismatched levels of urgency.

* Provide cues that convey correctly perceivable information on task-allocation, because confusion between required human action and automation-activity deteriorates intervention.

\section{Overall findings}

With successful validation of the designed assessment framework, the first objective of this thesis, i.e. to design efficient means to evaluate potential improvements in driver support, has been achieved. The results of the five tested concepts show that the driver's supervision and intervention tasks benefit from different interface features. These findings underline the importance to apply testing of intermediate prototypes with the assessment framework and to identify unintended counterproductive effects on operator-performance when experimenting with multimodal interfaces. Although Illumination did not demonstrate additional support for intervention, it did not have the disadvantage of causing distraction either, as is the case with icon-based explanatory information. Illumination is therefore 
considered a generally recommended design direction for both support for supervision and intervention. Based on these conclusions also the second objective of this thesis, i.e. to recommend interface-features that support drivers in performing their changing task, has been achieved.

\section{Final conclusion}

Automated driving is intended to improve safety and raise comfort. Discussion in this thesis how the driver's changing role influences the practicality of these advantages reveals that further improvements in cooperation between driver and vehicle are urgently required. Chapter 9 of this thesis describes a few of these improvements.

Without these improvements the change in driver's role will reduce the advantages of automated driving. This leaves the benefits of driving automation to be deceptive. Despite expected future technological advances, driving automation of passenger vehicles within existing infrastructure will remain to demand a changing role for the driver. Moreover, cooperation between driver and vehicle remains imperative to safe and comfortable vehiclecontrol. Therefore, future studies should focus on improving this cooperation by means of improving driver vehicle interfaces.

This thesis addresses the persisting need to support the change in role of the driver from just driving to supervising and intervening. By doing so it delivers an important contribution to a more prevalent human-centred development of a future range of automated vehicles intended to take benefits from raised comfort and safety. 


\section{Samenvatting}

Automobielfabrikanten introduceren automatisch rijden als comfortfeature. Dit sluit aan bij de lange traditie om het gemak van autorijden te vergroten. Naar verwachting draagt automatisch rijden ook bij aan verhoging van verkeersdoorstroming en -veiligheid, doordat de technologie sneller en accurater reageert op het detecteren van relevante objecten. Ondanks de technologische vooruitgang behoudt de bestuurder echter de eindverantwoording voor veilig rijden op de openbare weg. Naast wettelijke aansprakelijkheid, is de reden hiervoor ook dat betrouwbare toepassing van automatisch rijden alleen mogelijk is binnen de grenzen van de beschikbare technologie. Voorbeelden hiervan zijn de herkenning van wegmarkering en het meten van volgafstanden.

De veelheid aan mogelijke verkeers- en wegsituaties beïnvloeden sterk of het systeem wel of niet binnen haar grenzen kan functioneren. Het is daardoor een grote uitdaging om verantwoording te nemen voor veilige besturing van het automatische voertuig. In feite verandert automatisch rijden de rol van de bestuurder van actieve voertuigbeheersing naar supervisie van het systeem met af en toe de noodzaak om in te grijpen. Als het systeem bijvoorbeeld niet meer in staat is om relevante informatie te detecteren, moet de bestuurder ingrijpen en als back-up optreden. Omdat interventie meestal onverwachts en plotseling nodig is, is deze taak moeilijk en belastend.

Supervisie is evenmin een gemakkelijke taak, doordat het moeilijk is om alert te blijven. De veranderende rol van de bestuurder, inclusief de verantwoordelijkheid voor supervisie van het automatisch rijdende voertuig, is dus niet alleen een wettelijke verplichting: het is vooral een veeleisende taak. Gezien de bedoeling om comfort te verhogen, kenmerkt dit niet alleen de ironie in toepassing van automatisch rijden, het is ook de reden waarom zorgvuldige ontwikkeling van nieuwe voertuiginterfaces nodig is. Dergelijke interfaces dienen de bestuurder te helpen bij de supervisie van het automatisch rijden en bij het veilig en bekwaam overnemen van de rijtaak, wanneer dit nodig is.

Om bij te dragen aan de ontwikkeling van dergelijke interfaces stelt deze thesis twee doelen: (a) het ontwikkelen van een efficiënte manier om potentiële interface-verbeteringen te evalueren, en (b) het doen van aanbevelingen ten aanzien van interface-eigenschappen die bestuurders ondersteunen in het uitvoeren van hun veranderende rijtaak.

\section{Beoordelingsaanpak}

Een specifieke aanpak is ontwikkeld om op efficiënte manier potentiële interfaceverbeteringen te evalueren. Met deze aanpak vindt evaluatie plaats op grond van de volgende drie beoordelingsaspecten: (1) Situation Awareness (SA) om het begrip van de bestuurder te beoordelen ten aanzien van hoe het systeem reageert op verschillende situaties. (2) Accident 
Avoidance (AA) om bekwaamheid te testen in het snel en correct oplossen van een kritische verkeerssituatie. (3) Concept Acceptance (CA) om bij bestuurders de acceptatie van nieuwe interface-eigenschappen te meten.

De aanpak is bedoeld voor evaluatie in een rijsimulator. Beoordeling van SA, AA en CA is alleen mogelijk binnen relevante testsituaties. Daarom zijn simulaties van verkeersscenario's die kenmerkend zijn voor automatisch rijden een integraal onderdeel van de aanpak. Parallel aan de twee nieuwe eisen voor de bestuurder (te weten supervisie van het automatisch rijden en ingrijpen indien nodig), zijn de verkeersscenario's verdeeld in twee categorieën: (i) Potentieel gevaarlijke situaties hebben aandacht van de bestuurder nodig (echter zonder dat er een directe noodzaak is om in te grijpen), (ii) kritische situaties vereisen een ingreep van de bestuurder om een ongeluk te vermijden.

\section{Validatie van de beoordelingsaanpak}

Met behulp van een pilottest is de beoordelingsaanpak, inclusief de gesimuleerde verkeersscenario's, gevalideerd. Analyse van rijprestaties en de benodigde mentale inspanning van deelnemers tonen per scenario verschillen aan in aard, urgentie en moeilijkheidsgraad van de desbetreffende rijtaak. Deze verschillen bevestigen dat de verkeersscenario's zijn onder te verdelen in de beoogde categorieën en daardoor representatief zijn voor de veranderende rijtaak (te weten supervisie van het systeem en ingrijpen indien nodig).

Tijdens de pilottest is gebruik gemaakt van drie concepten. Deze concepten zijn zodanig samengesteld dat ze ondersteuning bieden op niveaus die uiteenlopen van: (A) enkel auditieve waarschuwingen, (B) waarschuwingen inclusief instructiewoorden zoals "attentie" of "neem over", tot (C) waarschuwingen met relatief omvangrijke ondersteuning door grafische uitleg van systeemmodus. Trendverschillen in de behaalde testresultaten ten aanzien van het vermijden van een ongeval ( $A A$ ) en het begrip van de situatie (SA) komen overeen met de verschillen in beoogd ondersteuningsniveau van de concepten. Dit toont de kwaliteit van de beoordelingsaanpak aan om relevante verschillen tussen mogelijke interface-oplossingen te kunnen onderscheiden.

De aanpak is met name succesvol in het onderscheiden van inadequate ondersteuning. Daarentegen toont het voor de interventietaak weinig vermogen tot het onderscheiden van de meest optimale ondersteuning. Naast de aanbeveling dat experts de beoordelingsaanpak toepassen, toont deze aanpak ook de waarde om vroegtijdig inadequate ondersteuning te kunnen uitsluiten. Daarmee levert de beoordelingsaanpak een belangrijke bijdrage aan de eerste doelstelling, het ontwikkelen van een efficiënte manier om potentiële interfaceverbeteringen te evalueren. 


\section{Concepten}

Voor het doen van aanbevelingen voor interface-eigenschappen die bestuurders ondersteunen bij hun veranderende rijtaak (de tweede doelstelling) is de beoordelingsaanpak toegepast om in totaal vijf interface-concepten te beoordelen. Gebaseerd op de kenmerken van de veranderende rijtaak (vereiste supervisie en ingrijpen indien nodig) maken alle concepten gebruik van waarschuwingssignalen op twee niveaus: (1) 'softwarnings' vragen om aandacht van de bestuurder, en (2) 'hardwarnings' eisen dringende interventie. De concepten $A$, B en C zijn voorheen reeds geïntroduceerd. Concept $A$ is bedoeld als referentie en omvat alleen auditieve soft- en hardwarnings. De andere concepten bevatten signalen die zijn toegevoegd aan diezelfde auditieve signalen. Concept B versterkt de hardwarnings met instructiewoorden voor benodigde interventie. Concept $C$ ondersteunt softwarnings met grafische uitleg van veranderingen in systeemmodus. Het vierde concept ondersteunt soft- en hardwarnings door informatie over systemmodus te combineren met instructie voor de bestuurder. Daartoe geeft het een grafische weergave van een bestuurder-avatar.

De grafische informatie van concepten B, C en D wordt in het voertuig (achter het stuur) gepresenteerd en vereist daardoor aandacht binnen in de auto. Veranderingen in modus van het automatisch rijden vinden echter overwegend hun oorsprong buiten het voertuig, namelijk in de weg- of verkeerssituatie. Het vermoeden is daarom dat een interface die informatie overdraagt over de plaats waar buiten het voertuig relevante gebeurtenissen plaatsvinden, de gewenste aandacht van de bestuurder verhoogt. Er is daarom een vijfde concept ontwikkeld: (E) 'Illuminatie'. Tijdens relevante situaties verlicht dit concept randen van de voorruit en/of zijruiten. Door te variëren in lengte, plaats, intensiteit en kleur van de verlichting, maakt het onderscheid in soft- en hardwarnings. Bovendien stuurt het op deze manier de aandacht van de bestuurder naar de plek buiten de auto waar aandacht vereist is. Tevens worden de hardwarnings van dit concept versterkt door een tactiele stimulus: Op het moment dat interventie verlangd wordt, vibreert de voorzijde van de bestuurdersstoel. Dit is bedoeld als aansporing om in te grijpen.

De concepten zijn beoordeeld in drie tests: een rijsimulatortest, een tussentijdse videoenquête op internet en een tweede rijsimulatortest. Aan de eerste en tweede rijsimulatortest namen respectievelijk 24 en 37 mensen deel. 100 mensen namen deel aan de video-enquête.

\section{Illuminatie versus grafische informatie}

De verwachting is dat concept Illuminatie (E) vooral interventie ondersteunt. In tegenstelling tot de concepten $\mathrm{C}$ en $\mathrm{D}$ biedt dit concept echter geen expliciete weergave van systeemmodus. Om te onderzoeken of bestuurders desondanks met illuminatie begrijpen wat de modus is van de voertuigautomatisering en waarom veranderingen in systeemstatus optreden, is concept $E$ met behulp van de internet-enquête getest op Situation Awareness (SA). De uitkomsten tonen aan dat Illuminatie een correcte begrip van systeemstatus geeft. Illuminatie is zodoende een belangrijke ondersteuning voor supervisie. 
Vervolgens zijn in de tweede rijsimulatortest het referentieconcept (A), het grafische concept (D) en het illuminatie concept (E) getest op ondersteuning van supervisie en interventie.

\section{Ondersteuning van supervisie}

De tests tonen aan dat attenderen op mogelijk gevaarlijke situaties door middel van illuminatie in de voorruit de Situation Awareness van bestuurders vergroot in vergelijking met conventionele grafische interfaces. Ondanks dat expliciete weergave van systeemmodus ontbreekt, laat het zien dat sturing van de aandacht van de bestuurder naar de relevante plek buiten het voertuig het begrip van die situatie doet toenemen. Een plausibele verklaring hiervoor is dat het aanbieden van informatie waar aandacht vereist is, de gereduceerde informatie over waarom aandacht vereist is, compenseert. Tevens geeft illuminatie in de voorruit, in vergelijking met een conventionele icoon-gebaseerde waarschuwing (concept D), ook een significant betere detectie van potentieel gevaarlijke verkeerssituaties die in het perifere gezichtsveld van de bestuurder verschijnen.

De beide uitkomsten met betrekking tot het sturen van aandacht en de verbeterde detectie van potentieel gevaarlijke situaties, bevestigen dat illuminatie veelbelovend is als ondersteuning van de supervisie taak. Tevens toont de subjectieve beoordeling (Concept Acceptance) een duidelijke voorkeur van bestuurders voor Illuminatie. Bovendien biedt illuminatie een algemeen toepasbare en niet erg opdringerige manier om aandacht te sturen. Dit is ook een belangrijk voordeel omdat de veranderende rijtaak continue supervisie vraagt.

\section{Ondersteuning van interventie}

Voor ondersteuning van interventie toont noch het grafische interface concept (D), noch het illuminatie concept $(E)$, verbeteringen in vergelijking met het referentie concept $(A)$. Dit is ondanks dat: (i) concept $D$ instructie omvat van gewenste interventie, (ii) Illuminatie een sterkere stimulus bevat (namelijk de toegevoegde tactiele stimulus voor ingrijpen), en (iii) de oorspronkelijke bedoeling van illuminatie is om met name de interventie taak te ondersteunen. Uitgebreide analyse van de mogelijke oorzaken van deze onverwachte resultaten bieden echter veel inzicht voor de verdere ontwikkeling van interface-eigenschappen die de interventie taak dienen te ondersteunen. De aanbevelingen uit deze analyse zijn als volgt:

* Vermijd omvangrijke uitleg en het presenteren van veel grafische details tijdens kritische situaties, omdat dergelijke aspecten sterk afleiden en de prestaties van het ingrijpen doen verminderen.

* Gebruik signalen waarmee bestuurders vertrouwd zijn. Dit is belangrijk omdat onbekende signalen kunnen leiden tot onjuiste interpretatie van de urgentielevels. Dit verslechtert de interventie.

* Wees voorzichtig met redundant gebruik van meerdere sensorische kanalen voor het overbrengen van één en dezelfde waarschuwing. Door deze combinatie ontstaat namelijk gemakkelijk een te hoog en onjuist urgentielevel. 
* Gebruik signalen waarmee de taakverdeling tussen mens en machine correct wordt geïnterpreteerd. Dit is belangrijk omdat verwarring tussen vereiste actie van de bestuurder en systeemactiviteit de interventie verslechtert.

\section{Algemene conclusie}

Met de validatie van de beoordelingsaanpak is de eerste doelstelling van deze thesis behaald: het ontwikkelen van een efficiënte manier om potentiële interface-verbeteringen te evalueren. Testresultaten van de vijf concepten tonen aan dat bestuurders baat hebben bij verschillende ondersteuning voor supervisie enerzijds en interventie anderzijds. Deze resultaten onderstrepen het belang van de beoordelingsaanpak om vroegtijdig concepten te testen en tegenstrijdigheden te ontdekken. Illuminatie toont goede ondersteuning van supervisie, maar geen ondersteuning bij interventie. Evenmin veroorzaakt het dan echter afleiding zoals wel het geval bleek bij icoon-gebaseerde grafische concepten. Illuminatie is daarom een aanbevolen oplossing voor zowel ondersteuning van supervisie als interventie. Met deze conclusies is ook de tweede doelstelling behaald: het doen van aanbevelingen ten aanzien van interface-eigenschappen die bestuurders ondersteunen in het uitvoeren van hun veranderende rijtaak.

\section{Slotconclusie}

Het uiteindelijke doel is dat automatisch rijden de verkeersveiligheid, de verkeersefficiëntie en het comfort verhogen. Daarom is in hoofdstuk 9 ook besproken hoe de veranderende rol van de bestuurder (ten gevolge van automatisering) samenhangt met de haalbaarheid van deze doelen. De overwegingen laten zien dat aanzienlijke verbeteringen in de samenwerking tussen de bestuurder en het voertuig nodig zijn voordat automatisch rijden daadwerkelijk die beoogde voordelen biedt.

Zonder verbeteringen in samenwerking tussen bestuurder en voertuig zal de negatieve verandering van de nieuwe bestuurdersrol de waardering voor automatisch rijden gering houden. Ondanks verdere technologische ontwikkelingen, blijft in de bestaande infrastructuur voertuigautomatisering deze nieuwe rol verlangen van bestuurders. Een goede samenwerking tussen bestuurder en voertuig blijft daardoor noodzakelijk voor de veilige en comfortabele beheersing van een voertuig. Toekomstig onderzoek zal zich daarom moeten richten op verbetering van die samenwerking door vernieuwing van bestuurder-voertuig interfaces.

Dit proefschrift benadrukt de aanhoudende noodzaak voor ondersteuning van de veranderende rol van de bestuurder (m.b.t. supervisie en interventie). Daarmee levert het een belangrijke bijdrage aan een sterker op de gebruiker gerichte benadering voor de ontwikkeling van automatisch rijdende voertuigen opdat verkeersveiligheid en comfort worden vergroot. 


\section{Preface}

This thesis concerns travelling and more specifically the way we travel. Indeed, this thesis is about letting go of the steering wheel. I enjoyed very much working on this subject. Nevertheless, I am glad that I could occasionally hold the supporting hands of people at my side. Therefore I like to thank those with whom I was lucky to be travelling with.

First of all, I like to thank Prof. Arthur Eger and Prof. Mascha van der Voort for being my promotors. Arthur gave me a lot of freedom to define my own research focus. I enjoyed discussing different use scenarios for automated driving. Cooperation with industry made the research focus on driving automation within existing infrastructure. I appreciate very much your support for the decisions taken during this process.

Mascha's expertise in human-centred design of driver assistance systems was very helpful right from the beginning. Mascha, your dedication to guide me through the project encouraged me a lot. I appreciate your supervision very much.

The support from Ford's Research Centre in Aachen through University Research Project (URP) funding is gratefully acknowledged. It enabled me to contribute to research on driver-vehicle interfaces for three years. This has been a great time. I like to thank in particular Joseph Urhahne and Stefan Wolter for their commitment during the URProject. Many thanks also to the team members at Ford who shared valuable insights in automated driving: Reid, Guido, Manuel and Andreas. I also like to thank Martin and Johannes for sharing their knowledge in drivers' behavioural aspects.

Stefan Becker, you are a strong advocate of human-centred design and your focus on the subject is inspiring to me. I am thankful for your support and appreciate very much that you are a member of the doctoral board.

It is an honour to have Prof. Klaus Bengler from Technical University of Munich (TUM) and Prof. Andrew Morris from Loughborough University in the promotion committee. Thank you for the connections between our universities, the automotive domain and human-centred design. I think there is enough mutual interest for future contact and I appreciate your efforts for taking part in the promotion commission very much.

Prof. Marieke Martens and Prof. Vanessa Evers your feedback and time are very much appreciated. New projects have started and I am looking forward to further cooperation.

Many thanks to Julia and Joseph for supporting me in being my paranimfs. Thank you for sharing your PhD-experience with me. 
Combining research with educational tasks has often been a real challenge. Therefore, I like to thank Geert Dewulf and Thonie van den Boomgaard for their organizational support. Being for half a year more remotely placed from the educational duties, gave a considerable boost to this research. Furthermore, I like to thank all colleagues that supported me during that time. In particular I like to thank Ellen van Oosterzee for her outstanding patience and endurance to keep things going for the Bachelor final assignments. I also like to thank Marten Toxopeus for replacing me as the assignment coordinator. Chris, it was always nice to receive your post. Thank you all.

On the way to perform parts of the research several students assisted with their work. Niek, your professionalism and kind cooperation are outstanding. Your support in programming driving simulator scenarios has been very valuable to the project. Robin, your dedication to graphic design was a joy when developing the icon based concepts. Bart, thank you for your creative support in prototyping the illumination concept. Jana and Tom thank you for your kind support in exploring measurements techniques during the early phases of the research. Frank and Borce, sometimes studies turn out to be a detour. However, I enjoyed very much meeting you on my way travelling.

At different junctions in life some people are always at your side. That definitely counts for my parents, brothers, loving wife and children.

Furthermore, it is awesome to know that there is always One who wants to help at any path in life - and far beyond. Thank You. 


\section{Table of Contents}

Publications $\quad$ vi

About the author viii

Abbreviations $\quad$ ix

Summary $\quad x$

Samenvatting $\quad x v$

Preface $\quad x x$

Chapter 1. Introduction 1

$\begin{array}{ll}1.1 & \text { Automated driving }\end{array}$

1.2 Human Factors concerning driver's changing role 4

1.3 Research objectives 5

$\begin{array}{lll}1.4 & \text { Research scope } & 7\end{array}$

1.5 Thesis outline 8

Chapter 2. Automation of the driving task 11

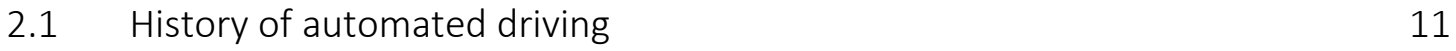

$\begin{array}{ll}2.2 & \text { The driving task } \\ 2.3\end{array}$

$\begin{array}{lll}2.3 & \text { Situation Awareness } & 18\end{array}$

2.4 Out-of-the-loop performance problems 20

2.5 Approaches to avoid OOTL performance problems 25

2.5.1 Improve controllability through raised SA 25

2.5.2 Automation of subtasks 26

$\begin{array}{ll}2.5 .3 \text { Shared authority } & 28\end{array}$

2.5.4 Shared control with non-driving tasks 28

2.6 Conclusions: required support for supervision and intervention 29

$\begin{array}{lll}\text { Chapter 3. } & \text { Research approach } & 33\end{array}$

3.1 Introduction 33

3.1.1 Approach for the assessment of driver's interaction 34

3.1.2 Approach to provide interface recommendations 35

3.2 Apparatus and scenarios for testing 35

3.2.1 Experimental research $\quad 35$

$\begin{array}{ll}\text { 3.2.2 Driving simulator } & 37\end{array}$

3.2.3 Traffic scenarios 41

3.3 Research outline 45

$\begin{array}{lll}\text { Chapter 4. Design exploration } & 48\end{array}$

4.1 Interface examples for driving automation 48

4.2 Design-exploration with experts 54

4.3 Design potential 57 
$\begin{array}{lll}\text { Chapter 5. } & \text { Assessment framework } & 60\end{array}$

5.1 Introduction 61

5.2 Concept of framework 62

5.2.1 Assessment aspects within the framework 62

5.2.2 Scope of the framework 63

5.2.3 Simulated traffic scenarios within the framework 63

$\begin{array}{lll}5.3 & \text { Measurement methods } & 64\end{array}$

5.3.1 Measurement of Situation Awareness (SA) 64

5.3.2 Performance measures (AA) 65

5.3.3 Measurement of Concept Acceptance (CA) 66

5.4 Methodology 66

5.4.1 Experimental design and procedure 66

5.4.2 Participants and instructions 68

5.4.3 Materials 68

$\begin{array}{lll}5.5 & \text { Assessment of scenarios } & 70\end{array}$

$\begin{array}{lll}5.6 & \text { Results } & 72\end{array}$

5.6.1 Assessment of Situation Awareness 73

5.6.2 Assessment of Accident Avoidance 76

5.6.3 Assessment of Concept Acceptance 77

$\begin{array}{lll}5.7 & \text { Discussion } & 77\end{array}$

5.7.1 How reliable is the framework?

5.7.2 Consistency of the measures 78

5.7.3 Congruency of measurement scores with predefined support levels 79

5.7.4 How effective is the framework? 80

$\begin{array}{lll}5.8 \text { Conclusions } & 81\end{array}$

Chapter 6. Understanding of automation mode with illumination 84

$\begin{array}{lll}6.1 & \text { Introduction } & 85\end{array}$

$\begin{array}{lll}6.1 .1 & \text { Research scope } & 85\end{array}$

6.1.2 Research approach and outline 86

6.2 Method 86

$\begin{array}{lll}6.2 .1 & \text { Concepts } & 87\end{array}$

$\begin{array}{lll}6.2 .2 & \text { Scenarios } & 88\end{array}$

6.2.3 Variables and measures $\quad 89$

6.2.4 Survey design 90

6.2.5 Respondents' instruction and task 91

$\begin{array}{lll}6.2 .6 & \text { Respondents } & 91\end{array}$

$\begin{array}{lll}6.3 & \text { Results } & 92\end{array}$

6.3.1 Perception of automation mode 92

6.3.2 Understanding automation mode and changes 95

6.3.3 Interpretation driver's role 97

6.3.4 Acceptance: How suitable were signals for the situation? 98 
6.3.5 Influence of illumination on perceived hazardousness 100

$\begin{array}{ll}\text { 6.3.6 Learning } & 100\end{array}$

$\begin{array}{lll}6.4 & \text { Discussion } & 101\end{array}$

6.4.1 Mode awareness and interpretation of driver's role 102

6.4.2 Concept acceptance, false alarms and perceived level of hazard 103

$\begin{array}{ll}\text { 6.4.3 Limitations } & 104\end{array}$

$\begin{array}{lll}6.5 & \text { Conclusions and recommendations } & 105\end{array}$

Chapter 7. Exploration and evaluation of support for supervision and intervention 108

$\begin{array}{lll}7.1 & \text { Introduction } & 109\end{array}$

7.1.1 Behavioural improvements of raised LOAs 110

7.1.2 Supervision with now-and-then intervention 111

7.1.3 Considering modalities for concept development 113

$\begin{array}{lll}7.1 .4 \text { Concepts } & 116\end{array}$

$\begin{array}{lll}7.2 & \text { Method } & 118\end{array}$

$\begin{array}{lll}7.2 .1 & \text { Participants } & 119\end{array}$

7.2.2 Scenarios \& system description 119

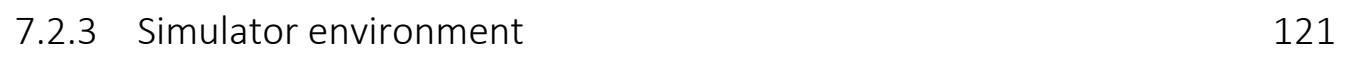

7.2.4 Experimental design \& procedure 122

$\begin{array}{lll}7.2 .5 & \text { Selected measurements } & 122\end{array}$

$\begin{array}{lll}7.3 & \text { Results on support for intervention } & 124\end{array}$

$\begin{array}{ll}\text { 7.3.1 Accident avoidance } & 124\end{array}$

7.3.2 Support for intervention: Situation Awareness (SA) 127

7.3.3 Support for intervention: Cognitive performance 128

$\begin{array}{ll}\text { 7.3.4 Support for taking back control } & 129\end{array}$

7.3.5 Support for intervention: conclusion 131

$\begin{array}{lll}7.4 & \text { Results on support for supervision } & 132\end{array}$

7.4.1 Hazard detection 132

7.4.2 Support for supervision: Situation Awareness (SA) 133

7.4.3 Support for supervision: Cognitive performance 134

$\begin{array}{lll}7.5 & \text { Concept acceptance } & 135\end{array}$

7.5.1 Perceived usefulness and satisfaction 135

7.5.2 Participants' perception of concepts 136

$\begin{array}{lll}7.6 & \text { Discussion } & 139\end{array}$

7.6.1 Performance expectations and main results 139

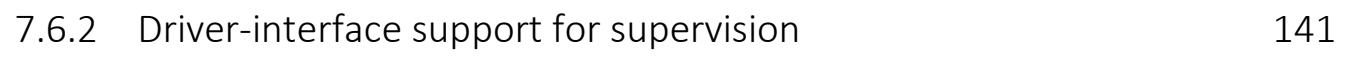

7.6.3 Driver-interface support for intervention 141

7.6.4 Limitations and long-term implications 143

$\begin{array}{lll}7.7 & \text { Concluding remarks } & 145\end{array}$ 
Chapter 8. Comparison of interface-types

$\begin{array}{lll}8.1 & \text { Introduction } & 147\end{array}$

$\begin{array}{lll}8.2 & \text { Method } & 147\end{array}$

$\begin{array}{lll}\text { 8.2.1 Scenarios } & 147\end{array}$

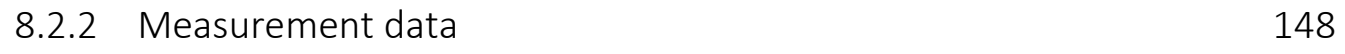

$\begin{array}{ll}\text { 8.2.3 Material \& Procedure } & 148\end{array}$

$\begin{array}{lll}8.2 .4 & \text { Analysis } & 148\end{array}$

$\begin{array}{lll}8.3 \text { Concepts } & 149\end{array}$

$\begin{array}{llr}8.4 & \text { Results } & 150\end{array}$

$\begin{array}{lll}8.5 & \text { Conclusions } & 152\end{array}$

$\begin{array}{lll}\text { Chapter 9. Conclusions and recommendations } & 155\end{array}$

9.1 Recommendations for evaluation of potential solutions 155

9.2 Design recommendations to support supervision and intervention 158

9.3 Discussion: influence of the driver's changing role on mobility 163

9.3.1 Safety 163

$\begin{array}{lll}\text { 9.3.2 Comfort } & 166\end{array}$

9.3.3 Context regarding car mobility 168

$\begin{array}{lll}9.4 & \text { Final conclusion } & 169\end{array}$

$\begin{array}{ll}\text { References } & 171\end{array}$

$\begin{array}{ll}\text { Appendices } & 185\end{array}$

Appendix A - Rating scale mental effort (RSME) 186

Appendix B - Questionnaire internet survey 187

Appendix C - Questionnaire Situation Awareness Global Assessment Technique (SAGAT) 194

Appendix D - Questionnaire Situation Awareness Rating Technique (SART) 195 


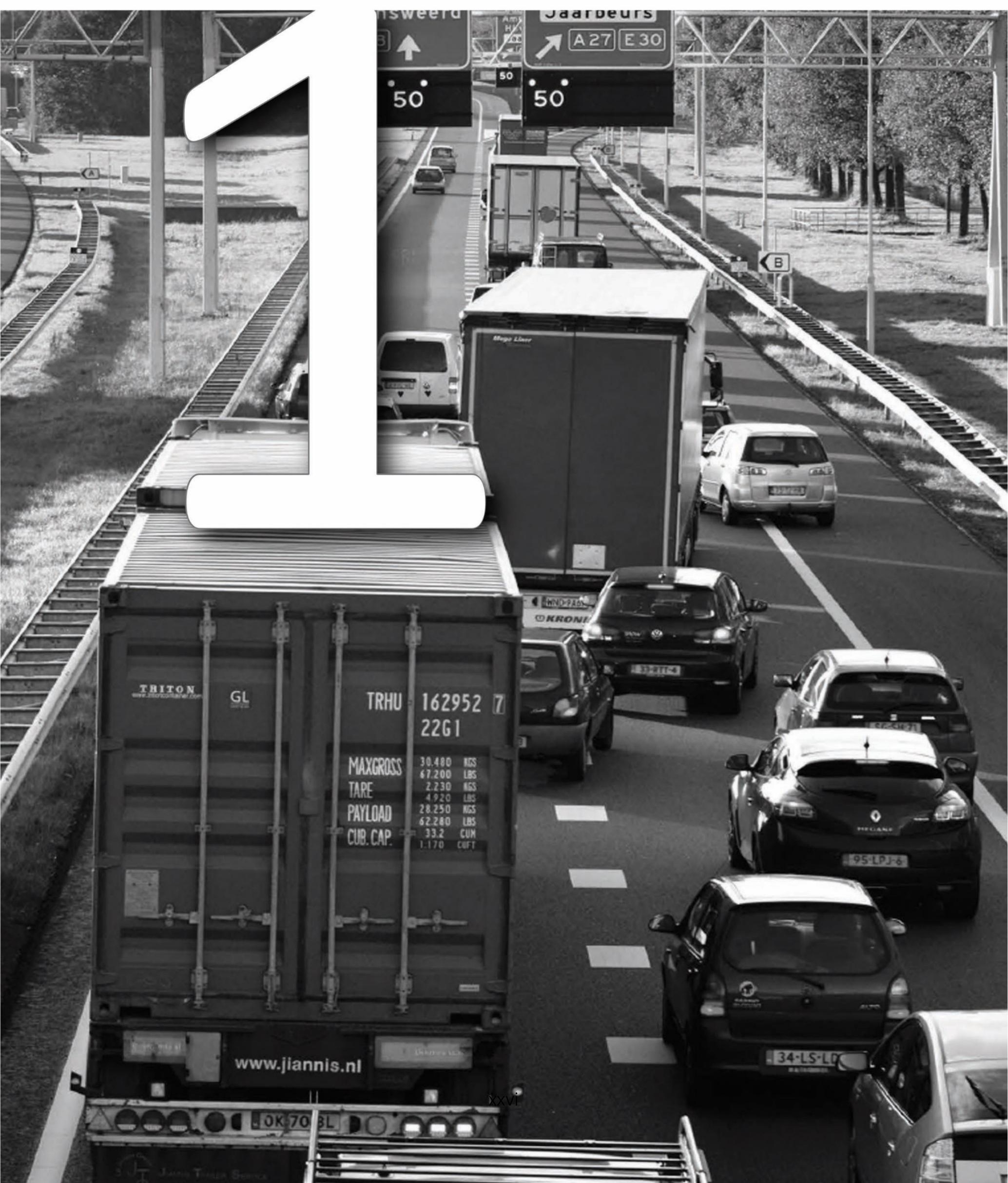




\section{Chapter 1. Introduction}

\subsection{Automated driving}

Automated driving has been a dream to many people for more than fifty years. In 1956 for example, General Motors revealed a futuristic show-car - called FireBird II - which conceptually featured an automated guidance system for application on "the highway of the future", where an electrical wire embedded in the roadway would send signals to guide future cars and avoid accidents (General Motors, 1956). The developers assumed that driving automation would have been rolled out in 2000. Although the development of automated driving turned out to take a lot longer, driving automation has been piloted ever since.

Until the ninety nineties, projects often relied on dedicated infrastructure - like magnets embedded in the roadway (Bergenhem, Shladover, Coelingh, Englund, \& Tsugawa, 2012). Since the ninety nineties, technology has been developed that allows automated driving without specific adaptation to road infrastructure. Sensors like ultrasonic, radar, lidar and video sensors acquire information from outside the vehicle, including road layout and traffic participants. Based on algorithms, the acquired traffic data and real-time map data, computers in the vehicle are able to calculate the appropriate path and timing to control actuators accordingly (Thrun, 2010).

It is only recently that automated driving has also become publically available for private vehicles. Examples are Tesla with the Autopilot (Bradley, 2016) and Mercedes who combines its Distronic Plus (ACC) with Active Lane Assist (Daimler, 2015) - furthermore all major car manufactures have announced plans to introduce systems that allow some automated driving (Bengler et al., 2014; Thrun, 2010). What is more, also from outside the automotive arena, industry is heavily investing: Google builds a series of driverless vehicles for testing purposes (Google, 2016; Guizzo, 2011) and is considered to bring automated driving vehicles on the market in combination with a ride-on-demand service (Lippert \& Clark, 2016).

Despite the increasing automation, the driver remains responsible for driving according to the Vienna Convention from 1968 (UN-ECE, 1968). The convention states: "Every moving vehicle or combination of vehicles shall have a driver." And: "Every driver shall at all times be able to control his vehicle (...)." In line with the driver's responsibility, Mercedes' Lane Keeping Assistant therefore comes with the obligation to frequently place hands on the wheel, otherwise the assistance function will be disengaged.

\section{Potential advantages of automated driving}

Why does automated driving gain so much interest? First of all, we may consider that for many technologically minded people the idea of driving automatically seems fascinating in itself. Indeed, the automobile is named after the ultimate idea to be mobile within an 'auto'-mated 
Table 1-1 Levels of automation in road transport (SAE International, 2013). System refers to the automated driving system

\begin{tabular}{|c|c|c|c|c|c|c|}
\hline ¿্য & Name & Definition & \begin{tabular}{|l|} 
Execution of \\
steering and \\
acceleration/ \\
deceleration
\end{tabular} & \begin{tabular}{|l|}
$\begin{array}{l}\text { Monitoring of } \\
\text { driving } \\
\text { environment }\end{array}$ \\
\end{tabular} & $\begin{array}{l}\text { Fallback } \\
\text { performance } \\
\text { of dynamic } \\
\text { driving task }\end{array}$ & $\begin{array}{l}\text { System } \\
\text { capability } \\
\text { (driving } \\
\text { modes) }\end{array}$ \\
\hline \multicolumn{3}{|c|}{ Human driver monitors the driving environment } & \multirow[b]{2}{*}{ Human driver } & \multirow[b]{2}{*}{ Human driver } & \multirow[b]{2}{*}{ Human driver } & \\
\hline 0 & $\begin{array}{l}\text { No } \\
\text { automation }\end{array}$ & $\begin{array}{l}\text { The full-time performance by the human driver of all } \\
\text { aspects of the dynamic driving task, even when } \\
\text { enhanced by warning or intervention systems. }\end{array}$ & & & & - \\
\hline 1 & $\begin{array}{l}\text { Driver } \\
\text { assistance }\end{array}$ & $\begin{array}{l}\text { The driving mode-specific execution by a driver assis- } \\
\text { tance system of either steering or acceleration/decel- } \\
\text { eration using information about the driving environ- } \\
\text { ment and with the expectation that the human driver } \\
\text { performs all remaining aspects of the dynamic driving } \\
\text { task. }\end{array}$ & $\begin{array}{l}\text { Human driver } \\
\text { and system }\end{array}$ & Human driver & Human driver & $\begin{array}{l}\text { Some } \\
\text { driving } \\
\text { modes }\end{array}$ \\
\hline 2 & \begin{tabular}{|l} 
Partial \\
automation
\end{tabular} & $\begin{array}{l}\text { The driving mode-specific execution by one or more } \\
\text { driver assistance systems of both steering and } \\
\text { acceleration/ deceleration using information about } \\
\text { the driving environment and with the expectation } \\
\text { that the human driver performs all remaining aspects } \\
\text { of the dynamic driving task. }\end{array}$ & System & Human driver & Human driver & $\begin{array}{l}\text { Some } \\
\text { driving } \\
\text { modes }\end{array}$ \\
\hline \multicolumn{3}{|c|}{ Automated driving system monitors the driving environment } & \multirow[b]{2}{*}{ System } & \multirow[b]{2}{*}{ System } & \multirow[b]{2}{*}{ Human driver } & \\
\hline 3 & $\begin{array}{l}\text { Conditional } \\
\text { automation }\end{array}$ & $\begin{array}{l}\text { The driving mode-specific performance by an auto- } \\
\text { mated driving system of all aspects of the dynamic } \\
\text { driving task (including latitudinal and longitudinal } \\
\text { control) with the expectation that the human driver } \\
\text { will respond appropriately to a request to intervene. }\end{array}$ & & & & $\begin{array}{l}\text { Some } \\
\text { driving } \\
\text { modes }\end{array}$ \\
\hline 4 & $\begin{array}{l}\text { High } \\
\text { automation }\end{array}$ & $\begin{array}{l}\text { The driving mode-specific performance by an auto- } \\
\text { mated driving system of all aspects of the dynamic } \\
\text { driving task, even if a human driver does not respond } \\
\text { appropriately to a request to intervene. If the human } \\
\text { driver fails to take control of the vehicle, the system } \\
\text { steers the vehicle to the side of the road in a } \\
\text { controlled manner and stops it. }\end{array}$ & System & System & System & $\begin{array}{l}\text { Most } \\
\text { driving } \\
\text { modes }\end{array}$ \\
\hline 5 & \begin{tabular}{|l|} 
Full \\
automation
\end{tabular} & $\begin{array}{l}\text { The full-time performance by an automated driving } \\
\text { system of all aspects of the dynamic driving task } \\
\text { under all roadway and environmental conditions that } \\
\text { can be managed by a human driver. }\end{array}$ & System & System & System & $\begin{array}{l}\text { All driving } \\
\text { modes }\end{array}$ \\
\hline
\end{tabular}

fashion, i.e. with minimum effort. In line with the ongoing pursuit of effort-less operation of vehicles, car manufacturers promote the introduced systems as comfort enhancing. Furthermore, the development and investments are also being justified by expectations to raise safety and increase road-efficiency. These are potential benefits that governments and policy-makers are keen on to adhere to (European Union, 2011). The reason behind these expectations is that automated cars would be more precise and faster to react under severe circumstances. These expectations are also reflected by decisions from Euro NCAP ${ }^{1}$ to adapt

\footnotetext{
${ }^{1}$ Euro NCAP (New Car Assessment Program) is a vehicle rating system on passive and active safety expressed with 'stars'. Highest ratings (typically up to maximally five stars) can only be achieved when a model is equipped with specific (active) safety features. These features might be optional but required to represent a substantial share of the available models equipped with the feature. Euro NCAP rating criteria evolve over time.
} 
their assessment programme in favour of vehicles equipped with semi-automated systems like Automatically Emergency Braking (AEB) ${ }^{2}$ or Lane Keeping Assist (LKA). As the technology required to fulfil this functionality is the same for automated driving and because of marketing advantages to have a high ranking, the Euro NCAP ratings may be one of the main drivers for market introduction of automated driving capability.

\section{Boundary conditions for automated driving}

Automated driving basically combines both longitudinal control (speed and distance) and lateral control (lane position). The capability of the automation to perform reliably is restricted to boundary conditions. In this respect, Figure 1-1 provides an example of a Congestion Assistant that allows automated driving during low speed stop\&go traffic on motorways. Boundary conditions influence the extent to which the above mentioned expectations will be met. Boundary conditions, in turn, relate to a complex interdependency between the technical parameters required for system operation and the driving circumstances, like road type or section, weather conditions and traffic density.

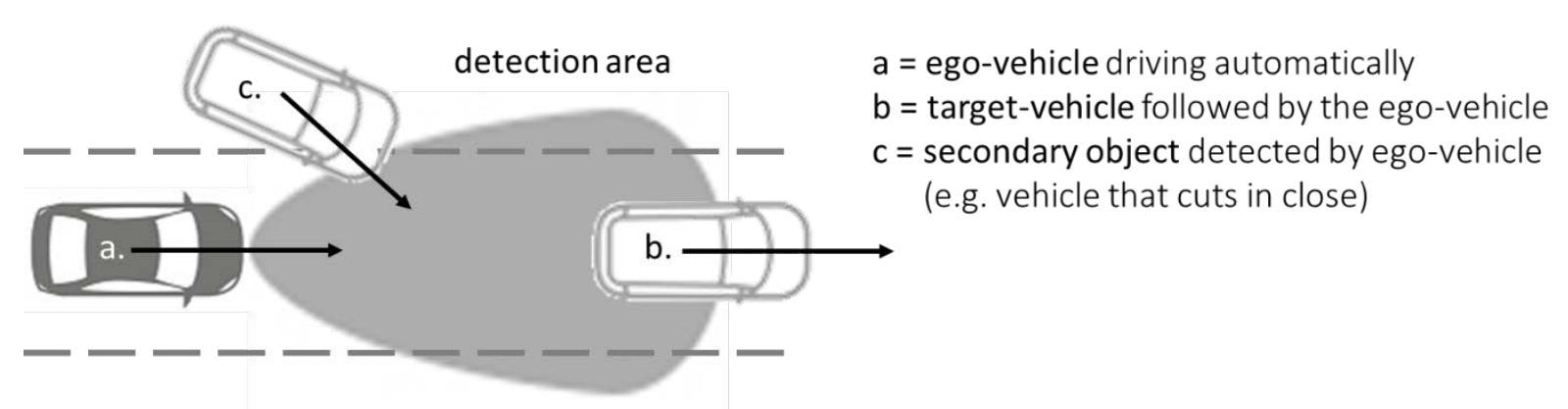

Figure 1-1 Example with schematic overview of main system boundaries for a Congestion Assistant (CA) system.

The boundaries consist of: (i) Recognition of road lines, (ii) recognition of a target-vehicle, (iii) driving on motorways, and (iv) driving below a speed threshold, for instance $50 \mathrm{~km} / \mathrm{h}$.

To discuss possible application of driving automation, SAE defined 6 levels ranging from "No Automation" (level 0) to "Full Automation" (level 5) (SAE International, 2013), see Table 1-1. The levels differentiate in circumstances that allow automation and circumstances that require human supervision. Only level 4 ("High Automation") and 5 ("Full Automation") involve complete automation of the driving task and exclude human intervention during automation. Nonetheless, automation in level 4 is restricted to specific circumstances, like operation on a dedicated road-track. Outside these areas human operation is still required. Only level 5 automation would consist of driverless operation anywhere. It is a misconception however, that the levels should be interpreted as a technological roadmap naturally leading to

\footnotetext{
${ }^{2} \mathrm{AEB}$ is intended to protect against collision with vulnerable road users, like pedestrians and cyclists.
} 
implementation of the final level at some point in time. Actually, experts doubt whether full automation (level 5) with driverless private vehicles able to operate on any road is achievable in a conceivable future time-span (Etemad, 2015; Nieuwenhuijsen, 2015; Van Witsen, 2016).

It is worth mentioning that some of these automation levels are already implemented today. For example an automatically operating bus-connection ParkShuttle (Fornasiero, 2011) at level 4 and Tesla's Autopilot at level 2. All automation levels, except for level 5, will require some form of human intervention when any of the boundary conditions are not met. Therefore, the human operator is required to function as a back-up in case the automation fails or stops. On public roads, this is likely to occur frequently. For example during roadworks, road obstruction, or when experiencing severe weather conditions.

\subsection{Human Factors concerning driver's changing role}

Basically, the levels illustrate that in a majority of applicable situations for automated driving, the driver remains ultimately responsible for safe operation. As a consequence this preserves an important task for the driver: supervision of the automation with occasionally the necessity to intervene. Because intervention often occurs unexpectedly and requires fast responses; this task is difficult and causes high workload (Stanton, Dunoyer, \& Leatherland, 2011). Despite potential advantages of automated driving, researchers have time and again warned against downsides of such implementation of automation (Brookhuis, De Waard, \& Janssen, 2001; Endsley \& Kiris, 1995; Martens et al., 2008; Rudin-Brown \& Parker, 2004; Saad, 2004; Saffarian, De Winter, \& Happee, 2012).

The reason behind these concerns is apart from the difficult human requirements when intervention is needed, that partially automated driving basically changes the driver's role from actively operating the vehicle to passively supervising the automation. Whereas supervision is something humans are not particularly good at, due to low vigilance and behavioural adaptation (Martens \& Van den Beukel, 2013).

The concerns raised by Human Factors experts can be summarized by Out Of The Loop (OOTL) performance problems, meaning that the human driver is placed out of the control loop, i.e.: is being excluded from actively operating the vehicle. Being out of the loop may lead to a series of performance problems, like; erratic mental workload (Stanton \& Young, 2005); behavioural adaptation (Rudin-Brown \& Parker, 2004); reduced situation awareness; inadequate mental model of automation capabilities (Bishop, 2005), and (on the long term): skill degradation (Endsley \& Kiris, 1995; Saffarian et al., 2012).

\section{Support needed for driver's changing role}

In contrast to technology for active safety (like ABS and ESP) that take over in case of driver limitations (e.g. a driver who cannot cope with the situation), the OOTL-problems of automated driving show the difficulty of the driver now needing to take over control in case of system 
limitations. Several authors have addressed this irony of automation, e.g. (Bainbridge, 1983; Merat, Jamson, Lai, \& Carsten, 2012; Norman, 1990). In order to take over in case of system limitations, the human driver needs to understand what the system does and does not do, and he/she needs to be ready to retake control whenever the system meets its limitations. If the driver is not ready, not alert, has lost situational awareness, is engaged in other activities, has lost certain skills (due to automation) or is not capable to take over control in the situations that the system cannot cope with either, safety will be jeopardized. This shows that supervisory control should be considered a more difficult human task than manual control, since the demand on human cognition is increased, while the demand on human action decreases (Young, Stanton, \& Harris, 2007). We therefore get the worst combination: low alertness and high momentary stress when something critical occurs (Martens, 2007). Without extra measures, we can therefore expect during critical situations after a sustained period of automated driving, that the driver will be out of the control loop and unable to resume control effectively. This is why drivers of automated vehicles are in need of solutions that provide support for supervision, as well as support in anticipation of possible intervention.

\subsection{Research objectives}

Automated driving causes the role of the driver to change: From actively operating the vehicle to passively supervising the system with occasionally a necessity to intervene. Considerations with regard to the technological achievements and possible applications of automated driving (as for instance illustrated with the SAE-levels, see Table 1-1) show that this change in role does not represent a temporary transition until complete automation would be achieved, but marks a fundamental change how the human, is required to retain responsibility as a supervisor.

This responsibility is not merely a legal requirement, but for most a demanding task. This is because the driver is placed out of the control loop but still needs to act as a back-up and, consequently, is required to intervene when automation meets its limitations. These situations might occur unexpectedly and during time-critical circumstances. Apart from the demands placed on the driver when intervention is required, the maybe even more important downside is that supervision isn't a role humans are particular good at, due to low vigilance and behavioural adaptation. Therefore, carefully designed driver-interfaces are needed to support drivers with their additional supervisory task, as well as to support them retrieving control safely and adequately when required. The main aim of this thesis is therefore to recommend interface features that provide the desired support for both supervision and intervention.

Recommendations for the development of appropriate solutions are on two levels: (1) with regard to evaluation of potential solutions and (2) with regard to interface features that contribute to desirable solutions. To provide these recommendations insight in how interface features provide potentially improved interface-solutions are collected through the design and evaluation of several possible interface variations. 
An assessment framework to evaluate potential interfaces with regard to the combination of desired support for supervision and intervention is however not readily available (Geyer et al., 2014; Van Waterschoot \& Van der Voort, 2009). The first objective of our research is therefore to propose such framework. The corresponding research question is:

How to assess driver's interaction with partially automated driving during interface development?

We analysed assessment aspects that are particularly important to supervisory performance and successful intervention. Applying the proposed assessment aspects in a driving simulator experiment with scenarios representative for partially automated driving, allowed us to evaluate the framework. A subsequent test with predefined interfaces demonstrated the framework's applicability to asses potential interface solutions. The supervisory task requires visual demand. Illumination of the windscreen's sideways creates visual cues that provide reference upon location and severity of an event. However, this concept does not provide explicit explanations why there is a need for attention and this potentially hampers understanding automation mode or mode changes (Stanton et al., 2011).

In order to test the mental model drivers create when illumination is applied, the second research question to be answered is:

Does illumination in the windscreen help to gain mode awareness and to understand the driver's role?

Almost 100 respondents answered an internet-based survey to assess driver's understanding and mode awareness when using illumination in the windscreen. The video-based situations shown in the survey as well as the used measures for situational awareness, were adopted from the previously defined framework. The results revealed that illumination in the windscreen provides mode-awareness and therewith contributes to support for supervision. Further exploration of the illumination concept and comparison with more conventional and visually detailed interfaces in the instrument cluster, allows in-depth assessment of the pros and cons of a variety of interface-directions. This exploration varies with regard to level of detail, location and modality of provided feedback and allowed answering our third research question:

What are the recommended interface features that will provide desired support for both supervision and intervention?

Finally, reflection on the results from all three previous studies allowed us to discuss overall findings and therewith to answer this thesis' main objective:

How to support drivers with their changed role to supervise and (occasionally) intervene when driving automatically? 


\subsection{Research scope}

Since the concept of automated driving comes with a wide variety of possible applications and levels of system-control, and because of the given time frame and confined resources, a selection with regard to the scope of this research must be made.

First of all, this research will focus on automation intended for passenger vehicles, because they have a major share in traffic participation. Since passenger vehicles are operated by nonprofessionals, the changed role of the driver is especially expected to have an impact on performance from passenger vehicles. To gain improvements in supervising and intervention, it is important that vehicle interfaces are adapted to the capabilities of ordinary drivers. Furthermore, if drivers do not accept the interface support, they might not use the automation and there will be no gained benefits for raised comfort or increased road efficiency. Nonetheless, our recommendations for interface solutions might be applicable to a broader scope than passenger vehicles alone.

This research furthermore focusses on the application of automation in existing infrastructure, which subsequently includes mixed traffic. That is, automated vehicles and conventional vehicles will need to share the same infrastructure. In accordance with the Vienna Convention on Road Traffic (UN-ECE, 1968), our scope also includes the driver's responsibility for safe driving.

From a technical point of view, the scope is the application within technical and system design's boundary conditions that represent current state of the art. Technical boundary conditions include for example recognition of lane markers and object detection. Boundary conditions based on system-design would be set to allow sufficiently safe operation. An example is when operation is restricted to specific road types, or below a certain speed threshold. Although technical possibilities will advance, our scope is not on improving the automation's systemdesign itself. Improved automation-design might reduce the need for supervision and intervention, however our assumption is that the level of $100 \%$ failure-safe (or confident technological fall-back solutions) is still a long way off (Etemad, 2015; Van Witsen, 2016). So the need for supervision and intervention might reduce, but according to our assessment it will not diminish. As a consequence of not focussing on potential improvements to automation-design, acceptance within our research refers to acceptance of the interface solutions developed, not on acceptance of the automation-system as such or automated driving in general.

The combination of automation restricted to boundary conditions and remaining driver's responsibility for safe driving means that our application of driving automation meets level 2 "Partial Automation" and 3 "Conditional Automation" (SAE International, 2013). (Level 4 "High automation" is restricted to specific road conditions and does therefore not apply to our primary scope.) The difference between levels 2 and 3 is that level 2 assumes immediate availability, and level 3 pre-notified availability of the driver. The matter of defined differences 
is considered irrelevant for our research, because it is expected that drivers will perform other tasks during automated driving and are therefore not likely to be in either level anytime available without any extra measures (i.e. interface-support). This is also why we use in this thesis the words 'partial automation' in a more general context than strictly defined within the automation level of the same name.

Our application of automated driving furthermore focusses on congestion assistance. A Congestion Assistant (CA) provides driving automation (i.e. automated longitudinal and lateral control) during low-speed scenarios of congested driving on motorways. The reason for this scope on congestion assistance is four-fold: (a) This assistance entails application of driving automation that holds a long history in desired alleviation of the driving task under boresome circumstances (Bergenhem et al., 2012); (b) Congestion assistance receives consumers' acceptance and is among highest rankings of desired ADAS in passenger vehicles (Brookhuis, van Driel, Hof, van Arem, \& Hoedemaeker, 2009); (c) In the framework of the ongoing European projects, congestion assistance is notably mentioned as having potential to increase traffic efficiency (adaptIVe, 2016; EU, 2011; Mäkinen et al., 2010); (d) Several car-makers have announced introduction of congestion assistance systems, some of them referring to as Traffic Jam Assist (e.g. (Audi, 2016)).

Future changes to legal aspects and liability are not taken into direct considerations for development of our interface-solutions. As mentioned before, the driver's final responsibility for safe driving is taken as a reference. With the driver's changing role, this sets a requirement to enable drivers to take responsibility. Therefore, current legislation and liability concerns underline the importance of adequate interface-solutions to support drivers in their new role. Changing legal aspects might allow driver-less vehicles on public roads in the future. Also the liability for traffic accidents might change from the human operators to the manufacturer of the equipment. Given the significant legislative efforts to establish such changes, the insecure outcomes and expected long time-frame to implement them, changes to legal aspects and liability are not taken into direct considerations in our research.

Finally, as this thesis is about human aspects of driving, we often use the word 'driver' and then we refer to both male and female typology of the human operator. For text efficiency and ease of reading we might refer to the driver with 'he' only, although we mean both men and women.

\subsection{Thesis outline}

Chapter 2 starts with analysing how the characteristics of the change in driver's role influences the demand for new interface-solutions. A short review of the history of automated driving creates a frame of reference for the potential advantages of automated driving. Then, this chapter reviews human-centred consequences of driving automation (i.e. drivers' out of the loop (OOTL) performance problems), along with an analysis how drivers gain contextual awareness (so called Situational Awareness - SA) important to perform the driving task. 
Through these analyses, we were able to conclude Chapter 2 with a description of what we want to achieve: A compilation of baseline design directions for desirable interface solutions in order to provide optimal support for supervision and intervention.

Chapter 3 explains our approach how we want to achieve this goal. The approach consists of first developing an assessment framework to test potential interface-solution on relevant aspects within circumstances representative for automated driving. Thereafter, the approach is making recommendations on design-directions for desirable interface-support through a series of tests with a variety of interface-types.

Chapter 4 explores potential solutions. These potential solutions are based on reviewing existing interface-ideas for interaction between driver and assistance functions comparable to automated driving. Also the outcomes of two workshops with experts from the automotive and human-centred-design domains contributed to potential solutions. Therewith, this chapter provides directions to the design of interface-concepts for further studies.

The design and evaluation of the framework is covered in Chapter 5 and includes a first brief investigation of interface-solutions. Then, Chapter 6 and 7 present two explorative studies, each with a description of the background, method, results and a discussion. Chapter 6 focusses merely on support for supervision through assessment of driver's understanding and system awareness for a particular concept: directional feedback of potential hazards through illumination in the windscreen. Further exploration of this concept is described in Chapter 7. This includes support for intervention as well as comparison with more conventional but visually detailed interfaces. This allowed in-depth assessment of the pros and cons of a variety of interface-directions.

A short wrap up and comparison of the results from all three previous studies is provided in Chapter 8. Finally, Chapter 9 discusses the findings of this thesis and - in line with this thesis' aim - provides recommendations for evaluation and development of appropriate interaction solutions and subsequent interface-features that support the driver's changing role to supervise the system with occasionally the necessity to intervene, when driving automatically. 


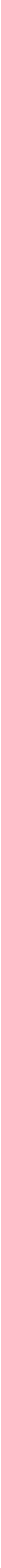




\section{Chapter 2. Automation of the driving task}

Motivated by expected advantages for safety, comfort and traffic efficiency, industry and research place enormous efforts on automating the driving task. As explained in the introduction, the development of automated driving resembles a large domain of possible applications which have particular influence on the driver's changing task. Through a short review of the history of automated driving, this chapter first creates a frame of reference with regard to the potential advantages of automated driving (section 2.1). Then, this chapter provides a review of how different manifestations of automation influences the driving task (section 2.2). This review reveals causes for driver's out-of-the-loop (OOTL) performance problems due to automation, which consequences will be explained in section 2.4. Before that, section 2.3 will explain how drivers gain contextual awareness - so called Situational Awareness (SA) - because achieving SA is an important necessity for performing the driving task. Then, section 2.5 reviews existing approaches to overcome OOTL performance problems. The gathered knowledge allows section 2.6 to conclude with a compilation of baseline designdirections for desirable interface solutions in order to provide optimal support for supervision and intervention.

\subsection{History of automated driving}

First considerations for automated driving entailed the introduction of a dedicated infrastructure - like magnets embedded in the roadway (Bergenhem et al., 2012). Based on this idea, General Motors was in 1956 among the first to show a concept (called "FireBird II") to the public. This concept featured an electric wire embedded in the roadway that would send signals to guide vehicles (General_Motors, 1956). It took until the nineties of last century before first prototypes were shown. A typical example is from 1997 when the California PATHconsortium demonstrated an eight-car platoon manoeuvring under complete automatic control, including lane changes, with drivers showy waving both hands to the public (Rajamani, Tan, Law, \& Zhang, 2000). While the PATH-initiative is intended to increase the capacity of highway lanes, the magnet-based technique is also implemented to raise capacity and manoeuvring precision for specific applications. Examples are automated guided vehicles (AGVs) in container terminals, like in the port of Rotterdam (Vis \& Harika, 2004). Or: ParkShuttle, who started in 2006 with driverless buses to connect a metro station with a business park, also in Rotterdam (Fornasiero, 2011). This automatic transport system has been developed further and is applied in Masdar City (Abu Dhabi) as Personal Rapid Transit (PRT) system (2getthere, 2016). A third example is the automated bus-system in Eindhoven, called Phileas, which allowed manual operation during mixed traffic in the city centre and rapid automatic operation over dedicated bus lanes to more remote areas (Shladover, 2007). In this project, the automatic operation enabled smaller bus lanes and offered advantages for infrastructural implementation. Along these developments for automatic operation with 
dedicated infrastructure, solutions are also being developed that work independently from road infrastructure. Sensors like ultrasonic, radar, lidar and video sensors acquire information from outside the vehicle, including road layout and traffic participants. Based on algorithms, the acquired traffic data and real-time map data, computers in the vehicle are then able to calculate the appropriate path and timing to control actuators accordingly (Thrun, 2010). From the start of this century, data acquiring has been enhanced through exchange of data with other vehicles (V2V Communication) and infrastructure (V2I Communication). These developments were accompanied with several research projects, like: The DARPA Urban Challenge in 2007 where teams from different research groups showed the capability of robotic cars to concurrently perceive the vehicle's environment, stabilize its motion and to react with suitable driving manoeuvres (Campbell, Egerstedt, How, \& Murray, 2010; Kammel et al., 2008). While robotic cars during this challenge drove driverless in a closed urban environment with pre-defined traffic scenarios, researchers from Braunschweig Technical University involved in the Stadtpilot project, drove with their prototyped vehicle Leonie automatically over the city's inner ring road during rush hour between normal traffic (Saust, Wille, Lichte, \& Maurer, 2011). Within the Grand Cooperative Driving Challenge (GCDC) vehicles of different kind (i.e. a mix of heavy and passenger vehicles) and different make (multivender) drove automatically in platoons of about six vehicles (van Nunen, Kwakkernaat, Ploeg, \& Netten, 2012). This challenge specifically focused on development and deployment of cooperative driving systems, i.e. systems that cooperate in a platoon while they share data on driving dynamics among one another. Road trains and truck platoons have also been piloted in various countries, some examples are: KONVOI (Germany), SARTRE (EU co-funded FP7 project), iQFleet (Sweden) (Bergenhem et al., 2012). As mentioned in the Introduction, manufactures like Daimler and Tesla recently made automated driving publically available for private vehicles by combining Distronic Plus (ACC) with Active Lane Assist (Daimler, 2015), respectively through introduction of 'Autopilot' (Bradley, 2016).

\section{A history of expectations}

Apart from improving road efficiency and raising comfort, driving automation propagated already from its conception to increase safety. Affirmed by technical advances, driving automation remains to hold strong expectations on safety improvements. These expectations support ambitions like 'Vision Zero', a Swedish road safety policy from 1997 - stating that in the long run, it is unacceptable for anyone to die while using the road transport system (Fahlquist, 2006). Similar policies have been adopted in other countries. Since the adoption of Vision Zero there has been criticism on its practicability (Rosencrantz, Edvardsson, \& Hansson, 2007). Although new requirements from Euro NCAP will motivate manufacturers to equip more vehicles with life-saving technologies based on automated driving, considerable human factors concerns continue to exist with the introduction of automated driving. These concerns basically contain the notion that driving automation will change the driver's role and this changed role is expected to place major cognitive and physical demands on drivers of private 
cars when utilizing the automation. To gain a better understanding of these challenges, the next section analyses how the driver's role changes.

\subsection{The driving task}

Michon provides a model of the driving task consisting of three consecutive levels, i.e. the strategic, tactical and operational level (Michon, 1985). At the strategic level drivers prepare their journey; this concerns general trip planning, route, transportation mode, time, etc. At the tactical level drivers exercise manoeuvring control, allowing to negotiate the directly prevailing traffic circumstances, like crossing an intersection or avoiding obstacles. Here drivers are mostly concerned with interacting with other traffic and the road system. The operational level involves the elementary tasks that have to be performed to be able to manoeuvre the vehicle, mostly performed automatically and unconsciously (like: steering, using pedals or changing gears). Executing a tactical or operational task always facilitates achieving the goals of a task on a superordinate level.

\section{Model of the driving tasks as a series of control-loops}

McRuer considers driving a sequence of operations, characterised by: "visual search", then "decision-making" and subsequently "effecting the desired actuation" (McRuer, Allen, Weir, \& Klein, 1977). Other authors use different names, but basically all consider driving as a set of control-loops, being performed within one or several sequences of input, throughput and output. Although summarized with the single word throughput, this sequence contains a broad and complex range of cognitive aspects, like: attention, expectations, training, reasoning and cognitive capabilities. A divide in more detailed steps could help further understanding of this sequence. Endsley and Kaber (1999) divides throughput in "generating" and "selecting" to compile four processing steps: (a) Monitoring: Scanning displays or the system's environment to perceive information regarding system status and/or the ability to perform tasks, (b) Generating: Formulating options or strategies to achieve tasks, (c) Selecting: Deciding on a particular option or strategy to perform tasks, and (d) Implementing: Carrying out the chosen option. Matthews, Bryant, Webb, and Harbluk (2001) distinguish five processing steps: (i) perception; (ii) comprehension; (iii) projection, (iv) decision-making and (v) implementing. This division explains the 'throughput'-sequence in terms of comprehension, projection and decision-making, wherein projection includes an assessment how possible courses of action may or may not change the driving task, based on comprehension how the detected information relates to the state of the environment. Then, decision-making is based on this assessment. Both four-phase and five-phase models give explanation how execution of the final output-phase depends on a series of preceding cognitive processes taking place during the throughput-phase, see Figure 2-1. The throughput-phase could therefore be considered a mental processing-phase. It becomes clear that this processing-phase is the most complex part of task-operation and conceals most difficulties of car-driving (Thomas, Morris, Talbot, \& Fagerlind, 2013). Development of effective support therefore requires most attention to the throughput-phase. (A note to the reader: the four and five phase models will be returned on 
in other sections of this chapter to explain some of the phenomenon intended to improve driver-vehicle interaction.)

(a)

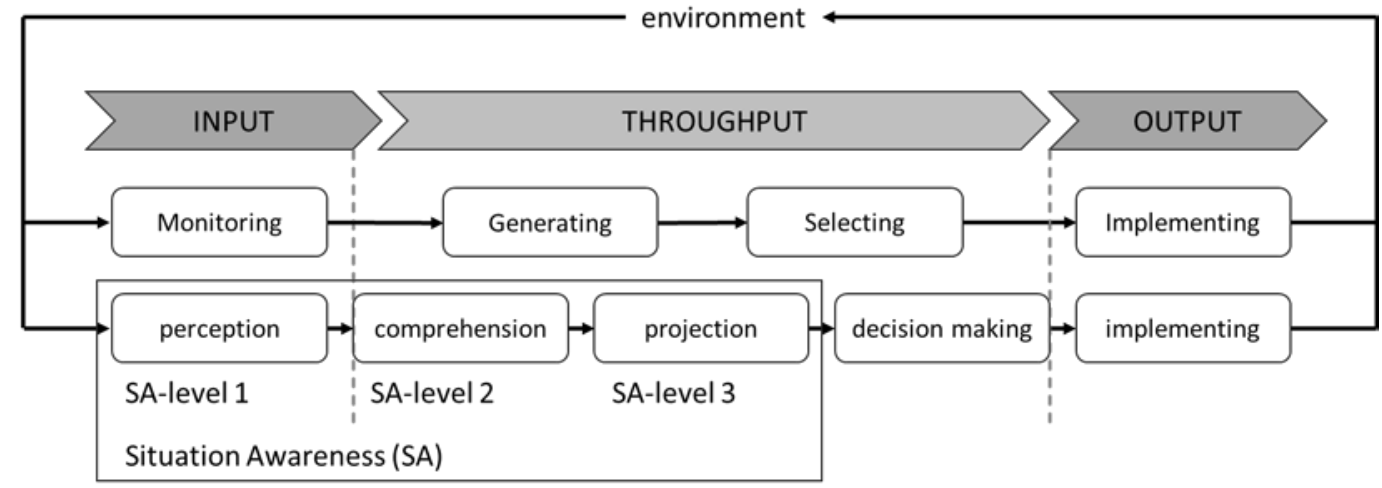

Figure 2-1 Models of the driving task as a series of control-loops (a) four phase model according to Endsley and Kaber (1999), (b) five phase model according to Matthews et al. (2001)

\section{Human-Product Interaction}

To provide basic understanding how driving assistance influences human-vehicle control, this thesis refers to the 'Human-Product-Interaction' (HPI) model (Dirken, 1997), see Figure 2-2a. Basically, this model explains that the cooperation between driver and technology can effectively be represented with series of input, throughput and output executed by both entities, i.e. human and technology. Then, this model contains the notion that output from the driver is input for the machine (and vice versa). For example, speed (vehicle output) contains information about the machine's state (i.e. perceived velocity) and this information is considered as input signal which the human may decide upon to change settings for cruise control. The interface moderates the exchange between input and output of both entities. Furthermore, the direct connection between output and input represents feedback upon which either machine or human makes corrections and adjustments by themselves. With highly assisted tasks, such control-loops with self-directed adjustments dominantly take place at the side of the machine. Then drivers become less involved, see Figure 2-2.b. Furthermore, the model explains means for drivers to gain authority over task-execution: With closed-loop control, the human operator consciously perceives the machine-output and checks whether this outcome resembles desired results. With open-loop control the machine retrieves more authority, i.e. the driver does not intentionally compare machine's output with desired outcomes and basically entrusts desired execution to the vehicle. 
(a)
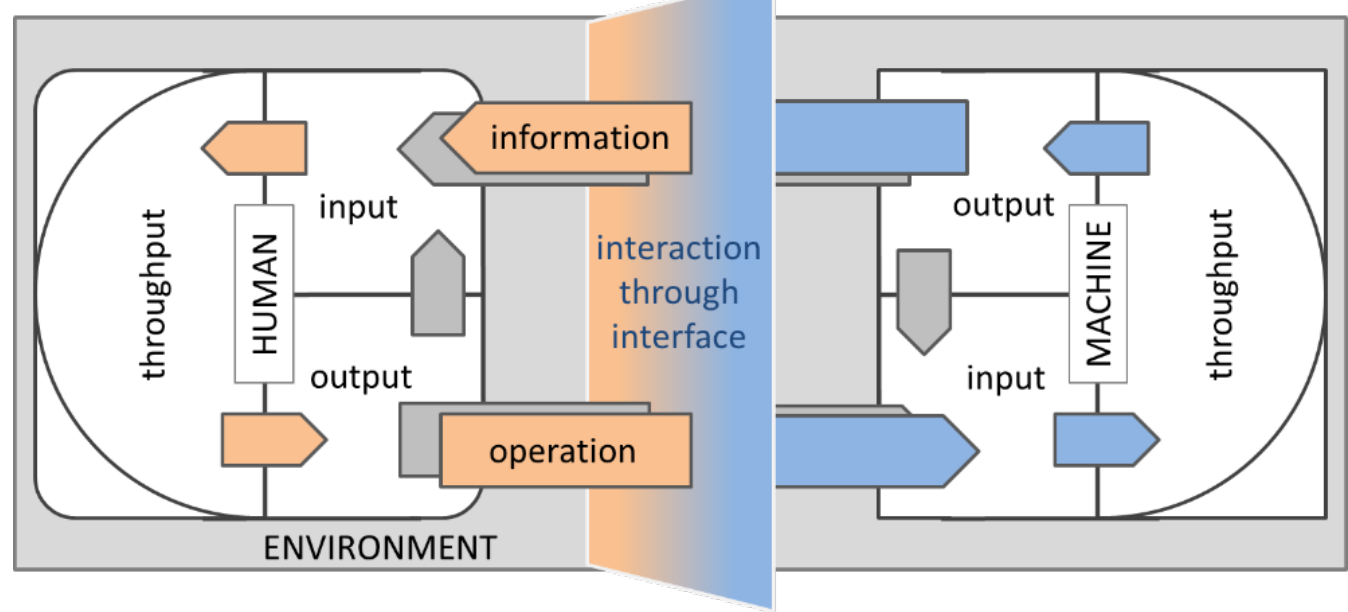

(b)
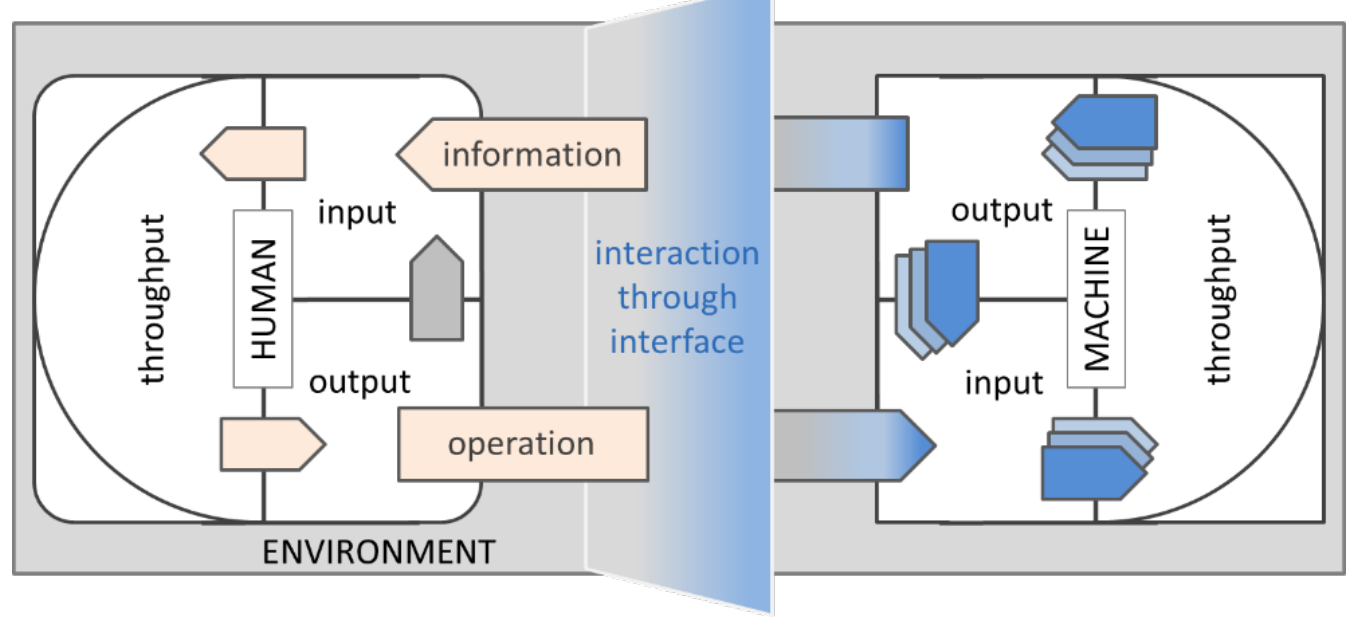

Figure 2-2 Human-Product-Interaction model (HPI) proposed by Dirken (1997) (a) generic example for interaction and control-sequences between human and machine. (b) Example with control-sequences of a highly assisted task; the human becomes less involved in the overall control-loop.

Performance levels

From a human perspective, required performance for executing tasks is often analysed in terms of three different levels distinguished by Rasmussen (1983): the knowledge-based, rulebased and skill-based level. These levels fit well to the driving task (Hoedemaeker, 2000), because differentiation between the levels refers to involved mental effort and to the proportion the driver is involved in the control-loop. With regard to the latter, a distinction is made whether the control-loop is being phased through in a closed-loop or in an open-loop fashion. At the highest knowledge-based level, human behaviour is goal-controlled and represents a more advanced level of reasoning. This is the level at which people develop new ways of problem solving. Performance at knowledge-based level is therefore applied in novel situations. It requires considerable attention and effort and is therefore demanding. Knowledge-based tasks are performed within a closed-loop process. Rule-based behaviour is characterised by the use of rules and procedures to select a course of actions in a familiar situation. The rules can be acquired through experience or can be based upon prior 
instructions (training). When driving, rule-based behaviour involves interpreting everyday situations and applying rules and regulations that fit that situation. Once a rule is chosen the actions are carried out in a rather automatic fashion. The control process is often an open-loop one. At the lowest skill-based level, highly practiced tasks are carried out. This level represents a type of behaviour that requires very little attention, without consciously controlling a task. Actions are performed in an automated manner. The control process is an open-loop one, i.e. there is no continuous feedback mechanism. Only when something goes wrong in this openloop mode, this will trigger task performance to be carried out at a higher level.

Causes and probabilities of errors differ per performance levels (Rasmussen, 1982). Considering how potential errors on each of these levels influence overall performance will provide additional insight in the influence assistance has on the driving task. Skill-based performance holds the advantage of fast responses and requires very little attention. However, the presentation of information that triggers automatic responses can be so strong, that inattention to other important information is the main cause for errors if tasks are performed at this level (Martens, 2007). Rule-based performance involves tasks that are characterized by a strong top-down control: A situation triggers choice of a particular schemata and then actions are applied according to this scheme. Therefore, misinterpretation-errors, causing operators to apply the wrong rule, are the main risk for deteriorated performance at this level. Problems may as well occur if people lack knowledge about the rule that should be applied. Knowledgebased performance involves tasks that require a high level of cognitive attention to interpret new information and to acquire solutions. Errors on this level are mainly caused by inaccurate knowledge, inadequate analysis-skills or task overload as knowledge-based tasks are demanding. Furthermore, the task is impaired by adding another (sub-)task (Patten, Kircher, Östlund, \& Nilsson, 2004). In general, drivers operate more homogeneously and predictable at skill-based and rule-based levels than at knowledge-based level (Martens, 2007). The probability for an error to occur is therefore generally lower for tasks performed at the first two levels. What we observe with implementation of automation is that drivers are being alleviated from the operational task which they typically perform at rather reliable levels of skill-based and rule-based performance. In parallel, the newly introduced supervision task requires performance on a more-demanding and less predictable level, i.e. knowledge-based level.

While referring to the amount of mental effort needed to execute a task, Rasmussen considers individual differences in task performance. Apart from cognitive capabilities, differences in driving experience and familiarity with driving situations influence the required mental effort. For example; regulating speed is considered an operational task in most general circumstances. However, during reverse parking, regulating speed might require performance on rule-based or even knowledge-based level. These dependencies on situation and driving experience can be made more explicit by placing Rasmussen's task performance model and Michon's hierarchy of the driving task in one overview: See Figure 2-3. 


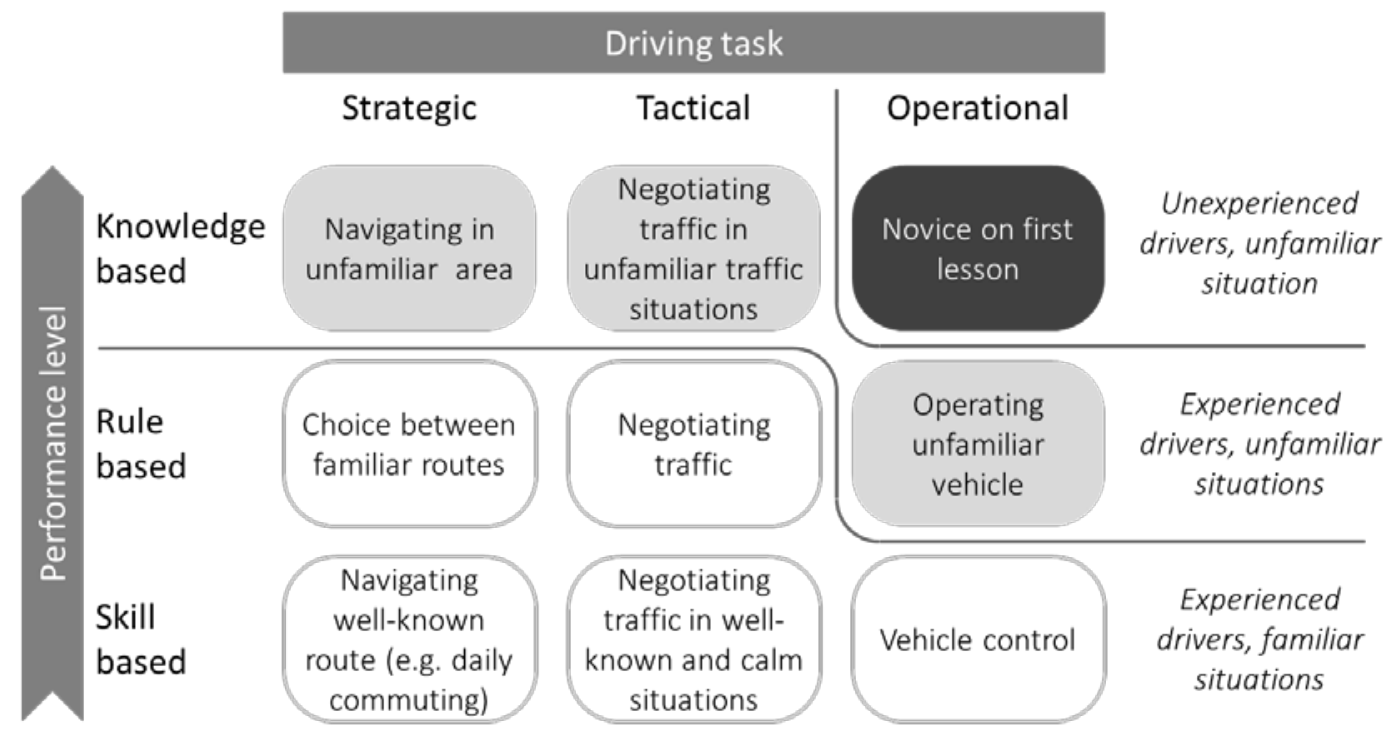

Figure 2-3 Characterization of the driving task based on Michon's taxonomy of the driving task and performance levels.

Note. Examples are adapted from Hale, Stoop, and Hommels (1990).

\section{How ADAS influence the driving task}

Considerations with regard to performance levels explain that experienced drivers execute a majority of driving tasks on rule-based or skill-based level. This is a favourable situation because the probability for errors to occur is lower on these levels. As explained, this is because successful performance of the knowledge-based task depends heavily upon the performer's fundamental cognitive capabilities to diagnose, and analyse required measures and to understand the situation. From a safety point of view, it is therefore most beneficial if assistance would support drivers when tasks are performed at knowledge-based levels and that the assistance helps to execute remaining tasks as much as possible on rule-based and skill-based levels (Martens, 2007; Van den Beukel \& Van der Voort, 2009).

The examples in Figure 2-3 show that the performance level which a driver needs in order to execute a task, is also dependent on contextual knowledge. If contextual knowledge is not present, the required performance level raises. Experienced drivers for example could need knowledge-based performance when passing an unfamiliar crossing. Required performance levels also raise when drivers are impeded in their ability to compose contextual knowledge. This is the case with automation: The driver is (temporarily) removed from the control loop and then mentally not available, or reduced available, to receive stimuli from the traffic situation in order to remain contextual aware. If then operation is required because automation has stopped, the required performance level actually rises to higher levels, e.g. requiring rule-based and knowledge-based performance. Therewith the task has become more demanding.

So far, analysis of the influence of driving automation on the driver's task, revealed two main causes for so called out-of-the-loop (OOTL) performance problems: reduced contextual knowledge and an increase of required performance-levels. OOTL performance problems will 
be explained in more detail in section 2.4. Referring to before mentioned influence from the extent to which drivers build up contextual knowledge, we will first explain the psychological construct that explains how people build up this knowledge, i.e.: Situation Awareness (SA).

\subsection{Situation Awareness}

The perception and understanding of elements required for dynamic tasks is covered with the psychological construct Situation Awareness (also called Situational Awareness), abbreviated with SA. Endsley (1995b) defines SA in terms of three levels: "(1) the perception of elements in the environment within a volume of time and space, (2) the comprehension of their meaning, and (3) the projection of their status in the near future". With respect to the driving-task: Driving requires perception of the elements within the road-traffic environment which are needed for motion-planning. Furthermore, the driving-task requires understanding of these elements in order to make correct decisions for timing of the manoeuvring and to respect correct tactical judgement. There is general consensus that drivers need SA in order to perform the driving task. If we recall how the driving task is divided according to (Matthews et al., 2001) (i.e. (i) perception; (ii) comprehension; (iii) projection, (iv) decision-making and (v) implementing), it is apparent that SA encloses the first three steps of performing the driving task. This illustrates that SA is theoretically a prerequisite for the remaining steps and a necessity to enable performance of the complete driving task. In this research, measurement of SA will therefore not only serve as a method to assess driving performance but is also intended as a means to gain insight how SA supports the driving task. In contrast, reduced situation awareness relates to impaired decision making: Within several studies when intervention was needed, this lacking or inadequate situation awareness has been identified as one of the primary causes for accident occurrence (De Winter, Happee, Martens, \& Stanton, 2014; Endsley, 1996; Gold, Damböck, Lorenz, \& Bengler, 2013; Matthews et al., 2001). Despite general consensus that drivers need SA, there is a variety of opinions on how SA should be defined and, more important, there is debate upon applicable techniques to measure SA.

Indistinctness about measurement of SA originates from diverging opinions on the precise scope of SA. Some researchers question if SA represents a psychological construct in its own right or if it rather represents a catch-all term encompassing various elements of human cognition (like perception, workload and working memory)? Furthermore, there is discussion whether SA refers to the process of gaining awareness (Fracker, 1991) or rather to a cognitive product of information-processing (Endsley, 1995b), like a mental model that reflects systemunderstanding. Or is SA maybe a combination of both (Kokar \& Endsley, 2012)? The differences between definitions come with variety between underlying psychological models to describe the phenomenon. Afore stated definition by Endsley is based on a model for information processing, where others like Bedney and Meister (in: Lagervik and Gustavsson (2006)) use an activity theory model and therewith refer more to the product (result) of SA. Besides the fact that Endsley's definition is most widely adopted (Charlton, 2002; Salmon et al., 2009), there is another reason to use Endsley's definition within the scope of this thesis: Its underlying model 
to reveal the cognitive knowledge and understanding necessary for driving performance, provides us with more useful information than only looking at the result. This is because insight from an information processing point of view would help the development process with knowledge about the underlying mechanisms to provide desired support. Furthermore, this research considers already the results of good SA (i.e. effective driving performance) through driving simulator testing (see section 1.4 Research Scope and section 3.1.1 Approach for the assessment of driver's interaction). To gain further understanding and allow in next chapters of this thesis selection of an applicable measurement method, this section continues with an overview of available methods to measure SA.

* Freeze probe techniques involve the administration of queries during 'freezes' in a simulation (Salmon et al., 2009). The queries relate to probes and their answers are assumed to be representative for SA, e.g.: "Is there currently (i.e.: during 'freeze') a vehicle on the neighbouring lane?" During these 'freezes' the screens of a simulation are typically blanked and the queries are randomly chosen from a set of relevant probes. The primary advantage of freeze-probe techniques is their direct nature. A disadvantage, however, is their intrusiveness upon primary task performance. Within this category, the Situation Awareness Global Assessment Technique (SAGAT) (Endsley, 1995a) is most commonly used. Although especially developed for the aviation domain, the method is also applicable for SA assessment in driving (Matthews et al., 2001).

* Real-time probe techniques also use probes. The technique is intended to be less intrusive, while an expert administrates the real-time probes during task performance without interrupting or pausing the tasks that are being executed (Salmon et al., 2009). A disadvantage is that task execution is nonetheless influenced by the direct and continuous presence of a test-taker. This is likely to cause test-behaviour. Typical application is for time-taking supervisory tasks in control-rooms, like video-surveillance. Besides the disadvantage of influencing task-performance due to test-behaviour, measuring SA for the driver's changing role as explained in the Introduction involves in addition to supervision also intervention, which includes emergency take-over requiring quick responses. Therefore, real-time probe techniques are not considered applicable for the research in this thesis.

* Self-rating techniques involve self-assessment by participants based on standardized queries. The main advantage is their non-intrusiveness, since they are typically administrated post-trial (Salmon et al., 2009). However, self-rating techniques are criticized, due to interference of SA with task performance, their dependence on memory capacities and because of participant's inability to rate levels of SA - especially with regard to accurately measuring poor SA as participants may not realise that they have inadequate SA in the first place (Endsley, Selcon, Hardiman, \& Croft, 1998). Due to the ease of application (fast and low cost) self-rating techniques are nonetheless wide-spread used and the Situation Awareness Rating Technique (SART) (Charlton, 2002) is most popular. 
* Performance measures allow indirect assessment of SA, for example lane position or crash avoidance (Charlton, 2002; Matthews et al., 2001). Their advantages are that they are objective and non-intrusive (Salmon et al., 2009). The main problem when applying performance measures for SA-assessment is however the underlying assumption that efficient performance is achieved as a result of efficient SA. However, it may be that efficient performance is achieved despite an inadequate level of SA, or that poor performance is achieved regardless of a high level of SA (e.g. a novice driver with good $\mathrm{SA}$, but inferior driving skills). However, performance measures would be valuable as a back-up and extra reference with regard to the success of performing a task.

Apart from the inapplicability to use real-time probe techniques in this research, it is undefined what SA-measurement technique would be most applicable. Performance measures are being anticipated anyhow within our approach to use driving simulation (see section 3.1.1 Approach for the assessment of driver's interaction). Additional techniques to measure SA should provide desirable insight in the cognitive understanding necessary for driving performance. Both freeze-probe and self-assessment techniques serve this aim, but (as explained) they both have particular disadvantages. Selection of an appropriate technique for SA-measurement will therefore be accounted for during development of the assessment framework in Chapter 5.

\subsection{Out-of-the-loop performance problems}

So far, this chapter focussed on the driving task and how assistances influences this task in general. The current section explains the specific problems arising from automation of the driving task and its subsequent out-of-the-loop (OOTL) performance problems. The causes for OOTL performance issues can be summarized as follows: (1) Automation reduces Situation Awareness and therefore more effort is required to regain control, (2) the control-task has become more difficult due to risen levels of required task-performance (i.e. from dominantly skill-based and rule-based tasks to knowledge-based tasks). In general, the consequences are increased risk that control is unsuccessful and that errors occur. In order to gain insight in how potential interface solution could provide desirable driver-support to overcome these problems, this section explains the consequences in more detail.

\section{Overreliance and inappropriate trust}

Overreliance describes an operator's mind-set in which he or she trusts the system to such extent that counterchecks on automation performance and automation mode are neglected. As a result situations in which automation performance is reduced might not, or too late, be detected. Sometimes an inappropriate level of trust could be the result from mode-confusion, like an operator believing the system is in a particular mode, but in reality it is not. Good awareness of the operational envelope is important for drivers to anticipate beforehand on changes due to approaching system's boundary limits. As creating awareness of the operational envelope might reduce surprises, this is also likely to help driver readiness in case 
he or she is required to retake control (Seppelt \& Lee, 2007). Hence, we recommend that driver's support should provide insight in the system's operational envelope.

\section{Behavioural adaptation}

Behavioural adaptation means that the driver starts to change behaviour and takes more risks since the driver workload is lower with the system. In low risk situations humans tend to adapt their behaviour to restore their personally preferred level of task-occupation. Automation might easily be perceived as a low risk situation due to overreliance. Driver behaviour might therefore be adapted to being involved in more risk-full situations and therewith (partially) diminishing the safety advantages that the automation is trying to achieve. An example is to allow oneself longer travelling times without taking a break during automated driving and subsequently hampering correct performance of the supervisory task. Also drivers have been observed to adapt their lane-change behaviour to achieve higher cruise speeds when driving with ACC (Rudin-Brown \& Parker, 2004). Awareness of the operational envelope (as explained above) is intended to help gaining the right expectations and could therewith influence adaptation in a preferable manner. Since, behavioural adaptation is related to people's midto long-term experience with a system, it is however difficult to anticipate the consequences of this problem more precisely.

\section{Inadequate mental model}

A mental model is an individual's cognitive representation of how a system operates (Norman, 1983). Mental models enable an individual to describe, explain, and make predictions how a system performs tasks. These expectations and subsequent predictions are influenced by the individual's prior experience with other products and tasks within the application-area. Hence, mental models of particular systems may also be structured from knowledge of other systems, from prototypes, or even from incorrect information. Therefore, Norman argued that mental models require time to evolve, and that they may be incomplete and even imprecise (Norman, 1983). An inadequate mental model of automation capability occurs when a driver misunderstands the conditions (i.e. technical envelope) within which the automation is able to function correctly. An example is a driver using Adaptive Cruise Control in stop-and-go traffic and who merges out to take an exit from the motorway. If the pre-set target speed is high, the car will start accelerating on an empty exit-lane instead of reducing speed (Larsson, Kircher, \& Andersson Hultgren, 2014). Experiences from other domains have shown that an inadequate mental model can have severe consequences (Sarter \& Woods, 1995; Young et al., 2007).

\section{Mode confusion}

The reduced involvement in actual vehicle control also causes reduced awareness of the situations associated with performing these tasks. An example of mode-confusion is often reported in association with ACC, e.g. (Kazi, Stanton, Young, \& Harrison, 2005), where drivers in a reflex have pushed the brake without realizing that this also terminated ACC and are subsequently vainly waiting for the vehicle to accelerate again. Lack of mode-awareness (or confusion) has been linked with many accidents in aviation (Young et al., 2007). Hence, 
avoiding mode confusion will be very important for safe application of driving automation. Reduced mode awareness might be due to several reasons: One reason is inappropriateness in which mode-information is being conveyed. With other words, an operator simply does not understand what the provided mode-information means. With raising complexity and different available modes, mode confusion might easily occur, causing a mismatch between what an operator considers to be the mode the system is in and the actual mode. Another reason for confusion might be insufficient transfer of information when a mode-change occurs. In other words: An operator simply doesn't notice a change. Thirdly, a reason could be inadequate possibilities to check mode-information at any desired moment. Even when mode-information would be transferred in an efficient manner, for reasons of confidence and comfort (e.g. rather recognising status information than being obliged to recall information (Nielsen, 1992)), it is important that a system for driving automation purports driver's recognition of modeinformation at any time. Mode confusion might also arise from other ADAS working in parallel of driving automation. Thus, a system which only functions at low speed might be automatically disabled as speed increases, at which point a system with a fixed minimum speed may or may not be available. The two systems might have similar, but not totally equal functionalities, leading to potential mode confusion and a lack of awareness by the driver about what automation functions are currently supporting him/her. Related to the potential confusion from other assistance systems working in parallel of driving automation is also the danger for erroneous counter-reactions. An example is a congestion assistant being designed to rely on detection of a target vehicle for providing lateral control. If detection suddenly fails (e.g. because the target vehicle changes its lane and no new target is present), the driver would be requested to take over. However, if at the same time the system falls back to longitudinal control, i.e. ACC (note: lateral control is often designed as an addition to longitudinal control) and the set speed is high, the vehicle would start accelerating. It is likely that such behaviour would interfere with the intentions of the driver, causing a dangerous situation. Based on these concerns it is cautiously recommended to let the automated system not provide counter reactions after mode-changes. Consequently, if an operator is required to retake control, then he/or she should take over completely without the system still operating to some extent.

\section{Reduced driver readiness and situation awareness}

Driver readiness refers to the driver's mentally required condition to perform control and to how much time the driver needs to recover control (Gold et al., 2013). Since driver readiness involves the driver's mental condition it is an overarching concept that includes Situation Awareness. Like SA, driver readiness can be affected by fatigue or by engagement in nondriving related tasks. The readiness to respond also differs between individuals and driving conditions (Key, Morris, \& Mansfield, 2016). When the driver is placed out of the control-loop (i.e. not continuously involved anymore in decision-making), the need to be situation aware reduces and as a consequence, the level of gained situation awareness also reduces (Endsley \& Kiris, 1995). Reduced situation awareness relates to impaired decision making and has been identified as one of the primary causes for accident occurrence (Endsley, 1996). Hence, 
reduced SA - and subsequently reduced driver readiness - is at the core of OOTL performance problems and many researchers have evaluated driver's minimally required response times for drivers to gain sufficient situation awareness and to recover control successfully - however these results are somewhat inconclusive. Literature indicates that drivers are capable of performing fast corrective actions to retrieve some operational control over the vehicle in about one or two seconds (Gold et al., 2013) (Radlmayr, Gold, Lorenz, Farid, \& Bengler, 2014), but it might take six to more than ten seconds to cognitively get back into the control loop, regain situation awareness, and stabilize steering control reliably (Merat, Jamson, Lai, Daly, \& Carsten, 2014). Thus, the interval times during which the cognitive processing and actions to retrieve control need to take place cannot be easily defined in quantitative terms. In qualitative terms, the interval times necessary for pre-warning depend on task difficulty and the drivers' residual level of SA. However, the underlying problem is that sufficient pre-warning is typically conducted in pre-known situations, whereas the more difficult situations occur unexpectedly in short time-spans. If then the automation reaches its functional limits, the remaining timespan to avoid a critical situation is for the human driver often too short either to react adequately. Potential solutions are two-fold: (1) Based on interpretation of sensor-data, algorithms should be optimised to detect dangerous driving behaviour earlier and more reliably (Urhahne, Piastowski, \& Van der Voort, 2015); (2) the driver-vehicle interface should be optimised to keep the driver situation aware at a sufficient residual level (Van den Beukel \& Van der Voort, 2011, 2016a). In the transition back to manually driving, drivers then need to expand situation awareness of the road conditions, the vehicle state and the surrounding traffic. This does not necessarily mean that the driver needs to know every detail of different automation stages and the technical background, but rather, that the driver knows what can be expected at what moment in time of the automation. The automation, on the other hand, should be able to provide output that is directly intuitive for the operator, and is transferred fast.

\section{Confusion about the driver's role}

A counter-part of mode confusion is confusion about the driver's role. Providing modeinformation is important because it allows drivers to gain insight in who is doing what. However, mode-information typically indicates the mode the automation is in while only indirectly explaining the driver's role - if at all. From deduction the driver needs to reveal what task is left and this again leaves room for misinterpretation ("if the system does lane keeping, does that mean that I am responsible for longitudinal control?"). Moreover, mode-changes are often the result from exceeding system's boundary limits and are therefore likely to appear suddenly and unexpectedly. Hence, these circumstances hamper the ability to interpret the mode-information correctly. Therefore it is important to support drivers by clearly indicating their role, especially at moments when a transition in control is desired. Of course, a challenge is especially in time-critical moments. Then, there is no time left for detailed explanations and cues to evoke desired driver behaviour should be very intuitive and fast to comprehend (Norman, 1990), cf. Petermeijer, de Winter, and Bengler (2016). 


\section{Inappropriate workload}

During automation workload is typically low because the driver is placed remote from the control loop. Low levels of workload are related to vigilance, reduced situational awareness and behavioural adaptation. Although these consequences are issues in themselves and despite the fact that automation is intended to relieve human task operation, automation causes (compared to completely human operation) also instances of extra workload or even overload if human tasks to retake control are required in unexpected and/or critical situations. The complex interaction between human and system operation might in critical situations cause moments with high levels of workload and stress. Therefore we recommend to design the interaction in such a way that the mental workload is at a moderate level (not too high and not too low). Within European projects (for instance AIDE) concepts for a workload manager have been developed that reduce the availability of secondary tasks in moments that are likely to require extra or full driver's attention (Broström, Engström, Agnvall, \& Markkula, 2006).

\section{Skill degradation}

If decision-making and implementation of tasks is consistently and dominantly performed by automation, there will come a time when the driver will not be as skilled in performing that function. This is because skill decay occurs with disuse (Rose, 1989). Skill degradation following automation failure has shown considerable causes in inferior intervention-performance (Endsley \& Kaber, 1999). Therefore, avoiding skill degradation is very important when the system needs to account for malfunction and/or automation failures.

\section{Conclusions}

Above detailed explanation of the problems associated with driver's placement out of the control-loop during automated driving, provides insight in how we want to influence drivervehicle interaction during automated driving in order to support drivers with his changing role, i.e. a role to supervise the automation with incidentally a necessity to intervene. The aspects to improve driver-vehicle interaction with, can be summarized as follows:

* Provide insight in the system's operational envelope;

* Provide information on system's reliability;

* Help drivers to build up correct mental models of driving automation;

* Transfer information on mode-changes fast and effectively;

* Allow drivers to recognise automation state directly and unambiguously at any desired moment;

* Support drivers to remain situational aware during automation;

* Support drivers to expand situation awareness fast and effectively when necessary;

* Provide instruction on the required driver's role in a way which is understood intuitively and fast.

Based on these outcomes and on reviewing existing approaches to overcome OOTL performance problems in the next section (section 2.5), this chapter will conclude in section 
2.6 with important baseline design-directions for desirable interface-solutions in order to provide optimal support for supervision and intervention.

\subsection{Approaches to avoid OOTL performance problems}

Based on existing research (Engström \& Hollnagel, 2007; Flemisch et al., 2012; Hollnagel, 2011), four base principles to overcome OOTL problems are distinguished:

* Improve controllability through raised SA (section 2.5.1)

* Automation of subtasks (section 2.5.2)

* Shared authority (section 2.5.3)

* Shared control with non-driving tasks (section 2.5.4).

\subsubsection{Improve controllability through raised SA}

As we have seen in the previous section, the return from out-of-the-loop is generally one of the main issues and this influences directly the availability of the driver. Research on the relationship between driver's availability and accident avoidance show that when there is less time for accident avoidance (i.e. shorter TTC) the quality of the intervention manoeuvres markedly reduces (Gold et al., 2013). For instance, visually checking mirrors decreases as well as the quality of trajectories to swerve out. Although drivers show compensating behaviour to react faster and brake stronger when the situation is more urgent (i.e. when there is less time available), these reactions are also coupled with more sudden and impulsive braking behaviour often with unnecessarily strong decelerations rates. Then, these reactions to avoid an accident become a new safety threat. On the contrary, if available time increases, the performance level with which drivers demonstrate accident avoidance also increases. Therefore, driver-vehicle performance is generally improved by timely warnings. The same counts for raised levels of SA. That means if an interface helps to raise SA so does the chance for effective accident avoidance (Gold et al., 2013; Van den Beukel \& Van der Voort, 2013). Results from an experiment of the author to test driver's ability to retrieve human control during time-critical take-over scenarios showed that the ability to retrieve control is positively influences if drivers gain increased levels of SA (Van den Beukel \& Van der Voort, 2013). These results provide an important insight that interface-solutions that help to gain raised levels of Situation Awareness in critical situations will support intervention. Jin and Kaber (2009) researched how each level of SA (i.e. perception, comprehension, and projection) influences driving performance in hazardous situations. Their results indicate that tactical driving tasks require higher SA and cognitive abilities for successful performance, as compared to operational and strategic tasks. Subsequently, their research confirms that error avoidance benefits most from supporting the tactile tasks. Furthermore, their results support the notion that low-level driving behaviour (e.g. lane keeping, distance keeping) may be automatic and skill-based and rely less on SA under normal driving conditions. On the contrary, when driving automation fails during extreme circumstances, driver's performance to take over control is directly enhances by raised levels of SA. 


\subsubsection{Automation of subtasks}

The ability to recover from automation failures influenced by different Levels of Automation (LOAs) was intensively researched by (Endsley \& Kaber, 1999). In their tests, Endsley and Kaber composed ten theoretically different LOAs by assigning automation to any of the four phases for task-execution as explained in section 2.2, i.e.: (a) Monitoring; (b) Generating; (c) Selecting, and (d) Implementing. See Table 2-1. Task performance was then assessed with a computerbased game-like test and required both operational and tactical skills. This was because objects with different size and speed travelled on a computer screen and had to be eliminated before they reached the centre. Stopping moving objects resembles accident avoidance and the required visual-motoric task-operation, consisting of information retrieval, information processing, decision-making and acting, applies to the driving task very well. Therefore results from these tests provide insight how automation of subtasks influence the ability to recover from failures induced by driving-automation. Automation levels varied between e.g. advising on a strategy, imposing a strategy or automatically executing a (humanly defined) strategy. The ability to recover from automation failures was assessed by deliberately (but unannounced) stopping the automation. Then, performance was measured after failure and compared between different LOAs.

Table 2-1 Levels of Automation defined by Endsley and Kaber (1999)

\begin{tabular}{lllll}
\hline & & & FUNCTIONS \\
\cline { 2 - 5 } LEVEL OF AUTOMATION (LOA) & MONITORING & GENERATING & SELECTING & IMPLEMENTING \\
1. Manual Control & Human & Human & Human & Human \\
2. Action Support & Human/Computer & Human & Human & Human/Computer \\
3. Batch Processing & Human/Computer & Human & Human & Computer \\
4. Shared Control & Human/Computer & Human/Computer & Human & Human/Computer \\
5. Decision Support & Human/Computer & Human/Computer & Human & Computer \\
6. Blended Decision Making & Human/Computer & Human/Computer & Human/Computer & Computer \\
7. Rigid System & Human/Computer & Computer & Human & Computer \\
8. Automated Decision Making & Human/Computer & Human/Computer & Computer & Computer \\
9. Supervisory Control & Human/Computer & Computer & Computer & Computer \\
10. Full Automation & Computer & Computer & Computer & Computer \\
\hline
\end{tabular}

Result from the Endsley and Kaber study showed that the ability to recover from automation failures improves when automation is applied in part while still requiring some operator interaction in the implementation phase (called Action Support in their study). Also overall operator/system performance (independent of automation failure) proved to be best for LOAs involving partial automation of the implementation aspect of a task. The results of this test also provide useful insight with respect to support of the driver's supervisory task: With regard to option-generating, purely human generation of options (Action Support and Batch Processing) performed far better than joint human-computer generation of options (LOA levels $4,5,6$ and 8). The fact that the joint human-machine generation of options produced worse performance than generation by either the human or machine component alone is in agreement with other research (Selcon, 1990). This low performance can be explained by distraction and doubts that humans encounter during joint human-computer selection of 
options and this is an important notion for designing supervisory support. Because conventional interfaces with icon-based information regarding automation mode and required driver's role can be considered a joint human-computer solution for decision-making, this result feeds the notion that icon-based interfaces for driving automation might cause distraction and confusion when intervention is needed.

Another approach for automation of subtasks is to make the automation adaptable. Adaptable automation places ultimate responsibility for controlling the level of automation with the driver (Oppermann, 1994). This was found to alleviate drawbacks that were attributed to static automation: Miller and Parasuraman (Miller, Funk, Goldman, Meisner, \& Wu, 2005; Miller \& Parasuraman, 2007) suggested that dynamic delegation of control from the driver to the automation, or retrieving control from the automation, offers a method for flexible humanautomation interaction which enhances system performance while maintaining user workload at a manageable level. Experiments from Parasuraman, Galster, Squire, Furukawa, and Miller (2005) showed that an interface which allowed such delegation of control between human and machine increased overall performance and reduced task completion time for unpredictable situations. The act of delegation itself may also serve to reduce a user's tendency to be complacent and instead promote attention towards monitoring system status and task completion (Martens \& Van den Beukel, 2013).

An important view on the automation of subtasks is also to distinguish between longitudinal and lateral control. Based on a study by Carsten, Lai, Barnard, Jamson, and Merat (2012) drivers feel more capable of turning their attention away from driving when given lateral support as compared to when they have longitudinal support. This provides important insight in understanding how the actual task being substituted affect operator engagement in the overall driving task. Carsten et al.'s study shows that lateral and longitudinal control have fundamentally different properties in terms of the amount of required preview. Automation of longitudinal control (i.e. ACC) has less impact on general driver engagement and situation awareness than automation of lateral control (i.e. a lane-keeping system). Furthermore, the extent to which failure-recovery is influenced by either automation of longitudinal or lateral control is largely influenced by the demandingness of the driving situation. When the driving situation becomes more demanding, performance of lateral control is more impaired than performance of longitudinal control (Ma \& Kaber, 2005; Rudin-Brown \& Parker, 2004).

Based on above collected insight how levels of automation influence driver-vehicle interaction when driving automatically, the following recommendations can be made in order to provide desirable support for supervision and intervention:

* Driver's performance is generally most improved by physical implementation assistance. 
* The driver must remain involved in the implementation part of a task to avoid decrease in task performance during transitions to manual control (e.g. recovery after automation failure).

* Avoid confusion due to joint human-computer involvement in option-generation.

* Consider driver-initiated (dynamic) delegation of control between driver and vehicle as a means to promote attention to the driver's supervisory task.

* Support of lateral control is most needed to improve performance after automation failures

\subsubsection{Shared authority}

With the notion that the driver retains ultimate responsibility for safe driving, concepts are being developed based on possibilities to deliberately share authority. Within such concepts the driver and automation are intended to work as 'team-members' and complement one another for managing the driving task as a whole. While the ultimate authority is still at the driver, the interface should then serve as a means for cooperating and sharing the authority (Young et al., 2007). Attuning the cooperation might also be a dynamic process that could change over time (Flemisch et al., 2012). Other researchers have proposed similar ideas, like Norman (1990) who reflects on automation acting as a human co-driver and Schutte (1999) refers to the roles of driver and automation as 'complemation'. The constitution how Automated Parallel Parking (APP) was originally introduced is a nice illustration of this approach (Pohl, Sethsson, Degerman, \& Larsson, 2006): The technology calculates the most optimal path and moves the wheel accordingly. At the same time, the driver is in control of timing the manoeuvre by using the pedals and let go or stop the vehicle. As parking requires unhindered crossing of other traffic participants, this allocation of functions between man and machine enables the driver to hold ultimate authority - after all, the driver remains in the control-loop. In addition, automation of the demanding steering manoeuvre frees up cognitive load from the driver to be more attentive to monitoring and timing the manoeuvre. While this approach contains a favourable aim to use the capabilities of technology and exploit the human's strengths while compensating for their weaknesses, the approach only yields as long as a situation is involved at least one team-member is good at. If the task-situation is not well suited for either team-member, it is still the driver that remains responsible and is required to act. To summarize, allocating tasks to create such a combination that driver and vehicle performance complement one another is strongly recommended.

\subsubsection{Shared control with non-driving tasks}

One of the main ideas of increasing automation is to allow the driver to do other things than driving without compromising. To expect the driver to stay in the loop, as long as the automation is fully capable of handling the situation, is considered unnecessary. Shared control is a framework whereby human and automation cooperate to achieve the required control action together (Saffarian et al., 2012). Therewith, this framework is comparable to the 
concept off shared authority. However, along with approaches for shared authority, approaches for shared control include potential solutions to alternate between vehicle-control and non-driving tasks. In this approach the operator and the automation are also viewed as one team that needs to be in the loop. The original idea of shared control was to have the automation deliver its input for transitions in control only when necessitated by an outer cue. However, this input could also be used to keep the driver at a concealed level in-the-loop and produce direct interruption of driver's engagement in non-driving tasks. Especially controltypes that facilitate fast exchange of information and intuitive interaction when intervention is needed, embrace this approach - for instance: controls in the style of the $\mathrm{H}$-control described by Flemisch et al. (2008) and haptic control by Abbink, Mulder, and Boer (2012). A strong point of this approach is the efficient way how control is handed back to the other team player when it becomes necessary. For fast and effective information transfer, system-output used as userinput and transferred via the neuro-muscular system, e.g. by means of force-feedback, seems promising (Mulder, Abbink, \& Boer, 2012).

\subsection{Conclusions: required support for supervision and intervention}

This chapter explained that besides expected benefits for safety, comfort and traffic efficiency, the automation of the driving task fundamentally changes the required skills and cognitive demand of the human operator. In short, the driver's role changes to supervision with occasional necessities for intervention. While being placed outside direct control of the vehicle, this changing role causes several performance problems, like: behavioural adaptation, mode confusion, reduced Situation Awareness, inappropriate workload and skill degradation. The driver's need of sufficient SA was found key in order to intervene when required. After a review of measurement methods to assess SA, it remained nonetheless undefined what SAmeasurement technique would be most applicable in this thesis' research. Selection of an appropriate technique for SA-measurement will therefore be accounted for during development of the assessment framework in chapter 5. Insight in the origins of OOTLproblems, their consequences with respect to SA and driver performance in general, together with a review of existing approaches to overcome automation induced performance problems in the previous section, provides us with important insight in how interface-solutions should preferably improve the interaction between driver and vehicle when driving automatically. In order to provide optimal support for supervision and intervention, this chapter therefore concludes that desirable interface solutions should be aligned with the following baseline design-directions:

* Provide insight in the system's operational envelope and create awareness for the conditions that influence changes in automation-state. In other words, the driver needs to be aware of system-limits, i.e. system's boundary conditions. Most boundary conditions relate to sensor limitations and system design choices. The interface should help in communicating these conditions. An example is to indicate whether road markings are registered. If a driver then enters a section with bad road conditions this 
awareness would help to anticipate and understand that the lane markings might be insufficient for the system to deal with. Raised understanding of system-limits and awareness of state-changes is also expected to help raising appropriative trust in the automation and to avoid negative behavioural adaptation. In this respect, providing information on system's reliability might be beneficial.

* Along with insight in the system's operational envelope and boundary conditions, the driver should be provided with adequate information when changes in automationstate occur. This information should be transferred fast and effectively. In addition, an interface needs to enable drivers to check the automation-state at any desired moment and to understand this information directly and unambiguously. Information on system's limits and subsequently changes in available automation mode should help drivers to build up correct mental models of driving automation.

* In addition to awareness of boundary conditions and changes in automation-state, the identification of hazardous situations along with directional information on the location, distance and criticality of such situation is assumed to be key for the interface in helping the driver to react appropriately and timely. In this respect, it is especially important to note that driver's performance for intervention benefit more from supporting lateral control (for example identification of potential hazards from aside) than from longitudinal support.

* Another important aspects that interface-solutions should address is to help drivers remain situational aware during automation. Preferably, drivers remain involved in the implementation part of a task to avoid insufficient SA during transitions to manual control. Also, the interface should help drivers to expand situation awareness fast and effectively to allow adequate intervention when necessary.

* Interaction should be designed as to keep mental workload at a moderate level through enhancing driver-readiness; keep the driver sufficiently involved in taskoperation and provide continues feedback on task-execution, for example through indicating system's reliability. Furthermore, the design should anticipate that (semi-) automated vehicles will result in drivers addressing attention to non-driving tasks. Therefore, solutions that actively moderate the driver's involvement between performing secondary tasks and primary driving task when required, could be beneficial.

* Provide instructions on the required role of the driver, especially at moments of modechanges in order to avoid confusion about the required driver's role. These instructions should be provided in a way which is understood intuitively and fast. In this respect care is necessary with providing explanatory information as it might cause confusion if human and computer are jointly involved in decision-making.

- Provide timely and self-explaining warnings. Enable the driver to come back in the loop in a fast and easy way: The automation, should provide output that is directly intuitive for the driver, and is transferred fast. 
This chapter explained human-centred design challenges and contributions for the implementation of driving automation. Through collection of baseline design directions conclusions have been provided on basic principles how new interface-solutions could contribute to desirable driver-vehicle interaction that supports drivers with their changing role. These directions are an important source for inspiration for the design process starting in chapter 4 . Next, chapter 3 will present the overall research approach employed in this thesis. 


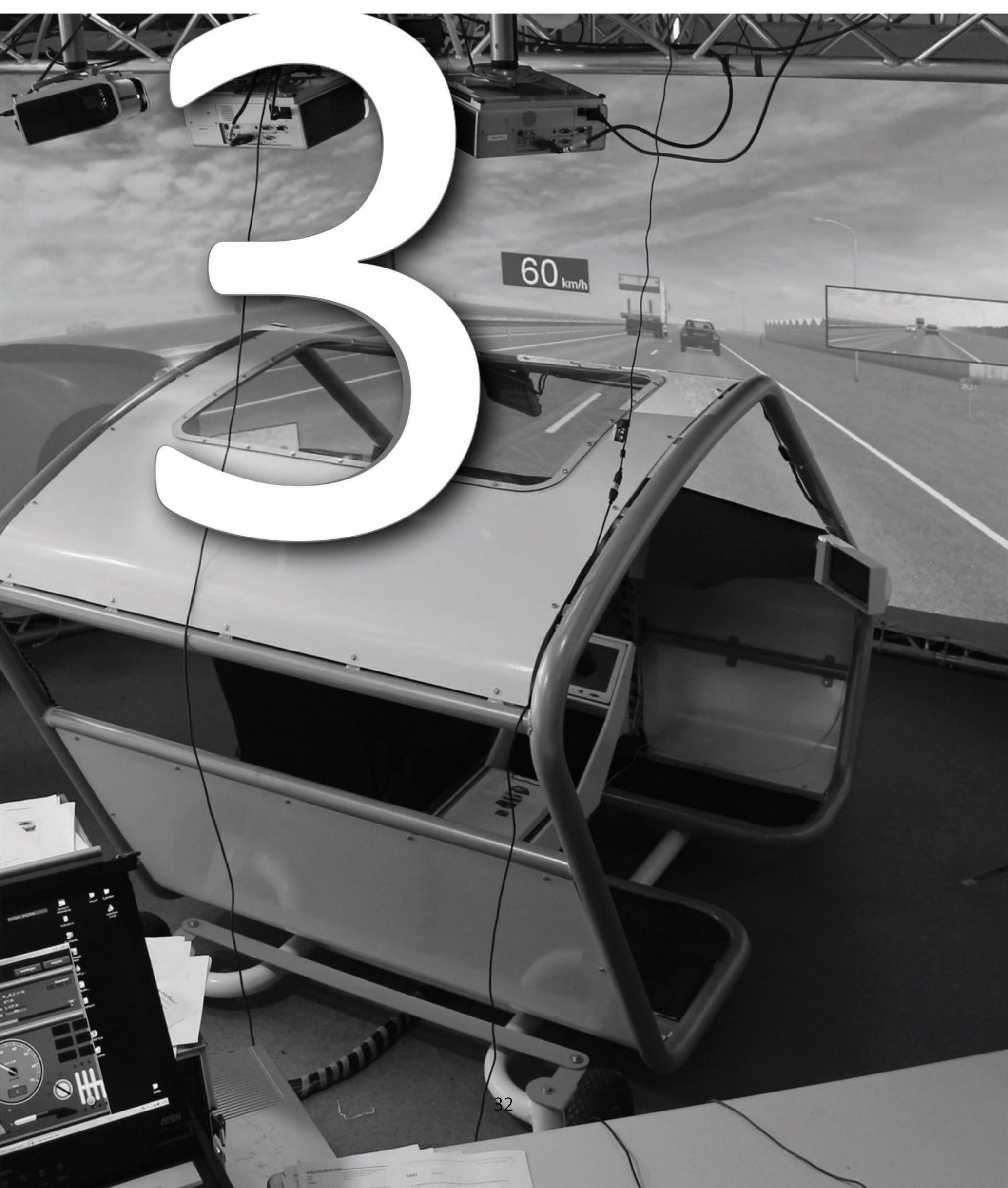




\section{Chapter 3. Research approach}

\subsection{Introduction}

The goal of this thesis is to provide recommendations for designing an interface that supports drivers in performing supervisory tasks with (occasionally needed) intervention, during automated driving. Because the introduction of automated driving fundamentally changes the driver's role from actively operating the vehicle to a rather passive role of supervising the automation, the creation of appropriate solutions is likely to introduce some disruptive designs compared to existing interface solutions. Small changes to traditional interfaces will probably not be sufficient to support the driver's changing role. We also observe, that the automotive industry is not only in need of appropriate solutions (Hesse et al., 2011; Hesse et al., 2012; Naujoks, Purucker, Neukum, Wolter, \& Steiger, 2015; Saffarian et al., 2012), but also needs evaluation procedures to assess the driver's changed role and performance criteria to test against potential solutions (Landau, 2002; Nirschl, 2007). Therefore, recommendations in this thesis for the development of appropriate interface solutions are intended on two levels: (1) with regard to evaluation of potential solutions and (2) with regard to interface-features that contribute to desirable solutions.

To define an approach for fulfilling this two-fold aim, we need to recognise that:

* Interactive systems that utilize advanced technologies can rarely be completely specified upfront. That is, before some design work has been done;

* Design is rarely a straightforward process and typically involves much iteration and exploration of both requirements and design solutions;

* The interface to an interactive system is in itself a complex phenomenon while consisting of all parts with which people come into contact, physically (e.g. knobs and buttons), perceptually (e.g. things to see and hear) and conceptually (e.g. trying out interaction).

Therefore we aim at an overall research approach which is exploratory and multidisciplinary.

Such approach involves assumptions based on existing research and preliminary exploration that guide the direction of potential solutions. These solutions are then applied to empirical evaluation based on qualitative and quantitative assessment in order to generate insight in the appropriateness of these potential solutions. This is why such approach is also adopted for this thesis. Since different disciplines hold different methods and techniques to help with this process, we need to combine in our approach methods from different disciplines too. Benyon summarizes this approach with "the process to design interactive systems requires a fusion of skills" (Benyon, 2010). As a result, our approach can be defined as mixed methods research (Creswell \& Clark, 2007; Johnson \& Onwuegbuzie, 2004). Retrieving data from multiple methods provides rich datasets. Quantitative results could for example be enhanced with findings from qualitative data. Therewith, mixed method helps to have more in-depth 
information and knowledge of the problem as well as the characteristics that thrive potential solutions (Creswell \& Clark, 2007). It may also assist to increase the findings' reliability and credibility through comparison of evidence found from different methods. Furthermore, one method may compensate for the other if a method appears to have shortcomings. Therefore, the reliability of the overall assessment approach increases with mixed methods. Hence, applying a mixed methods approach is both a necessity due to the complexity of developing new interactive systems, as well as an advantage to gain effective insight in recommendable interface-directions.

\subsubsection{Approach for the assessment of driver's interaction}

With regard to the first level of our intended recommendations, i.e. evaluation of potential solutions, our main objective is to answer: How to assess driver's interaction with partially automated driving? To obtain this objective, our approach includes definition of an assessment framework to allow qualitative and quantitative evaluation. Apart from selecting relevant assessment aspects and subsequent measurement techniques, this definition also requires validation and testing of the framework's reliability before we are able to derive meaningful recommendations from its assessment results. In line with the dual characteristic of the driver's changing role, our framework needs to assess performance with respect to both supervision and intervention. As supervisory performance is strongly related to driver's understanding how system-activity influences demand for human intervention (like understanding the required human (re)actions due to changes in automation-state), assessment of supervisory control should especially address cognitive performance. Intervention tasks, on the other hand, are strongly related to operational capabilities to perform fast and accurate counter-measures and undertaking actions timely and adequately to solve a critical situation. Assessment should therefore include task performance, i.e. speed, accuracy and effectiveness of taken actions. The assessment also needs to account for overall appreciation and acceptance of potential solutions. Without driver's acceptance of the offered interface-support, they will not be willing to use it and hence these solutions will not be effective (Venkatesh, 2000). Dislike of interfaces may even reduce correct interaction due to mental stress associated with irritation. This is why testing of acceptance and perceived comfort is important (Nielsen, 2005). Hence, our approach is to define a framework that includes assessment of (a) Situation Awareness, (b) Accident Avoidance and (c) Acceptance. The review and selection of appropriate means to measure these aspects will be part of development of the framework in Chapter 5. Furthermore, the assessment framework should provide testing conditions which are as close to real-world circumstances as possible. Therefore we envision testing by means of driving simulation for which scenarios need to be selected representative for automated driving. As explained in the previous section, the mixed methods approach allows to gain more in-depth information and knowledge about potential solutions. However multi-criteria assessment also makes it more difficult to compare the data and bring them into meaningful contact. Subsequently, validation of the framework's 
outcomes demands particular attention. Therefore, a two-fold approach for validation of the framework will be applied: (1) Assess the extent to which results retrieved from several measures correlate among one another with respect to identifying different levels of support. (2) Test the framework with pre-defined interface concepts in order to measure correlation between concept-scores and predefined concept-support. Consequently, along with defining the framework, also three exemplary interface-concepts will be introduced in order to pilottest the proposed framework.

\subsubsection{Approach to provide interface recommendations}

With regard to identification of recommendable design-features, our objective is to produce well-founded interface design recommendations relevant to design practice and relevant to real-world circumstances. Therefore our approach anticipates iterative steps between prototyping potential solutions and evaluation. Although the literature and guidelines regarding human-machine interface design is extensive, an approach to derive initial design directions from this information alone is considered insufficient. This is due to the generic nature of the guidelines whereas the driver's changing role demands dedicated support. Our approach therefore starts with an expert workshop to identify promising directions for interface-solution, based on generic interface design recommendations in combination with expert judgements. Thereafter, our approach anticipates three steps of probing potential solutions and evaluating them within our previously defined framework. The first step includes evaluation with preliminary designs used during the framework's validation. The driver's changing role is dominated by a demand for supervision. This is why the second step especially evaluates a potential interface solution to illuminate objects and situations outside the vehicle that require supervision. Then, step 3 provides an extensive exploration and evaluation of three interface-solutions (one based on 'illumination', another being a rather conventional display concept and a third base-line concept), tested with regard to support for both supervision and intervention. After this series, our approach employs an overall comparison of all assessed concepts, before collecting final recommendation on interface-features that offer adequate support which drivers need in order to perform supervisory tasks with (occasionally) intervention, during automatically driving.

\subsection{Apparatus and scenarios for testing}

\subsubsection{Experimental research}

Since the selected explorative approach consists of a series of experiments that repeatedly measures all the main assessment aspects throughout the development, selection of appropriate means for testing requires special attention. The main object of testing in this thesis is driver-behaviour. To include driver-behaviour in the testing environment, the approach favours experimental research. Means for experimental research should be able to combine with this thesis' explorative approach. That is, it should support test taking with 
prototypes available early in the design process. Methods for experimental research generally differentiate with regard to their level of complexity (see Figure 3-1) and this differentiation influences both validity and controllability. Validity represents the extent to which a method reveals behaviour that would also emerge under non-experimental, i.e. real, circumstances. Controllability regards the extent to which the examiner can control that each participant is confronted with the same experimental conditions. Therefore, validity and controllability are important criteria for the selection of methods for experimental research. Furthermore, the availability of the assessment means (i.e. availability of test-objects like prototypes within representative circumstances) and safety concerns (i.e. risks placed on participants and surroundings during an experiment) are important too.

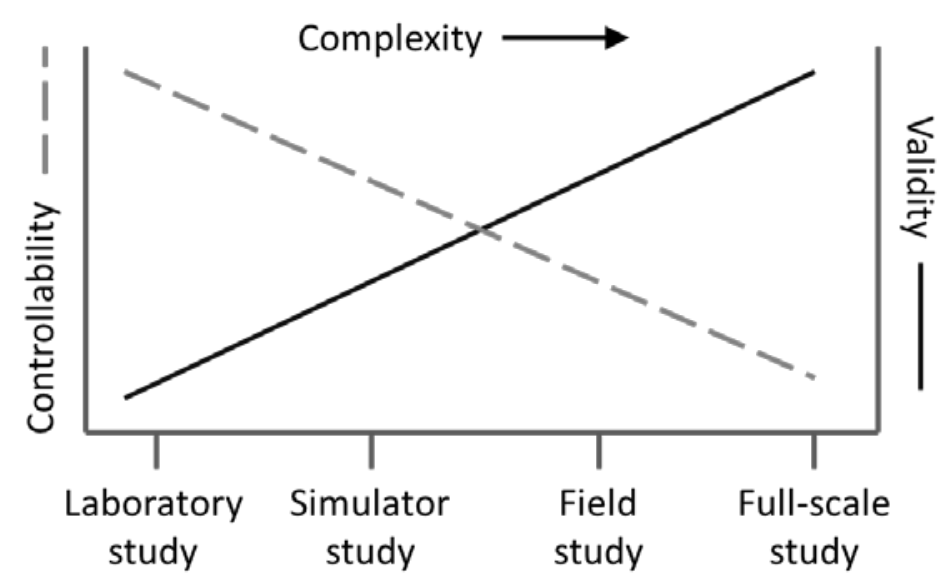

Figure 3-1 Complexity of different methods for experimental research as a function of validity and controllability

Figure 3-1 indicates four types of possible experimental research methods:

* Laboratory studies typically examine single aspects under highly controlled circumstances. Therefore, this method holds the advantage of high reproducibility and low safety risks. However, the disadvantage is reduced validity because the laboratory circumstances often represent real world situations only at a limited scale or for single instantiations.

* Simulator studies allow, compared to laboratory studies, a more comprehensive examination of assessment aspects, within a simulated environment that represent real-world circumstances. General advantages are high controllability (that in turn, contributes to reliability and reproducibility) and low safety risks. The validity of simulator studies depends on the sophistication of the simulation. And this in turn relates to the feasibility of the simulator apparatus at hand to produce close-to-reality circumstances. Another advantage is that simulator studies allow testing when prototypes are available early in the design process. 
* Field studies evaluate a system under real life circumstances with a focus on a single or reduced amount of aspects. Its limited scope provide field studies moderate feasibility, while offering at the same time good validity. Disadvantages are moderate controllability and safety risks.

* Field operational tests (FOT) comprise large scale evaluation of a system under real life situations. Test taking focusses on acquiring data from a large sample typically during prolonged times in order to cover as much as possible the operational situations that are to be expected during the lifespan of the product. Therewith, this method benefits from high validity. However, for application in this thesis' research FOTs are not feasible due to the inability to have prototypes reliably available on such large scale. What is more, the method would cause high safety risks.

Based on afore review of available research methods, driving simulator studies are most applicable for this thesis' research. This is due to: (1) the difficulty to test with prototypes in real-world early within the development process; (2) controlled environments are preferred for reliably and reproducibly testing; (3) Some of the traffic situations important to the assessment of the driver's changing role are too dangerous to test in real life circumstances (e.g. scenarios that require intervention).

As mentioned, the sophistication of available means for driving simulation provide a trade-off for the possibilities to simulate different and realistic road-traffic situations and behaviours of road-users. Nonetheless, the assessment of potential solutions within situations representative for real-world circumstances is essential to our approach. Therefore, the next section (3.2.1) will first investigate the available capabilities of our driving simulator and thereafter section 3.2.2 will select scenarios that are both representative for the driver's changing role, as well as applicable for simulation in our facilities. The explorative approach in this thesis consists of a series of experiments that repeatedly measures all the main assessment aspects throughout the development. Consequently, the development of scenarios that are representative for the driver's changing role and the availability of such scenarios in the driving simulator's facilities, provide important generic research tools that will be applied throughout this research.

\subsubsection{Driving simulator}

The physical set-up of the driving simulator consists of a car mock-up placed in front of a visual screen. The visual screen divides in three parts. Each part measures $2.70 \mathrm{~m}$ in width and $2.30 \mathrm{~m}$ in height. The centre part is placed in front of the vehicle at a distance of $2.95 \mathrm{~m}$ to the $\mathrm{H}$-point ${ }^{3}$ of the driver's seat position. In the horizontal plane, the parts at the left and at the right of the centre are positioned at $120^{\circ}$ angle with the centre piece. Three video projectors display each

\footnotetext{
${ }^{3} \mathrm{H}$-point refers to the hip joint of a 50th percentile male occupant, according to (SAE International, 2005).
} 
the corresponding part of the traffic-simulation and the projected parts are seamlessly connected to provide one driving scene with $180^{\circ}$ field of view. Figure 3-2 gives an impression of the used simulator setup. The size and position of the screens offer an immersive driving impression. The simulator is non-moving based. Therefore, motion is seen but not sensed by the user's vestibular system. This could be a potential cause for simulator sickness. However, experiments in the past with situations of rather homogenously driving and small motionchanges showed negligible influence on motion sickness. Because our scope with automated driving is on traffic jam assistance, i.e. highway scenarios with reduced speeds, the simulator is also considered applicable for our research needs. The facility is characterized as a midfidelity simulator and based on J. D. Lee et al. (2013) the application of this type of simulator is in line with our needs. Nonetheless, the characteristics of our driving simulator cause some limitations to the composition of traffic scenarios - which will be explained and accounted for when detailing our driving simulator scenarios in section 3.2.3.

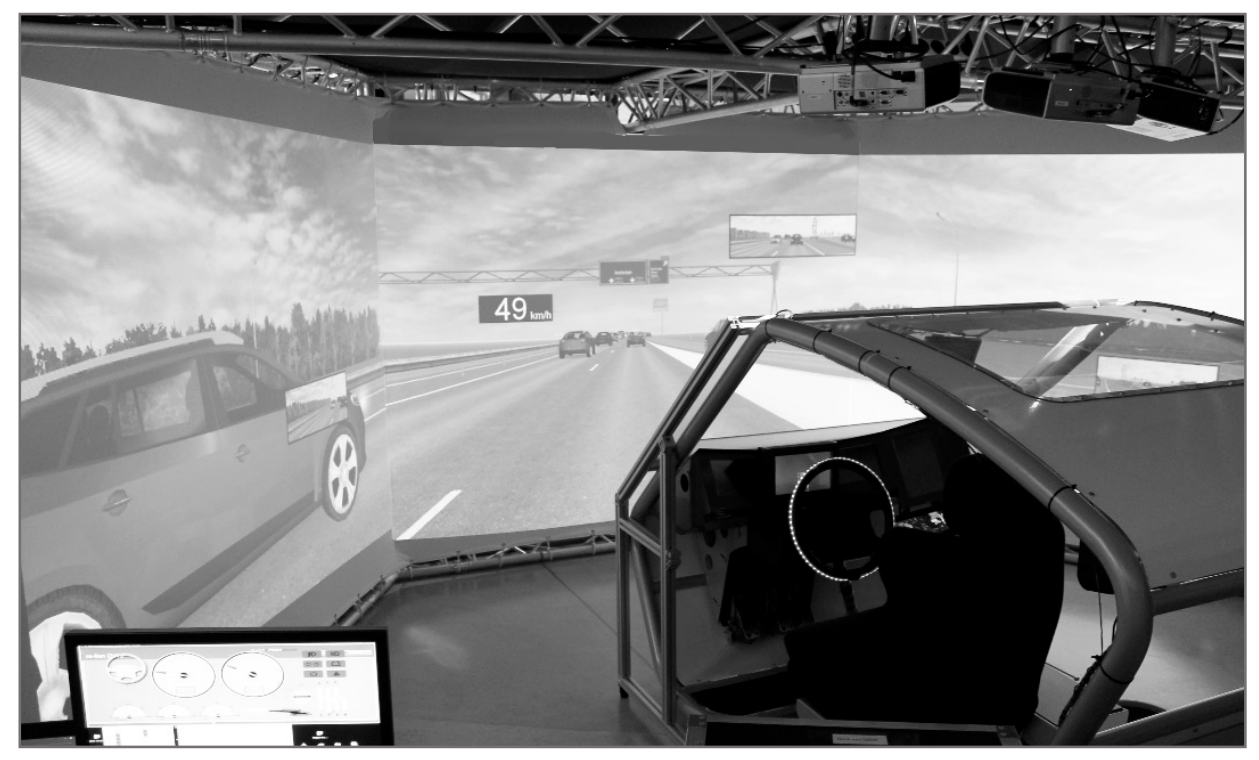

Figure 3-2 Driving simulator environment

The virtual environment is generated with simulation software developed by Re-lion. The software consists of two parts: Lumo World allows to generate simulated geometry, like road layout and environment (e.g. landscape and buildings). Lumo Drive defines the vehicle dynamics and driving control of both the ego-vehicle and other traffic participants. Programmed vehicle behaviour is based on algorithms that define absolute positions in time and space or relative positions. When based on relative positions the vehicle is for example set to keep a minimum distance to other vehicles much like adaptive cruise control does in real vehicles. Programming based on absolute positioning allows to create repeatable scenarios that always offer identical possibilities and levels of difficulty to master a situation. This is because a particular vehicle is then programmed at a predefined position in time and space to perform a specific manoeuvre, like accelerating, merging to another lane or exiting the motorway. The interruption on traffic flow due to such event might cause a necessity for a participant to intervene or create circumstances that add extra relevance for adequate 
supervision. Between trials, vehicle type and colour are randomly assigned from a predefined set of vehicle characteristics. Mirrors and vehicle speed are projected onto the outside screen. Driving data, like vehicle speed, following gap and lateral position are recorded at $10 \mathrm{~Hz}$. Furthermore, time-markers for pre-defined events facilitate the investigation of driving data after situations relevant for our research. Due to projection, the resolution on the screen is about 9dpi. As Risto (2014) reported, this resolution may hamper correct judgement of speeddifferences with vehicles at the longer driving distances. Due to our targeted application, low velocity and jammed driving conditions (i.e. shorter travelling distances), this characteristic of the simulator environment is not considered to influence performance during our driving situations.

The simulated world consisted of a road circuit with a total length of about $28 \mathrm{~km}$ and is schematically depicted in Figure 3-3. The simulated road was dominated by a two-lane motorway and included sections with a motorway merge, off- and on-ramps, both single and dual lane curves. To add realism, vehicles on the left lane drove the speed of vehicles on the right lane plus 5\%. Using predefined scenarios allows to start at any desired point along the track. The simulated road circuit in Lumo World combined with desirable traffic behaviour programmed with Lumo Drive therewith enabled creation of a variety of scenarios.

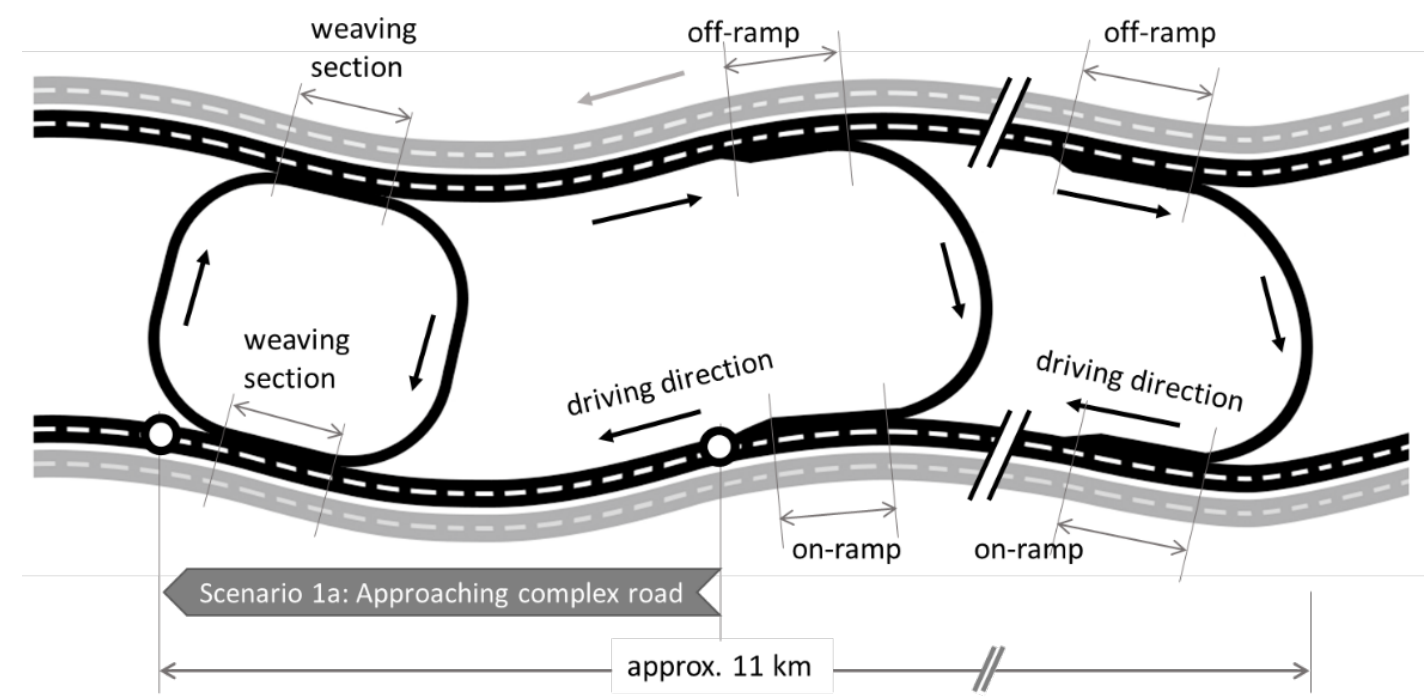

Figure 3-3 Schematic overview of simulated road circuit in Lumo World. Positioning of the scenarios was divided over the road circuit.

Note. The example shows the location of scenario 1a (Complex road) before a weaving section with combined on- and off-ramp. (Picture not to scale).

The mock-up car used in our simulation has an automatic gearbox. Both the exterior and interior is tailor-made to allow simulator testing and does not represent a specific brand or model. The mock-up is equipped with traditional control devices, like steering wheel, indicators and pedals. Five screens are placed in the interior that allow to offer output and display vehicle data or other information like a map or entertainment. Furthermore, the interior is equipped with 4 loudspeakers at each corner of the interior and vibro-tactile pods in the seat-pan. 


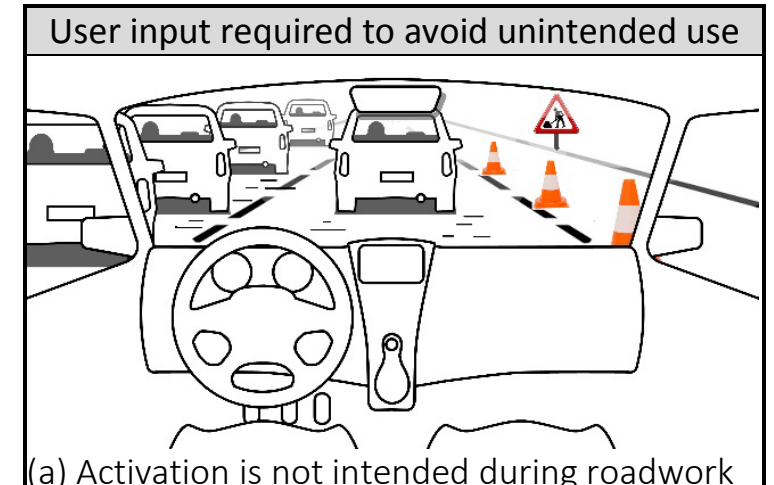

(a) Activation is not intended during roadwork

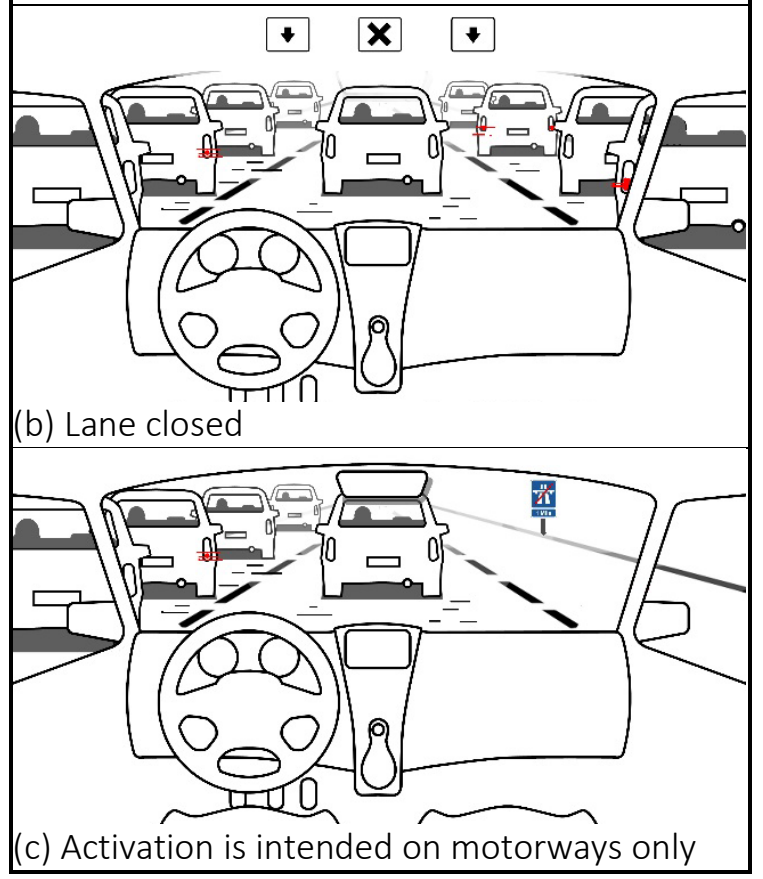

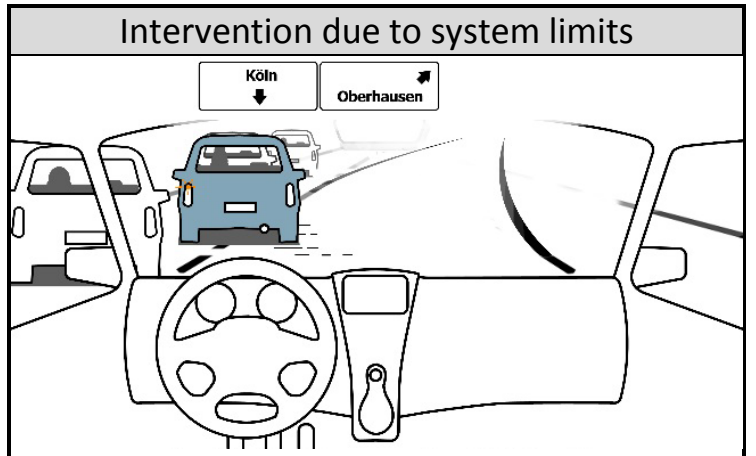

(d) Target-vehicle leaves lane: no new target

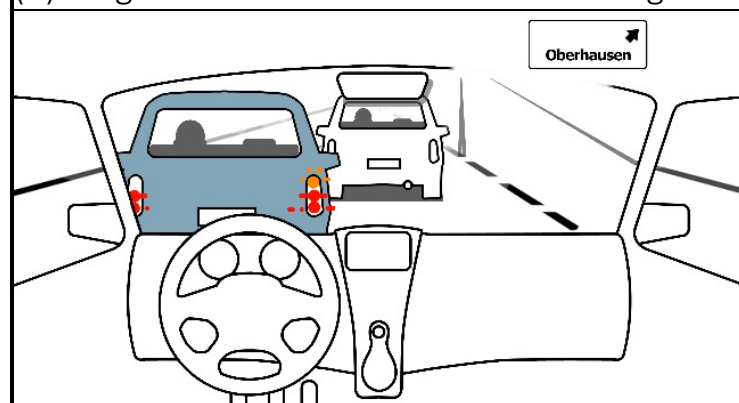

(e) A neighbouring vehicle comes in too close

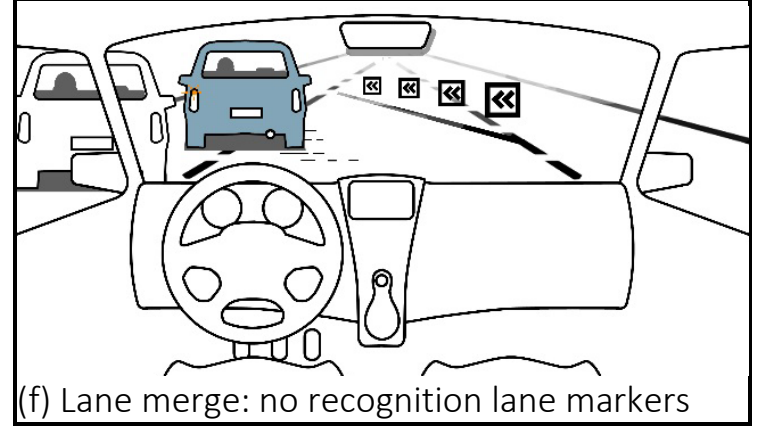

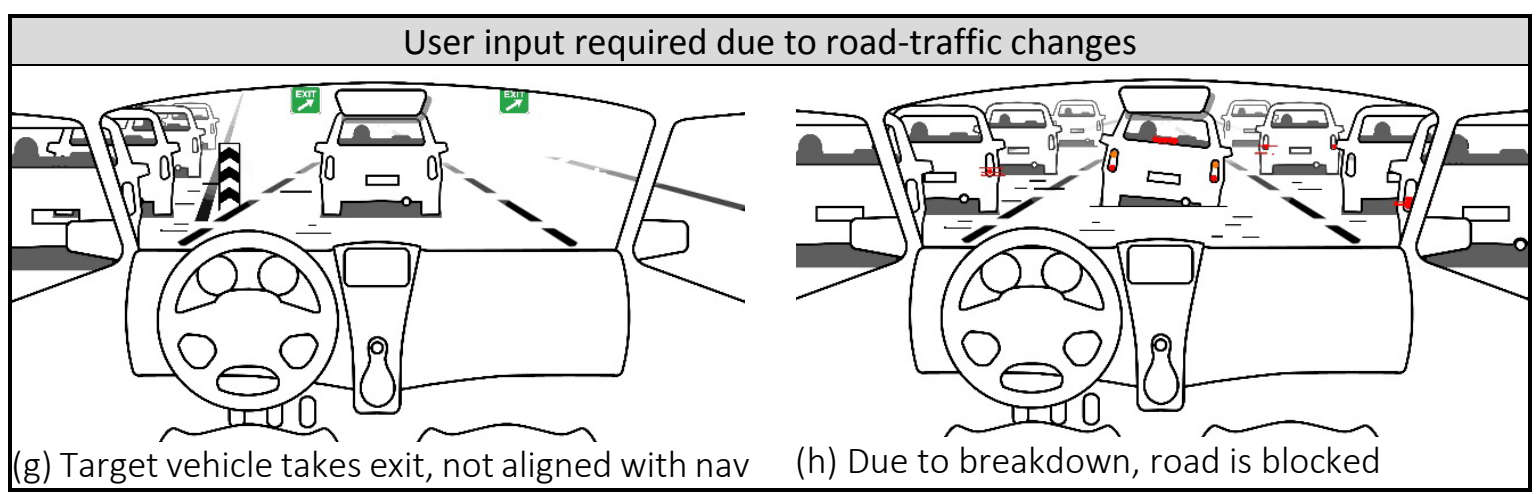

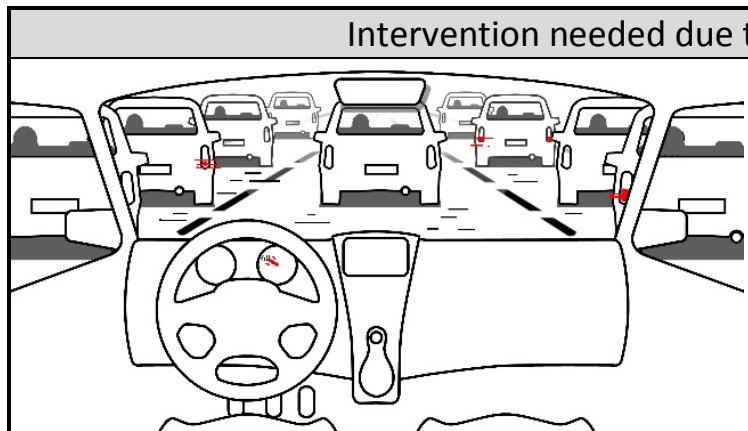

(i) traffic-speed raises above threshold

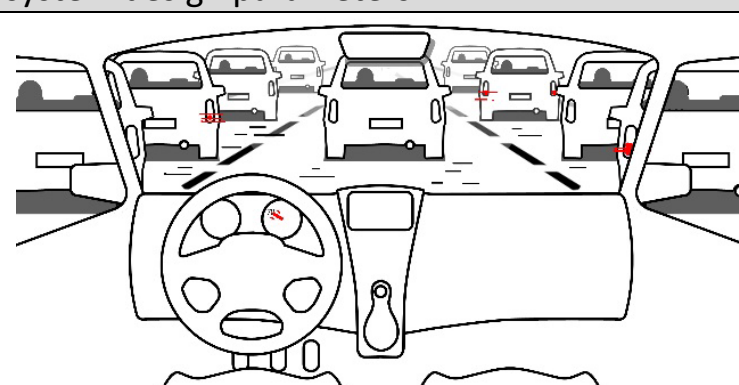

(j) Activation fails: speed is above threshold

Figure 3-4 Selected scenarios based on review of several catalogues with use cases. 
By default the screens and other stimuli are inactive and only display information if specifically programmed. The generic interior mock-up and programmable displays allow to try-out and do experiments using a variety of perceptual stimuli, providing different cues for required action or other feedback.

Based on the above description with our driving simulator capabilities, base principles of our approach to simulate scenarios will be three-fold: Firstly, an ego-vehicle will be 'launched' at a specific point within the simulator world driving directly automatically. This ensures that every participants has the same start with a specific scenario. Secondly, at specific points in time and space another traffic participant is programmed to perform a specific action that induces a raised need for supervision or requires intervention. Thirdly, measurement techniques (described in section 5.3) then allow to assess driver's awareness of the situation and ability to solve the situation.

\subsubsection{Traffic scenarios ${ }^{4}$}

Golden rule in driving simulator research is that test conditions include the physical environment, restrictions on available information, time limitations, etc. representable for the real world circumstances (Harris, 2002; Tideman, Van der Voort, \& Van Arem, 2010). To define scenarios representable for automated driving as referred to in the introduction, we acknowledge that scenarios should reflect a demand for relevant supervision and intervention to represent the driver's changing role. This demand, in turn, originates from specific technical boundary conditions - like recognition of lane markers - and system design choices. The choices in system design are made to ensure sufficient safe system operation, for instance: restriction to apply automation only on motorways. As explained in section 1.4 (Research Scope) the particular focus within this research is on driving automation during traffic jams, i.e. Traffic Jam Assist. In general, this application is set by the following boundary conditions: (a) application on motorways, (b) during low-speed stop\&go traffic, (c) availability of a targetvehicle within detection-range on the same lane and/or recognition of road-lines. As technology advances, system design's conditions might open up and allow more advanced system operation in future. Our base assumption is nonetheless that also future vehicle-driver interaction will need to account for restrictions due to boundary conditions. Furthermore, as technology advances, the demandingness of intervention when automation limits are reached, might even grow stronger as exercise reduces. To be representable for automated driving capabilities as currently being developed, we reviewed several catalogues with use-cases: One scenario-catalogue from a manufacturer's internal research documentation (Gunia et al., 2011); several reports with scenarios for an information, warning and intervention (IWI)

\footnotetext{
${ }^{4}$ Section 3.2.3 is based on: Beukel A.P. van den, Voort M.C. van der, Eger A.O. (2015). Towards a Framework for Testing Drivers' Interaction with Partially Automated Driving. In: Intelligent Transportation Systems (ITSC), 2015 IEEE 18th International Conference on. IEEE, 2015. pp. 1902-1907.
} 
strategy collected within the EU-funded interactIVe project (Bolovinou, Kotsiourou, \& Amditis, 2013; Hesse et al., 2012; Mäkinen et al., 2010), and also earlier work with envisioned future scenarios of dual mode vehicles collected during the CityMobil project (Martens et al., 2008). All, provided valuable input for relevant scenarios. Based on this review, the thesis' particular focus on congestions assistance, previously explained simulator restrictions and user preferences for ADAS (Van Driel, 2007), an adequate approach for our driving simulations contain the following base assumptions:

* Driving is automated with regard to both lateral and longitudinal control;

* With a speed-threshold limited to $50 \mathrm{~km} / \mathrm{h}^{5}$;

* At motorways.

With the preconditions of:

* Recognition of lane markings (i.e. road lines);

* Recognition of a target vehicle on the same lane, and;

* A minimally required gap-distance.

If any of these boundary conditions are not being met, this would cause termination of the automation.

In order to be representative for the dynamic and diverse character of possible road and traffic situations associated with automated driving in practice, our approach is to provide a set with sufficiently different levels of required comprehension and ability to solve a situation. We therefore distinguish two categories, which we call 'hazardous' and 'critical' scenarios. 'Hazardous' scenarios are defined to enclose situations with a need for extra attention from the driver, but without the necessity for intervention. 'Critical' scenarios are defined to represent situations which require driver's intervention in order to avoid an accident. Based on afore mentioned catalogue reviews and base assumptions a list was created with 10 representable scenarios, which are visualized in Figure 3-4. The figure visualizes that the need for either supervision or intervention is evoked by four generic occasions collected through the catalogue-review:

Unintended use (e.g. during road works, closed lane or non-motorway driving)

* System limits (e.g. lane ends, lost target-vehicle or violation of minimally required gapdistance)

* Road-traffic changes (e.g. blocked road, unanticipated exit-lane)

* Specific design parameters (e.g. speed-traffic is above speed-threshold)

\footnotetext{
${ }^{5}$ This means that automation would only be available below $50 \mathrm{~km} / \mathrm{h}$.
} 


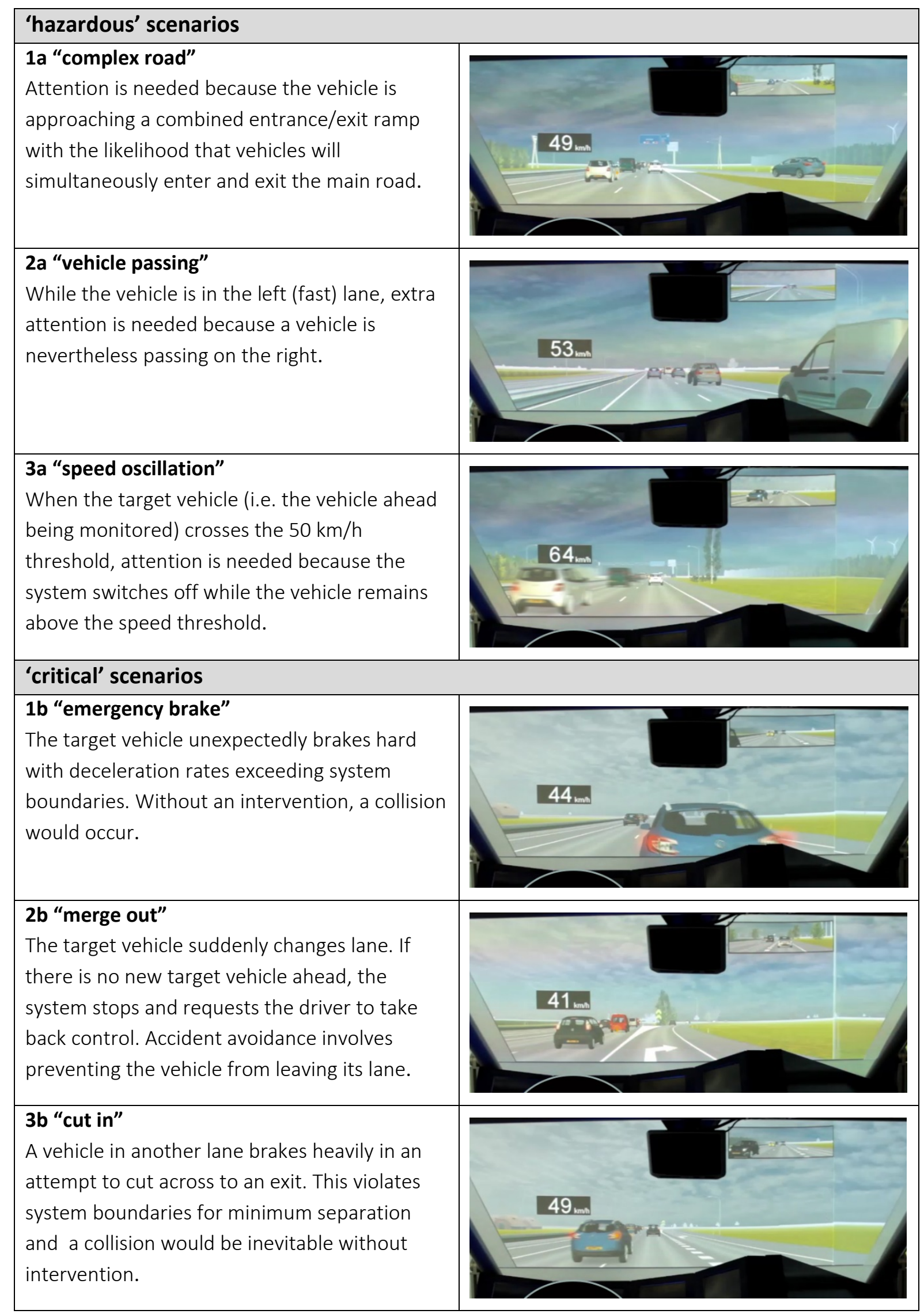

Figure 3-5 Defined 'hazardous' and 'critical' scenarios 
Finally, these scenarios were reduced to a set of six, based on practical considerations linked to our driving simulation capability. For example, we did not have the availability of a "closed lane" scenario on the road circuit's layout (See Figure 3-3). Simulator restrictions also caused the exclusion of a situation with failing road lines. The remaining six scenarios were equally divide over the two categories, i.e.: three hazardous and three critical scenarios. The proposed set is displayed in Figure 3-5 and consists of the following hazardous scenarios (which entails situations with a need for extra driver's attention, but without the necessity for intervention):

* Scenario 1a "complex road" - In this scenario, the ego-vehicle approaches a combined on and off ramp. Although the ego-vehicle continues on the main road, driver's attention is needed because the likelihood that some vehicles will enter or exit the main road simultaneously causes potential danger.

* Scenario 2a "vehicle passing" - While the ego-vehicle is driving at the left (fast) lane, a vehicle passes at the right violating traffic rules. Therefore, extra attention is needed.

- Scenario 3a "speed oscillation" - Within this scenario, traffic slows down to approximately $35 \mathrm{~km} / \mathrm{h}$ and later on accelerates again. When speed transgresses 50 $\mathrm{km} / \mathrm{h}$ attention is needed because the system would terminate if follow-speed would continue to be above the system's speed threshold.

The 'critical' scenarios enclose situations which require driver's intervention in order to avoid an accident:

* Scenario $1 b$ "emergency brake" - Within this scenario a target vehicle performs an emergency brake unexpectedly with deceleration rates exceeding system boundaries. Without intervention a collision would therefore be inevitable.

* Scenario 2b "merge out" - The ego-vehicle drives at an entrance road that transgresses into a combined on and off ramp. Navigation instructions are set to stay on the combined on and off ramp, that is to exit the motorway again. Just before the end of the exit, the target-vehicle decides to change lane. As there is no new target-vehicle, the system requests the driver to take back control and stops automation. Without intervention the vehicle roles out uncontrolled. Hence, accident avoidance involves in this scenario preventing the vehicle from leaving the lane.

* Scenario 3b "cut in" - While the ego-vehicle passes an exit, a neighbouring vehicle cuts in unexpectedly and brakes strongly in an attempt to take the exit in time. This is a critical situation because system boundaries for minimum required follow-distance are being violated. Therefore a collision would be inevitable without intervention.

Our approach anticipates assessment of these scenarios with respect to their ability to generate different levels of difficulty for supervision and intervention in Chapter 5: Assessment framework. 


\subsection{Research outline}

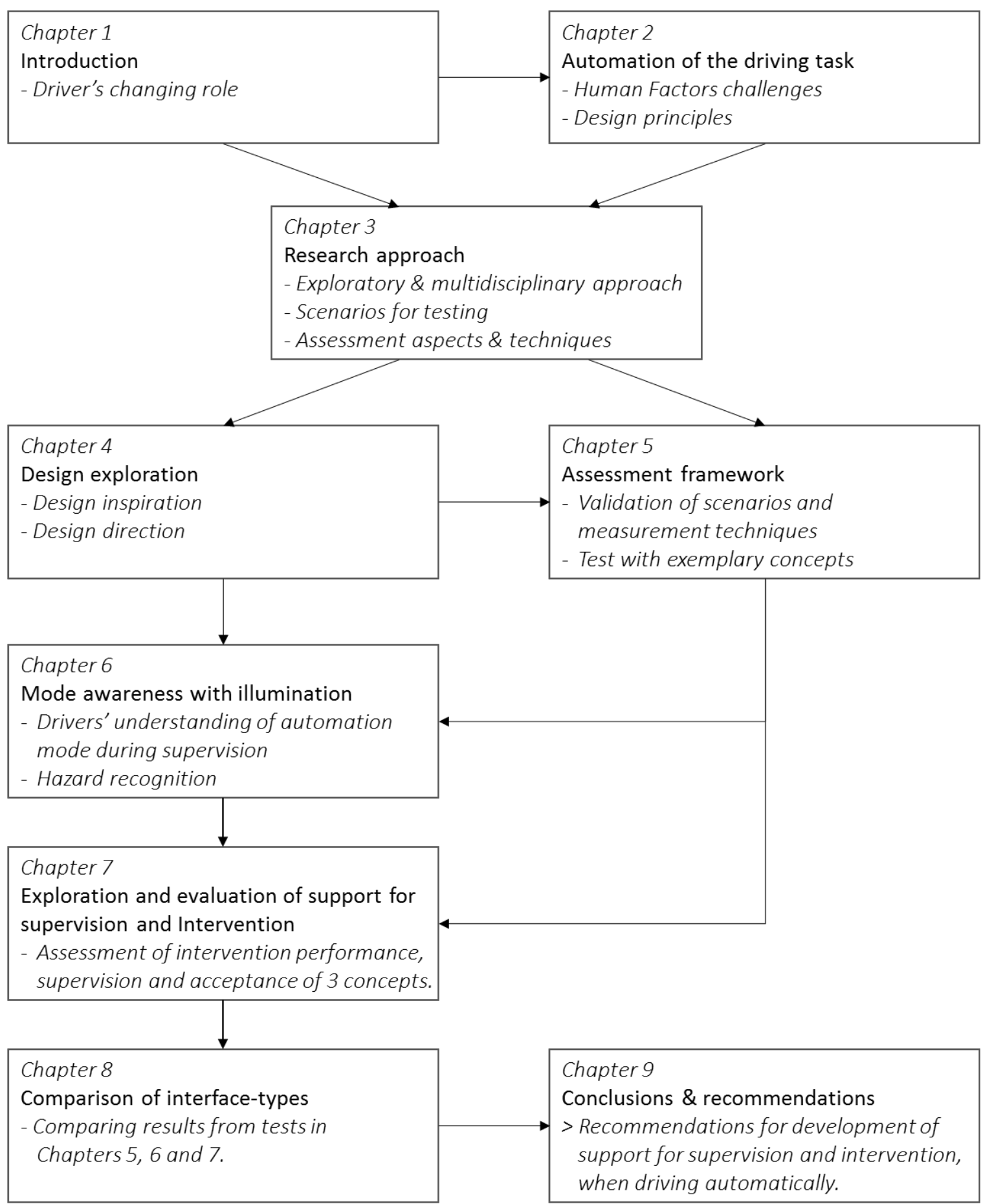

Figure 3-6 Schematic overview of research outline with explorative steps between development, probing out and evaluation.

Figure 3-6 visualizes the overall approach with reference to the chapters in this thesis. After Chapter 2 has been collecting general design directions, Chapter 4 provides an initial exploration based on a workshop with experts from the automotive sector in order to identify 
potential interface solutions for further development. Next, Chapter 5 focusses on the development and evaluation of the assessment framework by means of a driver-simulator experiment that includes testing of a first set of potential solutions. Thereafter, other potential support features are studied in two successive experiments: Chapter 6 focusses primarily on support for supervision through testing system-understanding with a specific visual cue (i.e. directional illumination in the windshield). Chapter 7 then explores and evaluates support for both supervision and intervention of three concepts within an elaborate driving simulator study. In the end, the outcomes of all three studies are compared with one another in Chapter 8. The 9th and last chapter presents final conclusion and recommendations for designing interfaces that supports drivers in performing supervisory tasks with (occasionally) intervention when driving automatically. 


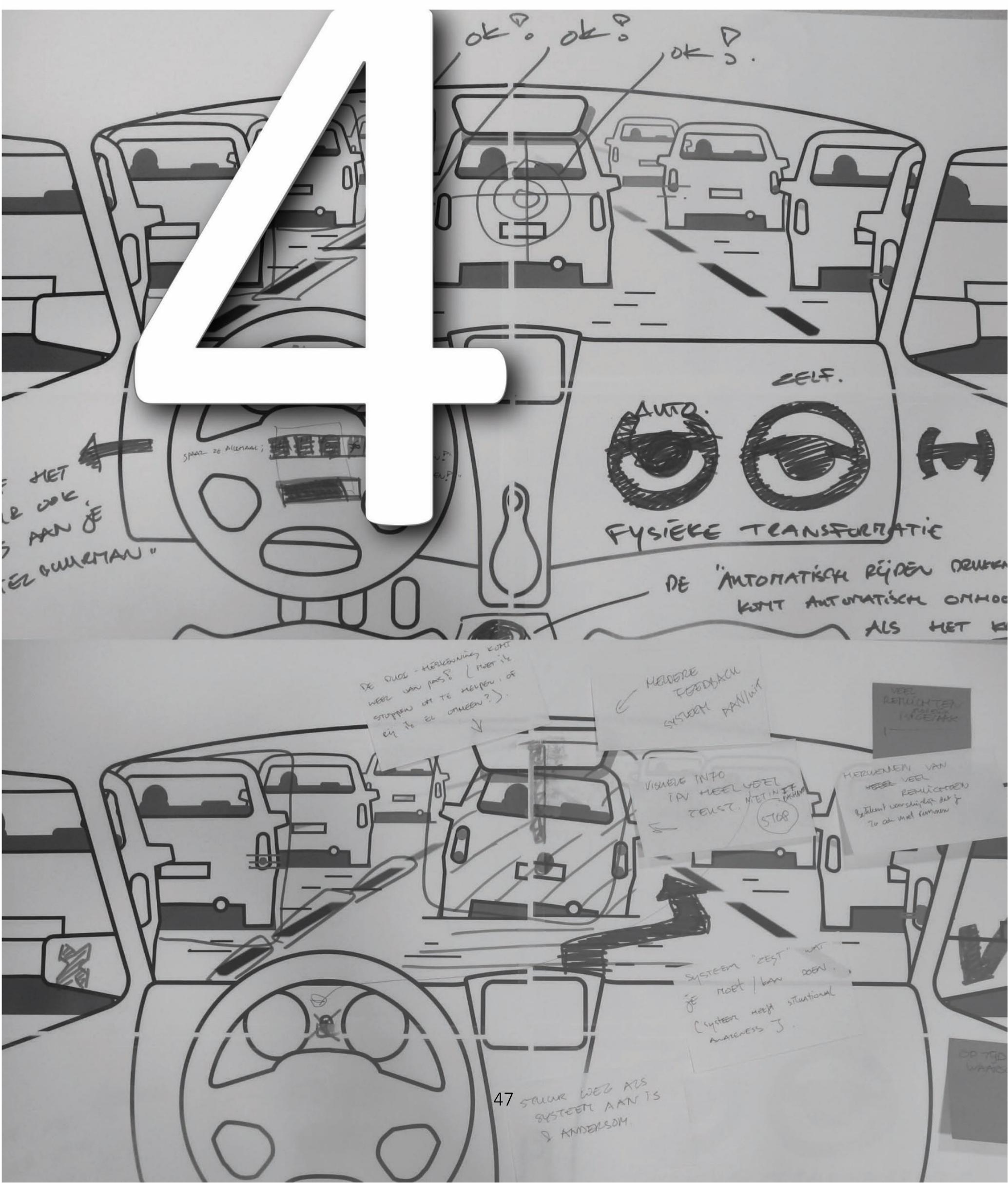




\section{Chapter 4. Design exploration}

As discussed in Chapter 2, development of solutions to support the driver's changing role is challenging, because solutions need to provide two-fold support. Support is needed for: (a) drivers' understanding what the system does and does not do, as well as for; (b) drivers' readiness to retake control adequately and fast whenever the system asks him/her to. Existing driver-vehicle interfaces comprise of more or less standardized input-devices, i.e. steering wheel, gear shifter and pedals, and output-devices that convey information about the vehicle's condition, like speed and fuel level. While traditionally displayed with gauges and screens on the dashboard, vehicle-output is rapidly expanding with in-vehicle information systems (IVIS), e.g. navigation, and infotainment (Becker, Hanna, \& Wagner, 2014). From this point, a difficulty is for instance, that potential solutions to support the driver's changing role might easily introduce (new) conflicts. A display continuously depicting detailed information about the system's capabilities and its operational envelope could result in display clutter and then cause confusion and distraction (e.g. (Morris, Reed, Welsh, Brown, \& Birrell, 2015)). Ecological, simple and self-explaining means for cooperation between driver and automation need to be designed that are tuned to the specific driver's role. This chapter therefore explores potential solutions. This exploration is based on a review of existing interface-ideas for interaction between driver and assistance functions comparable to automated driving and a workshop with experts from the automotive and human-centred design domains.

\subsection{Interface examples for driving automation}

Table 4-1 Three main parts of a driver's interface for driving automation.

\begin{tabular}{ll}
\hline Interface part & Explanation \\
\hline a) Controls & $\begin{array}{l}\text { Controls to choose between activation, de-activation or resume } \\
\text { and type of support (lateral and/or longitudinal). }\end{array}$ \\
\hline b) Mode Information & $\begin{array}{l}\text { Information to inform drivers about system-state and state- } \\
\text { changes, i.e.; available or unavailable, active or non-active, } \\
\text { malfunction. }\end{array}$ \\
\hline c) Alerts & $\begin{array}{l}\text { Attracting driver's attention to reduce a potential threat (soft } \\
\text { warning) or warning for an immediate danger (hard warning). The } \\
\text { alert may include instructions upon the appropriate type of } \\
\text { intervention. }\end{array}$ \\
\end{tabular}

Based on publications on the internet, workshops during conferences, literature study and exchange of information with experts from the automotive domain, this section reviews seven existing interface examples related to automated driving. It needs to be stressed that this review is not intended to represent state-of-the-art in automotive $\mathrm{HMI}$, neither is it intended to assess or analyse in detail usability performance of specific in-vehicle interface-solutions. 
On the contrary, this review is intended to be inspirational and explorative with regard to composing a base direction for potential solutions. Therefore the attempt is to cover a wide spectrum of possibilities. Examples are being selected that are rather different and complementary to one another. To facilitate communication about potential solutions, the present research discerns three general interface parts, i.e. (a) Controls, (b) Mode information, and (c) Alerts, which are explained in Table 4-1. The characteristics of the interface examples reviewed in this section, each focusses on a potential solution for at least one interface part.

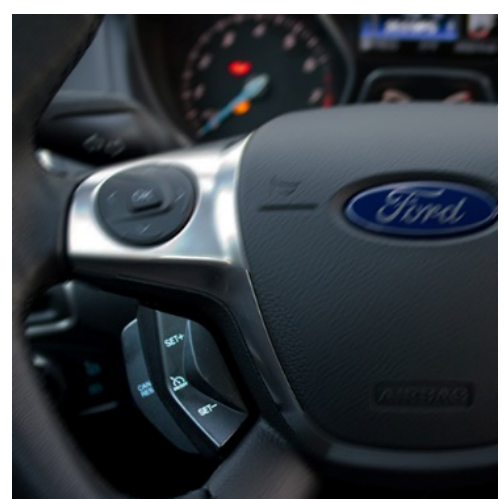

(a)

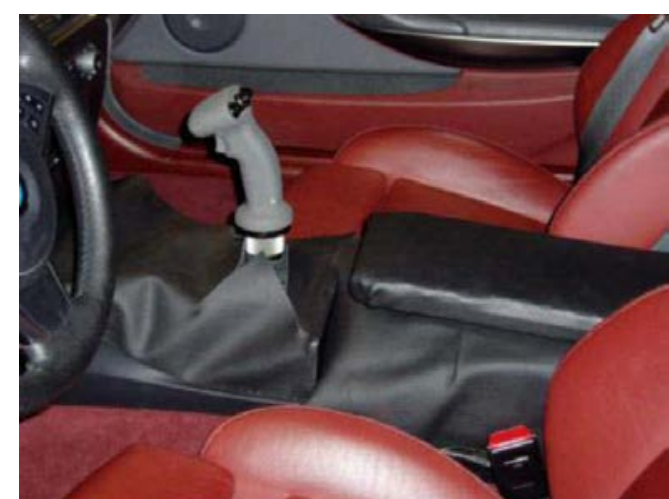

(b)

Figure 4-1 Two examples with controls for activation of driving automation. (a) Conventional controls for activation of longitudinal automation placed on the steering wheel (Picture by author) (b) Mock-up car augmented with active side stick experimented in Flemisch, Bengler, Bubb, Winner, and Bruder (2014).

With regard to controls for automated driving, Figure 4-1 shows two examples. Common practice is to place controls for activation and deactivation on the steering wheel, like shown in Figure 4-1a. Because the driving assistant's controls for activation or deactivation directly influence whether drivers need to use primary vehicle's controls or not, it figures to combine the assistant's controls with primary vehicle's controls, e.g. a steering wheel. In contrast to traditional vehicle's controls which have the necessity to use both hands and feet for vehicleoperation, joystick-like solutions allow complete control with only one hand, see for example Figure 4-1b. A joystick-like control might therewith contain some general advantages for vehicle's operation. Studies have shown that joystick-like interfaces are more intuitive for untrained drivers (Flemisch et al., 2014). This could be an indication that such controls are less effort-taking. Along with that being an advantage in itself, this may also ease combining driving control with secondary tasks. Such simplification may be an important improvement due to the growing demand to use in-vehicle information systems (IVIS). Furthermore, joystick-like devices have shown to ease changes between giving and taking back control. Joystick-like controls may therewith improve the driver's ability to remain in full authority over the driving automation (Flemisch et al., 2014).

With regard to mode information (interface part b), Figure 4-2 provides an example of a prototyped interface that was intended to convey system-state by depicting whether or not boundary conditions are met. The top-centre icon (2) depicts for example recognition of road 
lines and the upper-right speed-threshold related to traffic jams. An advantage of this concept is that offering information about the technical boundary conditions that allow system operation may improve driver's understanding of the system and - on the long run - improve driver's ability to anticipate changes in system-state. However, heuristic evaluation (a method proposed by Nielsen (1992)) applied to this example discloses two prevalent issues: (a) It is difficult to understand to what system-conditions the icons refer, i.e. the icons are not selfexplanatory, and (b) if all indicators turn green it remains unclear whether this information means that the system is available, or being activated (or maybe it means something else). This example illustrates that drivers need to deduct from information about individual system conditions the overall system state and - more importantly - their own required role. The required interpretation involved in this deduction of information may easily cause confusion or misperception.

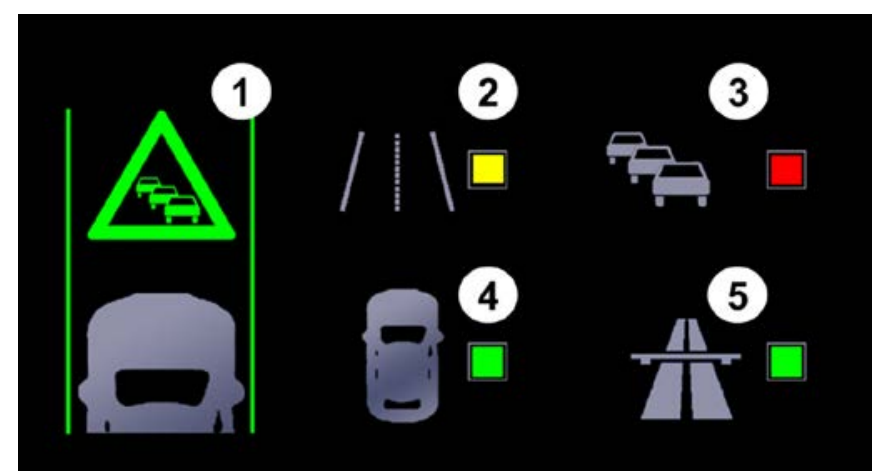

Figure 4-2 Congestion Assistant (CA) information screen with (1) representing system activity/availability.

The icons 2-5 indicate required system conditions, i.e; (2) lane marking detection, (3) preceding vehicle and traffic jam indicator, (4) ego vehicle condition indicator; (5) road type indicator. Checkbox colours: Green = Condition fulfilled; Yellow = Transition condition; Red = Condition not fulfilled. (Picture adopted from Naujoks et al. (2015)).

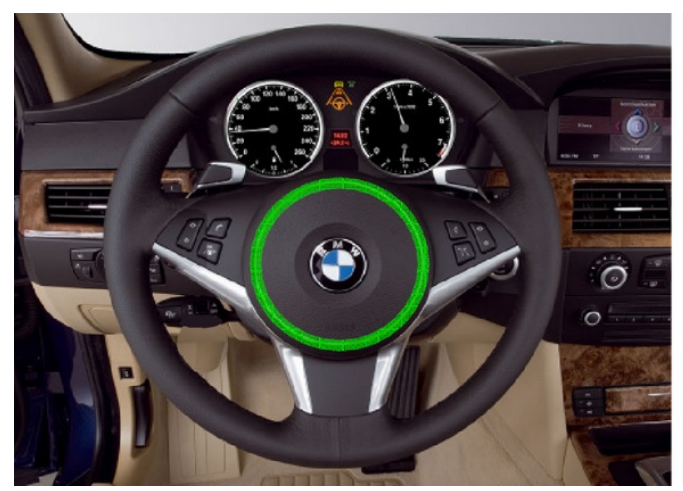

(a)

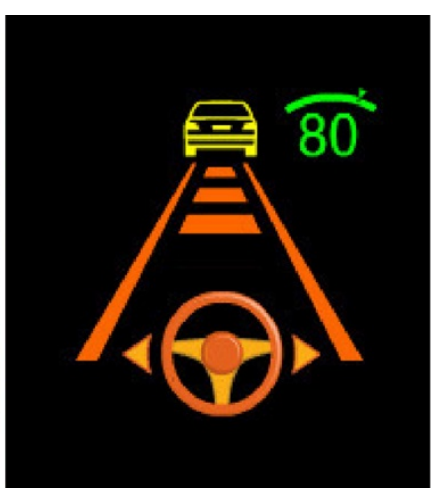

(b)

Figure 4-3 HMI-prototype for lateral automation (Schaller, 2009). (a) A light emitting ring around the steering wheel indicates status of lateral automation, like: activation, availability and termination. (b) Graphics behind the steering wheel provide information about the status of lateral automation in addition to longitudinal automation (ACC). 
Figure 4-3 shows a solution specifically focussing on mode information for lateral automation, proposed by Schaller (Schaller, 2009; Schaller, Schiehlen, \& Gradenegger, 2008). This interface is intended to provide information in addition to information on longitudinal control during low speeds (i.e. ACC with Stop \& Go). A light emitting ring on the steering wheel conveys system-state of the lateral automation. Different colours and looming (glowing) effects differentiate between required attention level (alert or warning). The ring is designed to light up with green colour when lateral control is active. If the vehicle's speed oversteps a pre-set maximum speed-threshold for lateral control, the light ring starts blinking to incite the driver to retake control. As long as speed changes gradually, this interface-behaviour is intended to be not too obtrusive. However, when driving conditions obstruct system-performance unexpectedly (for example: failed recognition of a target-vehicle due to the vehicle in front swerving out), the system would urge the driver to immediately retrieve lateral control. Then, the light ring blinks red. Supposed advantages of this concept are (a) the visibility within the driver's peripheral field of view, (b) easy recognition without competition from comparable but different interface-signals, and (c) the unobtrusiveness especially when speed oscillates around the speed-threshold (Schaller, 2009). Through differences in colour and intermitting pattern this concept is able to convey different levels of urgency. While focussing on the assessment of system-acceptance, the Schaller study did not aim at optimisation of the HMI itself. Therefore no conclusions are available with regard to correct understanding of different system-states as influenced by the behaviour of the light emitting ring. Nonetheless, heuristic evaluation of this interface reveals that the colour coding might be misinterpreted. For example; "red" is often associated with a prohibition to do something, whereas in this concept red blinking of the light ring meant termination of lateral automation and as a consequence the driver was just requested to act. Furthermore, although intended to be visible within the driver's peripheral field of view, when the driver is supervising the traffic scenery the visual cue on the steering wheel might be too remote to establish a good cognitive connection between traffic situation and required intervention.

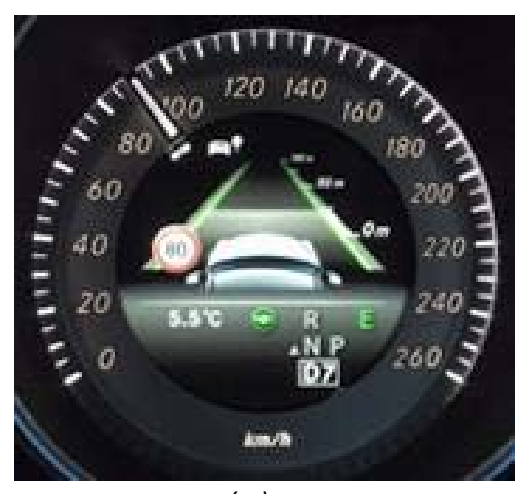

(a)

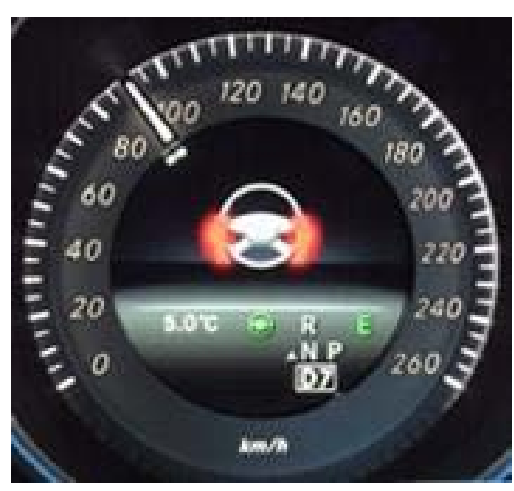

(b)

Figure 4-4 Example of Mercedes-Benz's graphical interface for Distronic-plus with Steering Assist, showing: (a) system-state with a bird's eye-view (e.g. recognition of road lines) and a small steering wheel icon below the vehicle-avatar, (b) alert for hands-on-the-wheel obligation. 
Similar to the previous prototype, Mercedes-Benz introduced driving automation as lateral automation (named "Steering Assist") in addition to longitudinal automation ("Distronic-plus") (Daimler, 2015). System-state of the lateral automation is depicted with a small steering wheelicon in the instrument cluster (placed behind the steering wheel), see Figure 4-4a. Recognition of lane-markers and a target-vehicle, as well as system's settings like speed and gap-distance are depicted in a bird's eye-view above the icons. To prevent the driver from being inattentive the lateral automation includes the obligation to remain the hands on the steering wheel. If the hands are not on the wheel for a sustained period of time, a warning will be raised like depicted in Figure 4-4b. This warning should remind the driver of returning the hands on the wheel. If the driver keeps ignoring the warning, the automation is being terminated. This example illustrates the complexity of providing information about technical boundary conditions simultaneously to providing drivers with necessarily feedback, alerts and instructions. Reactions on internet-fora seem to indicate that the behaviour of the lateral automation is easily confused with other assistance features (MB-world, 2015). Maybe this is due to the information-density and small icons.

With regard to Alerts (see interface part c in Table 4-1), developers realize that condensed icon-based information presented in an instrument cluster may withhold the driver from his attention outside the vehicle. Therefore, some researchers and automotive suppliers have been experimenting with advanced interfaces that use illuminated areas in the wind-shield or side windows to steer driver's attention to relevant locations outside the vehicle. See Figure 4-5 for two examples. Specifically the projection of red illumination in the windshield resembling brake-lights might help to provoke stronger reactions when driver's intervention is needed, see Figure 4-5a. Figure 4-5b presents a concept from Continental that is based on utilizing light strips throughout the interior (Continental, 2013). The lights lit up to indicate where a probably dangerous situation would be. The signal can 'move': to capture and steer attention into a specific direction.

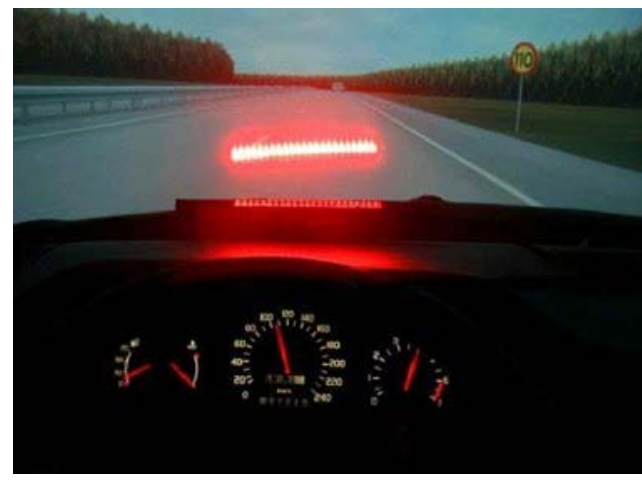

(a)

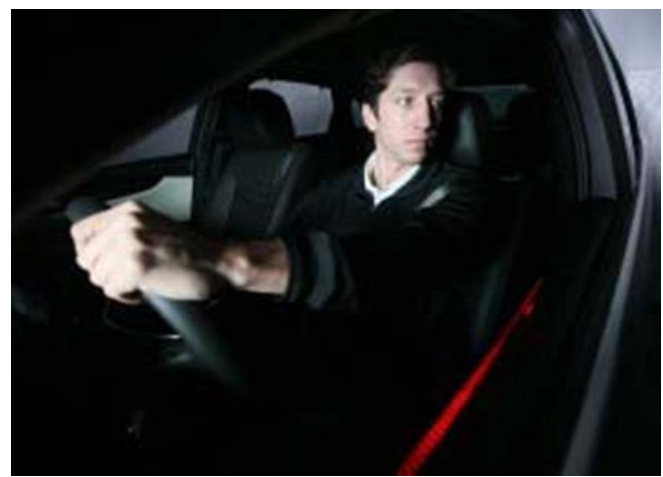

(b)

Figure 4-5 Two examples with light strips in the wind screen or side windows. (a) Brakelights are being mimicked and (b) Continental experimented with light strips that lit up to indicate where a probably dangerous situation occurs (Continental, 2013). 


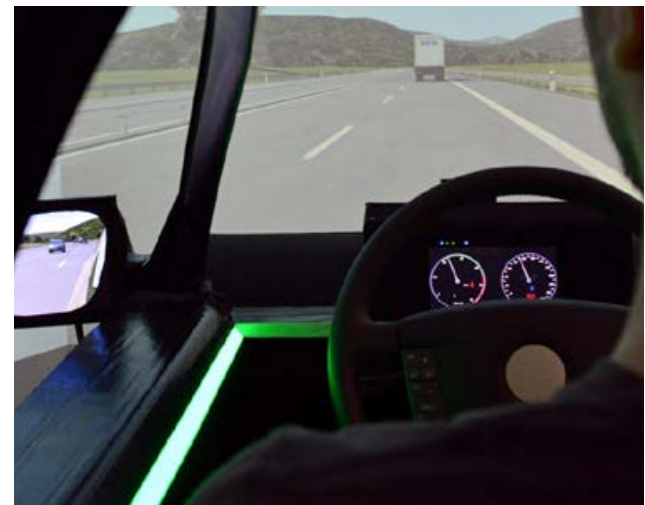

(a)

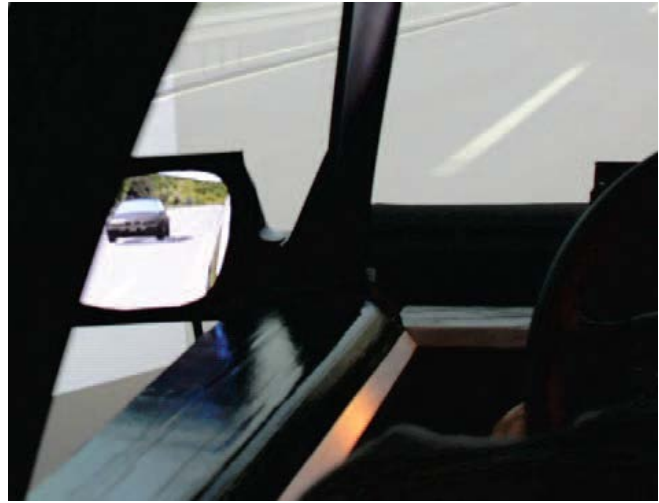

(b)

Figure 4-6 Light patterns to indicate distances to rear vehicles in order to support lane changes. (Locken, Muller, Heuten, \& Boll, 2015) (a) The green light indicates a safe distance to the rear vehicle (visible in the rear view mirror) (b) The red light pattern indicates lane obstruction.

Locken et al. (2015) studied the application of light strips to support lane change manoeuvre, see Figure 4-6. In this application a driver had to decide if he or she can change lane in front of a faster closing car or brake to keep a safe distance to a slower car in front. The light pattern improved recognition of appropriate opportunities to overtake. This might help drivers in decision making and revealed the potential of light patterns to convey urgency. However, abrupt warning patterns, led to worse performance of the participants. This example illustrates that the specific design of light-pattern to create alerts holds a promising direction and at the same time requires delicate balance between conveying a correct level of urgency without causing unacceptable levels of annoyance. Moreover, this study focussed on using light strips for lane change manoeuvres. Further research is required to test whether illumination is successful in directing driver's attention to a wider variety of traffic scenarios.

As explained in Table 4-1, the review in this section considered design solutions for driver's interaction with driving automation in terms of three parts; (a) Controls, (b) Mode information, and (c) Alerts. Based on the reviewed examples, Table 4-2 provides a short summary of a preliminary base direction for potential solutions with references to the interface-parts and reviewed examples.

Due to constraints with regard to time and available resources, the specific focus for further development and evaluation of potential solutions needs to be confined. As explained in Chapter 2, the driver's changing role especially relates to changes on a cognitive level due to being placed out of the control-loop. As a consequence support is especially needed with regard to drivers' understanding what the system does and does not do, and drivers' state to retake control adequately and fast whenever the system asks him/her to. Therefore, the present research will specifically focus on parts b (Mode information) and c (Alerts). 
Table 4-2 Short summary with preliminary base-direction for interface-solutions to control automated driving

Interface part

(a) Controls

Controls to choose type of support

(lateral and/or longitudinal) and

level of function activation

(operating, standby and

deactivation)

\section{(b) Mode information}

Continuously displayed mode

information to help drivers access and correctly understand systemstate at any time, and (ideally) anticipate state-changes on time

\section{(a) Alerts}

Directing the driver's attention towards the location that requires attention outside the vehicle while conveying the associated level of urgency and (ideally) the appropriate type of intervention

\section{Examples}
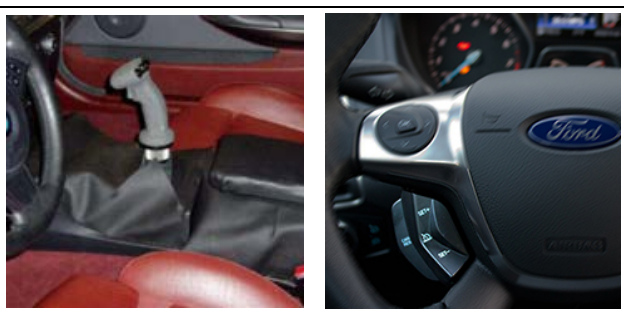

Figure $4-1 b$

Figure 4-1a
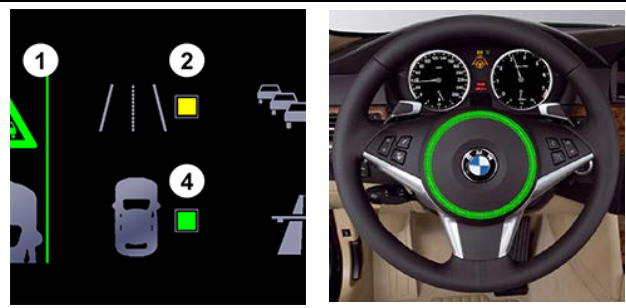

Figure 4-3

Figure 4-2

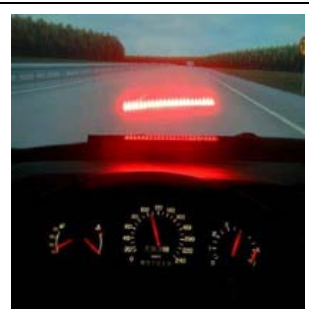

Figure 4-5

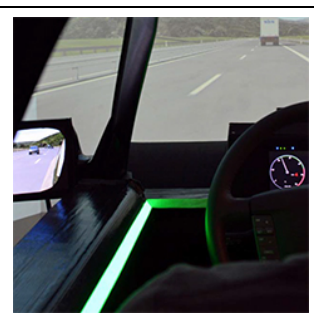

Figure 4-6

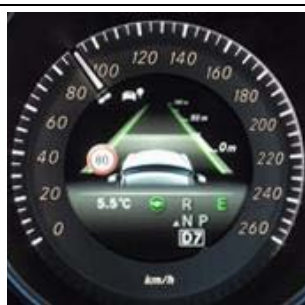

Figure 4-4a

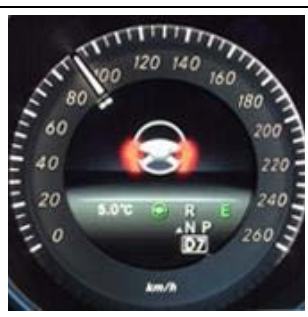

Figure $4-4 b$

\subsection{Design-exploration with experts}

In addition to the review of existing interface ideas in previous section, two expert-workshops have been organised to gain further insight in desirable interaction of drivers with vehicleautomation and to identify a base direction for interface solutions.

The workshops were attended by experts in engineering, design and development upon invitation by the author. The first workshop at the University of Twente on March 6th, 2013 included six general experts on human centred design. All participants had at least five years of experience in human centred design. The second workshop took place at Ford in KölnMerkenich (Germany) on March 19th, 2013 and was attended by five experts on driver-vehicle interfaces and four experts on driving automation. The participants in the second workshop held between three till fourteen years of work-experience in their domain. See Figure 4-7 for an impression of the workshops.

The main objective of both workshops was to create a shared view of interface (driver-system interaction) issues that need to be accounted for when developing a congestion assistant and identify directions for interface-solutions. 
The intended focus of automation was explained in term of a Congestion Assistant (CA). Predefined use-situations provided a frame of reference during the workshop. It was explained that use situations referred to the context, user characteristics and goals involved in user's interaction with CA. A collection of ten use situations was presented on A1-sized drawings. These use-situations were identical to the ten scenarios collected in section 3.2.3 (see Figure 3-4). and provided a set of situations representative for the driver's changing role with respect to supervision and intervention. Extra templates were provided to draw up additional situations if participants felt a particular scenario was omitted. Groups of 3 participants were then asked to list issues with regard to the driver-vehicle interaction associated with a particular use-situation. For example, an issue identified with Figure 3-4a 'Activation is not intended during roadwork' was: "The driver feels frustrated for not being allowed to activate the assistant during roadworks."

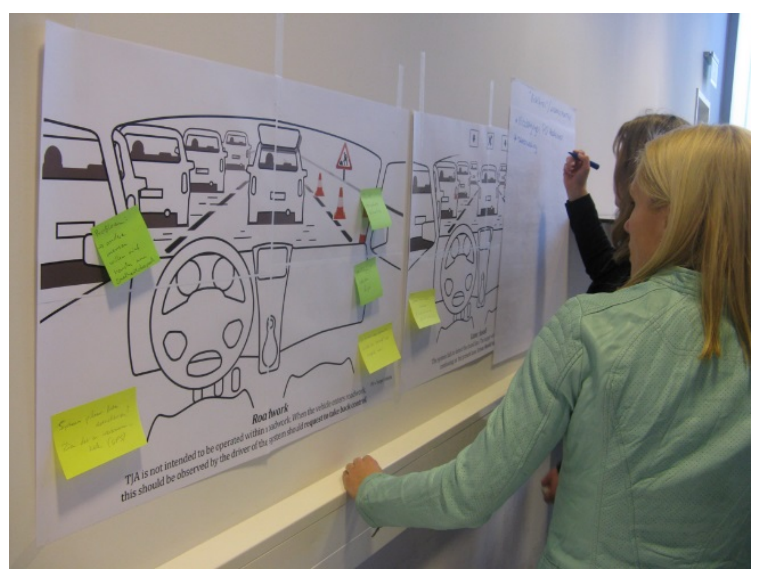

(a)

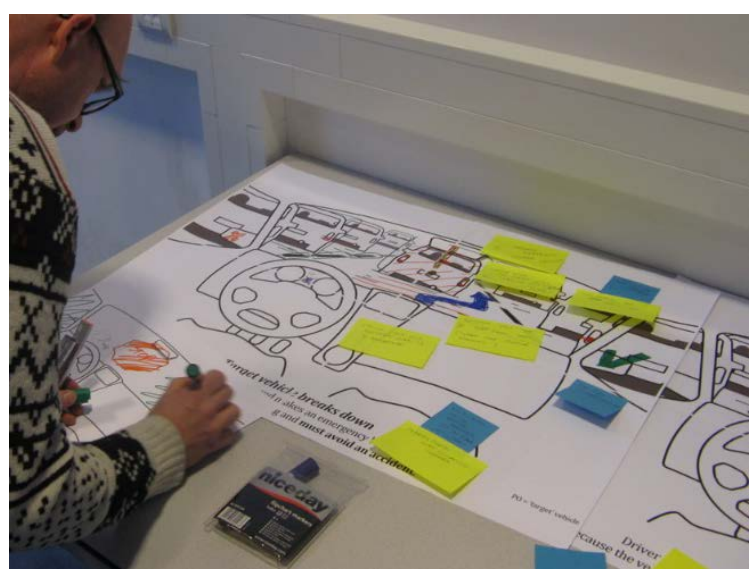

(b)

Figure 4-7 Experts during the first workshop at University of Twente; (a) exchanging opinions, and (b) capturing ideas.

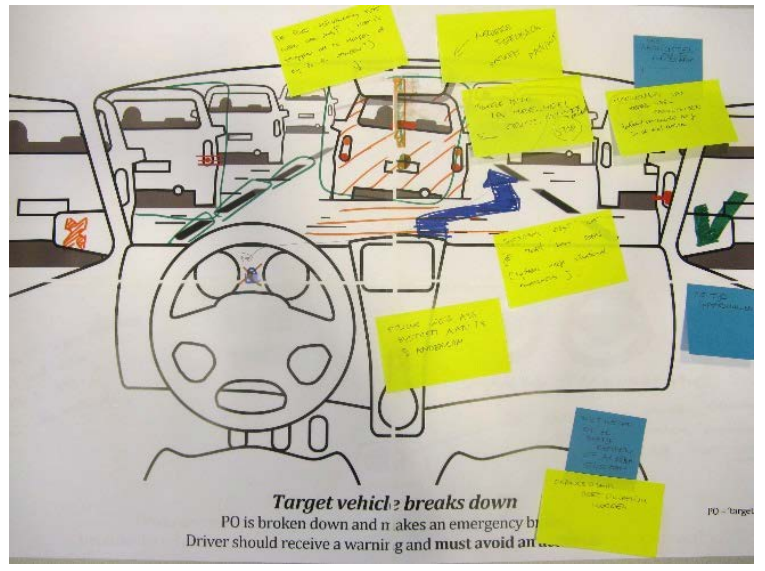

(a)

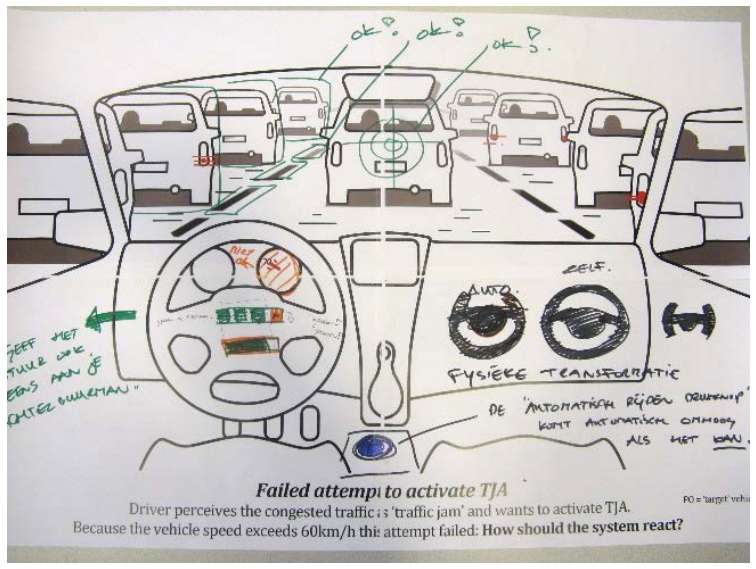

(b)

Figure 4-8 Examples of collected ideas: (a) Ideas to offer support for required intervention by suggesting mitigation (b) Sketched ideas to create controls and in-vehicle information in order to mediate the driver's role between supervising the automation and being engaged in secondary tasks. 
To solve the identified issues as covered in the scenarios, participants were invited to bring in ideas. Ideas could be expressed by writing them down on post-its and sticking them to the A1 posters with scenarios, or by adding sketched ideas to the posters (e.g. Figure 4-8b). The visual connection between use-situation, potential issues and possible solutions was intended to generate insights both with respect to what characteristics of the driver-vehicle interaction raise largest demands for support, as well as what interaction-aspects provide directions for potential solutions. Figure 4-8 provides two examples of collected ideas.

After collecting preliminary ideas, participants were asked to exchange their ideas and improve them. No agreement was requested within the group about the appropriateness of an idea. However, it was encouraged to help one another with improving the collected ideas. At the end, participants were asked to rate the ideas by assigning stars to those ideas they felt promising. The selection was based on participant's individual opinion of what idea comprised promising support for the driver's changing role. Possible rating ranged from zero to a maximum of three stars per idea. No strict assessment criteria were provided, but the moderator asked to anticipate general applicability and impact. Participants were asked to assign larger impact to solutions which are intended to solve more severe issues.

The list below summarizes the issues that have been identified during the workshops and which were complementary to the issues already identified in section 2.4 concerning out-ofthe-loop (OOTL) performance problems. A majority of issues addressed system design aspects and these issues will be listed first:

* It is not known what minimal amount of comfort the driver should be offered for the system to be perceived beneficial (in terms of gained comfort outperforming additional demands for supervision and intervention).

* There is lacking knowledge about potential technical fail-safe solutions. What happens for example when a driver does not intervene despite a take-over request?

* The unavailability of the Congestion Assistant within road work areas is a potential threat for acceptance (especially when no road work is going on, but speed is limited to low velocities)

* The driver would feel unsafe (reduced trust) if the driver needs to take over (too) frequently.

* Lacking information about the destination of the target-vehicle, might cause problems. There is a danger to continue on a lane unintentionally while road lanes split up in two directions. If not causing a direct safety issue, this would cause irritation.

* It is not known whether the system would allow corrections. This is important because drivers may want to perform corrections to the driving automation (e.g. adjusting lateral or longitudinal lane position) without having the intention to retrieve full human control.

* Basically, system's recognition of driving behaviour is tunneled to cover behaviour in front of the ego-vehicle and within the own lane. Better recognition of neighbouring 
vehicles at other lanes would be beneficial, especially when this information allows the system to anticipate potential lane changes of traffic participant surrounding the 'ego' vehicle.

The following issues referred more specifically to aspects that could be influenced by interfacedesign:

* Limited insight in the system's conceptual design causes reduced understanding what the system recognises and what not.

* Incorrect perception of the relationships between (sub)systems is a potential threat for drivers' general understanding of the systems at hand. It is often unclear how (sub)systems are interrelated and to what extent system-state of one function influences system-state of another. Would, for example, a Congestion Assistant and ACC be perceived separate and independent systems, or does longitudinal control add on lateral control?

* The influence of correct perception of an alert on performance is not known: Does it matter whether the driver misperceives an alert as an attention-signal whereas it was intended as take-over request, as long as the driver at least addresses more attention to the driving task?

* Prolonged automated driving endangers that hands and/or feet are not in place if intervention is required.

\subsection{Design potential}

In addition to the identified issues listed in the previous section, experts during the workshops selected promising ideas. Combining possible solutions from both workshops, the following basic ideas have been collected:

* Providing insight in the system's capabilities may improve acceptance and system understanding. Explanatory information about system's performance could be provided to the driver when the situation allows and may include information about automation-reliability. (For example, situations could be logged and then explained at a later stage why extra attention was requested.)

* Intervene in secondary tasks which users are involved in to actively direct attention to the driving task. (For example, visual information of a nomadic device could be interrupted with a warning overlay when take-over is required.)

* Allow access to secondary tasks only through a dedicated driver-vehicle interface. This allows to moderate driver's involvement in non-driving tasks to a level that is acceptable with regard to required attention.

- The interface should indicate location of potential danger as much as possible by referring to the actual location outside the vehicle where this potential danger 
originates. This is expected to help bringing drivers back in the control-loop more effectively than when raising icon-based alerts in the instrument-cluster.

* Apply output-stimuli to the user that transfer information fast and provide directions upon recommended actions for intervention. (For example force feedback in the pedals could help with faster and stronger break-reactions.)

* Attract attention towards recommended controls that need input for take-over, e.g. brakes or steering wheel.

* Place a (visual) interface on the steering wheel to explain the lateral control, e.g. lit up ring or vibration.

* Apply 'looming' for the indications of an alert. For example, an alert gradually develops visually and/or audibly towards a warning. If a driver reacts fast, less warning is necessary. Therefore, the beginning of a looming alert could be designed to be less annoying and this is probably positive for acceptance.

* The vehicle should inform about irregular traffic behaviour with an alert (pre-warning). An example is when a vehicle on the neighbouring lane swerves a bit and is positioned close to the lane marking. This might be an indication that this vehicle attempts to change lanes.

* Recognition of turn-indicators from the target-vehicle and/or neighbouring vehicles would help to warn early about possible change of direction.

* Improve timely warnings through advanced road-information based on GPS data. For instance warn early when a motorway splits and, as a result, lanes separate into two different directions.

- Use vehicle-to-vehicle data to gain more accurate information about the intention of other vehicles.

To summarize, solutions should allow review of automation-state at any time. This information should be continuously available. Furthermore, alerts should be provided which either ask for attention (soft warnings) or urge for intervention (hard warnings). Ideally, alerts should direct the driver's attention towards the location that requires attention and convey the type of intervention. The review with examples has shown that existing solutions often address more particularly either mode information or alerts. Potential solutions that will be developed and assessed within the present research may not always address mode information and alerts to the same extent. However, the set of assessed solutions is intended to cover both. In this respect, (a) providing explanatory information on technical pre-conditions required for systemoperation and (b) providing directional cues on the location where attention is needed while conveying appropriate level of urgency, provide promising directions for further development. 


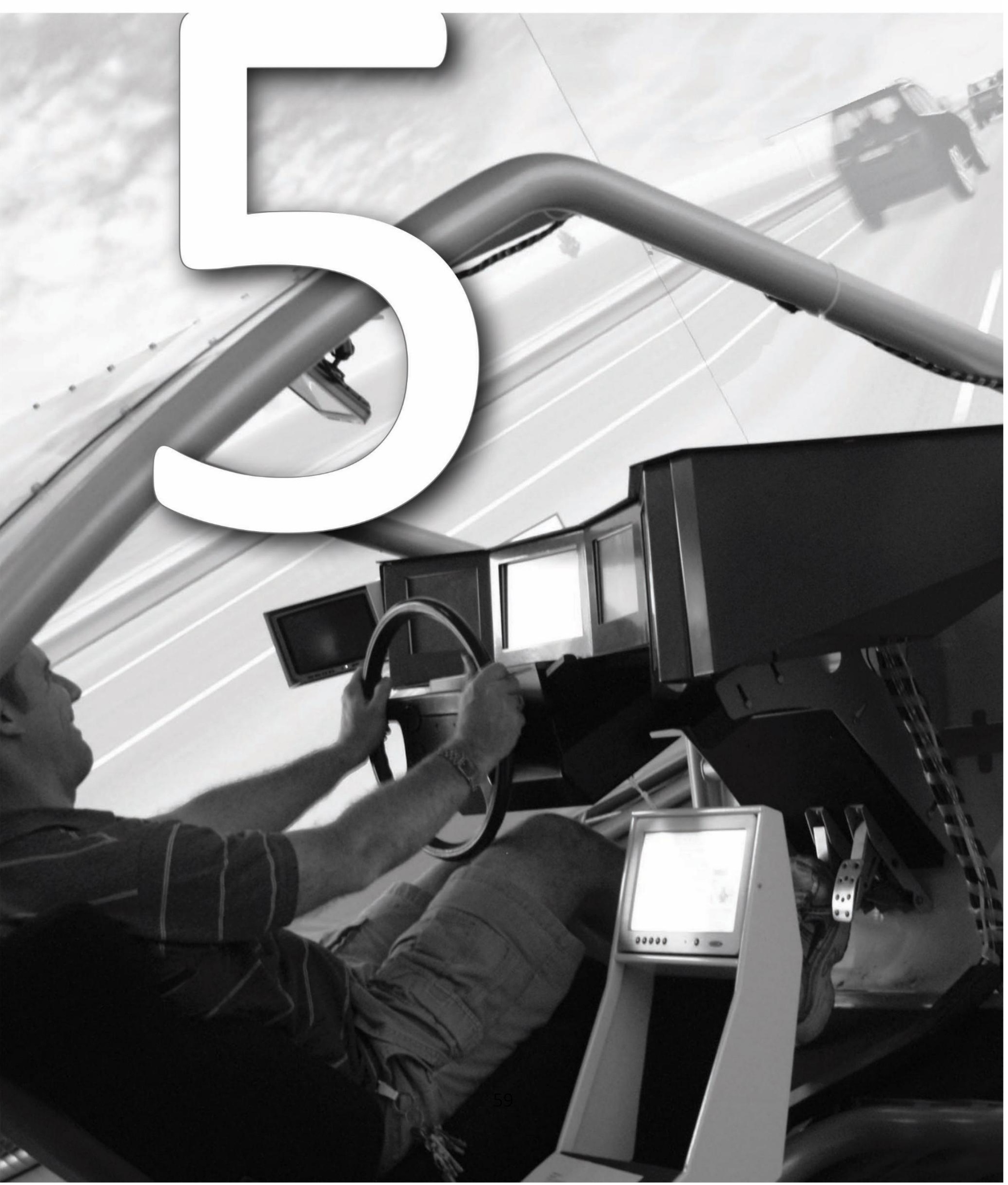




\section{Chapter 5. Assessment framework}

This chapter ${ }^{6}$ is based on:

Van den Beukel, A. P. \& Van der Voort, M. C. (2016). How to Assess Driver's Interaction with Partially Automated Driving Systems - a Framework for Early Concept Assessment. Applied Ergonomics (2017), pp. 302-312 DOI: 10.1016/j.apergo.2016.09.005.

Abstract - The introduction of partially automated driving systems changes the driving task into supervising the automation with occasionally a need to intervene. To develop interface solutions that adequately support drivers in this new role, this study proposes and evaluates an assessment framework that allows designers to evaluate driver-support within relevant real-world scenarios. Aspects identified as requiring assessment in terms of driver-support within the proposed framework are Accident Avoidance, gained Situation Awareness (SA) and Concept Acceptance. Measurement techniques selected to operationalise these aspects and the associated framework are pilot-tested with twenty-four participants in a driving simulator experiment. The objective of the test is to determine the reliability of the applied measurements for the assessment of the framework and whether the proposed framework is effective in predicting the level of support offered by the concepts. Based on the congruency between measurement scores produced in the test and scores with predefined differences in concept-support, this study demonstrates the framework's reliability. A remaining concern is the framework's weak sensitivity to small differences in offered support. This chapter concludes that applying the framework is especially advantageous for evaluating early design phases and can successfully contribute to the efficient development of driver's in-control and safe means of operating partially automated vehicles.

Keywords: assessment framework, driving automation, interface design.

\footnotetext{
${ }^{6}$ In comparison to the original paper, section 5.5 (Assessment of scenarios) has been inserted. The contents of section 5.5 is adapted from:

Beukel A.P. van den, Voort M.C. van der, Eger A.O. (2015). Towards a Framework for Testing Drivers' Interaction with Partially Automated Driving. In: 2015 IEEE 18th International Conference on Intelligent Transportation Systems (ITSC). IEEE, 2015. pp. 1902-1907. ISBN 1467365955.
} 


\subsection{Introduction}

The automotive industry has started to introduce driver assistance systems that allow the automation of both lateral and longitudinal driving controls during specific situations (e.g. motorway cruising) within the existing infrastructure. The systems combine existing subsystems, such as Adaptive Cruise Control (for longitudinal control) and Lane Keeping (for lateral control). Although such combinations enable full automation, their application is restricted by technical boundary conditions (e.g. detection of road lines and adjacent vehicles) and, for safety reasons, by system-design conditions (e.g. driving on a motorway at speeds below a specific threshold) (Naujoks et al., 2015). Due to the limitations on the availability of the system, it is considered a partially automated system (Gasser \& Westhoff, 2012). In this application, exceeding the boundary limits is likely to occur due to changing environments (for example, road works) or the behaviour of other road users. Given that the driver remains responsible for safe driving, this partial automation requires the driver to be ready to act as a back-up (and to retake control) in case the automation fails or stops. As a consequence of the partial automation, the role of the driver changes from actively operating the vehicle to supervising the system with occasionally a need for intervention. Given that the need for intervention can occur unexpectedly, and requires a fast response, this task is difficult and creates a high workload (Martens \& Van den Beukel, 2013; Stanton et al., 2011). Further, humans are not particular good at performing supervisory tasks since these are associated with low vigilance leading to slow reactions and errors in deciding when intervention is needed (Kaber \& Endsley, 2004; Ma, 2006). Carefully designed driver-interfaces are therefore needed not only to support drivers in this additional supervisory task, but also to support them in safely and adequately retaking control when required. Given this dual characteristic of the changed driver's task, it is desirable that interfaces offer at least two distinctive types of support: (1) support for supervisory tasks to improve the cognitive understanding of how a system reacts to different situations (Jamson, Merat, Carsten, \& Lai, 2013); and (2) support related to operational capabilities to react rapidly and adequately to resolve a critical situation (Martens \& Van den Beukel, 2013). Given that an assessment framework to evaluate potential interfaces with regard to this combination of aspects is not readily available (Geyer et al., 2014), the overall aim of this study is to propose such a framework. Initially, appropriate assessment aspects for both types of desired support will be determined. The subsequent challenge is to validate if the proposed combination of assessment aspects provides reliable outcomes, i.e. that they do not contradict each other. This validation is the second aim of our study. Moreover, an applicable framework should have predictive value: the measurement aspects defined should demonstrate a discriminant capacity regarding the effectiveness of the assessed interface-support. The latter will be evaluated by pilot-testing exemplary interface solutions within our proposed framework. Assessing the predictive value of the framework constitutes the third aim of our study. That is, the interface solutions discussed in this study serve as a means to evaluate the framework - the development of optimised solutions was not, at this stage, a goal in itself. 
As such, this chapter aims to answer three questions:

* What assessment aspects should be included in the framework?

* How reliable are the measurements applied for the assessment aspects of the framework?

* Is the proposed framework effective to predict the level of support offered by interfaces?

In answering these questions, we first, in Section 5.2, identify relevant aspects for assessment and introduce the framework's basic concept. Then, potential measures for the identified assessment aspects are reviewed in Section 5.3. Section 5.4 explains the methodology chosen to test the proposed framework. Before presenting the results of the tests in Section 5.6, Section 5.5 will first review whether the scenarios are considered successful in creating circumstances representative for supervision and intervention tasks. The results are then discussed in Section 5.7 in terms of what they mean with respect to the framework's reliability as well as the framework's effectiveness in identifying adequate interface-support for partially automated driving. Finally, Section 5.8 draws conclusions with respect to the framework's merits when it comes to developing interface solutions for drivers of partially automated vehicles.

\subsection{Concept of framework}

\subsubsection{Assessment aspects within the framework}

Supervisory control is strongly related to driver's understanding of how the system reacts to difficult situations in combination with knowledge and understanding of the required human (re)actions (Jamson et al., 2013; Jin \& Kaber, 2009). As such, assessments of supervisory control should especially address cognitive performance, an aspect well covered by the psychological construct 'Situation Awareness' (Endsley, 1995b). Intervention tasks, on the other hand, are strongly related to operational capabilities in terms of performing fast and accurate countermeasures and undertaking adequate and timely actions to resolve a critical situation (Merat et al., 2014). Consequently, intervention assessments should especially address task performance. Moreover, both aspects are complementary: even with correct understanding, adequate control could fail (Summala, 2005). In addition to cognitive performance and task performance, a framework should also assess perceived comfort since raising comfort is, in general, an important goal in the development of Advanced Driver Assistance Systems (ADAS) (Bengler et al., 2014). Further, partial automation creates ambiguity between comfort and safety: although driving control is taken away from the human operator (the driver), the human driver should retain final responsibility for safe driving (Bainbridge, 1983). Consequently, success in partially automated driving will to a considerable extent depend on whether carrying out supervisory control (including occasional intervention) will be less effort than the nonautomated driving task itself. Given that we focus on assessing the interface support itself, the 
framework is not intended to assess network improvements or system acceptance. To summarise the above arguments, the assessment aspects within our framework will focus on:
a) Increased situation awareness;
b) Driver's performance in critical situations;
c) Acceptance of the offered support.

\subsubsection{Scope of the framework}

Drawing on section 1.4 (Research scope) and Chapter 3 (Research approach), this paragraph briefly describes the framework's further qualities:

a) The framework allows comparison, early in the design process, between levels and types of support in order to distinguish the relative appropriateness of interface solutions.

b) The framework can be applied in driving simulator experiments. This is desirable because: (1) real-world prototype testing is difficult early within a development process; (2) controlled environments are preferable for testing reliability and reproducibility; and (3) it is too dangerous to test some of the traffic situations that are critical to partial automation in real-life circumstances.

c) The framework can assess drivers' interactions with partially automated driving systems. Scenarios that represent cooperation between automation and a driver's supervisory and intervening tasks are an inherent part of it, see: paragraph 3.2.3.

\subsubsection{Simulated traffic scenarios within the framework}

Appropriate scenarios were identified in a previous study (Van den Beukel, Van der Voort, \& Eger, 2015) and also presented in paragraph 3.2.3. The scenarios can be divided into two categories: (1) 'hazardous' scenarios requiring extra attention, but not intervention, from the driver; and (2) 'critical' scenarios where drivers need to intervene to avoid an accident. In line with currently available systems, our scenarios focus on vehicle automation within congested traffic. On a somewhat arbitrary basis, we imposed a speed threshold, such that automation would only be available below $50 \mathrm{~km} / \mathrm{h}$. Figure 3-5 in section 3.2.3 presented an overview of the scenarios, Table 5-1 provides a summary. Based on assessment of accident occurrence and mental effort associated with the individual scenarios, section 5.5 will review whether the scenarios embody different levels of required understanding and ability to solve a situation. This is important, because such differences are considered necessary to create circumstances representative for supervisory and intervention tasks as introduced by partially automated driving. 
Table 5-1 Defined traffic scenarios identical to Figure 3-5

\begin{tabular}{|c|c|}
\hline Hazardous scenarios & Critical scenarios \\
\hline $\begin{array}{l}\text { 1a "complex road" } \\
\text { Attention is needed because the vehicle is } \\
\text { approaching a combined entrance/exit ramp } \\
\text { with the likelihood that vehicles will } \\
\text { simultaneously enter and exit the main road. }\end{array}$ & $\begin{array}{l}\text { 1b "emergency brake" } \\
\text { The target vehicle unexpectedly brakes hard } \\
\text { with deceleration rates exceeding system } \\
\text { boundaries. Without an intervention, a collision } \\
\text { would occur. }\end{array}$ \\
\hline $\begin{array}{l}\text { 2a "vehicle passing" } \\
\text { While the vehicle is in the left (fast) lane, extra } \\
\text { attention is needed because a vehicle is } \\
\text { nevertheless passing on the right. }\end{array}$ & $\begin{array}{l}\text { 2b "merge out" } \\
\text { The target vehicle suddenly changes lane. If } \\
\text { there is no new target vehicle ahead, the system } \\
\text { stops and requests the driver to take back } \\
\text { control. Accident avoidance involves preventing } \\
\text { the vehicle from leaving its lane. }\end{array}$ \\
\hline $\begin{array}{l}\text { 3a "speed oscillation" } \\
\text { When the target vehicle (i.e. the vehicle ahead } \\
\text { being monitored) crosses the } 50 \mathrm{~km} / \mathrm{h} \\
\text { threshold, attention is needed because the } \\
\text { system switches off while the vehicle remains } \\
\text { above the speed threshold. }\end{array}$ & $\begin{array}{l}3 \mathrm{~b} \text { "cut in" } \\
\text { A vehicle in another lane brakes heavily in an } \\
\text { attempt to cut across to an exit. This violates } \\
\text { system boundaries for minimum separation and } \\
\text { a collision would be inevitable without } \\
\text { intervention. }\end{array}$ \\
\hline
\end{tabular}

\subsection{Measurement methods}

This section defines the measures and measurement techniques that will be applied to our identified assessment aspects: (a) gained situation awareness; (b) driver's performance in critical situations; and (c) acceptance of the offered operational support.

\subsubsection{Measurement of Situation Awareness (SA)}

Endsley (1995b) defines SA in terms of three levels: "(1) the perception of elements in the environment within a volume of time and space, (2) the comprehension of their meaning, and (3) the projection of their status in the near future". Given that these levels align with the first three processing steps generally involved in driving (i.e.: (i) perception; (ii) comprehension; and (iii) projection (to be followed by (iv) decision-making and (v) implementation) (Matthews et al., 2001), see Figure 2-1: The driving task, in Section 2.2), SA is theoretically considered a necessity in performing the overall driving task. As a result, a measurement of SA would allow a fundamental assessment of the consequences of changing the driver's role from actively operating the vehicle to supervising the automation. Measuring Situation Awareness will provide insight into the quality and effectiveness of the offered support in terms of cognitive performance. However, given the multivariate nature of $\mathrm{SA}$, its measurement offers considerable challenges (Endsley \& Garland, 2000) and requires further considerations before inclusion in our framework. 
Salmon, Stanton, Walker, and Green (2006) compared various SA measurement techniques for strategic and operational tasks in a simulated environment. Based on their research, probing techniques and self-rating techniques appear appropriate for our aims. For probing approaches, the Situation Awareness Global Assessment Technique (SAGAT) (Endsley et al., 1998 ) is most commonly used. Probing techniques measure SA directly and objectively, but require a simulated environment. A simulation is required to enable 'freezing' a situation and allow probing questions such as "is there currently (i.e. during the 'freeze') a vehicle in the adjacent lane?" (see also Table 5-2). Although the answers are considered to reflect SA, there is a danger that probing may influence primary task performance. Self-rating techniques involving participants' self-assessments have the advantage that they are non-intrusive in that they are typically administrated post-trial but are affected by participant's limited ability to accurately rate levels of SA (Endsley et al., 1998). Despite this apparent disadvantage, the Situation Awareness Rating Technique (SART) (Charlton, 2002) that adopts this approach is widely used because it is easy to apply and a low-cost approach.

In an earlier experiment that measured SA in simulated control-retrieving tasks, the authors found differences between SART and SAGAT approaches (Van den Beukel \& Van der Voort, 2013) in that the longer period before situation retrieval with the SAGAT approach had a counter-productive influence on SA accuracy when compared to using the SART. Studies by other authors also raise questions regarding the reliability and validity of SAGAT and SART measurement methods (Endsley et al., 1998; Salmon et al., 2006). Most studies show results that favour the SAGAT, for example by demonstrating better face validity (Salmon et al., 2006). Nevertheless, there is little information available from experiments on measuring SA in timecritical driving situations (Gold et al., 2013; Van den Beukel \& Van der Voort, 2013). Consequently, we do not rely on a single measurement method and further recognise that both techniques are to an extent complementary. Whereas the SAGAT offers an objective SA, the SART assesses how drivers perceive themselves to be aware of elements relevant for task performance. This is especially relevant as drivers appear to lack an appreciation of their SA and any gaps in it (Endsley et al., 1998; Walker, Stanton, \& Young, 2008).

\subsubsection{Performance measures (AA)}

According to (Charlton, 2002), "the application of performance testing includes evaluating the design of equipment and systems, particularly where human performance is critical to successful operation". Performance tests should therefore be based on the actual task. In our situation, this concerns final responsibility for safe driving and the task of retrieving control if the automated system fails or cuts out. In the driving scenarios simulated, this safe-driving response is reflected in attempts to avoid accidents through a variety of actions such as braking or swerving. On this basis, we consider a combination of the following measures important in assessing driving performance within our framework:

Accident Occurrence: observed collision or leaving the highway. 
* Collision Avoidance: observations of successful manoeuvring to avoid danger, without an Accident Occurrence.

* Time-To-Collision (TTC) at specified moments provides a quantitative assessment of how well a collision has been avoided. The interval until an accident would have occurred is based on parameters that reflect the severity of impact, i.e. gap distance and deceleration?

Within our framework, the above performance measures are grouped to create a single dependent variable referred to as 'Accident Avoidance' (AA).

\subsubsection{Measurement of Concept Acceptance (CA)}

Van der Laan, Heino, and De Waard (1997) offer an ADAS Acceptance measure that distinguishes two dimensions: Perceived Usefulness and Satisfaction. This measure is incorporated in our framework because it relates acceptance to perceived usefulness - an aspect we previously identified as important in appraising partially automated driving systems (see Section 5.2). Moreover, the ADAS Acceptance measure is widely adopted and validated (Brookhuis et al., 2009).

\subsection{Methodology}

In identifying the required assessment aspects and subsequent measurement techniques, the previous sections have answered our first question: what assessment aspects should be included in the framework? In order to assess how reliable the proposed measures are (our second question) and to validate the framework's effectiveness in predicting the support that interfaces offer (our third question), we conducted a pilot test of the proposed framework using predefined interfaces. The aim was to answer the second and third questions by: (a) evaluating the coherency between measurement outcomes; and (b) evaluating whether measured differences between concept scores matched the purposefully designed differences in the support offered by the different concepts. The test is based on a driving simulator experiment which is now explained.

\subsubsection{Experimental design and procedure}

To allow a comparison between the measurement scores, the independent variables for the experiment were 'Scenario' and 'Concept'. Scenario was manipulated within subject: each participant was confronted with the three hazardous situations and the three critical situations

\footnotetext{
${ }^{7}$ In our driving simulator we calculated TTC according to the formula (Vogel, 2003): TTC $(\mathrm{t})=\mathrm{V}(\Delta \mathrm{x} / \Delta \mathrm{a})$, where $\Delta \mathrm{x}$ is the gap, i.e. distance between the front of the own vehicle and the rear of the vehicle in front. $\Delta a$ is the difference in deceleration rates between the vehicle in front and own vehicle. The calculation is similar to that in SAE Standard 19244 - option A for computing TTC (Green, 2013; SAE, 2015).
} 
Table 5-2 Example of probe-taking to measure SA with a SAGAT Questionnaire

\begin{tabular}{|c|c|c|}
\hline Level of SA: & Question: & Options: \\
\hline 1) Perception & $\begin{array}{l}\text { The simulation just "froze", what } \\
\text { type of vehicle is alongside you? }\end{array}$ & $\begin{array}{l}\text { o Minibus } \\
\text { o Small passenger car } \\
\text { o Delivery van } \\
\text { o Sports Utility Vehicle (SUV) } \\
\text { o Other: } \\
\text { o I don't know }\end{array}$ \\
\hline 2) Comprehension & $\begin{array}{l}\text { What caused the system to seek } \\
\text { your attention? }\end{array}$ & $\begin{array}{l}\text { o The target vehicle in front braked heavily } \\
\text { o I am approaching heavy traffic } \\
\text { o A neighbouring vehicle came too close } \\
\text { o Faulty road lines } \\
\text { o Other: } \\
\text { o I don't know }\end{array}$ \\
\hline $\begin{array}{l}\text { 3) Projection: } \\
\text { Anticipated future } \\
\text { state }\end{array}$ & $\begin{array}{l}\text { If the simulation restarts after this } \\
\text { "freeze", what situation might } \\
\text { require your extra attention or } \\
\text { intervention? }\end{array}$ & $\begin{array}{l}\text { o Other users' traffic violations } \\
\text { o Reaching the end of the motorway } \\
\text { o Entering roadworks } \\
\text { o Other users wanting to enter my lane } \\
\text { o Something different: } \\
\text { o I don't know }\end{array}$ \\
\hline
\end{tabular}

\subsubsection{Participants and instructions}

Twenty-four people with at least one-year's driving experience were recruited. Participants were either students or university staff, their ages ranged from 21 to 39 (Average: 26.7). As the experiment was intended to validate the assessment framework, participant characteristics were treated as a control variable. As such, selected participants were rather homogeneous rather than representative of potential users of partially automated vehicles. Within each simulation (trial), the participant was 'launched' with immediate automatic driving. Participants were informed that they were responsible for safe driving. They were told that, due to changes in the traffic environment or the behaviour of other road users, situations could occur which would require extra attention or intervention to avoid an accident. To make the situation more realistic, a tablet mounted in the centre console enabled participants to read mail and review a calendar, see Figure 5-3. Given that participants remained responsible for safe driving, they were advised to divide their attention between such activities and monitoring the road situation and to retake control when they assessed this as necessary.

\subsubsection{Materials}

The study was carried out using the University of Twente's driving simulator. This includes a $180^{\circ}$ viewing angle with three projection screens and a simulated motorway with predefined behaviours by other road users. Mirror images and speeds were projected onto the side screens (see Figure 5-2). Participants were seated in a mocked-up vehicle equipped with a physical steering wheel, physical accelerator and brake pedals and an automatic gearbox allowing participants to take full control if necessary. All the vehicles 'drove' at about 50km/h 
with time headways between $1 \mathrm{~s}$ and $1.5 \mathrm{~s}$ in order to simulate a heavy traffic situation. The position of the neighbouring vehicles was identical within each specific scenario to ensure that all participants had the same situation to resolve. Vehicle speed, lane position and participant's input (if any) were recorded at a frequency of $10 \mathrm{~Hz}$. The TTC (Time-to-Collision) was calculated immediately after completing Scenarios 1b ("Emergency Brake") and 3b ("Cut in").

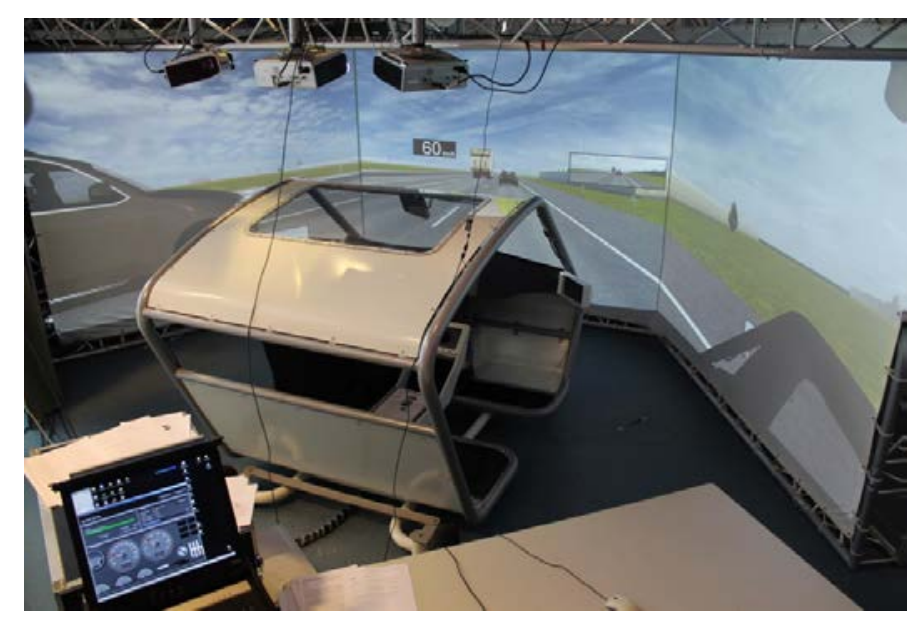

Figure 5-2 Driving simulator environment

An interface supported the drivers in their supervisory tasks by requesting either extra attention (a so-called 'soft warning') or an intervention (a so-called 'hard warning'). Through screens and audible feedback, three different interface configurations ('Concepts') were offered as shown in Figure 5-3. These concepts were not optimised to offer support in line with the latest understandings but designed to reflect different levels of support for supervision and intervention. As such, the concepts were intended to probe whether our defined framework is capable of identifying meaningful differences in the performance of, and satisfaction with, the alternative concepts.

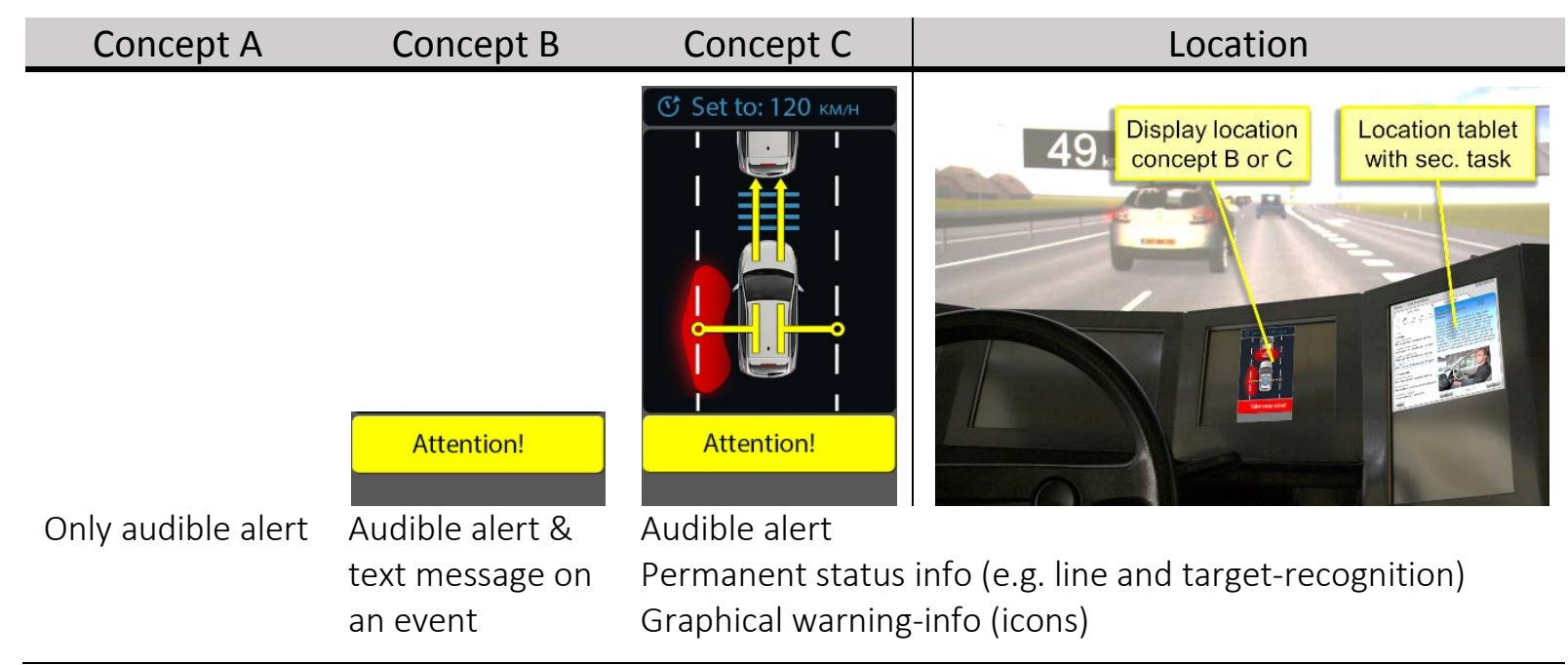

Figure 5-3 Concepts and their characteristics. The concepts were reconfigured to provide different levels of interface-support with a focus on mode information and alerting the driver. 


\subsection{Assessment of scenarios ${ }^{8}$}

The scenarios introduced in section 3.2.3, were selected to provide an assessment-context representative for partially automated driving. Therefore, scenarios have been created as a set with different levels of required understanding and ability to solve situations. Consequently, a distinction is made between 'hazardous' scenarios (requiring extra attention but no intervention) and 'critical' scenarios in which intervention is required to avoid an accident. Before analysing in the next section results on the framework's reliability and effectiveness to predict levels of support offered by interfaces, this section will first verify whether the scenarios are successful in creating circumstances with the intended differences in level of difficulty. In particular, we assume that the critical scenarios will be perceived more strenuous than the hazardous scenarios. But we are also interested in other differences, like whether scenarios are within their category comparably difficult or not, and - if not - why. According to section 3.2.3 scenarios 1a (Complex road), 2a (Vehicle passing) and 3a (Speed oscillation) comprise hazardous scenarios. Scenarios $1 b$ (Emergency brake), 2b (Merge out) and 3b (Cut in) comprise critical scenarios.

Only critical scenarios had a designed risk for accident occurrence. Most accidents occurred in scenario $1 b$, i.e. 8 times $(n=23)$. Scenario $2 b$ denoted no accident $(n=24)$ and scenario $3 b$ only one $(n=24)$. As expected, no accidents occurred in the hazardous scenarios.

To gain more insight in the difficulty of the scenarios, workload was measured using a selfadministered questionnaire, the Rating Scale Mental Effort (RSME) (Zijlstra, 1993), see Appendix A. The results with mean mental effort scores per scenario are shown in Table 5-3.

Table 5-3 Mental effort scores (RSME) per scenario

\begin{tabular}{|c|c|c|c|c|c|}
\hline & Scenario & Mean & SD & $\mathrm{N}$ & \\
\hline \multirow{3}{*}{ 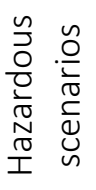 } & 1a Complex road & 34.4 & 20.7 & 24 & \\
\hline & 2a Vehicle passing & 29.4 & 16.9 & 24 & \\
\hline & 3a Speed oscillation & 27.3 & 18.0 & 23 & 7 \\
\hline \multirow{3}{*}{ 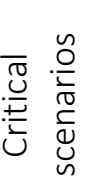 } & 1b Emergency brake & 41.7 & 24.2 & 24 & * \\
\hline & 2b Merge-out & 42.5 & 20.3 & 24 & \\
\hline & 3b Cut-in & 36.7 & 19.5 & 24 & \\
\hline
\end{tabular}

$* \mathrm{p}<0.05$

Note. RSME scale ranges from 0 to 140 . For reference: 20 = "just a little"; 40 = "some effort"; 85 = "great effort"; 112 = "extreme effort".

\footnotetext{
${ }^{8}$ In addition to the original paper (Van den Beukel \& Van der Voort, 2016b) on which Chapter 5 is based, this section has been inserted from Van den Beukel et al. (2015).
} 


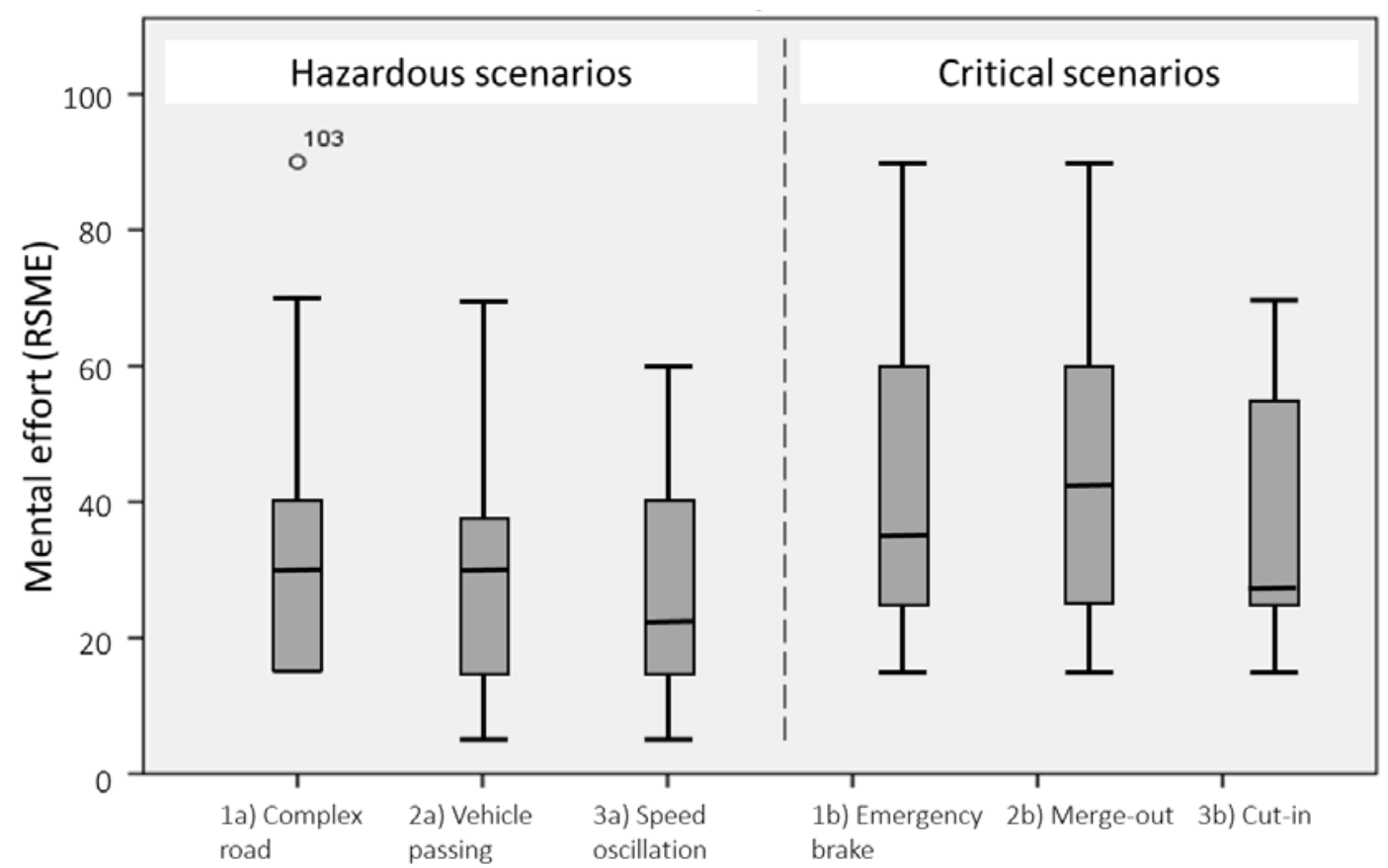

Figure 5-4 Boxplot with mental efforts scores (RSME) per scenario.

Note. The whiskers show minimum and maximum scores.

Figure 5-4 shows that mental effort differed substantially between the two groups of scenarios. The mean RSME score was highest for scenario 2b (Merge out) (Mean=42,5, SD=20,3). Results from pair-wise t-tests confirm that in line with their design all three critical scenarios showed significant higher RSME scores than the hazardous scenarios 2a (Vehicle passing) and 3a (Speed oscillation), see also Table 5-3.

Among hazardous scenarios, 1a (approaching complex road) required most effort ( $M=34.4$, $S D=20.7)$. The required effort was comparable to the critical scenarios: There was no significant difference in RSME score between scenario 1a "Complex road" ( $M=34.4, S D=20.7)$ and scenario $1 b$ "Emergency brake" ( $M=41.7, S D=24.2) ; t(22)=1.752, p=0.094$. There was neither a significant difference between scenario $1 \mathrm{a}$ and scenario $3 \mathrm{~b}$ "Cut in" ( $M=36.7, \mathrm{SD}=19.5)$; $t(23)=0.548, p=0.589$. These results indicate that the perceived effort for scenario $1 \mathrm{a}$ in which participants approach a complex road is comparable to the critical scenarios $1 \mathrm{~b}$ and $3 \mathrm{~b}$.

The results show that the scenarios succeeded in providing different levels of 'difficulty'. The critical scenarios generally required more effort than the hazardous scenarios - as was also intended. Most differences in required effort between critical and hazardous scenarios were significant. When comparing measures between the critical scenarios, we see that scenario $1 \mathrm{~b}$ was based on objective measures (Accident Occurrence) most dangerous. However, it did not require most effort, nor was it perceived most demanding. The most demanding and strenuous scenario was $2 b$ (entering a combined entrance and exit lane). The hazardous scenario which required most mental effort (1a: "Complex road") had scores comparable to critical scenarios. Interestingly, both scenarios with highest scores from each category (i.e. 1a "Complex road" and $2 b$ "Merge out") resemble each other as both involve most change in visual road 
complexity. The high score for $2 b$ "Merge out" is remarkably, since within the critical category this scenario had least danger of collision.

The high score for scenario 1a could be explained by order-effects: it was the first scenario participants encountered and they were then inexperienced on what to expect. Although order-effects could indeed have influenced scores, the other scenario with highest RSMEscores (2b) was for each participant the last one. Comparison of the traffic characteristics anchored in the scenarios rather reveal that mental effort was associated with visual change much more than with actual danger of an accident. Due to the similarity between scenarios $1 \mathrm{a}$ and $2 \mathrm{~b}$ with respect to visual road complexity, a plausible explanation for the required mental effort is that gradually evolving complex road situations are perceived more strenuous as a very sudden and dangerous but short traffic event.

Furthermore, we see that the scenarios did in general not require very high levels of mental effort. For reference; the standardized RSME score defines a level of "85" as "great effort" and "112" as "extreme effort" (Zijlstra, 1993). Mean scores for scenarios ranged between 20 ("just a little") and 40 ("some effort"). Although there were large individual difference, there were no scores higher than 90. These relatively low scores are likely due to the dominantly 'calm' driving situations, i.e. motorway driving with low speeds. Another explanation could be the application of simulation, since it takes away the real risks of reduced performance. As simulator resources restricted the creation of more heterogeneous road environments (for instance it was not possible to add more variety in road layout and signs), we presume that a 'richer' environment would probably have helped raising perceived effort to more realistic levels. Nonetheless, the framework's intended application in the present research focusses on comparable assessment between interface-concepts, therefore it is particularly important that the scenarios denote identifiable different levels of difficulty - which they do.

To summarize this assessment of the driving simulator's scenarios, accident occurrence rates and differences in mental effort confirm the scenarios' successfulness in creating contexts relevant for the cooperation between partial automation and drivers' tasks. Therefore, it is concluded that the scenarios are representative for supervisory and intervention tasks as introduced by partially automated driving and the scenarios will be applied in the present framework.

\subsection{Results}

Section 5.4 described the methodology we used to test predefined concepts on: (a) Situation Awareness, (b) Accident Avoidance and (c) Concept Acceptance. This section reports the results of this test which lead in the next section to a discussion on the reliability of the measurements included in the framework and on the effectiveness of the proposed framework in predicting the levels of support offered by the interfaces. As explained in the Introduction, adequate interfaces should offer at least two types of support: support for supervision and 
support for intervention. Consequently, the framework defined two categories of scenarios in which to test the concepts: hazardous scenarios, requesting supervision; and critical scenarios, requiring intervention. In order to reflect on our findings in the next section, we need in this section to determine whether measured scores were specific to a particular scenario or independent of the scenario.

\subsubsection{Assessment of Situation Awareness}

Table 5-4 Results of independent t-tests comparing (a) SAGAT and (b) SAGAT-Level2 scores of the three concepts in critical scenarios.

(a)

\begin{tabular}{|c|c|c|}
\hline & imple & $\mathrm{N}$ \\
\hline \multirow{6}{*}{ 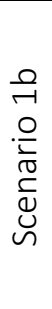 } & & 1 \\
\hline & Concept B & 8 \\
\hline & Concept A & 7 \\
\hline & Concept C & 8 \\
\hline & Concept B & 8 \\
\hline & Conc & 8 \\
\hline \multirow{6}{*}{ 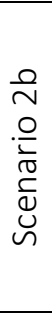 } & Concept A & 8 \\
\hline & Concept B & 8 \\
\hline & Concept A & 8 \\
\hline & Concept C & 8 \\
\hline & Concept B & 8 \\
\hline & Concept C & 8 \\
\hline \multirow{6}{*}{$\begin{array}{l}\frac{0}{m} \\
\text { 은 } \\
\stackrel{0}{0} \\
\stackrel{0}{0} \\
\tilde{u}\end{array}$} & Concept A & 8 \\
\hline & Concept B & 8 \\
\hline & Concept A & 8 \\
\hline & Concept C & 8 \\
\hline & Concept B & 8 \\
\hline & Concept C & 8 \\
\hline \multirow{6}{*}{ 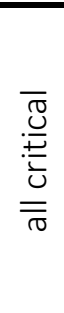 } & Concept A & 23 \\
\hline & Concept B & 24 \\
\hline & Concept A & 23 \\
\hline & Concept C & 24 \\
\hline & Concept B & 24 \\
\hline & Concept C & 24 \\
\hline
\end{tabular}

\begin{tabular}{|c|c|c|c|c|}
\hline \multicolumn{2}{|c|}{ SAGAT } & \multirow{2}{*}{\multicolumn{2}{|c|}{$t \quad d f$}} & \multirow[b]{2}{*}{ Sig. } \\
\hline Mean & SD & & & \\
\hline 1.86 & 0.38 & 0.49 & 13 & 0.635 \\
\hline
\end{tabular}

\begin{tabular}{lllll}
1.86 & 0.38 & & & \\
\hline 1.86 & 0.38 & -0.45 & 13 & 0.659
\end{tabular}

\begin{tabular}{lllll}
2.00 & 0.76 & & & \\
\hline 1.75 & 0.46 & -0.80 & 14 & 0.438
\end{tabular}

\begin{tabular}{llllll}
2.00 & 0.76 & & & \\
\hline 1.88 & 0.83 & 0.57 & 14 & 0.577
\end{tabular}

\begin{tabular}{lllll}
1.63 & 0.91 & & & \\
\hline 1.88 & 0.83 & 1.26 & 14 & 0.227
\end{tabular}

$1.38 \quad 0.74$

\begin{tabular}{lllll}
\hline 1.63 & 0.91 & 0.60 & 14 & 0.559
\end{tabular}

\begin{tabular}{llllll}
1.38 & 0.74 & & & \\
\hline 2.00 & 1.20 & -1.08 & 14 & 0.298
\end{tabular}

$2.50 \quad 0.53$

\begin{tabular}{lllll}
\hline 2.00 & 1.20 & -0.55 & 14 & 0.590
\end{tabular}

$\begin{array}{ll}2.25 & 0.46\end{array}$ $2.25 \quad 0.46$

\begin{tabular}{lllll}
\hline 1.91 & 0.84 & -1.94 & 45 & 0.847 \\
1.96 & 0.75 & & & \\
\hline 1.91 & 0.84 & 0.16 & 45 & 0.870 \\
1.88 & 0.74 & & & \\
\hline 1.96 & 0.75 & 0.39 & 46 & 0.700 \\
1.88 & 0.74 & & &
\end{tabular}

(b)

\begin{tabular}{|c|c|c|c|c|}
\hline \multicolumn{2}{|c|}{ SAGAT-L2 } & \multirow[b]{2}{*}{$\mathrm{t}$} & \multirow[b]{2}{*}{ df } & \multirow[b]{2}{*}{ Sig. } \\
\hline Mean & SD & & & \\
\hline 0.86 & 0.38 & -1.08 & 13 & 0.302 \\
\hline 1.00 & 0.00 & & & \\
\hline 0.86 & 0.38 & 0.98 & 13 & 0.346 \\
\hline 0.63 & 0.52 & & & \\
\hline 1.00 & 0.00 & 2.05 & 14 & $0.060^{*}$ \\
\hline 0.63 & 0.52 & & & \\
\hline 0.75 & 0.46 & -0.61 & 14 & 0.554 \\
\hline 0.88 & 0.35 & & & \\
\hline 0.75 & 0.46 & 0.51 & 14 & 0.619 \\
\hline 0.63 & 0.52 & & & \\
\hline 0.88 & 0.35 & 1.13 & 14 & 0.278 \\
\hline 0.63 & 0.52 & & & \\
\hline 0.75 & 0.46 & -0.61 & 14 & 0.554 \\
\hline 0.88 & 0.35 & & & \\
\hline 0.75 & 0.46 & 0.00 & 14 & 1.00 \\
\hline 0.75 & 0.46 & & & \\
\hline 0.88 & 0.35 & 0.61 & 14 & 0.554 \\
\hline 0.75 & 0.46 & & & \\
\hline 0.78 & 0.42 & -1.29 & 45 & 0.205 \\
\hline 0.92 & 0.28 & & & \\
\hline 0.78 & 0.42 & 0.88 & 45 & 0.385 \\
\hline 0.67 & 0.48 & & & \\
\hline$\underline{0.92}$ & 0.28 & 2.19 & 46 & $0.033^{* *}$ \\
\hline 0.67 & 0.48 & & & \\
\hline
\end{tabular}

${ }^{* *} p<0.05 \quad{ }^{*} 0.05<p<0.10$

Note. SD = Standard Deviation. SAGAT scores range from 0 ("low") to 3 ("high"). SAGAT Level2 scores range from 0 ("low") to 1 ("high"). Where (close to) statistically significant $(p<0.10)$ differences between scores were found, the higher scores are underlined and the lower scores indicated by italics.

Situation Awareness (SA) was measured in the three critical scenarios ( $1 b, 2 b$ and $3 b$ ) using both proposed techniques: probing (SAGAT) and self-assessment (SART). Further, both 
techniques measure SA on three (somewhat different) levels. The SAGAT levels are identical to the three levels included in the adopted SA definition (see Section 2.3.). The SART levels include: (1) cognitive demand (SART-D), (2) supply of cognitive resources (SART-S) and (3) situational understanding (SART-U) (Charlton, 2002) ${ }^{9}$.

Table 5-4a presents the SAGAT results for the critical scenarios. Using the SAGAT we are able to identify the worst performing option (in the vast majority of cases, concept $C$ had the lowest SA score) but it was difficult to identify the best support: both the other concepts ( $A$ and $B$ ) frequently came out on top and, moreover, the differences were small and the differences in the SAGAT scores were generally not statistically significant.

The only SAGAT score that produced a statistically significant difference for SA was for Level 2 (Comprehension), see Table 5-4b (Level 1 and Level 3 scores not shown). Based on $t$-test results, a close to significant superiority of concept $B$ over concept $C$ was observed in Scenario 1b ("Emergency Brake") and a significant difference was found in when the critical scenarios were combined into one group, where concept B again outperformed concept $C$.

The overall SART scores and the SART sub-scores for the individual levels did not reveal any statistically significant differences between the concepts but, as with SAGAT, concept C was generally the worst performer (see Table 5-5). The failure of SART to identify significant differences between concepts is in line with comparable findings from other research (Walker et al., 2008).

Table 5-5: SART and SART-U scores per concept in critical scenarios

\begin{tabular}{|c|c|c|c|c|c|c|}
\hline \multirow[b]{2}{*}{ Scenario } & \multirow[b]{2}{*}{ Concept } & \multirow[b]{2}{*}{$\mathrm{N}$} & \multicolumn{2}{|c|}{ SART } & \multicolumn{2}{|c|}{ SART-U } \\
\hline & & & Mean & SD & Mean & SD \\
\hline $1 b$ & Concept A & 7 & 4.83 & 1.56 & 3.90 & 0.94 \\
\hline \multirow{2}{*}{$\begin{array}{c}\text { Emergency } \\
\text { Brake }\end{array}$} & Concept B & 8 & 5.11 & 2.16 & 4.29 & 1.44 \\
\hline & Concept C & 8 & 3.98 & 1.89 & 3.58 & 1.28 \\
\hline \multirow{3}{*}{$\begin{array}{c}2 \mathrm{~b} \\
\text { Merge-out }\end{array}$} & Concept A & 7 & 5.59 & 1.60 & 5.21 & 1.11 \\
\hline & Concept B & 8 & 5.14 & 1.64 & 4.83 & 0.99 \\
\hline & Concept C & 8 & 4.54 & 2.70 & 4.50 & 1.59 \\
\hline \multirow{3}{*}{$\begin{array}{c}3 b \\
\text { Cut-in }\end{array}$} & Concept A & 7 & 4.50 & 2.29 & 4.08 & 1.51 \\
\hline & Concept B & 8 & 3.79 & 2.79 & 4.54 & 1.17 \\
\hline & Concept C & 8 & 4.58 & 1.92 & 4.46 & 1.10 \\
\hline \multirow{3}{*}{$\begin{array}{c}\text { All } \\
\text { critical } \\
\text { scenarios }\end{array}$} & Concept A & 23 & $\underline{4.98}$ & 1.84 & 4.42 & 1.31 \\
\hline & Concept B & 24 & 4.94 & 2.16 & $\underline{4.56}$ & 1.18 \\
\hline & Concept C & 24 & 4.37 & 2.12 & 4.18 & 1.35 \\
\hline
\end{tabular}

Note. SD = Standard Deviation. SART scores range from -5 ("low") to 13 ("high"). SARTU scores range from 1 ("low") to 7 ("high"). In the category combining all the critical scenarios, the highest scores are underlined and lowest scores marked in italics.

\footnotetext{
${ }^{9}$ An overall SART-score is calculated according to the formula SA-SART $=U-D+S$ (Charlton, 2002).
} 
Due to time reasons (see Section 5.4.1), Situation Awareness was only measured for the hazardous scenarios (requesting attentiveness from the driver) using the SAGAT (see Table 5-6). Here, again, the SAGAT did not produce any statistically significant differences in the scores for the three concepts, including when the three levels were combined (see Table 5-6a). However, the SAGAT Level 2 sub-scores did, as shown in Table 5-6b. Based on $t$-tests, a close to significant superiority of concept $C$ over both concepts $A$ and $B$ was observed in scenario $1 \mathrm{a}$ ("Complex Road") and a significant difference was found between concepts A and C in scenario 2a ("Vehicle Passing"). Moreover, once the three hazardous scenarios were combined in a single comparison, concept $C$ was shown, to a high statistical probability, to be the best performer and concept $A$ the worst.

Table 5-6 Results of independent t-test comparing (a) SAGAT and (b) SAGAT-Level2 scores between concepts in hazardous scenarios.

(a)

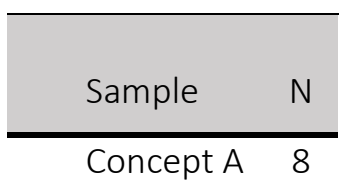

\begin{tabular}{cccccl}
\hline \multicolumn{2}{c}{ SAGAT } & & & \\
\cline { 1 - 2 } Mean & SD & & $t$ & df & Sig. \\
\hline 2.25 & 0.71 & 0.97 & 14 & 0.349
\end{tabular}

$\stackrel{0}{\rightarrow}$ Concept B 8

$\stackrel{\circ}{\frac{0}{\pi}} \overline{\text { Concept A } 8}$

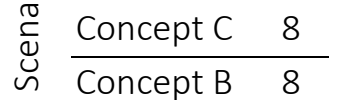

$\begin{array}{ll}1.88 & 0.83\end{array}$

\begin{tabular}{lllll}
\hline 2.25 & 0.71 & 0.00 & 14 & 1.00
\end{tabular}

$\begin{array}{ll}2.25 & 0.46\end{array}$

\begin{tabular}{lllll}
\hline 1.88 & 0.83 & -1.11 & 14 & 0.285
\end{tabular}

\begin{tabular}{ll} 
Concept C & 8 \\
\hline Concept A & 8
\end{tabular}

\begin{tabular}{lllll}
2.25 & 0.46 & & & \\
\hline 1.13 & 1.25 & -1.23 & 14 & 0.238
\end{tabular}

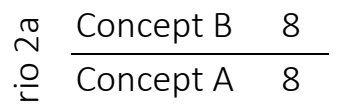

$1.75 \quad 0.7$

\begin{tabular}{lllll}
\hline 1.13 & 1.25 & -1.51 & 14 & 0.154
\end{tabular}

\begin{tabular}{lllll}
2.00 & 1.07 & & & \\
\hline 1.75 & 0.71 & -0.55 & 14 & 0.590
\end{tabular}

\begin{tabular}{lllll}
2.00 & 1.07 & & & \\
\hline 1.50 & 1.07 & -0.94 & 14 & 0.365
\end{tabular}

Concept A 8

$\stackrel{\pi}{m}$ Concept B 8

은 Concept A 8

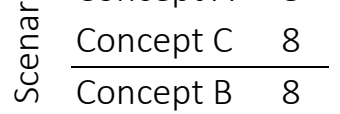

\begin{tabular}{lllll}
2.00 & 1.07 & & & \\
\hline 1.50 & 1.07 & -0.51 & 14 & 0.619
\end{tabular}

\begin{tabular}{lllll}
1.75 & 0.89 & & & \\
\hline 2.00 & 1.07 & 0.51 & 14 & 0.619
\end{tabular}

Concept C 8

Concept A 24

\begin{tabular}{lllll}
1.75 & 0.89 & & & \\
\hline 1.63 & 1.10 & -0.88 & 46 & 0.382
\end{tabular}

产 $\frac{\text { Concept B } 24}{\frac{0}{0}}$

$\begin{array}{ll}1.88 & 0.85\end{array}$

\begin{tabular}{ll}
1.88 & 0.85 \\
\hline 1.63 & 1.10
\end{tabular}

$\begin{array}{lll}-1.34 & 46 & 0.189\end{array}$

\begin{tabular}{lllll}
2.00 & 0.83 & & & \\
\hline 1.88 & 0.85 & -0.51 & 46 & 0.610
\end{tabular}

$2.00 \quad 0.83$ (b)

\begin{tabular}{|c|c|c|c|c|}
\hline \multicolumn{2}{|c|}{ SAGAT-L2 } & \multirow[b]{2}{*}{$\mathrm{t}$} & \multirow[b]{2}{*}{$d f$} & \multirow[b]{2}{*}{ Sig. } \\
\hline Mean & SD & & & \\
\hline 0.63 & 0.52 & 0 & 14 & 1.00 \\
\hline 0.63 & 0.52 & & & \\
\hline 0.63 & 0.52 & -2.05 & 14 & $0.060^{*}$ \\
\hline 1.00 & 0.00 & & & \\
\hline 0.63 & 0.52 & -2.05 & 14 & $0.060^{*}$ \\
\hline
\end{tabular}

\begin{tabular}{lllll}
1.00 & 0.00 & & & \\
\hline 0.25 & 0.46 & -1.00 & 14 & 0.334
\end{tabular}

$0.50 \quad 0.53$

\begin{tabular}{lllll}
\hline 0.25 & 0.46 & -2.16 & 14 & $0.049^{* *}$
\end{tabular}

\begin{tabular}{lllll}
$\underline{0.75}$ & 0.46 & & & \\
\hline 0.50 & 0.53 & -1.00 & 14 & 0.334
\end{tabular}

$0.75 \quad 0.46$

\begin{tabular}{lllll}
\hline 0.50 & 0.53 & -1.00 & 14 & 0.334
\end{tabular}

$0.75 \quad 0.46$

\begin{tabular}{lllll}
\hline 0.50 & 0.53 & -1.66 & 14 & 0.120
\end{tabular}

$0.88 \quad 0.35$

\begin{tabular}{lllll}
\hline 0.75 & 0.46 & -0.61 & 14 & 0.554
\end{tabular}

\begin{tabular}{ll}
$0.88 \quad 0.35$ \\
\hline 0.46
\end{tabular}

\begin{tabular}{lllll}
\hline 0.46 & 0.51 & -1.15 & 46 & 0.256
\end{tabular}

$0.63 \quad 0.49$

\begin{tabular}{lllll}
\hline 0.46 & 0.51 & -3.34 & 46 & $0.002^{* * *}$
\end{tabular}

\begin{tabular}{lllll}
$\underline{0.88}$ & 0.34 & & & \\
\hline 0.63 & 0.49 & -2.05 & 46 & $0.047^{* *}$
\end{tabular}

$0.88 \quad 0.34$

${ }^{* * *} p<0.01{ }^{* *} 0.01<p<0.05 \quad{ }^{*} 0.05<p<0.10$

Note. SD = Standard Deviation. SAGAT scores range from 0 ("low") to 3 ("high"). SAGAT-Level 2 scores range from 0 ("low") to 1 ("high"). Where (close to) statistically significant $(p<0.10)$ differences between scores were found, the higher scores are underlined and the lower scores indicated by italics. 
Interestingly, observing that concept $\mathrm{C}$ is the best performer (in terms of Situation Awareness) in hazardous situations is in sharp contrast with the previous finding where it was the worst performer in critical scenarios - an observation which will be reflected upon in the Discussion of this chapter (Section 5.7)

\subsubsection{Assessment of Accident Avoidance}

Accident Avoidance was only calculated within scenarios $1 \mathrm{~b}$ and $3 \mathrm{~b}$ because the other scenarios did not incorporate a designed risk of collision. As explained in Section 5.3.2, 'Accident Avoidance' is a combination score that assess accident occurrence, TTC (Time-toCollision) and successful collision avoidance. The calculated Accident Avoidance scores are based on the following assumptions:

* The best score ("1") denotes a successful collision avoidance. That is, before the simulation froze, the participant brought the car to a safe standstill or swerved aside to successfully avoid the other vehicle;

* Scores between 1 and 4 are transformed TTC values, with $T_{T C} C_{\text {transformed }}=\operatorname{EXP}(1 / T T C)$. The TTC (Time-to-Collision) value was measured at the moment the simulation froze. This transformation means that lower scores reflect longer TTCS (i.e. a better performance) than higher scores (closer to " 4 ") where the collision is more imminent;

* The worst score (" 4 ") denotes the occurrence of an accident.

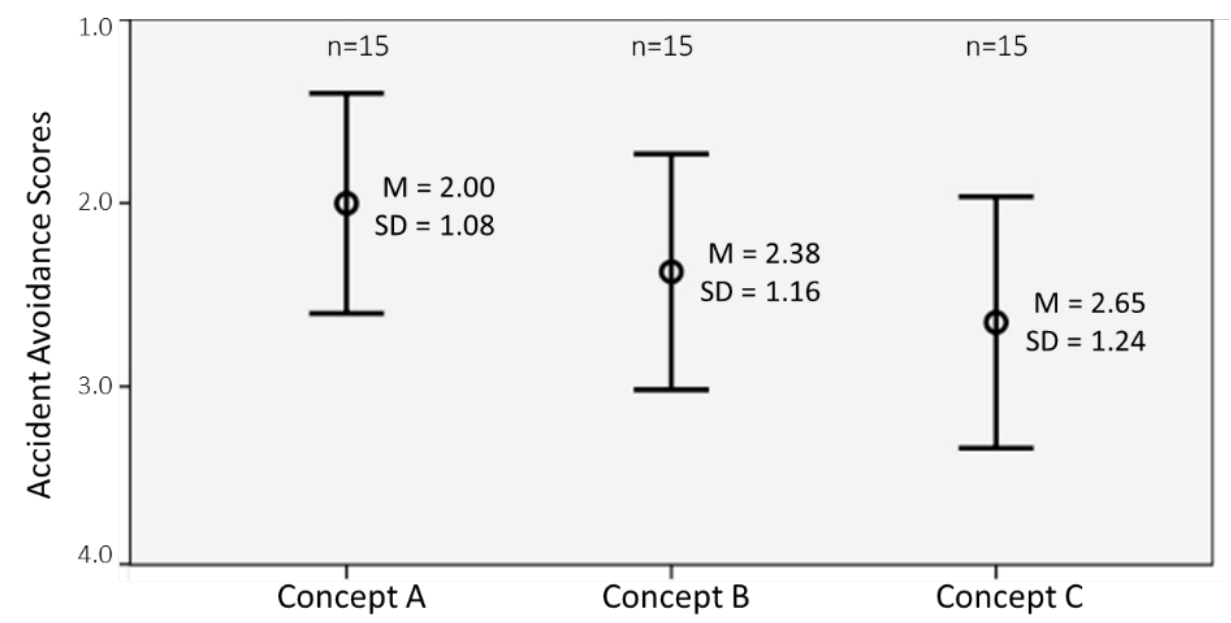

Figure 5-5 Mean Accident Avoidance Scores per concept.

Note. $\mathrm{M}=$ Mean score and SD = Standard Deviation. Error bars show 95\% Confidence Intervals. A score of "1.0" indicates accident avoidance by swerving aside or bringing the car to a standstill. A "4.0" denotes an accident occurred and scores between 1.0 and 4.0 are a transformation of TTCvalues based on $\mathrm{TTC}_{\text {transformed }}=\operatorname{EXP}(1 / \mathrm{TTC})$.

Due to simulator failures, our 48 tests resulted in only 45 valid measurements, with 15 scores for each of the three concepts. We calculated a concept-ranking based on these 45 Accident Avoidance scores (see Figure 5-5). The mean rank for Concept A was 19.2, for Concept B 22.9 
and for Concept $C$ 26.8. These results suggest that concept $A$ is "the best" and C "the worst". However, to identify if the difference in the ranking scores between the best and the worst concepts was statistically sound, we subjected them to a paired ranking test which showed that the difference was not statistically significant (Mann-Whitney $U=77.5, \mathrm{n}_{1}=\mathrm{n}_{2}=15, p=$ 0.142 two-tailed).

\subsubsection{Assessment of Concept Acceptance}

Concept Acceptance was measured using a scale developed to distinguish both Perceived Usefulness and Satisfaction (Van der Laan et al., 1997). This scale was applied after the simulation tests were complete and the findings reflect the participants' overall impressions. Independent t-tests showed that concept $C(M=2.50, S D=0.73)$ scored significantly better than concept $\mathrm{A}(M=2.00, S D=0.68)$ in terms of perceived usefulness $(t(44)=-2.40, p<0.05)$ (See Table 5-7). However, when it came to satisfaction, the scores (not shown) between the concepts were not significantly different.

Table 5-7: t-test results comparing the Perceived Usefulness of the three concepts.

\begin{tabular}{lcccccl}
\hline Sample & N & Mean & SD & t & df & Sig. \\
\hline Concept A & 23 & 2.00 & 0.68 & -1.25 & 45 & 0.217 \\
Concept B & 24 & 2.31 & 0.99 & & & \\
\hline Concept A & 23 & 2.00 & 0.68 & -2.40 & 44 & $0.021^{* *}$ \\
Concept C & 23 & $\underline{2.50}$ & 0.73 & & & \\
\hline Concept B & 24 & 2.31 & 0.99 & -0.74 & 45 & 0.466 \\
Concept C & 23 & 2.50 & 0.73 & & & \\
\hline
\end{tabular}

${ }^{* *} p<0.05$

Note. $\mathrm{SD}=$ Standard Deviation. Scores range from 1 (not useful at all) to 5 (very useful). Highest scores are underlined and lowest scores marked in italics.

\subsection{Discussion}

\subsubsection{How reliable is the framework?}

To determine how reliable the framework is, we assess the reliability of the measurement scores obtained during its testing. To this end, we will now discuss the extent to which the measurement scores are related to the expected outcomes. Here, we investigate two aspects: (1) whether the different measurements identify similar levels of support for the various concepts (i.e., do the various measures (SA, AA and CA) identify the same concepts as being the best and worst performers?); and (2) whether the measured differences reflect the inbuilt differences in the support offered by the various concepts. 


\subsubsection{Consistency of the measures}

Adequate interfaces should offer support both for supervision and for intervention. Consequently, in our test framework, we incorporated hazardous test scenarios, requesting supervision, and critical scenarios, requiring intervention. In comparing different measures to see whether they show consistent winners and losers, we therefore need to take into account the different types of scenario. Hence, Table 5-8 provides a summary of the scenarios in which the various measures found differences in the performance of the various concepts.

In the critical scenarios, the measurement of SA was consistent in that both SART and SAGAT identify concept $C$ as the worst performer. However, neither technique was able to identify the overall best performer out of $A$ and $B$ although, on level 2, the SAGAT identified $B$ as outperforming $A$. When it came to measuring SA in the hazardous scenarios, the SAGAT identified concept $C$ as the best and concept $A$ as the least effective, the opposite outcome to that with the critical scenarios. It was only relevant to measure Accident Avoidance in two of our critical scenarios $1 b$ ("Emergency Brake") and $3 b$ ("Critical Cut-in"). Here, concept C was evaluated as the 'worst' and A again the 'best'. Our final measure, Concept Acceptance, reflected a combination of all scenarios and it was only in terms of Perceived Usefulness that the scale used was able to discriminate between the three concepts, with concept $C$ being seen as the most useful.

Table 5-8 Comparison of concept performance using different measurement approaches

\begin{tabular}{|c|c|c|c|c|}
\hline \multicolumn{2}{|r|}{$\begin{array}{l}\text { Scenarios } \\
\mathrm{C}=\text { critical, } \mathrm{H}=\text { hazardous }\end{array}$} & $\begin{array}{l}\text { Assessment Aspect } \\
\text { (Measure) }\end{array}$ & $\begin{array}{l}\text { Measurement } \\
\text { Method }\end{array}$ & $\begin{array}{l}\text { General Outcome } \\
\text { Concept performance }\end{array}$ \\
\hline \multirow{5}{*}{ C } & All critical scenarios & Situation Awareness (SA) & SART & 'best' uncertain; 'worst' C \\
\hline & $" \prime$ & $m "$ & SAGAT & 'best' uncertain; 'worst' C \\
\hline & $" \prime$ & $" \prime$ & SAGAT-level2 & 'best' B; 'worst' C ${ }^{1}$ \\
\hline & 1b "Emergency Brake" & Accident Avoidance (AA) & AA-scores & 'best' A; 'worst' C \\
\hline & 3b "Critical cut-in" & $" \prime \prime$ & AA-scores & 'best' $\mathrm{A}$; 'worst' C \\
\hline \multirow{3}{*}{$\mathrm{H}$} & All hazardous scenarios & Situation Awareness (SA) & SAGAT & 'best' C; 'worst' A' \\
\hline & 2a "Vehicle passing" & " $"$ & SAGAT-level2 & 'best' C; 'worst' A ${ }^{2}$ \\
\hline & All scenarios & Concept Acceptance (CA) & $\begin{array}{l}\text { Perceived } \\
\text { Usefulness }\end{array}$ & 'best' C; 'worst' A ${ }^{3}$ \\
\hline
\end{tabular}

Note. Table only includes outcomes where there were statistically significant differences; ${ }^{1}$ see Table $5-3 ;{ }^{2}$ see Table 5-5 and ${ }^{3}$ see Table 5-6 for complete results.

In judging these apparently contradictory results, one needs to recognise that the measures differed in being objective measures, like SA probing (SAGAT) and Accident Avoidance (AA), or subjective measures like Perceived Usefulness. It could be that specific characteristics of the individual concepts influenced the subjective rating of usefulness in a contradictory fashion and this will be discussed in the next section. The fact that both objective measures (i.e. SA (using SAGAT) and AA) identified the same concept as the worst performer in the critical 
scenarios is seen as an indication of the framework's reliability. Although the observed small differences and their limited statistical significance may limit confidence in the framework's reliability, this observation is not unusual and often inherently linked to testing within closeto-reality scenarios (De Winter et al., 2014). A possible explanation is that the scenarios and concepts we used to reflect partially automated driving (and the subsequent challenges in supervision where drivers have to occasionally intervene) combined to create situations in which the scenarios might have lowered performance to such an extent that the concepts were no longer able to compensate. In testing this hypothesis, a MANOVA revealed that there is indeed an effect of Scenario on the group of dependent variables (measures): Pillai's Trace = $0.409, F(14,122)=2.216, p=0.010$. However, the comparable test for the effect of Concept on the performance indicators (as a group) did not show a similar trend (Pillai's Trace $=0.171$, $F(12,124)=0.968, p=0.483)$. This reveals that task performance was influenced more by the scenarios than by the specific support offered by the individual concepts. Nevertheless, separate ANOVAs show that Concept has a significant relationship $(\alpha=0.10)$ with two particular performance indicators: with SAGAT-level2 Understanding $(F(2,50)=5.00, p=0.09)$ and with Perceived Usefulness $(F(2,39)=4.78, p=0.10)$. That is, despite the strong influence of Scenario on the measurements, meaningful differences between the concepts could be identified in terms of SAGAT-level2 Understanding and Perceived Usefulness. We interpret this as a significant support for the reliability of both measures. Due to the ordinal character of the measurement data, it was not possible to test the Accident Avoidance scores for the influence of Scenario. However, we do note that these scores were consistent with the SAGAT scores.

\subsubsection{Congruency of measurement scores with predefined support levels}

An additional means to assess the reliability of a measurement output is to see whether measured differences align with purposefully designed differences in the level of support offered by each concept. The concepts were deliberately designed to reflect different levels of support as outlined in Figure 5-3. Concept A provided an audible alert when attention was requested (in hazardous situations) and a different audible warning when intervention was required. Concept $B$ used the same audible alerts as $A$ but, in addition, at the same time displayed graphical instructions, such as "take over now", on the dashboard. Concept C was designed to especially support supervision by continuously displaying status information on a larger 6" screen. For example, this concept displayed the system's recognition of road lines and the target vehicle - information not provided by the other concepts. The differences measured in identifying the best and worst performing concepts (see above), would seem to tally with the differences in the concepts' designs. For example, during hazardous scenarios that require supervision, one would intuitively expect concept $C$ to be seen as the best option. Conversely, as concept $C$ was focussed on supervision rather than intervention, it was no surprise that concept $C$ was seen as offering least support in critical situations. Although concept $B$ was designed to give the most unequivocal instruction to intervene, the measurements show no real preferences between this and concept $A$ in a situation where intervention was needed, 
and this can maybe be explained by the small conceptual differences between the two concepts. Furthermore, the apparently contradicting result between concept $\mathrm{C}$ identified as providing least intervention support and at the same time participant's appreciation of concept $C$ in terms of perceived usefulness is probably caused by the opposing impacts of the concepts' characteristics on accident avoidance and on the appraisal of usefulness. That is, while concept $C$ was designed to be graphically the most informative, leading to the participants' appreciation of its usefulness, it could be that the need to digest this information competed with the task of avoiding an accident. Overall, the above discussion indicates consistency between the measurement scores and the predefined support levels.

\subsubsection{How effective is the framework?}

The previous section reflected on the framework's reliability in producing consistent data, and this section answers our final question: how effective is the framework in predicting adequate interface support? First, as shown by the effect that changing the 'Concept' had on individual performance scores, the framework was able to predict the success of the support options trailed within contexts representative of partial automation in real-world driving. These outcomes confirm the predictive power of the framework. Looking closer at the provided level of detail in predicting differences in the performance of the various concepts, we note that the framework has limited sensitivity when it comes to identifying small differences in the effectiveness of offered support. In terms of the support offered for intervention, the majority of the measures were successful in identifying the 'worst' performer, but less discriminatory when it came to identifying the 'best' concept. Although, this was attributed to the relatively minor conceptual differences between the two 'best' concepts (A and B), it is somewhat unsatisfactory as the optimisation of solutions tends to end up with evaluating gradual refinements. While having a larger group of participants could help by boosting confidence (and statistical significance) in the data, large-scale evaluations are somewhat difficult to implement early in a development process. Nevertheless, our results do indicate an approach that enables inadequate solutions to be rapidly excluded - a valuable contribution in itself.

A comparison of the measurement scores showed one apparent contradiction: concept $\mathrm{C}$ was in general perceived as the most useful option, but was performing the worst under critical conditions when intervention was required. As it was expected that participant's appraisal would be more dominantly influenced by how a concept performed in the critical scenarios than in the hazardous scenarios, this inverse relation between concept appraisal and concept support for intervention was considered a contradiction. As already discussed, a likely explanation for this apparently contradictory finding is that concept $C$ provided the mostdetailed status information. Being so informative could explain why this concept is perceived as the most useful but, at the same time, a distraction during critical situations when needing to take action to avoid an accident. Another explanation for why the participants preferred concept $C$ could be that they were unsure as to what sort of support was actually helpful, and therefore opted for the interface with the most elaborate feedback as 'the safest choice'. This 
highlights the potential dangers of drawing conclusions related to needed support based on self-assessment scores and also underlines the importance of the framework's quality to assess concepts with the selected combination of assessment aspects, i.e. AA, SA and CA.

\subsection{Conclusions}

The aim of this study was to propose and validate an assessment framework for driverinteraction concepts for use in partially automated vehicles. To this end, this chapter answered three questions: (1) What assessment aspects should be included in the framework?; (2) How reliable are the applied measurements in terms of assessing aspects of the framework?; and (3) Is the proposed framework effective in predicting the level of support offered by a concept? Three aspects were identified as suitable for assessment in building the framework: Accident Avoidance (AA), Situation Awareness (SA) and Concept Acceptance (CA). In order to represent realistic traffic situations that are relevant to partially automated driving systems, specific scenarios were incorporated in the framework to provide different levels of difficulty in terms of drivers needing to understand and resolve traffic situations.

The scenarios were divided into hazardous and critical situations, and, in each, the aspects assessed were largely consistent in identifying certain concepts as performing best and worst. Although the measured differences were small the relationships between Concept and SA probing (i.e. SAGAT) and between Concept and Perceived Usefulness were still significant after controlling for the influence of Scenario on task performance. Further, the Accident Avoidance measure showed a similar relationship between concept and performance as the SA measure (in particular when using SAGAT). The consistency between these measurements enabled us to positively answer our second question, and we conclude that the measurement of Accident Avoidance, Situation Awareness and Perceived Usefulness provided construct validity to our proposed framework.

Determining how effective our proposed framework is in predicting differences in the support offered by the various interfaces revealed some concerns. The framework showed limited sensitivity in identifying small differences in optimised support. Therefore, we would strongly recommend using the framework's results as a basis for a second round of evaluation based on expert judgement. That is, the framework offers a validated means to produce relevant assessment data, based on which expert designers can make further decisions as to which solutions or interface-directions are most appropriate. Moreover, the results show the framework's success in providing a supportive combination of objective and subjective assessments, enabling designers to put data into perspective and derive thoughtful and meaningful conclusions with respect to desirable and effective interface support. Based on pragmatic considerations, it is difficult to draw further conclusions on the predictive validity as this would require future verification of currently developed concepts under real-life circumstances. Nevertheless, our framework succeeded in identifying the least acceptable form of support, backed with statically significant results and reasoned explanations. On this 
basis, we conclude that our framework was successful in providing predictive power that enables the rapid rejection of inadequate interface supports early in the design process. Given that changes that prove necessary to resolve design failures are more expensive in later stages of the development, this is a valuable benefit.

This study has proposed a framework for assessing the interface support that drivers need when interacting with partially automated driving systems. The framework's ability to provide reliable and meaningful assessment data was successfully demonstrated. As such, the framework demonstrated its ability to contribute to the efficient development of driver's incontrol and safe means of operating partially automated vehicles. 


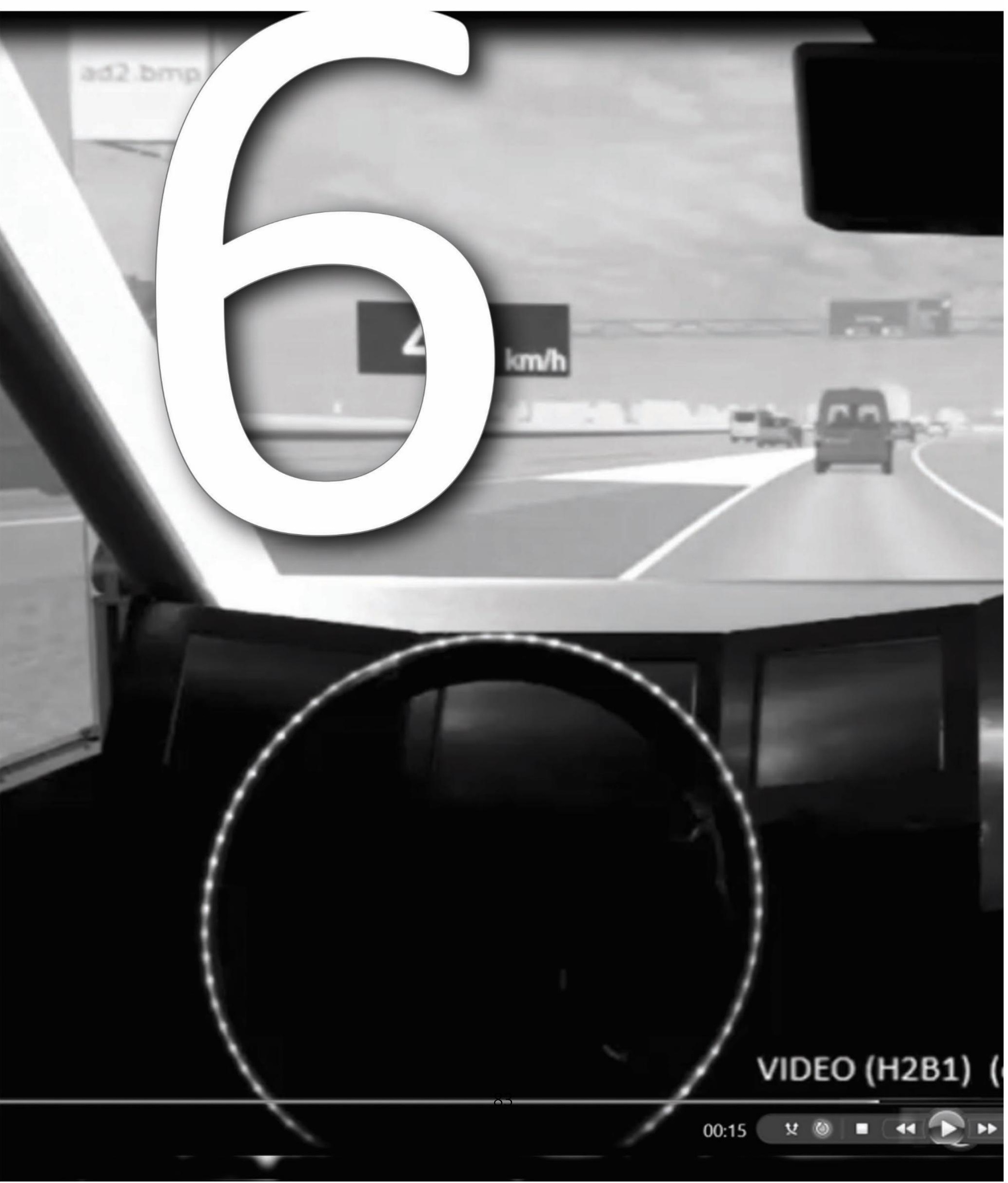




\title{
Chapter 6. Understanding of automation mode with illumination
}

This chapter is based on ${ }^{10}$ :

Van den Beukel, A. P. \& Van der Voort, M. C. (2016). Drivers and automation - Does directional illumination support mode awareness and understanding of driver's role? IET Intelligent Transport Systems. [Paper conditionally accepted on $25^{\text {th }}$ September 2016.]

\begin{abstract}
Partially automated driving changes the driving task into supervising the automation with occasionally a necessity to intervene. Illumination of areas in the windshield - called 'directional illumination' - is a potential solution for intervention-support. For supervision it is essential to perceive and understand automation-state (i.e. mode awareness), though little is known to what extent directional illumination supports mode awareness. An internet survey with video-clips of directional illumination within circumstances representative for partially automated driving measured respondents' understanding of automation-state and required action with a particular set of questions. The answers were considered representative for participant's mode awareness and were compared with mode awareness obtained with a base-concept. The base concept provided cues for automation mode, but without directional illumination. Results showed that directional illumination raised perception and understanding of automation-state noticeable when attention was requested for hazards located in the driver's side-views. In interpreting driver's role, directional-illumination did not show a contribution. Further development of explanatory information was recommended for events when changing road-situations interplayed with behaviour of other road-users. To raise alerts, directional illumination was perceived significantly more suitable than the base-concept. Therewith, this study contributes to further development of directional illumination as a support to supervise partially automated driving.
\end{abstract}

Keywords: directional illumination, driving automation, mode awareness, supervision support, interface design.

10 Citation in the original document was based on Vancouver's citation system and is replaced here by parenthetical referencing in APA-style to be consistent with the other parts of this thesis. 


\subsection{Introduction}

The introduction of automated driving (e.g. (Audi, 2016; Daimler, 2015)) amounts to so called level 2 systems (Bengler et al., 2014), consisting of partially automated driving (Gasser \& Westhoff, 2012; SAE International). 'Partial' refers to the system's restriction to drive automated only within predefined operational conditions, for example; driving on motorways, below a specific speed threshold and within minimally required follow distance (Naujoks et al., 2015). With partial automation, the driver remains fully responsible. He or she is therefore required to be any time available and to act as a back-up in case automation fails or stops (Merat et al., 2014; Strand, Nilsson, Karlsson, \& Nilsson, 2014; Van den Beukel \& Van der Voort, 2016b). As a consequence, partially automated driving is changing the driver's task from actively operating the vehicle into supervising the system with occasionally a necessity for intervention (De Winter et al., 2014; Van den Beukel \& Van der Voort, 2016b). This changing taskload adds on the already raising demand for supervision due to growing numbers of invehicle systems (Bengler et al., 2014; Götze \& Bengler, 2015). However, supervision is not a task humans are particularly good at due to e.g. low vigilance and inappropriate levels of workload (Bainbridge, 1983; Martens \& Van den Beukel, 2013; Toffetti et al., 2009). A cause for humans' difficulty to supervise driving automation is that automation decreases the visual demand of driving (Rudin-Brown \& Parker, 2004), allowing drivers to monitor the road ahead less. Several studies have shown that drivers who were supported by partial automation responded later to an event that required their intervention, like a breaking lead vehicle or a stationary cue, than unsupported drivers (De Winter et al., 2014; Hoedemaker \& Kopf, 2001; Rudin-Brown \& Parker, 2004). These examples explain why drivers of partially automated vehicles have need for renewed driver interfaces (Flemisch et al., 2014; Van den Beukel \& Van der Voort, 2016b), especially for interfaces that direct their attention to outside the vehicle, support detection of events and provide cues for mode awareness (Stanton \& Young, 2005).

\subsubsection{Research scope}

This study investigates the potential of supporting drivers of partially automated vehicles with so called 'directional illumination'. Within the scope of this study, directional illumination consists of highlighting edges of the windscreen and side-windows (with coloured LED-strips). The illumination is configured dynamically in order to indicate real-time when and where roadtraffic events occur that require attention. Like (Locken et al., 2015; Pfromm, Cieler, \& Bruder, 2013), size and location of the illumination are intended to indicate where attention is needed. Colour and brigthness convey level of urgency of the requested attention (Baldwin \& Lewis, 2014). Studies with similar illumination concepts confirm the potential of directional illumination as a signal to guide attention (Dziennus, Kelsch, \& Schieben, 2015; Kelsch \& Dziennus, 2015). In contrast to the quality of indicating where attention is needed, interfaces should ideally also indicate why attention is needed in order to improve user's understanding of automation-state (like availability, activation or malfunction), prediction of its future state and required action. This is because the ability to regain control benefits from correct 
expectation of changes in automation-state (Merat et al., 2014). With regard to indicating where and why, directional illumination and traditional graphical interfaces show contrary qualities. Traditional graphical interfaces use displays inside the vehicle to provide feedback on system-state and to instruct drivers accordingly (Damiani, Deregibus, \& Andreone, 2009; Harvey, Stanton, Pickering, McDonald, \& Zheng, 2011; Stanton \& Young, 2005). Therewith, traditional interfaces provide especially information why attention is needed, but the information itself often keeps the driver from observing where attention is needed. Studies confirm the visual distraction of graphical (screen) interfaces (Lansdown, Brook-Carter, \& Kersloot, 2004; Rogers, Zhang, Kaber, Liang, \& Gangakhedkar, 2011). Directional illumination, on the other hand, is designed to direct attention where needed. Nonetheless, also when drivers are supported by directional information, drivers need to conceive a minimum understanding why attention is needed in order to comprise required action. Since too complex explanatory information should be omitted to avoid distraction, driver's understanding when provided with directional illumination alone relies on his/her ability to deduce from the directional cues and observed road-traffic events what reaction (if any) is needed. Therefore, the aim of this study is to identify to what extent directional illumination is able to support mode awareness and understanding of driver's role.

\subsubsection{Research approach and outline}

To assess interfaces for driver assistance systems (like partial automation) it is important that test-circumstances include the dynamic behaviour of elements in the road environment that influences system awareness (Charlton, 2002). This study focuses on driver's ability to percieve and understand automation-state of the illumination-cues and is intended as a pre-test of the signals - before pursuiting driving simulator experiments. For this purpose, we compared levels of situation awareness that test persons obtained when using directional illumination with obtained situation awareness when using a base concept and conducted an internet-based survey showing videoclips with signal behaviour from either concept within situations representable for partially automated driving.

Section 6.2 presents the applied method to conduct this survey and explains how we measured mode awareness. Section 6.3 presents the results from the survey and section 6.4 discusses what these results mean for answering our research question. Finally, section 6.5 reflects with conclusions and recommendations on potential merits to apply directional illumination while helping the development of interface solutions that drivers need when driving partially automated.

\subsection{Method}

To gain insight into people's understanding of automation-state and state changes when provided with directional illumination in the windscreen, we conducted a survey among drivers, which was distributed in The Netherlands, Germany and United Kingdom. The survey 
consisted of videos showing scenarios representative for partially automated driving. The videos were taken from a driver's perspective and the illumination-behaviour was included in the videos. To avoid that taking the survey would require too much time, comparison of concepts was set up between subjects. Therefore, the survey included two samples - which were distributed independently from one another. After each video, respondents' understanding of automation-state and required action was assessed with a particular set of questions. The survey also asked for respondents' acceptance of the feedback signals. The next sections explain the applied method in more detail.

\subsubsection{Concepts}

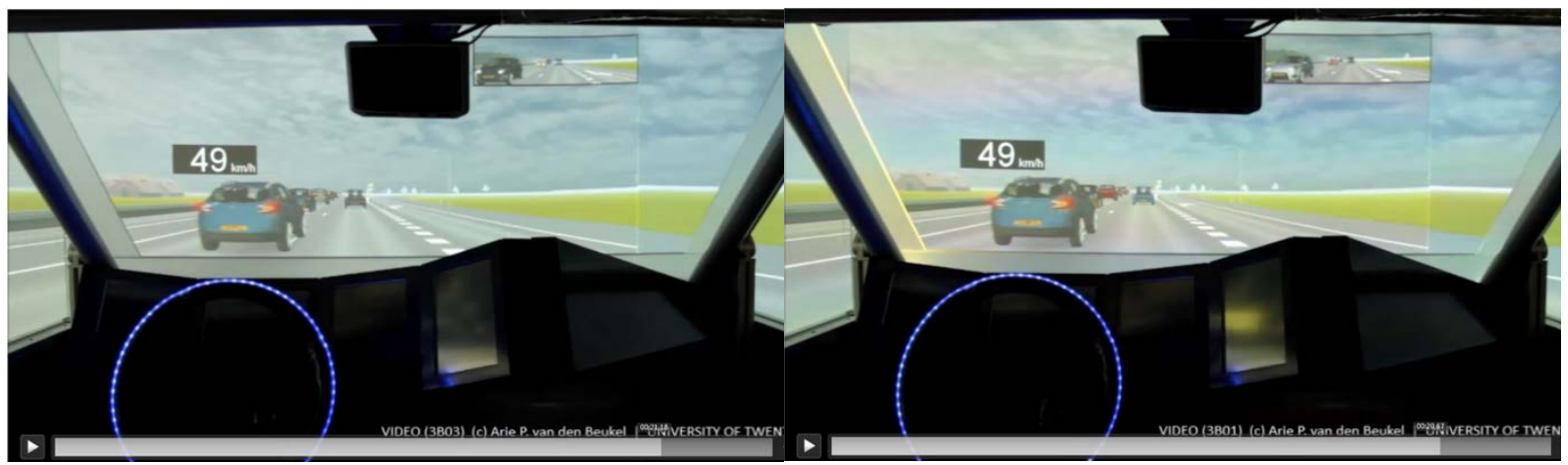

(a)

(b)

Figure 6-1 Illustration with concepts. (a) Shows the base concept with illumination around the steering wheel, but without 'directional' light cues. (b) The illumination concept provides in addition to the base concept 'directional' light cues. For example: yellow illumination of the left side of the windscreen to indicate a car cutting-in from the left.

The illumination behaviour included in the videos consists of two concepts, called 'illumination concept' and 'base concept'. Both concepts convey attentional cues on two levels. The first level concerns 'soft' warnings containing a request for attention duo to approaching a potentially dangerous road-traffic situation. The second level comprises 'hard' warnings where a driver is required to retake control because automation stops or becomes unavailable. Based on previous research (Van den Beukel \& Van der Voort, 2016b), both base concept and illumination concept use the same sound signals to distinguish between soft and hard warning. Both concepts also use a blue-illuminated ring around the steeringwheel as an indicator for automation-mode. That is, as long as the automation is active this ring lights up and it turns off again when the automation stops. See Figure 6-1 for an example of both concepts. The base concept comprises only the illuminated ring around the steering wheel and the sound signals. In addition to the base concept, the illumination concept consists of highlighting edges of the windscreen to provide a spatial cue where attention is needed. For example: Figure 6-1b shows a light-cue at the left side of the windscreen to warn for a car cutting-in from the left. In parallel to sound, the illumination concept conveys feedback on urgency with colour: a request for attention (moderate urgency, i.e. soft warning) is combined with yellow illumination and a required take-over (high urgency, i.e. hard warning) comes with red illumination. When using 
the illumination concept, the assumption is that the directional light-cues improve driver's observation of the road-traffic situation which in turn improves understanding why attention is needed (Jamson et al., 2013; Merat et al., 2014). Therefore, the above explained configuration of concepts was chosen to identify if the additional directional light-cue of the illumination concept raises understanding why attention is needed compared to the base concept without such cue.

\subsubsection{Scenarios}

Table 6-1 Overview with scenarios shown in the video-clips of the survey

\begin{tabular}{|c|c|}
\hline \multicolumn{2}{|c|}{ 'hazardous' scenarios (requesting supervision from the driver) } \\
\hline $\begin{array}{l}\text { 1: "Complex Road" } \\
\text { Need for attention induced by } \\
\text { infrastructure }\end{array}$ & $\begin{array}{l}\text { Attention is needed because the vehicle is approaching a } \\
\text { combined entrance/exit ramp with the likelihood that vehicles } \\
\text { will simultaneously enter and exit the main road. }\end{array}$ \\
\hline $\begin{array}{l}\text { 2: "Vehicle Passing" } \\
\text { Need for attention induced by } \\
\text { traffic-participant }\end{array}$ & $\begin{array}{l}\text { While the vehicle is in the left (fast) lane, extra attention is } \\
\text { needed because a vehicle is nevertheless passing on the right. }\end{array}$ \\
\hline $\begin{array}{l}\text { 3: "Approaching on/off ramp" } \\
\text { Need for attention induced by } \\
\text { infrastructure }\end{array}$ & $\begin{array}{l}\text { Attention is needed because the ego-vehicle approaches a } \\
\text { highway and the entrance-lane is a combined on- and off-ramp. } \\
\text { Attention is needed because vehicles can simultaneously enter } \\
\text { and exit. }\end{array}$ \\
\hline \multicolumn{2}{|c|}{ 'critical' scenarios (requiring driver's intervention) } \\
\hline $\begin{array}{l}\text { 4: "Merge-out target-vehicle" } \\
\text { Need for intervention induced } \\
\text { by system design }\end{array}$ & $\begin{array}{l}\text { The target vehicle suddenly changes lane. If there is no new } \\
\text { target vehicle ahead, the system stops and requests the driver } \\
\text { to take back control. Accident avoidance involves preventing the } \\
\text { vehicle from leaving its lane. }\end{array}$ \\
\hline $\begin{array}{l}\text { 5: "Close cut-in" } \\
\text { Need for intervention induced } \\
\text { by combination of traffic } \\
\text { behaviour and system design }\end{array}$ & $\begin{array}{l}\text { A vehicle in another lane brakes heavily in an attempt to cut } \\
\text { across to an exit. This violates system boundaries for minimum } \\
\text { separation and a collision would be inevitable without } \\
\text { intervention. }\end{array}$ \\
\hline
\end{tabular}

Note. Except for scenario 3, the scenarios are adopted from section 3.2.3. In the original section, scenario 1 was named " $1 a$ ", 2 was " $2 a$ ", 4 was " $2 b$ " and 5 was " $3 b$ ".

Table 6-1 explains the scenarios used in this study and provides visual examples. Except for scenario 3, the scenarios were identical to the scenarios introduced in section 3.2.3. Scenarios 1,2 and 3 involve events for which attention from the driver is requested, but these scenarios have no immediate danger for an accident - a category we called 'hazardous' scenarios. Scenarios 4 and 5 comprise so called 'critical' scenarios, which have a danger for collision. During these scenarios the concepts raise a 'hard' warning and requires the driver to retake control. The videoclips provided a simulated motorway environment in line with the described scenarios. Other vehicles drove in front, aside and behind the simulated vehicle on close distances, as to simulate traffic congestion. The timing when a soft warning or hard warning was raised depended on the specific traffic situation and is explained in Table 6-2. 
Table 6-2 Timing of soft and hard warnings for each scenario

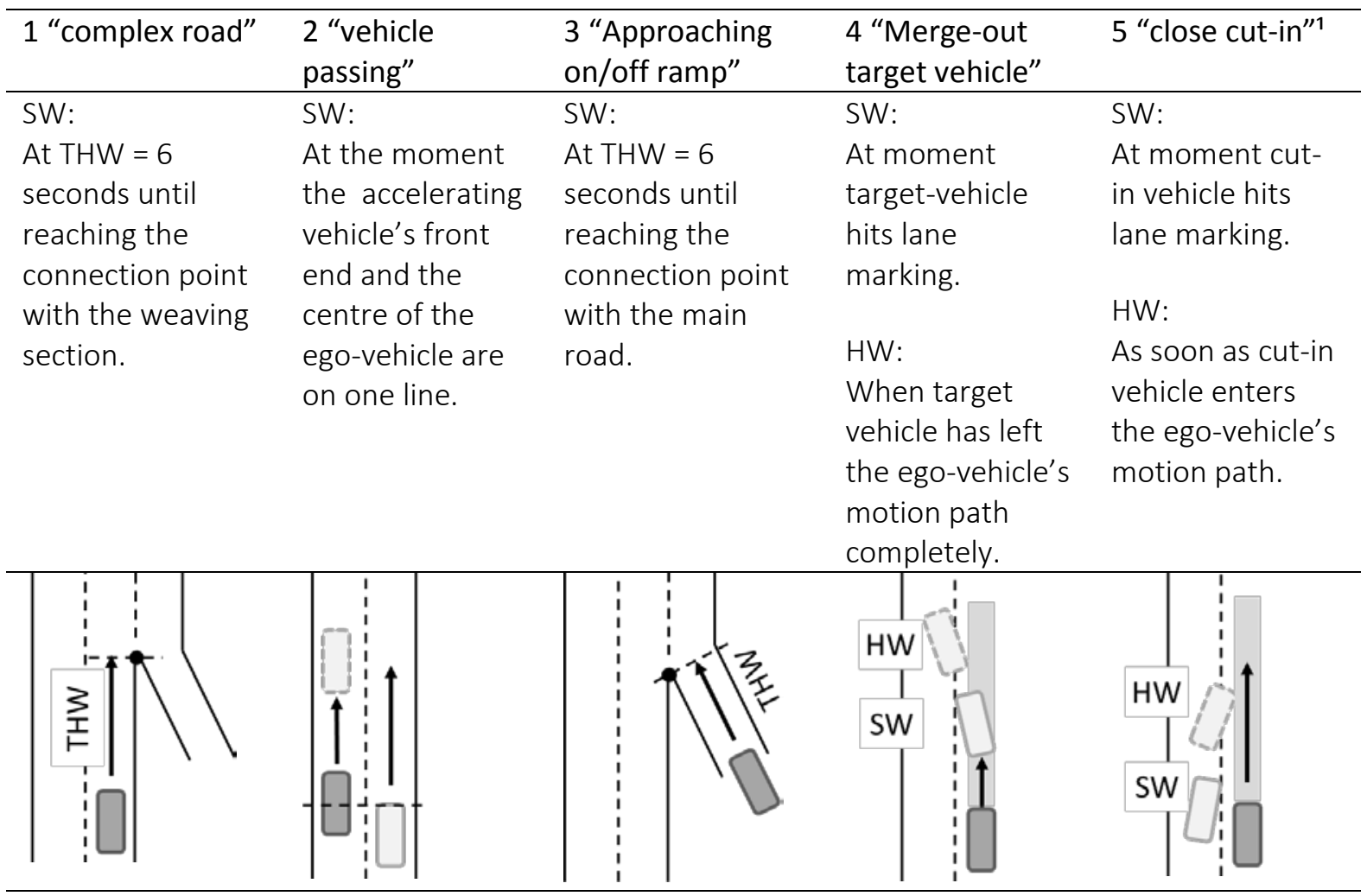

Note. SW = Soft warning, HW = Hard warning, THW = Time headway, $\left.{ }^{1}\right)$ Timing close cut-in is based on Urhahne (2016).

\subsubsection{Variables and measures}

The independent variables comprise Concept-type (illumination concept or base concept) and Scenario (shown with the videoclips). The dependent variables are Situation Awareness (SA) and Concept Acceptance. Measurement of SA covers cognitive capabilities with regard to driver's perception of automation-state and understanding of how a system reacts to different situations (Jamson et al., 2013; Jin \& Kaber, 2009). Subsequently, Situation Awareness is among the main psychological factors to investigate driver's performance with automation-systems (Stanton \& Young, 2005). Measurement of SA is therefore widely accepted in areas important to supervisory tasks of operators, like in aviation, air traffic control, power plant control, combat operations, etc. (Endsley \& Connors, 2008; Endsley \& Garland, 2000; Salmon et al., 2009). Endsley (1995b) defines SA in terms of three levels: "(1) the perception of elements in the environment within a volume of time and space, (2) the comprehension of their meaning, and (3) the projection of their status in the near future". In parallel to these SA-levels, we measured: (1) Operator's perception of automation-state (correct knowledge what state the automation is in); (2) Understanding why the automation is in a particular state; (3) Interpretation of driver's role (i.e. request for attention or required intervention). We based measurement of SA on an adapted freeze-probe technique. The freeze-probe technique is the most validated and widely adopted SA-measurement technique (Walker et al., 2008), but it required adaptation to meet the needs of the internet survey: The survey asked questions 
about the situation which 'happened' (i.e. had been visible) just before the end when the video stopped. Then, probes were taken with a combination of open and multiple choice questions. The difference with the regular freeze-probe technique is that the videos did not continue after questions had been put the user, but after each videoclip a new scenario started. This was done to allow randomization of the videoclips' order. Concept Acceptance was tested by asking the respondent's consent how suitable the signals were for the specific scenario, as well as how hazardous the situation was perceived.

\subsubsection{Survey design}

The survey was set-up as a between subjects comparison of concept and started with a short section about socio-demographic background and vehicle-usage, see Table 6-4. Thereafter, the survey showed video-clips with different traffic circumstances and signal-behaviour, see Appendix B. The questions were intended to find out participant's understanding of the signals. Table 6-3 shows the survey's set-up during this part. It started with four videos in random order. After each video, the survey either asked for respondents' perception of system-state or interpretation of their role. Thereafter, the survey always asked for respondents' understanding of system-state and their judgement on the signals' suitability. The questions on perception of system-state and driver's role were multiple choice. Participants' understanding of system-state was asked with an open question. The combination of multiple choice and open question was done to allow sufficiently easy response for respondents and at the same time acquire sufficiently detailed answers for qualitative assessment of respondents' understanding. The order of questions was mixed to avoid prejudice about the aspects to be evaluated in the videos.

After the first 4 videos (in randomized order), the survey always showed a video with scenario 3 ("Approaching combined on/off ramp"). Then, the survey showed the first videos (i.e. scenarios 1, 2, 4 and 5) again and in randomized order. Now, the survey asked for either respondents' perception or understanding, interchanging the aspects as asked with the first four videos. In addition, the survey asked in the second series how hazardously respondents perceived each situations. Rehearsal of the videos avoided that answering all five questions with each video would rely too much on visual memory. To avoid that respondents become accustomed to the situations shown in the videos, the order in the first and second series with four video-clips was randomized. Furthermore, in between the first and second series the survey always showed scenario 3, which was not included in the series. This setup was chosen to uncertain that respondents never saw a video directly repeatedly. When a participant finished watching a video, it could not be replayed. The survey could be interrupted and continued later, but needed to be finished within 72 hours. On exceedance of this time-span data were excluded from analysis.

The survey was set-up and hosted with web-based software from Qualtrics (www.qualtrics.com), see Appendix B. It was set-up bi-lingual in Dutch and English and 
distributed among people in the Netherlands, United Kingdom and Germany. To enable participation, respondents needed to confirm possession of a driving license and a minimum age of 20 years. Invitations included a link to the Qualtrics-website where the survey was posted. Invitations were sent via e-mail and social media within the authors' professional and private networks. Respondents were also encouraged to forward invitations within their own network. The authors' direct group of colleagues was instructed not to take the questionnaire because they could be familiar with the concepts. Because participation was anonymous and other than the socio-demographic questions no detailed personal data were taken, exact numbers about participant's occupation and education are not available.

Table 6-3 Survey path with videos and assigned questions

\begin{tabular}{|c|c|c|c|c|c|c|c|c|}
\hline \multicolumn{9}{|c|}{ Video-clips with scenario } \\
\hline 1 & 2 & & 5 & 3 & 1 & & & \\
\hline $\begin{array}{l}\text { Approaching } \\
\text { Complex road }\end{array}$ & $\begin{array}{l}\text { Vehicle } \\
\text { passing }\end{array}$ & $\begin{array}{l}\text { Merge-out } \\
\text { target- } \\
\text { vehicle }\end{array}$ & Close cut-in & $\begin{array}{l}\text { Approaching } \\
\text { combined } \\
\text { on-off-ramp }\end{array}$ & $\begin{array}{l}\text { Approaching } \\
\text { Complex } \\
\text { road }\end{array}$ & $\begin{array}{l}\text { Vehicle } \\
\text { passing }\end{array}$ & $\begin{array}{l}\text { Merge-out } \\
\text { target- } \\
\text { vehicle }\end{array}$ & Close cut-in \\
\hline \multicolumn{4}{|c|}{-----------------'Randomized order --------------- } & & \multicolumn{4}{|c|}{--------------------Randomized order ---------------- } \\
\hline Q3; Q2; Q4 & Q1; Q2; Q4 & Q1; Q2; Q4 & Q3; Q2; Q4 & Q3; Q2; Q4 & Q1; Q5 & Q3; Q5 & Q3; Q5 & Q1; Q5 \\
\hline \multicolumn{9}{|l|}{ Questions } \\
\hline \multicolumn{9}{|c|}{ Q1 (perception): What aspect of the automation changed shortly before the video stopped? (Multiple choice) } \\
\hline \multicolumn{9}{|c|}{ Q2 (understanding): Was there with regard to the traffic situation a reason to give signals? (Open question) } \\
\hline \multicolumn{9}{|c|}{ Q3 (projection): What do you think the signals at the end of the video wanted to tell you? (Multiple choice) } \\
\hline \multicolumn{9}{|c|}{ Q4: Consent with statement "The signals are suitable." (5-points Likert scale) } \\
\hline \multicolumn{9}{|c|}{ Q5: How hazardous was the situation? (9-point Likert scale) } \\
\hline
\end{tabular}

\subsubsection{Respondents' instruction and task}

After the socio-demographic questions, respondents received explanation about their task with a video-based instruction. The spoken text of this instruction is included in Appendix A. Participants were instructed to imagine themselves to be the responsible 'driver' of a vehicle that drives automatically. It was also explained that automation was only possible within boundary conditions, like travelling on motorways, with low speeds and while a target-vehicle is recognised. Respondents were informed that situations could happen which require extra attention or would require the driver to retake control. Participants were explained that in the videos the automation will announce signals (i.e. stimuli provided by the concepts) to either ask for attention or urge for intervention. However, respondents were not familiarized with the signals beforehand.

\subsubsection{Respondents}

Due to the survey's between subject set-up, data-sets from two survey-samples are created. Per question, the number of responses vary between 49 and 55 for sample one, and between 39 and 45 for sample two. This variation is due to not all questions being mandatory to answer 
and poses a mistake in the surveys' set-up discovered after the questionnaires were already being distributed. In total 100 people answered the questionnaire. (125 persons initially started the survey, but 25 persons exceeded the maximally available time-span resulting in a drop-out rate of $20 \%$.)

Table 6-4 lists socio-demographic data and shows that respondents' age ranged from 20 to 70 years (average: 44.2) and driving experience was in average 23.0 years. Vehicle-usage was dominated by commuting and business trips. Gender was comparably divided over both survey-samples with a minimum of $25 \%$ female respondents. Overall, both survey-samples show the same distribution of respondent's characteristics and therefore allow comparison. With respect to experience with partial automation, $82 \%$ of participants had experience with cruise control (equally divided over both surveys), None of the participants' vehicles was equipped with adaptive cruise control, but seven participants in survey 1 and one participant in survey 2 had vehicles equipped with automated parallel parking.

Table 6-4 Respondents socio-demographic characteristics

\begin{tabular}{|c|c|c|c|c|c|}
\hline General characteristics & Survey & Survey & Car usage & Survey & Survey \\
\hline $\mathrm{N}(\min .-\max )$. & $49-55$ & $39-45$ & commuting & $65 \%$ & $58 \%$ \\
\hline Average age (years) & 43.8 & 44.6 & business trips & $32 \%$ & $45 \%$ \\
\hline Av. driving experience (years) & 21.7 & 24.5 & delivering goods & $11 \%$ & $13 \%$ \\
\hline \multirow[t]{2}{*}{ Gender (\%) Male/Female } & $69 / 31$ & $75 / 25$ & shopping & $71 \%$ & $69 \%$ \\
\hline & & & visiting family \& friends & $92 \%$ & $89 \%$ \\
\hline Car ownership & Survey & Survey & holidays & $87 \%$ & $75 \%$ \\
\hline Private ownership & $84 \%$ & $71 \%$ & something else & $10 \%$ & $9 \%$ \\
\hline Company owned & $5 \%$ & $13 \%$ & & & \\
\hline Undefined (e.g. parent or friend) & $3 \%$ & $7 \%$ & & & \\
\hline No ownership & $8 \%$ & $9 \%$ & & & \\
\hline
\end{tabular}

\subsection{Results}

\subsubsection{Perception of automation mode}

Measurement of participant's perception of automation-state based on asking: "What aspect of the automation changed shortly before the video stopped? (Choose one option)". The options were: The automation...: (a) stopped, (b) became unavailable, (c) did not change, (d) became available, (e) became active, or (f) I don't know. During the two hazardous scenarios (1 and 2) the situation only required attention and option (c) was correct. At the end of the two critical scenarios (4 and 5) the automation stopped. Figure 6-2 compares percentages for correct perception of automation-state (i.e. percentages with correct answers) between the two concepts for all scenarios. The results show that in all scenarios the illumination concept provides better (more correct answers) or equally good perception of automation-state. 
Figure 6-3 visualizes the distribution of participants' selected options per scenario and per concept. Within scenarios 2 "Vehicle passing" (see Figure 6-3b) correct perception of automation-state was higher with the illumination concept (60\%) compared to the base concept $(41 \%): \chi^{2}(1, N=99)=3.64, p$-value $=0.056$ (two-tailed). The results also show that correct perception was difficult in this scenario: With the base concept almost half of the participants (44\%) did "not know" the automation-state in this situation compared to 29\% with the illumination concept (The larger amount of participants who "don't know" automationstate with the base concept is not statistically significant: $\chi^{2}(1, N=99)=2.53, p$-value $=0.112$, two-tailed). In scenario 2, the alert was induced by traffic behaviour aside (i.e. illegally overtaking). In scenario 1 "Complex road" (the other hazardous scenario) the alert was induced by a change in road situation ahead. When comparing results between both situations, analysis of regression revealed that Scenario significantly predicted perception scores, $\beta=0.232, t(185)$ $=3.320, p<0.005\left(R^{2}=0.056, F(1,185)=11.02, p<0.005\right)$. Concept showed less power to predict perception scores within the hazardous scenarios, $\beta=-0.133, t(185)=-1.861, p=0.064$ $\left(R^{2}=0.018, F(1,185)=3.46, p=0.064\right)$.

\section{Percentages correct perception automation mode}

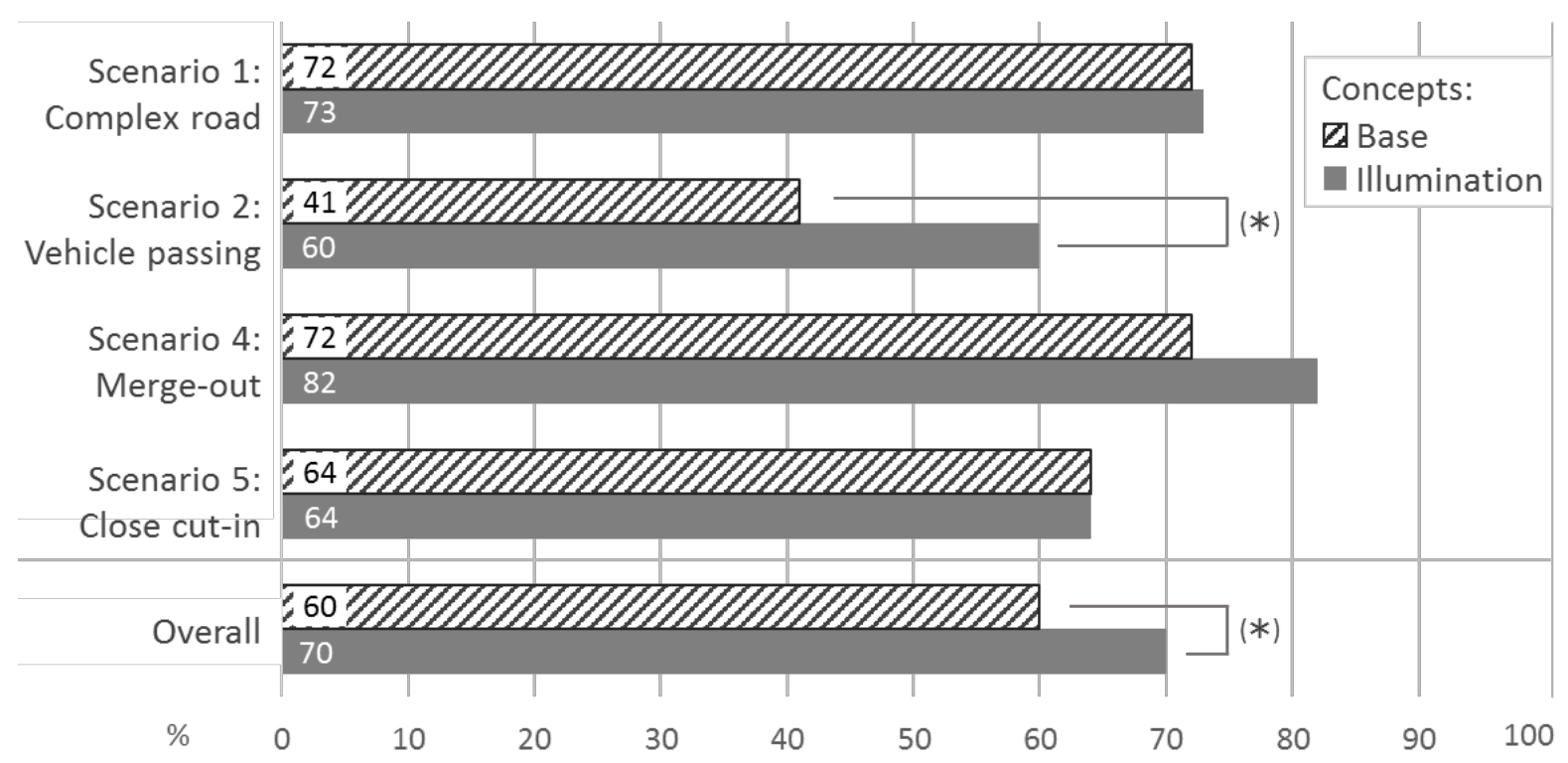

Figure 6-2 Percentages with participants' correct perception of automation mode.

Note. Where (close to) statistically significant differences were found, the scores are marked with "*" if $\mathrm{p}<0.05$ and with " $(*)$ " if $0.05 \mathrm{p}<0.10$.

Within the two critical scenarios (4: "Merging-out target-vehicle" and 5: "Close cut-in") a majority of respondents answered with either "automation stopped" or "automation became unavailable". In scenario 4, a target-vehicle disappears and a new target-vehicle is missing. Therefore, bot answers are considered correct: It makes the system become unavailable and it subsequently stopped. Results show slightly better perception with the illumination-concept (82\% correct perception), compared to the base-concept (72\% correct perception), see Figure 6-3c. These numbers do not denote statistical differences: $\chi^{2}(1, N=88)=1.197, p$-value $=0.274$ 
(two-tailed). Furthermore, in scenario 4 the base-concept shows a larger percentage (18\%) of people who "don't know" system-state - but, without statistically significant differences between the concepts $\left(\chi^{2}(1, N=88)=1.901, p\right.$-value $=0.168$, two-tailed $)$.

Although the answers of option (a) "The automation stopped" and option (b) "The automation became unavailable seem identical, there is in scenario 5 ("Close cut-in") a difference in meaning between both answers: Here automation stopped because the cut-in vehicle violated minimum required follow-distances. Based on assumed system-design, deceleration-rates of the ego-vehicle would not suffice to bring the vehicle to a safe stand-still. This is why automation stopped. The technical preconditions for automation, i.e. line and targetrecognition, plus driving on a motorway, did not change. Therefore, the answer "automation became unavailable" does strictly speaking not apply. However, based on general interpretation of the words "unavailable" and "stopped", it is defendable to consider both options correct. In the first case correct perception is $44 \%$ with the base-concept and $41 \%$ with the illumination-concept. See Figure $6-3 \mathrm{~d}$. In the second case, correct perception is with each concept identical in this scenario, i.e. $64 \%$.

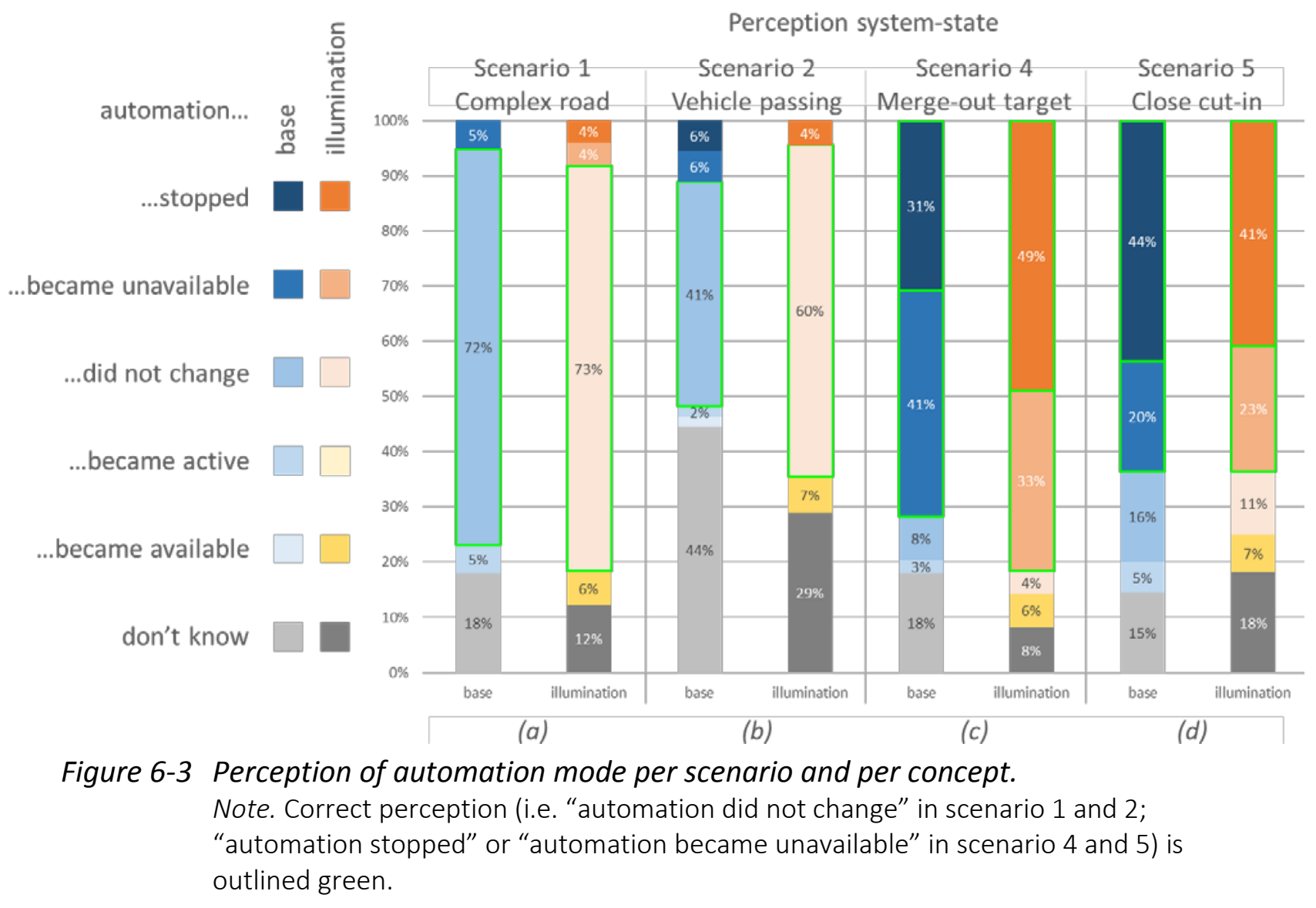

Overall, we see that correct perception of automation-state is better with the illuminationconcept (70\% correct perception) compared to the base-concept (60\% correct perception), see the bottom item in Figure 6-2. For this overall result both answers "automation stopped" and "automation became unavailable" are considered correct within the two critical scenarios. 
These numbers denote not quite statistically significant differences $\left(\chi^{2}(1, N=374)=3.82, p\right.$ value $=0.051$, two-tailed), but a trend that the illumination-concept improves correct perception of automation-state. Moreover, when we consider in scenario 3b ("Close cut-in") only the option "automation stopped" correct (because strictly speaking the other option does not apply), the significance of the difference in perception improves slightly: $\chi^{2}(1, N=374)=$ $4.01, p$-value $=0.046$, two-tailed (in favour of the illumination concept).

\subsubsection{Understanding automation mode and changes}

Measurement of understanding was based on respondents' answers to the question: "Was there with regard to the traffic situation a reason to give signals?" This was an open question and participants were asked to give their answer with a (short) explanation. Table 6-5 summarizes the results per scenario.

Results for understanding automation mode in scenario 1 ("Complex road") are in line with perception. Based on the road situation, it was likely that other traffic would enter the main roadway and at least $70 \%$ of respondents understood this. These results do not show differences between concepts. Around 10\% thought it was a more general alert for approaching an intersection, independent of traffic. $8 \%$ of respondents considered the alert unnecessary. With the illumination-concept two respondents thought that the signal was a warning for a vehicle coming too close.

Understanding of automation-state in scenario 2 ("Vehicle passing") does show differences between concepts: With the base-concept more participants misunderstood the signal. Only $53 \%$ of respondents had correct understanding, compared to $72 \%$ with the illuminationconcept. These differences are not statistically significant, but show a trend that understanding is better with the illumination concept: $\chi^{2}(1, N=88)=3.215, p$-value $=0.073$ (two-tailed). Furthermore, $10 \%$ of respondents considered the alert a blind-spot detection warning.

Results during scenario 3 ("Approaching combined on/off-ramp) show that the illuminationconcept caused misunderstanding. An alert was raised for entering a main road and only $21 \%$ of respondents understood this correctly with the illumination-concept, compared to $46 \%$ with the base-concept. A specific explanation why the illumination-concept scored worse is difficult to find. In general the situation was difficult to understand: While it was explained that the system would only work on motorways, the vehicle was in this scenario on an entrance-lane and respondents could have had doubts whether the entrance-lane was part of a motorway or not. The scores do also reveal a general difficulty to distinguish whether the signal (be it either from the base-concept or illumination concept) refer to a road-situation or to potentially dangerous behaviour of other road-users: Hence, a considerable part of respondents (almost $15 \%)$ gave in the category 'something different' reasons like: "vehicles coming too close", or "necessity to decide on travel-direction" and "car in blind spot". 
Table 6-5 Participants' understanding why an alert was raised

\begin{tabular}{|c|c|c|}
\hline $\begin{array}{l}\text { Number of participants who consider any of the following aspects the } \\
\text { reason why an alert was raised in... }\end{array}$ & $\begin{array}{l}\text { Base- } \\
\text { concept }\end{array}$ & $\begin{array}{l}\text { Illumination- } \\
\text { concept }\end{array}$ \\
\hline ...scenario 1 (Complex road): & $(n=38)$ & $(n=50)$ \\
\hline Because other vehicle wanted to enter the lane & $29(76 \%)$ & $35(70 \%)$ \\
\hline Because approaching entrance-lane (without reference to vehicles) & $3(8 \%)$ & $5(10 \%)$ \\
\hline No necessity to raise an alert & $3(8 \%)$ & $4(8 \%)$ \\
\hline Don't know & $2(5 \%)$ & $2(4 \%)$ \\
\hline Other reasons & $1(3 \%)$ & $4(8 \%)$ \\
\hline ...scenario 2 (Vehicle passing): & $(n=49)$ & $(n=39)$ \\
\hline Because a vehicle is overtaking from the right $(*)$ & $26(53 \%)$ & $28(72 \%)$ \\
\hline Because there is a vehicle in the blind-spot (and/or Lane-change warning) & $5(10 \%)$ & $4(10 \%)$ \\
\hline No necessity to raise an alert & $4(8 \%)$ & $3(8 \%)$ \\
\hline Instable traffic (accelerating and decelerating) & $5(10 \%)$ & - \\
\hline No idea / don't know & $4(8 \%)$ & $2(5 \%)$ \\
\hline Other reasons & $6(12 \%)$ & $2(5 \%)$ \\
\hline ...scenario 3 (Approaching on/off ramp): & $(n=48)$ & $(n=38)$ \\
\hline Attention for entering main road (without referring to who is in control) $*$ & $22(46 \%)$ & $8(21 \%)$ \\
\hline I should (take over to) enter lane & 9 (19\%) & $9(24 \%)$ \\
\hline Attention while system is merging into main roadway & $4(8 \%)$ & $6(16 \%)$ \\
\hline Attention traffic from the left & $3(6 \%)$ & $6(16 \%)$ \\
\hline There is no reason & $2(4 \%)$ & $3(8 \%)$ \\
\hline Other reasons / Something different & $7(15 \%)$ & $5(13 \%)$ \\
\hline I don't know & $1(2 \%)$ & $1(3 \%)$ \\
\hline ...scenario 4 (Merge-out target-vehicle): & $(n=38)$ & $(n=48)$ \\
\hline Because a the target-vehicle has left the lane (and there is no new target) & $12(32 \%)$ & $14(29 \%)$ \\
\hline Because lane ends & $1(3 \%)$ & $2(4 \%)$ \\
\hline Because I was leaving the motorway & 9 (24\%) & $12(25 \%)$ \\
\hline Because of coming curve & $2(5 \%)$ & $2(4 \%)$ \\
\hline Because choice of direction (lane) was required & $4(11 \%)$ & $11(23 \%)$ \\
\hline Don't understand/ don't know & $4(11 \%)$ & - \\
\hline Other reasons & $7(18 \%)$ & $8(17 \%)$ \\
\hline ...scenario 5 (Close cut-in): & $(n=53)$ & $(n=42)$ \\
\hline Because the vehicle that cuts in was too close $(*)$ & $12(23 \%)$ & $17(40 \%)$ \\
\hline 'Connection' to target-vehicle was interrupted by a new vehicle & $4(8 \%)$ & $2(5 \%)$ \\
\hline Because of an (unexpectedly) incoming car in lane & 7 (13\%) & $9(21 \%)$ \\
\hline Because of an incoming car in lane, who cuts in and brakes & $14(26 \%)$ & $6(14 \%)$ \\
\hline Car in front decelerates strong and unexpectedly & $10(19 \%)$ & $3(7 \%)$ \\
\hline Don't understand/ don't know & $1(2 \%)$ & $1(2 \%)$ \\
\hline Other reasons & $5(9 \%)$ & $4(10 \%)$ \\
\hline
\end{tabular}

Note. Results that denote statistically significant differences between concepts are marked "*" if $p<0.05$. Differences that show a trend $(0.05<p<0.10)$ are marked with: " $(*)$ ".

In scenario 4 ("Merge-out target-vehicle") understanding was generally low and results in Table 6-5 show that the concepts did not influence understanding of state-changes. Only $1 / 3$ 
correctly understood that the target-vehicle left the lane and that there was no new targetvehicle. The road situation was the same as in scenario 3 and again confusion whether the exitlane belonged to the motorway or not, could be an explanation for misunderstanding. Moreover, after the automation stopped, the uncontrolled 'ego'-vehicle ran out of its lane. It is likely that it was not the absence of a target-vehicle, but the road-position and behaviour of the 'ego'-vehicle that made respondents suspicious of the need for attention.

Although results for participants' perception within the close cut-in scenario (5) showed indifferent concept-scores, understanding of automation-changes show some results in favour of the illumination-concept, see Table 6-5. In this close cut-in scenario, not the cutting-in as such caused state-changes, but the close distance caused violation of minimum required follow-distance. With the illumination-concept respondents showed a trend to distinguish better ( $40 \%$ correct understanding) that a minimum follow-distance is being erupted, compared to the base-concept ( $23 \%$ correct understanding): $\chi^{2}(1, N=95)=3.514, p$-value $=$ 0.061 (two-tailed). However, if we limit correct response not only to reference of minimum distance, but also consider more generally that cutting in is dangerous and that this behaviour is often referred to in the answers, we don't observe differences between the concepts $\left(\chi^{2}(1\right.$, $\mathrm{N}=95)=0.375, p$-value $=0.541$, two-tailed $)$.

To summarize, if changes were only induced by the behaviour of other road users (i.e., scenario 2 "Vehicle passing" and 5 "Close cut-in"), respondents show better understanding of automation-state with the illumination-concept. In both scenarios signals are raised because of hazards that originate from the driver's side-views. Therefore, we consider these results a confirmation of the directional cue offered by the illumination-concept. If the alert is induced by the road situation ahead (i.e.; scenario 1 "Approaching complex road"), understanding is high but indifferent between concepts. When the situation is characterized by an interplay between road-situation and behaviour of other road users (i.e.; scenario 3 "Approaching an on/off ramp" and 4 "Merge-out target-vehicle"), understanding is low and we assume that confusion whether the alert (or warning) was induced by the road-situation or by the behaviour of other road users, disimproved correct understanding. Furthermore, we consider in these scenarios the similar scores between concepts an indication that directional-support of the illumination-concept just not pays off in these situations, but neither makes comprehension worse.

\subsubsection{Interpretation driver's role}

Adequate projection of future state (i.e. Situation Awareness on level 3) is demonstrated with correct interpretation of driver's role. Measurement of SA-level3 was therefore based on the survey's question: "What do you think the signals at the end of the video wanted to tell you?" Possible answers were: "I should take over"; "I should watch traffic carefully" and "I don't know". Table 6-6 provides an overview per scenario with the answers respondents gave. This table shows only within scenario 3 "approaching on/off ramp" differences between concepts 
for their support to interpret driver's role. Then, the illumination-concept (78\% correct interpretation) shows a trend for superior interpretation compared to the base concept (62\% correct interpretation): $\chi^{2}(1, N=93)=2.91, p$-value $=0.088$ (two-tailed). In all other scenarios, scores between concepts are indifferent and show relatively high values of correct interpretation. Interestingly, the previous section showed difficulties with understanding the situations in scenario 3 and 4 . Although these difficulties in understanding were based on similar confusion due to the interplay between road-situation and behaviour of other roadusers, a vast majority correctly recognised that their responsibility differed in both scenarios and correctly interpreted their role. In general, in $70 \%$ to $90 \%$ of occasions respondents were able to correctly interpret their role regardless what concepts they used.

Table 6-6 Percentages with interpreted driver's role within each scenario and per concept.

\begin{tabular}{|c|c|c|c|c|c|}
\hline \multirow[t]{2}{*}{ scenario } & \multirow[t]{2}{*}{ concept } & \multirow[t]{2}{*}{$\mathrm{n}$} & \multicolumn{3}{|c|}{ Percentages selected answers of driver's role } \\
\hline & & & $\begin{array}{c}\text { "I should take } \\
\text { over" }\end{array}$ & $\begin{array}{l}\text { "I should watch } \\
\text { traffic carefully" }\end{array}$ & "I don't know" \\
\hline \multirow{2}{*}{$\begin{array}{l}\text { 1: Approaching } \\
\text { complex road }\end{array}$} & Base & 44 & $7 \%$ & $77 \%$ & $16 \%$ \\
\hline & Illumination & 53 & $9 \%$ & $72 \%$ & $19 \%$ \\
\hline \multirow{2}{*}{$\begin{array}{l}\text { 2: Vehicle } \\
\text { passing }\end{array}$} & Base & 49 & $4 \%$ & $86 \%$ & $10 \%$ \\
\hline & Illumination & 39 & $5 \%$ & $85 \%$ & $10 \%$ \\
\hline \multirow{2}{*}{$\begin{array}{l}\text { 3: Approach. } \\
\text { on/off ramp }\end{array}$} & Base & 52 & $17 \%$ & $62 \%$ & $21 \%$ \\
\hline & Illumination & 41 & $12 \%$ & $78 \%$ & $10 \%$ \\
\hline \multirow{2}{*}{$\begin{array}{l}\text { 4: Merge-out } \\
\text { target-vehicle }\end{array}$} & Base & 45 & $87 \%$ & $2 \%$ & $11 \%$ \\
\hline & Illumination & 54 & $85 \%$ & $2 \%$ & $13 \%$ \\
\hline \multirow{2}{*}{$\begin{array}{l}\text { 5: Critical cut- } \\
\text { in }\end{array}$} & Base & 49 & $80 \%$ & $14 \%$ & $6 \%$ \\
\hline & Illumination & 39 & $79 \%$ & $15 \%$ & $5 \%$ \\
\hline
\end{tabular}

Note. Correct answers are indicated with italic and bold typed font. Percentages that denote statistically significant differences between concepts are marked " $*$ " if $p<0.05$. Differences that show a trend $(0.05<p<0.10)$ are marked with: " $(*)$ ".

\subsubsection{Acceptance: How suitable were signals for the situation?}

Figure 6-4 shows results for acceptance. Respondents were asked after each video with a particular combination of scenario and concept to rate how suitable the signal was for the situation. Respondents gave their consent to the statement "The signal was suitable for the situation" with a Likert-scale ranging from 1 ("totally disagree") to 5 ("totally agree"). Differences in concept-scores are in favour of the illumination-concept. Within two scenarios, the illumination-concept receives significant better acceptance, see Figure 6-4. Remarkably, these two scenarios (i.e. 2: "Vehicle passing" and 3: "Approaching combined on/off ramp") are both 'hazardous scenarios', requiring supervisory control. Since respondents were not able to compare both concepts directly, their opinion is based on the relation between situation and subsequent signal. Therefore, these results provide strong evidence that the illuminationconcept is accepted as a more suitable directional cue than the base-concept without 
directional feedback. Based on cumulative scores (taken all scenarios together), illumination $(M=3,57 ; S D=0,99)$ is perceived more suitable than the base concept $(M=3,12 ; S D=1,14)$. The difference between both concepts is extremely significant: $t(478)=4,597, p$-value $<0.001$.

\section{Statement: "The signal was suitable for the situation"}

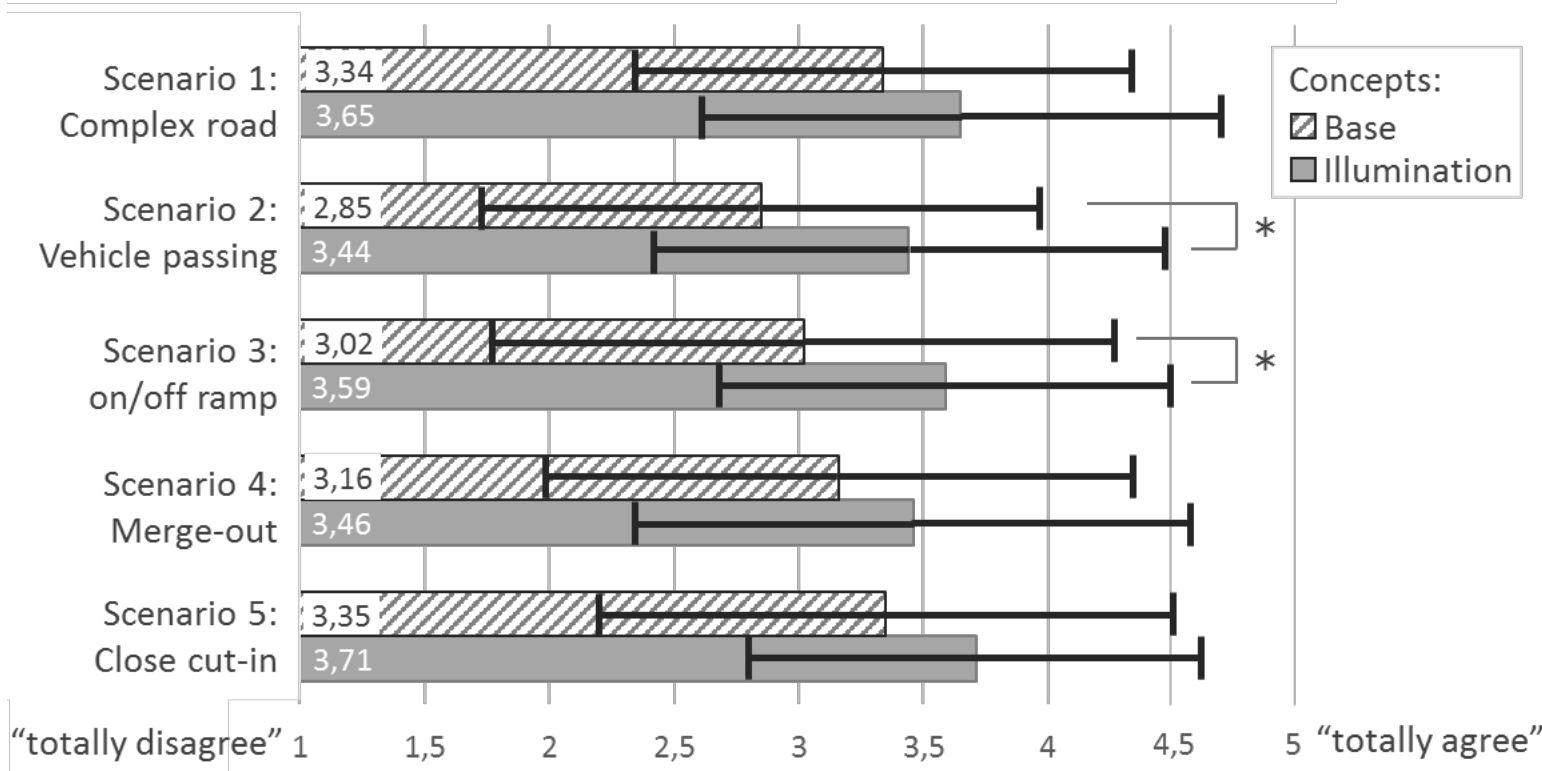

Figure 6-4 Participants opinion of signals suitability for the situation per concept

Note. Agreement with the signals suitability is measured on a 5-point Likert scale ranging from 1 "totally disagree" to 5 "totally agree". Where (close to) statistically significant differences between concepts are shown, the differences are marked with $*$ if $p<0.05$ and with $(*)$ if $0.05<p<0.10$. Error bars show Standard Deviation.

\section{Question: "How hazardous did you perceive the situation?"}

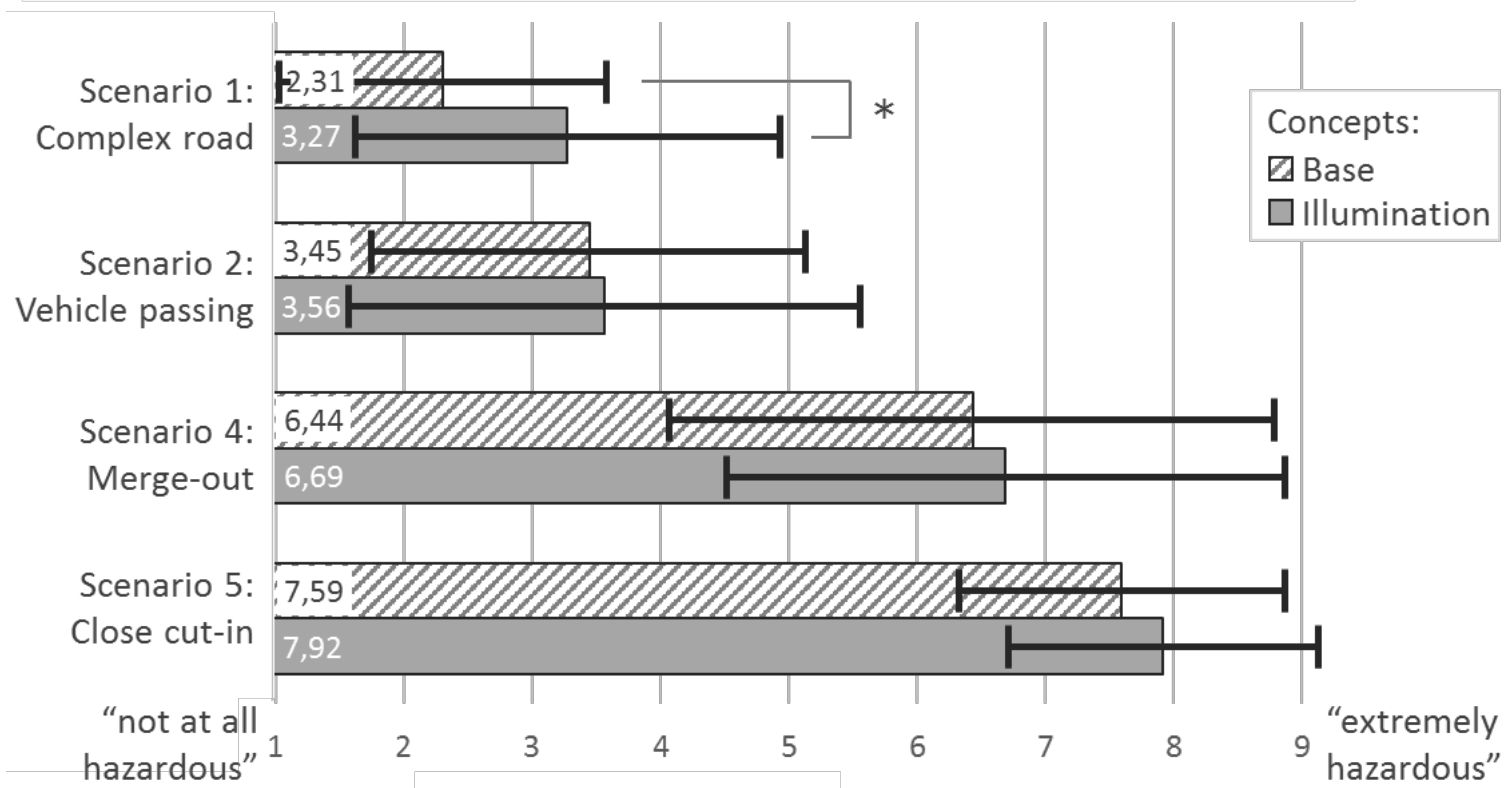

Figure 6-5 Perceived hazardousness of the concepts'signals in scenarios 1, 2, 4 and 5. Note. Results marked with $*$ denote statistically significant differences between concepts $(p<0.05)$. Error bars show Standard Deviation. 


\subsubsection{Influence of illumination on perceived hazardousness}

Figure 6-5 shows that the illumination-concept has influenced respondents' opinion how hazardous they perceived the situations to be. Within scenario 1 "Approaching complex road", this effect is significant. That is, respondents perceived the same scenario with the illumination-concept significantly more hazardous than with the base-concept (i.e. without directional feedback): $t(86)=2.962, p$-value $=0.004$. The relatively low scores in perceived 'hazardousness' are in line with the designed low level of urgency for this scenario, i.e. this scenario does not comprise an emergency situation.

\subsubsection{Learning}

The results in Table 6-7 show that learning occurred in scenario 2 only and that this learningeffect was achieved with both concepts. The base concept denotes largest improvement in this scenario and it is noteworthy that with the base-concept correct perception (41\%) was among the lowest levels. In other words: There was a large improvement potential. Within scenario 5 the base concept shows a trend of better performance at the second occasion compared to the first occasion. Within scenario 4, an opposite trend occurs: correct system awareness reduced from $87 \%$ to $72 \%$. It seems that the influence from circumstances (i.e. scenario) - by creating an improvement potential - was larger than the influence from concept-type to actually demonstrate learning.

Table 6-7 Learning per concept and per scenario based on rehearsal of a scenario with the same concept.

\begin{tabular}{lllll}
\hline Scenario & Concept & \multicolumn{2}{l}{$\%$ correct responses } & $p$-value \\
\hline \multirow{4}{*}{ 1: Complex road } & Interpretation & Perception & \\
& Base & $77 \%(n=44)$ & $72 \%(n=39)$ & $p=0.567\left(\chi^{2}=0.328\right)$ \\
& Illumination & $72 \%(n=53)$ & $73 \%(n=49)$ & $p=0.841\left(\chi^{2}=0.040\right)$ \\
\hline \multirow{4}{*}{ 2: Vehicle passing } & Base $*$ & $41 \%(n=54)$ & $86 \%(n=49)$ & $p<0.001\left(\chi^{2}=22.09\right)$ \\
& Illumination $*$ & $60 \%(n=45)$ & $85 \%(n=39)$ & $p=0.013\left(\chi^{2}=6.203\right)$ \\
\hline \multirow{5}{*}{ 4: Merge-out } & Base $(*)$ & Interpretation & Perception & \\
& Illumination & $87 \%(n=45)$ & $72 \%(n=39)$ & $p=0.091\left(\chi^{2}=2.863\right)$ \\
& & $85 \%(n=54)$ & $82 \%(n=49)$ & $p=0.676\left(\chi^{2}=0.235\right)$ \\
\hline \multirow{5}{*}{ 5: Close cut-in } & Base $(*)$ & $64 \%(n=55)$ & $80 \%(n=49)$ & $p=0.073\left(\chi^{2}=3.214\right)$ \\
& Illumination & $64 \%(n=44)$ & $79 \%(n=39)$ & $p=0.112\left(\chi^{2}=2.527\right)$ \\
\hline
\end{tabular}

Note. In scenarios 1 and 4 percentages correct perception in the second occasion are compared to percentages of correct interpretation at the first occasion. In scenarios 2 and 5 percentages of correct interpretation in the second occasion are compared to percentages with correct perception from the first occasion of experiencing the scenario. Where (close to) statistically significant differences between the first and second occasion are observed, the scores are marked with $*$ if $p<0.05$ and with ( $*$ ) if $0.05<p<0.10$. 


\subsection{Discussion}

To answer to what extent illumination supports mode awareness and understanding of driver's role, we measured three levels of situation awareness, i.e. perception of automation-state, understanding of automation-state and interpretation of driver's role. To achieve more insight in potential advantages or disadvantages of directional illumination we also measured acceptance and perceived hazardousness.

Table 6-8 Overall results for respondents mean scores for mode awareness, acceptance and perceived hazardousness.

\begin{tabular}{|c|c|c|c|c|c|c|c|c|c|}
\hline \multirow[t]{2}{*}{ Scenarios } & \multicolumn{5}{|c|}{$\begin{array}{l}\text { Percentages }{ }^{1} \text { correct mode awareness } \\
\text { in reference to: }\end{array}$} & \multicolumn{2}{|c|}{ Acceptance $^{2}$} & \multicolumn{2}{|c|}{ Hazardousness ${ }^{3}$} \\
\hline & base illu. & base & illu. & base & illu. & base & illu. & base & illu. \\
\hline 1: Complex road & 73 & 76 & 70 & 77 & 72 & 3.34 & 3.65 & 2.31 & 3.27 \\
\hline 2: Vehicle passing & 41 & 53 & $\underline{72}$ & 86 & 85 & 2.85 & $\underline{3.44}$ & 3.45 & 3.56 \\
\hline 3: Approaching on/off ramp & (not measured) & $\underline{46}$ & 21 & 62 & $\underline{78}$ & 3.02 & $\underline{3.59}$ & \multicolumn{2}{|c|}{ (not measured) } \\
\hline 4: Merge-out target-vehicle & 82 & 32 & 29 & 87 & 85 & 3.16 & 3.46 & 6.44 & 6.69 \\
\hline 5: Close cut-in & 64 & 23 & $\underline{40}$ & 80 & 79 & 3.35 & 3.71 & 7.59 & 7.92 \\
\hline overall & 60 & (not $c$ & cable) & 78 & 80 & 3.57 & $\underline{3.12}$ & (not & sured) \\
\hline
\end{tabular}

Note. "illu." refers to the illumination-concept. ${ }^{1}$ Percentages range from 0 to $100 \%$, values represent mean percentages per concept. If a concept scores significant $(p<0.05)$ better its value is typed bold and underlined. If a concept scores close to significantly better $(0.05<p<0.10)$ its value is underlined. ${ }^{2}$ Acceptance-scores range from 1 (not acceptable) to 5 (fully acceptable). ${ }^{3}$ Perceived hazardousness range from 1 (not at all hazardous) to 9 (extremely hazardous).

Table 6-8 provides overall results for all assessment aspects. Situation Awareness was generally high within the changing road situation ahead (scenario 1), illustrated by high scores on all three SA-levels independent of concept. In situations where attention or intervention was induced by the behaviour of other road users, i.e. scenarios 2 ("Vehicle passing") and 5 ("Close cut-in"), the illumination-concept demonstrated to be most supportive: In scenario 2 the illumination-concept shows a strong trend to increase correct perception and both in scenario 2 and 5 a trend for better understanding of automation-state. In contrast to scenario 1 where attention was needed ahead, scenarios 2 and 5 require attention to the driver's side-views. We consider the observation that the illumination-based concept demonstrates superior scores in those scenarios requiring attention to the driver's side-views a confirmation for the benefits of providing directional cues with illumination. 


\subsubsection{Mode awareness and interpretation of driver's role}

\section{Perception of elements important for mode awareness}

The illumination-concept demonstrates in all scenarios better perception of automation mode. Nonetheless, correct perception showed a maximum of about $70 \%$. The fact that respondents watched videos without neither the possibility nor the need to actively control the automation themselves, could be an explanation for this moderate perception of automation mode. When perception was lowest (scenario 2), the illumination-concept demonstrated most advantages, i.e. a close to significant superiority over the base concept with regard to correct perception of automation-state. On the one hand these results confirm the advantages of the illuminationconcept, but on the other hand demonstrate a need for further improvements. That is because in real-life circumstances it is likely that a driver will encounter more diversity of signals, also from other systems. In practise, correct perception might therefore be lower than our maximally measured $70 \%$ correct perception - values not considered very satisfying

\section{Understanding of automation mode}

Interpretation of respondents' written explanations of mode-understanding teaches us that the signals do (in general) not provide strong explanatory information why a signal is being raised. Furthermore, correct understanding differed strongly between scenarios. When signals are raised because of hazards originating from the driver's side-views, the illumination-concept provides better understanding. When the need for attention is induced by an interplay between road-situation and behaviour of other road users, understanding is generally low most likely due to confusion. Then, the directional cue of the illumination-concept seems less successful to provide explanatory information. The low scores for Understanding (between $30 \%$ to $45 \%$ correct understanding) in scenarios 3 ("Approaching on/off ramp") and 4 ("Mergeout target vehicle") feed this suspicion. Based on these observations, the extent of directional illumination to support mode awareness seems insufficient for events that include combinations of changing road-situations and behaviour of other road users. Therefore, further efforts are needed to discover appropriate solutions to provide explanatory information during such events. However, our concerns leave unimpeded that the illumination-concept generally demonstrated raised levels of understanding compared to the base concept.

\section{Interpreting driver's role}

The written remarks (collected with regard to understanding) show that respondents had difficulties to distinguish between an alert and an instruction - a difficulty that could have influenced interpretation of required driver's role. Nonetheless, percentages of correct interpretation of driver's role are generally good and (except for scenario 3 "Approaching on/off-ramp") concept-type did not influence interpretation of driver's role. As explained in section 2, neither concept provided explicit explanation why attention is needed and the aim of this study was to identify if directional cues allowed drivers to deduce what reaction is required. With regard to this aspect, the results do not provide strong evidence that directional 
illumination raises correct interpretation of driver's role. A possible explanation is that the instruction in combination with cues provided by the scenarios themselves, probably provided enough information to correctly interpret the required role reducing the need for concept support. Furthermore, the only scenario where the illumination-concept demonstrated significant better support to interpret driver's role (i.e. scenario 3) was also the scenario with generally lowest scores. A probable explanation for this observation is: when a situation is more difficult there is also more potential for improvements (enabling the illuminationconcept to show its benefits).

\section{Relation between perception, understanding and interpretation}

Correct perception of automation-mode and correct understanding does not always keep pace with one another. In scenario 4 ("Merge-out of target vehicle") correct perception is high: between 70 and $80 \%$. Correct interpretation of driver's role is more than $85 \%$ with both concepts, but correct understanding is low - approximately $1 / 3$ - with both concepts. On the one hand this result is promising: When the relation between behaviour of another road user (merge-out) and system-configuration (required target) is difficult to comprehend, the concepts provided nonetheless support to know correct automation-state and what is required from the driver. On the other hand, the illumination-concept does in this context not show additional support compared to the base concept.

\subsubsection{Concept acceptance, false alarms and perceived level of hazard}

\section{False alarms \& perceived hazardousness}

A concern is that illumination raises the perception of hazard level, i.e. make situations perceived to be in more urgent need for intervention. Although the additional level of 'hazardousness' conveyed with illumination is small, it is consistently observed in all scenarios. Besides, in scenario 1 - a scenario with a generally low hazard level - this effect is significant. A small increase would not necessarily be disadvantageous, as it might increase driver's carefulness. However, a larger influence raises two concerns. Firstly, the soft warnings (requesting attention) and hard warnings (requiring intervention) are designed to convey respectively low and high levels of urgency. If in practise the illumination-concept's soft warning is perceived as high urgency this would raise false warnings and cause misunderstanding. Secondly, urgency is in general related to annoyance (Baldwin \& Lewis, 2014) and if in practice perceived urgency is considerably higher than intended, this would raise annoyance and therefore lower acceptance. The potential influence of illumination on annoyance needs therefore investigation during further development of the concept.

\section{Acceptance}

When measured as a cumulative score over all scenarios and when measured in situations that involve a hazard within the driver's side-views (i.e. scenario 2 and 3), the illumination-concept was perceived significantly more suitable to raise an alert than the base concept. Besides, acceptance was measured between subject. That is, participants had no ability for themselves 
to compare relevant features (i.e. with or without directional illumination) within a specific scenario. Nonetheless, the acceptance-scores are higher for the illumination-concept and are therefore considered strong evidence that users recognise and reward the potential benefits of directional cues provided with the illumination-concept. However, a grade " 3,6 " (on a scale from 1 to 5) leaves room for improvement. Furthermore, the results do not provide insight in whether respondents found illumination more suitable as an alert and/or warning signal or as an indicator for automation mode.

\section{Improvement potential}

The illumination-concept offers noticeable support for mode awareness. Nonetheless, the percentages of increased mode awareness are in most cases small. Furthermore, the base concept demonstrates more learning support than the illumination concept in situations with generally low mode awareness. We could argue that the illumination-concept provides in general better mode awareness leaving reduced possibilities for further improvements. Nonetheless, results show that further improvements are desirable. After all, the contextual situation (i.e. Scenario) has more influence on correct mode awareness than maybe possible to compensate for through interface design. Most likely, additional measures are necessary which go beyond interface improvements, for instance training for supervisory tasks.

\subsubsection{Limitations}

A comment which must be made is that response frequencies per question varied between 49 and 55 for survey-sample one, and between 39 and 45 for sample two. This variation is due to not all questions being mandatory to answer and poses a shortcoming in the surveys' set-up discovered after the questionnaires were being distributed. Furthermore, the survey was filled out by participants themselves using their own equipment to watch the videos. The survey had no ability to control screen sizes. For participants' convenience the survey could be interrupted and continued (with time restrictions) at a later stage. Increased responses and more controlled circumstances to take the questionnaires may have improved data collection and might have boosted significance of the identified differences in concept support.

Also, this study was based on watching short video-clips without a need for actually retaking control and neither the temptation to monitor the road less, something that would be the case during prolonged driving with partially automation. Another comment concerns the absence of competing signals and immersion. In practice, more input from competing functions is likely to cause a larger variety of signals with might worsen correct perception. Therefore, care should be taken with interpreting the results for real-world circumstances.

With regard to perception of automation state this study reveals that the influence of Scenario on mode awareness is larger than the influence of Concept. Probably, the contextual situation defines situation awareness more than can be compensated for through interface-design. In real world circumstances, the driving situations and events are likely to be more diverse and 
immersive and might therefore have an even stronger influence on mode awareness. At the same time, in real world circumstances the need for support is larger as drivers are expected to monitor the road less when using partially automated driving.

Finally, a limitation is that mode awareness has not been compared with a traditional interface designed to provide mode-feedback. Consequently, further research is needed within circumstances closer to real-world situations and with additional concept comparison in order to make more reliable predictions on the ability of directional illumination to raise mode awareness and to improve drivers' understanding of the control task.

\subsection{Conclusions and recommendations}

The aim of this study was to answer to what extent illumination is able to support driver's mode awareness when driving partially automated. In particular, this study aimed at identifying if illumination raises driver's ability to understand his or her expected role when automation state changes (despite the absence of explanatory information). Respondents demonstrated with the illumination-concept generally higher levels of mode awareness than with the base concept. Since these difference are consistently, but in limited occasions observed and then show moderately statistical significance, we conclude that the results provide at most indications that illumination improves situation awareness.

The extent in which illumination supports the driver's supervisory role is especially noticeable in situations when supervision is induced by hazards in the driver's side-views, like alerting behaviour from neighbouring vehicles (i.e. scenario 2 and 5). Then, understanding of automation-state shows a trend to be better with illumination compared to the base concept. Furthermore, perception in scenario 2 is almost significantly better with illumination than without. Nonetheless, correct understanding was usually quite low (varying between $30 \%$ and maximally $70 \%$ correct understanding). Especially in situations when the need for attention is induced by an interplay between road-situation and behaviour of other road-users (i.e. scenario 3 and 4) respondents had difficulties to comprehend why a signal was raised. Providing solutions for explanatory information applicable for such situations is therefore an important recommendation for further development of supervisory support. Furthermore, the high scores with regard to correct interpretation of driver's role might be a trade-off of our particular option-based questionnaire, rather than the result of particular interface-features, like illumination. Therefore, further development of interfaces that combine illumination with driver's instruction is a second recommendation to improve supervisory support.

Another observation is that the illumination-concept seems to have influenced 'perceived hazardousness', i.e. made situations perceive more hazardous. Although this influence is small in our test, it could in practice be a potentially counter-productive effect (like a cause for misunderstanding) for which further research is needed. 
Taking all findings together, we conclude that the illumination-concept is a recommended direction for further development of interface-solutions to support the driver's supervisory role when operating partially automated vehicles. 


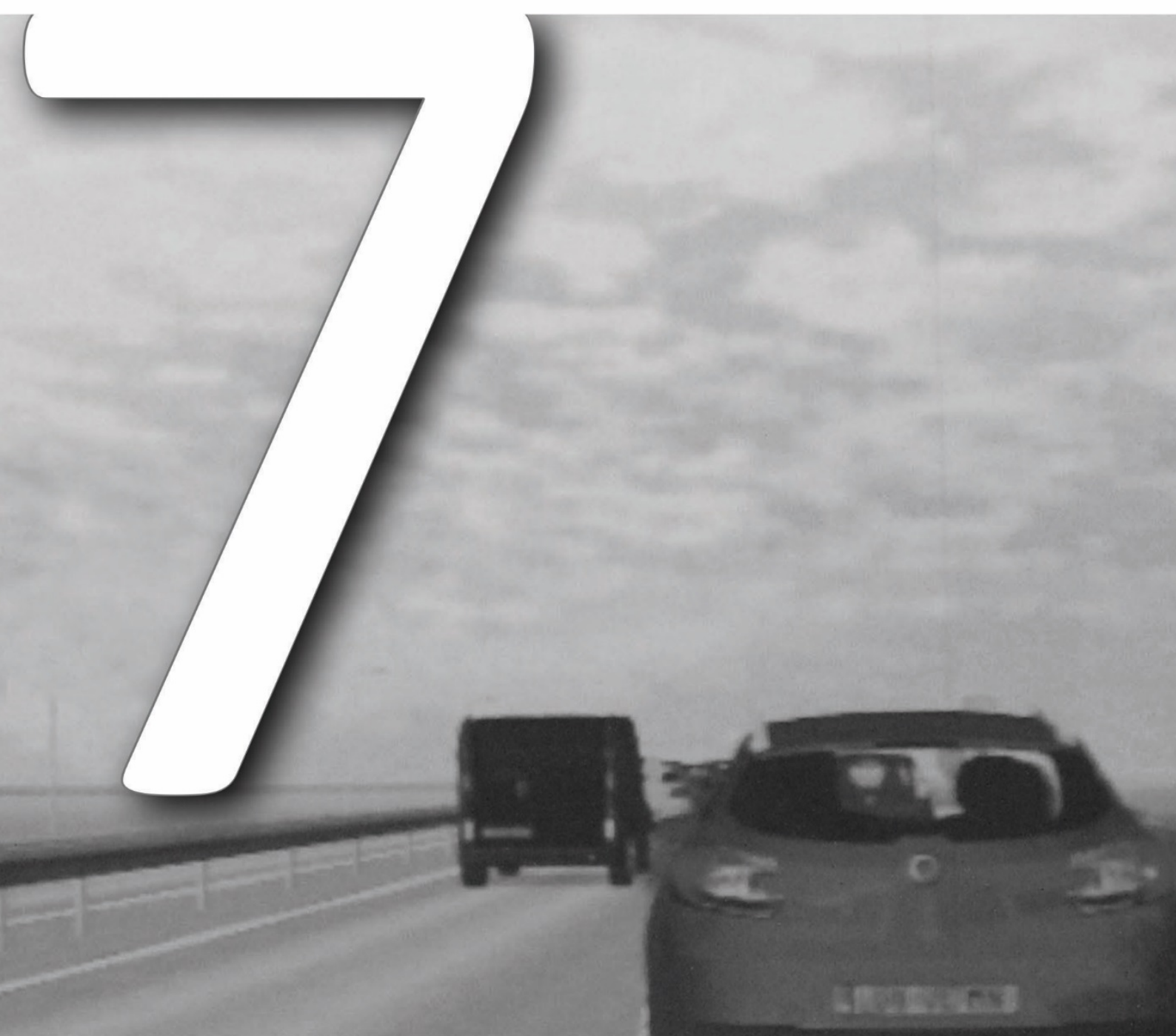




\title{
Chapter 7. Exploration and evaluation of support for supervision and intervention
}

This chapter is based on:

Beukel A.P. van den, Voort M.C. van der, Eger A.O. (2016). Supporting the changing driver's task: Exploration of interface designs for supervision and intervention in automated driving. Transportation Research Part F: Traffic Psychology and Behaviour. DOI: 10.1016/j.trf. 2016.09.009

Notes:

* In the original publication, the interface concepts were labelled A, B and C. To differentiate concepts from concepts introduced in Chapter 5 (with the same labels but different compilation), the second and third concept in this study is re-labelled to $D$, respectively $E$. Because the first concept in this study serves as a base reference and is identical to the first concept in Chapter 5, they both have the same label (i.e. A).

* In comparison to the original publication, section 7-3 (Results on support for intervention) has been added and is based on: Beukel A.P. van den, Voort M.C. van der. (2016). Driving Automation \& Changed Driving Task - Effect of Driver-interfaces on Intervention. In: Intelligent Vehicles (IV), 2016 IEEE International Conference on. IEEE, Gothenburg, June 20-22, 2016.

\begin{abstract}
Driving automation leads to a changing role for drivers, that is from manual vehicle control to supervising automation. Supervision of partial automation requires now and then intervention. Since the automation causes low vigilance and out-of-the-loop performance problems, this changing role is not well suited for human operators. To explore how drivervehicle interfaces can support drivers in their changed role, we tested three concepts. Concept A was a base-line reference, providing only acoustic warnings. Concept D presented statusinformation and warnings behind the steering wheel. Concept $E$ used illumination and haptic feedback in the seat-pan to direct attention outside the vehicle and to stimulate response. Concept E only provided vibro-tactile feedback when intervention was needed. Results of our study show improved support for supervision with the illumination-concept, i.e. better hazarddetection and raised levels of Situation Awareness in some scenarios relevant for supervisory control. Knowing that supervision will be the dominating driver's responsibility during partially automated driving, the illumination-concept is a recommended solution for support of the driver's changing role. Nonetheless, neither concept D, nor E, showed additional support for intervention compared to the baseline. It was hypothesized that the combination of concept E's stimuli for intervention-support caused counter-productive levels of annoyance. Furthermore, we concluded that intervention and supervision benefit from different interfacefeatures and discussed possible causes underlying ambiguity between support for supervision and support for intervention shown with concept $E$. Therewith, the considerations in this paper contribute to further development of - and knowledge about - appropriate driver-vehicle
\end{abstract}


interaction while vehicle-operation advances into operating partially automated driving systems.

Keywords: Automated driving; partial automation; driver-vehicle interface; supervision; intervention.

\subsection{Introduction}

Automotive industry has started introducing vehicles to the market that allow automated driving (Bradley, 2016; Daimler, 2015). Automated cars are assumed to raise comfort, cause less accidents, reduce congestions and decrease environmental impact of driving (EU, 2011; Infra \& Milieu, 2015). In line with roadmaps for the development of automated driving, the introduced systems are defined as partial automation, meaning that the driver should permanently monitor the automation and preserve final responsibility for safe driving (Bengler et al., 2014; Gasser \& Westhoff, 2012; SAE International, 2013). The reason behind this introductory level of automation and subsequent driver's responsibilities, is the complexity for an automated system to interpret or understand many contextual factors relevant to safe driving. Despite enormous technological achievements when introducing these systems, developers need to account for technological boundary conditions (Flemisch et al., 2014; Nieto, Otaegui, Vélez, Ortega, \& Cortés, 2015). In fact, Nieto et al. (2015) indicated reliability of hardware and software as well as resistance to harsh conditions some of the key challenges for development of ADAS' sensors. The definition of partial automation assumes drivers are available at all time to take over control of the vehicle if required(De Winter et al., 2014; Gold et al., 2013). In other words, the introduction of partial automated driving assumes that this capability is used in a way so that the driver is always sufficiently in the loop to take over control if requested by the automation or, more challenging, if necessary due to a hazard not perceived by the automation (Flemisch et al., 2014; Merat et al., 2014; Merat \& Lee, 2012; Toffetti et al., 2009). Obviously, the core difficulty with driver's interaction with partial automation is that it assumes driver's availability, though it is more likely that drivers will shift their attention to non-driving related tasks, while being placed out-of-the-loop. Consequently, during automation the driver's task changes from actively operating the vehicle to supervising the system (Martens \& Van den Beukel, 2013; Merat et al., 2012). However, supervision is not something humans are particular good at, due to low vigilance and behavioural adaptation, causing for example slower reaction times (Larsson et al., 2014), reduced attention to tasks (Farrell \& Lewandowsky, 2000), or misinterpretation (Martens et al., 2008; Merat et al., 2014). Nonetheless, supervision will, during automation, be the dominating driver's task and acceptance of partially automated driving is expected to depend heavily on the appraisal whether supervision (including now and then retrieving control) is less effort taking than a human driving himself or herself (Payre, Cestac, \& Delhomme, 2014; Van den Beukel et al., 2015). 
To summarize, despite the potential advantages of automated driving, partial automation brings the driver into a troublesome situation: being fully responsible for safe driving while having reduced authority and control (Bainbridge, 1983; Flemisch et al., 2014). Carefully designed driver-interfaces are therefore needed to support drivers in their changed role to supervise the automation and to support them retrieving control safely and adequately when required. Existing research however, often focuses on the relation which individual aspects have with a specific task, to a lesser extent on a holistic view of how driver performance is influenced by a combination of interface-aspects applicable in practice (Nirschl, 2007; Van Waterschoot \& Van der Voort, 2009). For instance, adequate support for the driver's changing role asks for improving the cognitive understanding of how a system reacts to different situations (i.e. support for supervision) and at the same time asks for improving the operational capabilities for reacting fast and adequately when solving a critical situation (i.e. support for intervention) (Van den Beukel \& Van der Voort, 2016b). Interface-aspects that show support for these subtasks individually will not necessarily withstand when combined in one overall interface. This research therefore aims at: (a) exploring potential solutions of driver-interfaces that integrate both support for supervision and intervention, and (b) evaluating these interfaces within circumstances that are representable for the complex practice in which partially automated driving will be applied. To this pursuit, the research is based on a combination of exploration with an experiment-based evaluation of proposed concepts. This section starts with reviewing interface-aspects that are important for the development of driver-support. Next, two interfaces are being composed and compared to a base-line concept in a driving simulator test. The simulator's testing conditions and applied measurement aspects are adopted from the framework defined in Chapter 5. Therewith, this study allows to assess the proposed concepts with regard to support for intervention (section 7.3), supervision (section 7.4) and acceptance (7.5). Based on comparison of these results with existing studies, section 7.6 discusses to what extent the applied interface-aspects are beneficial to create desirable support. Section 7.7 concludes with recommendations for the application and further development of interfaces, which supports the driver when driving automatically.

\subsubsection{Behavioural improvements of raised LOAs}

Despite the raised concerns with respect to the driver's changed role when utilizing partially automated vehicles, some positive behavioural change or compensating adaptation is being associated with application of raised levels of automation (LOAs):

* Drivers who have adapted to the benefits of raised comfort (provided by the automation) also demonstrate more homogenous traffic participation, resulting in safer and more efficient driving, e.g.; less lane changing and reduced over-taking (Jamson et al., 2013; Van Arem, Van Driel, \& Visser, 2006; Van Driel, 2007).

* If drivers are motivated or instructed to take benefit from the freed resources (due to partial automation) and use it for observing objects in the environment, higher levels 
of automation can result in improved situation awareness compared to manual driving (De Winter et al., 2014).

* Drivers who are familiarized with the technical boundary conditions of their assistance system, have higher awareness of how increased traffic density, or aggravated roadtraffic circumstances, influence system performance. These drivers show the capability to compensate with their attention-level (e.g. reduce their involvement in non-driving related tasks) for impaired system-performance (Donges, 1999; Gartenberg, McCurry, \& Trafton, 2011; Jamson et al., 2013; Merat et al., 2012).

* If expectations are aligned (e.g. drivers correctly anticipating system-state and -changes in system-state), then considerable improvement in drivers' ability to regain control is demonstrated (Larsson et al., 2014; Merat et al., 2014). Likewise, an expected stimulus during driving causes faster reaction times and is associated with more correct responses than an unexpected stimulus (Martens, 2007).

Besides, with prior warning, collision avoidance during automated driving situations (i.e. driver out-of-the-loop) is as good as during manually driving (driver in-the-loop) (Gold et al., 2013). This emphasises the importance to support drivers with their changed role (Merat et al., 2014) and means that drivers should be enabled to take their responsibility and intervene when required. Flemisch et al. (2014) formulated the required interaction in terms of: "drivers should have appropriate insight, authority and control".

\subsubsection{Supervision with now-and-then intervention}

This title characterizes the driver's changing role for which we want to develop support in terms of improved driver-vehicle interaction. Proposed solutions often address supervision or intervention separately and usually depart from theoretical considerations. Nonetheless, we want to explore and test potential solutions that combine support for supervision and intervention in single concepts, which are applicable for implementation within approximately five years. Therefore, we now review important considerations and proposed solutions from previous studies. In general, existing approaches differentiate between either leaving drivers involved in the control-loop or to have them back in the control-loop as fast and effectively as possible. The concerns and recommendations related to out-of-the-loop performance are discussed in Chapter 2, see for more explanation: Bainbridge (1983), Endsley and Kiris (1995), Brookhuis et al. (2001) and Martens and Van den Beukel (2013)

\section{Continuous information on system-state}

Automation-induced accidents are often caused by lack of automation-feedback (Norman, 1990). Besides lack of operator's knowledge about the operational envelope of a system, also difficulties to distinguish between the technical characteristics of similar but not identical systems, are often caused for operator's misunderstanding and subsequent failure to respond correctly (Martens, 2007). An extensive review of 32 studies measuring effects of automated driving on situation awareness (De Winter et al., 2014), confirms that a proper feedback system could alleviate much of the concerns in operability of partially automated driving. Therefore, 
researchers advise to provide continuous feedback on system-state, like providing information on activation, deactivation, availability and malfunction (Martens \& Van den Beukel, 2013; Nielsen, 2005). Then, proposals are often based on visual interfaces providing feedback on system's conditions and changes in system-state through a display. Although an on-road study by Stanton, Dunoyer, and Leatherland (2011) and a driving simulator study by Seppelt and Lee (2007) provide evidence that a visual display with continuous information on system-state improves driver's situation awareness, some studies have also raised concerns that the provided information could become a distraction. A continuous display of detailed capabilities and operational envelopes could result in display clutter and consequently confusion and distraction (Martens et al., 2008). The thoughts behind providing continuous information on system-state are to enable drivers to return more easily in the control-loop, because it provides information on the parameters that are important for perception, decision-making and response - the basic elements within a control-loop.

\section{Timely warnings}

Other studies explore support in terms of providing warnings that allow drivers to turn back in the control-loop on time and to demonstrate effective intervention. Gold et al. (2013) showed that providing a takeover request (i.e., a simple audio-visual warning) 5 - 7s in advance ensures that drivers of a highly automated car avoided a stationary object, even if they were not attending to the road prior to the takeover request. Van den Beukel and Van der Voort (2013) found that drivers who were out-of-the-loop and travelling with time headways of about $1.5 \mathrm{~s}$ (which are during manually driving considered 'safe'), failed in almost half of these occasions (47.5\%) to avoid collision with a broken down vehicle during an unexpected event. However, this study also showed that providing an improved level of situation awareness (through e.g. appropriate system feedback and timely warning) improves the ability for successfully taking back control.

\section{Cooperative control}

Many studies have addressed possible support of the intervention-task by keeping operators somehow involved in the control-loop (Abbink \& Mulder, 2010; Flemisch et al., 2014; Hoc, Young, \& Blosseville, 2009). Referring to sequences of task performance involving perception, decision-making and implementation, studies demonstrated that operator's ability to intervene and retrieve control is considerably better when being involved in the implementation-step (Endsley \& Kaber, 1999; Endsley \& Kiris, 1995; Kaber \& Endsley, 1997). In contrast, if the automated system failed, the removal of human control from the operational part resulted in inability to recover (Kaber \& Endsley, 2004). Research of how levels of automation influence operator's controllability often uses generic devices from the computerdomain. However, Flemisch et al. (2014) proposed an advanced stick-controller - based on haptic input and feedback, specifically for the automotive domain. The device enables drivers to remain involved in the operating-task and at the same time delegates automation depending on the circumstances. Also Mulder, Van Paassen, and Abbink (2008) as well as Mulder, Abbink, and Boer (2012) explored haptically enhanced automotive-devices, like haptic 
force-feedback in the steering wheel and a haptic pedal. They concluded that haptic control enabled the driver to remain in the loop with enhanced performance at reduced control activity. Therewith the haptic control enabled to take advantages of raised comfort through automation while mitigating the controllability issues of full automation.

\section{Acceptance \& comfort}

We acknowledge that besides effectiveness of the desired support, the acceptance of provided support is also important. In addition to possible distraction due to the transferred information, other negative side-effects need to be avoided too. Among these, it certainly needs to be accounted for that stimuli might become annoying or cause startle-reactions (Baldwin \& May, 2011; Blumenthal, 1996; Fagerlonn, 2011).

\section{Interface's scope}

Based on previous findings we assume that a driver-vehicle interface for partially automated driving provides appropriate support for supervision and intervention if it is characterized as follows:

The interface directs attention to the location where attention is needed with "correct" level of urgency. In addition, the interface provides appropriate feed back and feedforward with respect to foreseen and likely changes in system state without causing counterproductive effects, like distraction. Moreover, the interface enhances fast and effective human intervention if required.

If possible, we want to include advantages of previous findings within concepts that combine support for supervision and intervention. The next section therefore reviews how different modalities influence afore considerations. The goal is to compile different concepts that demonstrate potential advantages through comparison within meaningful circumstances and are realistic with respect to implementation within approximately five years.

\subsubsection{Considering modalities for concept development}

When considering appropriate modalities for development of the interface, we need to realize that the information we want to transfer does not only convey warning messages but also more content-rich (and often less urgent) information like status information. Furthermore, to weigh pros and cons of different modalities we need to understand that signal effectiveness is related to perceived signal's urgency, annoyance and semantics (Baldwin \& Lewis, 2014; Baldwin \& May, 2011). In other words, modality alone does not drive differences in signal effectiveness.

\section{Audible interfaces}

In general, auditory signals are recommended as a base attention retrieving signal especially for urgent situations, like primary collision avoidance warning (Kiefer et al., 1999; Tan \& Lerner, 1995). Auditory alarms are especially supportive to retrieve attention from distracted drivers 
(H. K. Lee, Suh, \& Benbasat, 2001). Concerns for an auditory interface are that they are more prone to annoyance and auditory signals receive often competition from In-Vehicle Information Systems (IVIS), like radio and navigation.

\section{Visual interfaces}

Visual interfaces have the advantage to enable more content-rich transfer of information. Besides, visual interfaces enable users their own pace of information retrieval. Often, perception of the signal can be interrupted and continued later on. In this respect (self-paced, pausing) a visual interface combines well with the visually dominated and highly changeable driving task. Concerns for a visual interface are as follows: (a) The information can become a distraction (as explained in the previous section), and (b) Visual signals can be easily overlooked within the stimulus-rich visual driving environment (Martens, 2007).

\section{Tactile interfaces}

It is intrinsic to tactile interfaces that they hold, in comparison to visual interfaces, a high base level of perceived urgency. This makes tactile interfaces less suitable to convey supervisioninformation. Compared to visual feedback, this modality also has a reduced resolution to convey a multitude of potentially relevant messages (Fitch, Hankey, Kleiner, \& Dingus, 2011). Haptic alerts are especially effective for cueing distracted drivers' attention back to the road (Green et al., 2008; C. Ho, Tang, \& Spence, 2005; J. D. Lee, Hoffman, \& Hayes, 2004). As an attention signal, tactile feedback has in this respect a comparable function as audible signals. In addition, a tactile stimulus can also help to select and speed-up correct control (Fitch et al., 2011; Flemisch et al., 2014). Due to the strong link of tactile stimulus with the neuro-muscular system tactile interfaces could help with affordance for action (Smisek, Van Paassen, Mulder, \& Abbink, 2013). Therefore tactile interfaces allow creation of combined devices for both feedback and control (Abbink \& Mulder, 2010).

\section{Signal urgency}

With respect to perceived signal's urgency, there is a fundamental relationship between the signal's intensity (frequency, wavelength, pace and duration, etc.) and perceived urgency. For example: If the frequency of a sound increases, and/or as the time interval between pulses of sound decreases, it is perceived as increasingly urgent (Edworthy, Loxley, \& Dennis, 1991; Hellier \& Edworthy, 1999). Likewise, as the wavelength of visible light increases (hue or perceived colour changing from green to yellow to red) it is perceived as more urgent (Chapanis, 1994; Wogalter, Conzola, \& Smith-Jackson, 2002). The behaviour of tactile stimuli is in this respect comparable to sound (Baldwin \& Lewis, 2014), meaning that if the frequency and/or pulse of a vibration increases, this is perceived more urgent. Furthermore, there is a direct relationship between perceived urgency and annoyance, such that as a signal becomes more urgent it is also perceived as more annoying (Baldwin \& May, 2011; Marshall, Lee, \& Austria, 2007). However, the context in which the signal is presented influences this relationship (Wiese \& Lee, 2004). More urgent signals are perceived as less annoying in 
conjunction with situations where the high urgency seems appropriate (collision warnings) relative to situations where it is less appropriate to receive a very urgent signal (e.g., navigation command or email alert) (Marshall et al., 2007).

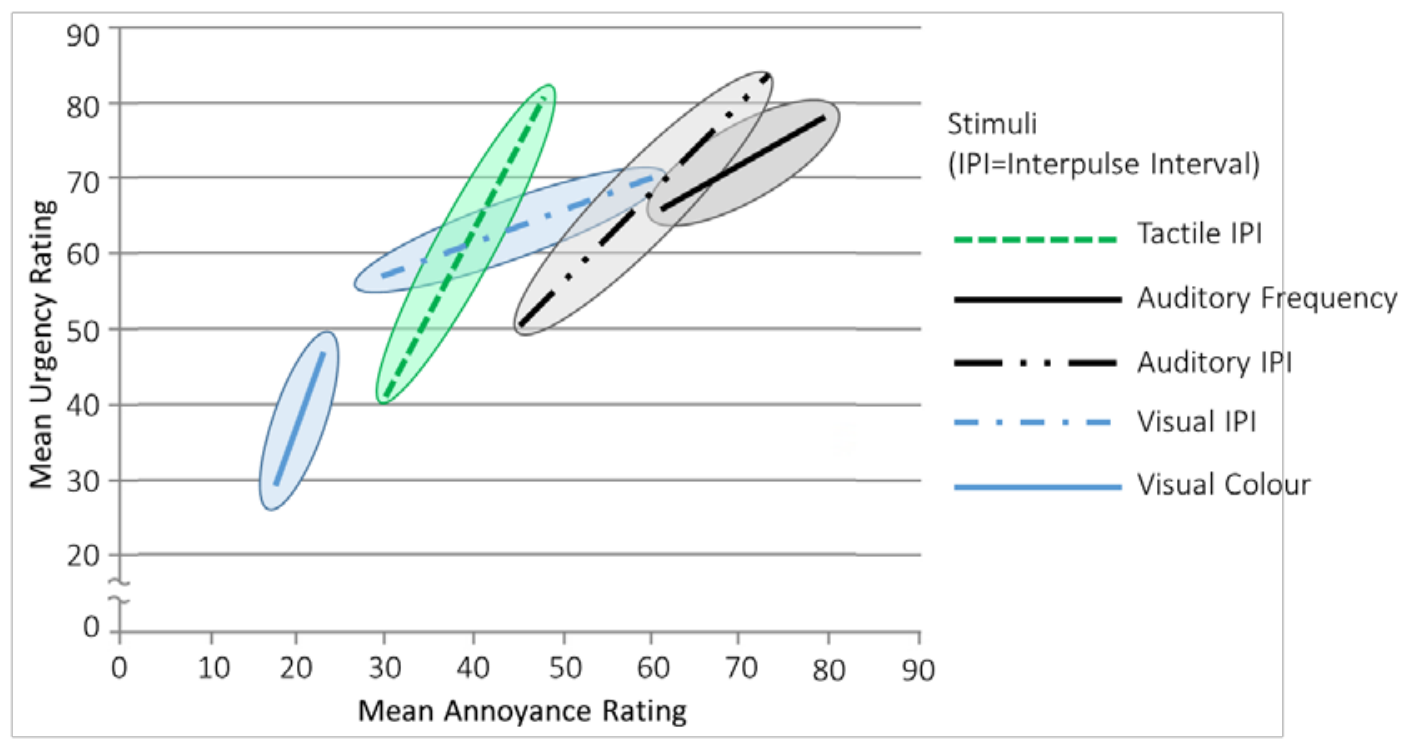

Figure 7-1 Visualisation of relative impact of visual, auditory, and tactile modalities on perceptions of urgency and annoyance, adapted from Baldwin and Lewis (2014). Note. The more vertical the line the greater the signal utility. That is, large increase in urgency can be achieved with minor increase in annoyance.

\section{Modality influences relation between urgency and annoyance}

Baldwin and Lewis (2014) has researched the trade-off between annoyance and perceived urgency for signals with different modality, see Figure 7-1. Their research showed that especially visual colour and tactile intermitting modality are potentially useful, because the characteristics of these modalities can be changed to provide more urgency, with a minimum effect on increasing annoyance (indicated by the steep slope of the urgency-annoyance lines of these signals in Figure 7-1). The research also showed that the visual colour interface has lowest base annoyance level and that the tactile interface has a higher baseline urgency level than a visual colour interface. The range-lengths and base-levels also provide insight on the stimuli applicability to provide different signals. For example, a stimulus with long range (e.g. tactile intermitting) could be manipulated to create a signal with moderate urgency (like an attention-alert) as well as high urgency (e.g. intervention-signal). However, the applicability is limited by threshold-levels of urgency: When urgency-levels are too high, their effectiveness for intervention-support (like crash avoidance) reduces due to startle effects on the driver (Baldwin \& May, 2011; Blumenthal, 1996). For further utilization of results from the Baldwin and Lewis (2014) study, it needs to be mentioned that the stimuli were single modal (i.e. different modalities were not tested simultaneously as a combined stimulus) and the stimulus was intended as attention-signal, not compiled to bring information-rich contents across. 


\section{Semantic factors}

Available data on the semantics of stimuli relate to utilization of words and colour. In line with expectations, the highest wavelengths visible to the human eye (i.e. $600-750 \mathrm{~nm}$; orange and red) are associated with high urgency (Braun, Sansing, \& Silver, 1994). Written words may express different levels of urgency, like "Danger" compared to "Notice" (Wogalter, Kalsher, Frederick, \& Magurno, 1998). Likewise, different semantics of spoken words allow differentiation in perceived hazard. Although we favour language-independent solutions, it is important for our interface-development to acknowledge that semantic factors (e.g. signal word) interact with circumstances (e.g. loudness) at which an auditory warning is made heard (Baldwin \& May, 2011; Edworthy, Hellier, Walters, Clift-Mathews, \& Crowther, 2003) and that this interaction can impact both perceived urgency and collision avoidance response. A typical example is provided by Baldwin and May (2011) showing with a collision avoidance task in a driving simulator test that the majority of people crashed when either receiving no warning or receiving an acoustic warning with the most urgent signal word "Danger" at an high intensity (85 dB). It was hypothesized that the extremely urgent acoustic alarm caused startle and was therefore not successful in avoiding crashes. In contrast to audible interfaces, combining written signal words with colours in visual interfaces allow creation of more moderate levels of perceived urgency (Braun, Sansing, Kennedy, \& Silver, 1994). That is; combinations of word and colour with similar semantics (e.g. using the word "Danger" on a red background) are not reported to cause inappropriate high levels of urgency.

\section{Multimodal interfaces}

In view of the pros and cons associated with the different modalities, it is understandable that researchers recommend to not rely on one modality but explore multimodal interfaces (PReVENT, 2009). Multimodal interfaces bring advantages when different modalities are utilized in a complementary fashion. For example, vision exists over time and sound exists over space (i.e. vision and sound are independent of respectively time and space). However, if too much information is provided information-overload occurs. Besides, users may have difficulties comprehending information coming from different modalities simultaneously, either disregarding or totally ignoring one or the other (H. K. Lee et al., 2001). Based on the considerations for the potential support provided by different modalities and the introduced vision on desired solutions that combine supervision and intervention, we have compiled two concepts with multimodal features and defined one base-concept for comparison. The concepts are explained in the next section.

\subsubsection{Concepts}

The concepts' function was to provide signals to either attract driver's attention for potentially hazardous situations or to urge for intervention. The signals to ask for attention are referred to as 'soft warnings'. The signals intended to request take-over are called 'hard warnings'. The concepts' signals and stimuli were composed as follows: 
* Concept A served as baseline, providing only audible signals. The audible soft warning was a high-frequency (approximately $1 \mathrm{kHz}$ ) "beep"-sound with a duration of $2.5 \mathrm{~s}$, transcending engine-sound with about $4 \mathrm{~dB}$. The hard warning consisted of an intermitting rattle-like sound at an intensity of $70 \mathrm{~dB}$ (roaring over engine noise with approximately $10 \mathrm{~dB}$ ) and a duration of 2.0s.

* The second concept (labelled " $\mathrm{D}^{11}$ ) provided in addition to audible signals also feedback upon system-state with a graphical icon, displayed behind the steering wheel. The audible warnings were the same as with concept $A$. Examples of how the graphical icon depicted different soft and hard warnings are provided with the inserted images in Figure 7-2.

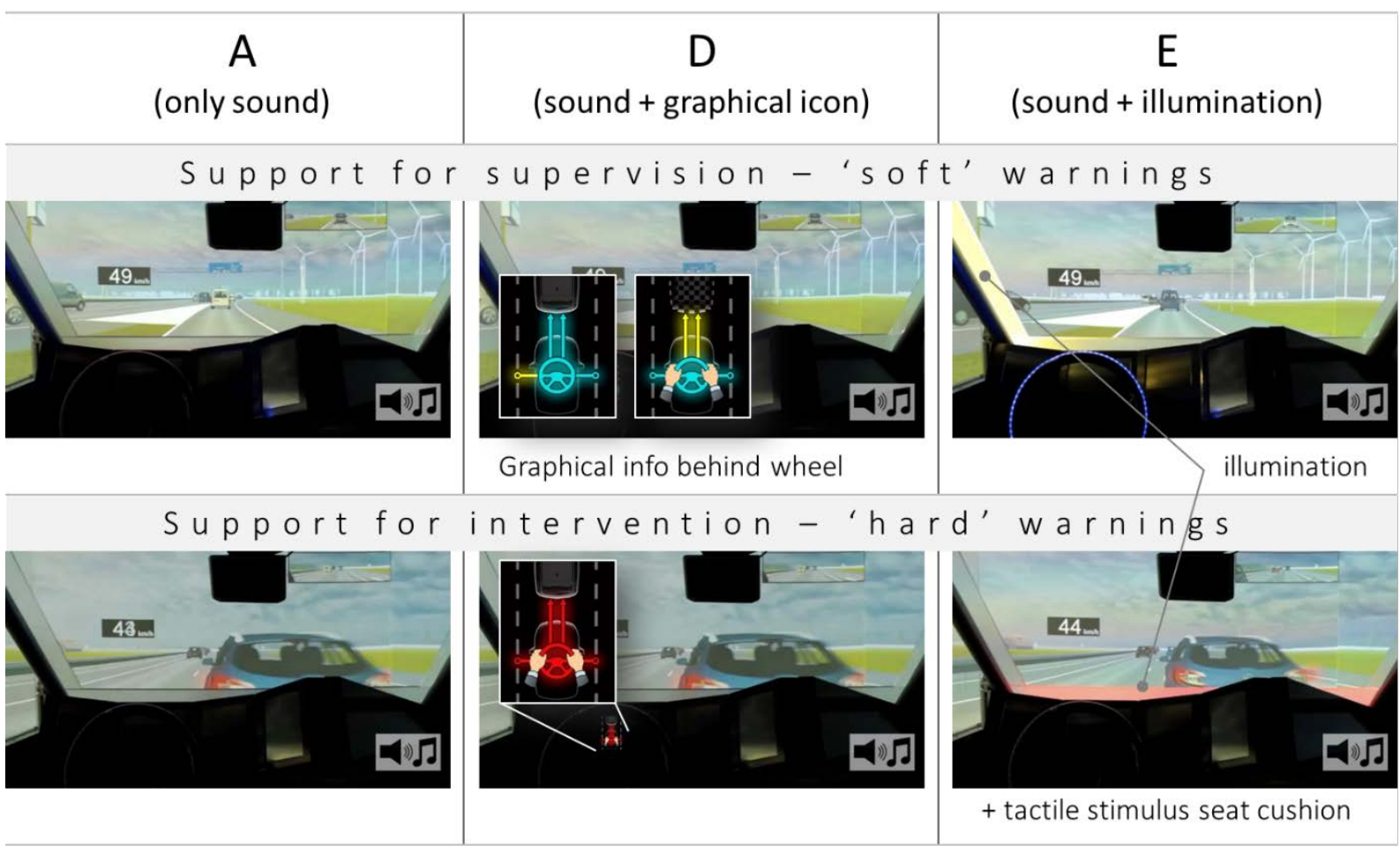

Figure 7-2: Concepts providing different combinations to utilize modalities for providing support for supervision and intervention. Concept $A$ intended a baseline concept providing only audible warnings.

* A third concept (labelled "E") offered the same audible warnings as A, but provided additional signals through illumination of the steering wheel and - occasionally - the windscreen. The illumination around the steering wheel represented the system to be active. Illumination at the sides of the windscreen or side windows was non-permanent. It lit op at the occasion of an event requiring either attention or intervention. The occurrence of illumination intended to attract attention away from non-driving tasks

\footnotetext{
${ }^{11}$ To distinguish the concepts in this chapter from previous concepts A, B and C tested in Chapter 5, the second and third concept in this chapter are labelled $D$ and respectively $E$. Concept $A$ in this chapter is identical with $A$ in Chapter 5 , i.e. the concept only provides sound-based alerts.
} 
and the location of illumination intended to direct driver's focus towards the location outside the vehicle where attention was needed. Furthermore, the colour of the illumination conveyed urgency and helped to distinguish between soft and hard warnings. The blue illumination around the steering wheel was visible as long as system control was active and faultless. Yellow illumination (in the side-windows or windscreen) pointed at needed attention, for example merging-in traffic from an onramp. Hence, this configuration conveyed a "soft warning". Red illumination conceived danger and urged for direct intervention to take back control (i.e. a "hard warning"). In addition to visually directing attention, the hard warning of concept E provided tactile feedback. Vibrotactile pots were placed in the front-end of the seat cushion intended to create an affordance for appropriate intervention (e.g. braking). The tactile stimulus existed of two pulses of about $600 \mathrm{~ms}$. The intended tactile affordance was similar to Fitch et al. (2011) who observed that a haptic seat helped distracted drivers to gain quick and accurate manual responses to a critical event. Similar findings were reported by Hoffman, Lee, and Hayes (2003).

Based on considerations derived from existing research - and explained in this section - the aim of our research was (a) to explore the possibilities for guiding focus towards relevant locus of attention outside the vehicle, (b) to adequately inform drivers about system-state, and (c) to create an affordance for action if intervention is needed. All, intended to support drivers in their changed role for supervision with now-and-then intervention. Clearly, the compilation of the concepts is not intended to test fundamental differences between interface modalities. In general, visual interfaces provide a large variety of different instantiations, like using colours, icons, screens with different possibilities for size and location. The visual characteristics between our concepts $D$ (icon-interface) and $E$ (illumination) are deliberately chosen to reflect different approaches: the icon-concept (D) allows to convey detailed information upon systemstate and related changes in the road-environment (like detection of road-lines) - but assumingly requires more cognitive load for information-processing. The illumination-concept (E) is intended to guide attention outside the vehicle presuming to help drivers return in the control-loop. Although, other instantiations could provide similar effects, and based on practicability the number of concepts was limited to three. Moreover, a Heads-Up Display (HUD) was considered, because the projected image at focus-distance outside the vehicle seems promising to promote driver's focus at the road scenery (Götze \& Bengler, 2015). However, the limited viewing-angle of current systems and subsequent inability to connect traffic-information from a variety of road-locations via a HUD to the driver, caused this technology to be excluded from the present exploration.

\subsection{Method}

The previous section reviewed interface-aspects important to support drivers with their changed role (i.e. supervising the automation with now-and-then intervention) and introduced 
potential concepts. The aim of this research was to propose solutions that demonstrate desired support. Therefore the introduced concepts will now be tested within circumstances representative for partially automated driving, corresponding with the assessment framework defined in Chapter 5. This section describes the applied within-subjects experiment design using the mid-fidelity driving simulator introduced in section 3.2.2. While providing the results of this experiment, next sections will assess the proposed concepts with regard to support for intervention (Section 7.3), supervision (Section 7.4) and with regard to acceptance (Section 7.5). Based on comparing results from this research with existing studies, Section 7.6 will then discuss the influence of the reviewed interface-aspects on desired support. Thereafter, the Section 7.7 concludes with recommendations on the identified interface-aspects that are beneficial to create the desired support for the driver's changing role when driving automatically.

\subsubsection{Participants}

Thirty-seven persons participated and their age ranged from 20 to 64 years (Mean $=47.0$, SD = 12.6). Seventeen female participants took part and also twenty males. All participants had normal or corrected to normal sight. Participants were recruited using announcements in local newspapers. None of the participants had experience with using automated driving from earlier driving simulator experiments. This was to avoid prior knowledge of the traffic scenarios and circumstances to be expected during the experiment. Other than possession of a driving licence for a minimum of two years and maximum age of 65 years, no particular criteria were used for recruiting participants. Participants did not receive compensation, but among participants three nation-wide accepted shopping-vouchers were raffled off as an incentive. The characteristics of the participants were diverse, like students, professionals, unemployed and retired people. Though participants were interested in the subject of automated driving, their base attitude was diverse too: Some people's expectations towards the technology run high, and others were more in general interested in automobiles and car-driving. Another considerable part of the participants had extrinsic motivation to participate since they considered our research to be very relevant for society. The occupation among participants was diverse too, like salesman, teacher, businessman, pilot, engineer and journalist.

\subsubsection{Scenarios \& system description}

During the experiment, the concepts were tested within a total of six different scenarios, identical to the scenarios defined in section 3.2.3. For convenience, the scenarios are summarized in Table 7-1. The hazardous scenarios encompass a need for driver's supervision due to reduced system's reliability. For example, the ego-vehicle approaches a combined onand off-ramp with other vehicles simultaneously entering and exiting the main road with short follow distances. The 'critical' scenarios required intervention while the automation was terminated. Within two critical scenarios, i.e. "1b: Emergency Brake" and "3b: Close Cut-in", intervention was necessary to avoid an accident. 


\begin{tabular}{|c|c|}
\hline $\begin{array}{l}\text { 1a "Complex Road" } \\
\text { Attention-need induced by } \\
\text { infrastructure }\end{array}$ & $\begin{array}{l}\text { Attention is needed because the vehicle is approaching a } \\
\text { combined entrance/exit ramp with the likelihood that vehicles } \\
\text { will simultaneously enter and exit the main road. }\end{array}$ \\
\hline $\begin{array}{l}\text { 2a "Vehicle Passing" } \\
\text { Attention-need induced by } \\
\text { traffic-participant }\end{array}$ & $\begin{array}{l}\text { While the vehicle is in the left (fast) lane, extra attention is } \\
\text { needed because a vehicle is nevertheless passing on the right. }\end{array}$ \\
\hline $\begin{array}{l}\text { 3a "Speed Oscillation" } \\
\text { Attention-need induced by } \\
\text { system design }\end{array}$ & $\begin{array}{l}\text { When the target vehicle (i.e. the vehicle ahead being monitored) } \\
\text { crosses the } 50 \mathrm{~km} / \mathrm{h} \text { threshold, attention is needed because the } \\
\text { system switches off while the vehicle remains above the speed } \\
\text { threshold. }\end{array}$ \\
\hline \multicolumn{2}{|c|}{ 'Critical' scenarios (requiring driver's intervention) } \\
\hline $\begin{array}{l}\text { 1b "Emergency Brake" } \\
\text { Intervention-need induced by } \\
\text { system design }\end{array}$ & $\begin{array}{l}\text { The target vehicle unexpectedly brakes hard with deceleration } \\
\text { rates exceeding system boundaries. Without an intervention, a } \\
\text { collision would occur. }\end{array}$ \\
\hline $\begin{array}{l}\text { 2b "Merge-out" } \\
\text { Intervention-need induced by } \\
\text { combination of behaviour traffic- } \\
\text { participant \& system design }\end{array}$ & $\begin{array}{l}\text { The target vehicle suddenly changes lane. If there is no new } \\
\text { target vehicle ahead, the system stops and requests the driver to } \\
\text { take back control. Accident avoidance involves preventing the } \\
\text { vehicle from leaving its lane. }\end{array}$ \\
\hline $\begin{array}{l}\text { 3b "Close Cut-in" } \\
\text { Intervention-need induced by } \\
\text { traffic-participant }\end{array}$ & $\begin{array}{l}\text { A vehicle in another lane brakes heavily in an attempt to cut } \\
\text { across to an exit. This violates system boundaries for minimum } \\
\text { separation and a collision would be inevitable without } \\
\text { intervention. }\end{array}$ \\
\hline
\end{tabular}

Apart from differentiation with regard to required supervision and intervention, the scenarios are also differentiated with regard to the elements in the traffic-road situation that cause increased demand for driver's support. Examples are demand induced by changes in infrastructure, behaviour of other road users, or system-design choices (see Table 7-1). With these elements the scenarios are representative for the dynamic character of road-traffic situations driving automation will encounter. The automation was modelled in our driving simulator environment as a Congestion Assistant, cf. Naujoks et al. (2015). Figure 1-1 provides a schematic overview with system boundaries. The Congestion Assistant basically keeps the ego-vehicle in the centre of the lane at a pre-set velocity and keeps a safe distance to the target-vehicle in front. For safety reasons, systems are often restricted to drive automatically beyond a specific speed threshold. In our case, this speed threshold was set to $50 \mathrm{~km} / \mathrm{h}$. Based on our modelled system, all scenarios involved highway driving at relatively low speed with dense traffic.

Afore mentioned scenarios "1b: Emergency Brake" and "3b: Close Cut-in" focus specifically on support for intervention. The 'hazardous' scenarios request supervision due to: (a) changes in road complexity (scenario "1a: Complex Road"), (b) hazardous behaviour of a neighbourvehicle (scenario "2a: Vehicle Passing"), and (c) system behaviour (scenario "3a: Speed Oscillation"). One peculiar scenario requested the driver to take over, without a direct danger of an accident. This scenario is labelled " $2 \mathrm{~b}$ : Merge-out". It is characterized by a lost target 
vehicle due to the vehicle in front merging out to the neighbouring lane leaving an empty lane in front of the ego-vehicle. Furthermore, an additional condition in this scenario involved a detection task, i.e. detection of potential hazard while entering a combined on- and off-ramp.

\subsubsection{Simulator environment}

The study was undertaken in the University of Twente driving simulator, as introduced in section 3.2.2. The projection provided a simulated motorway environment with trafficbehaviour in line with the scenarios described. Participants were seated in a mocked-up vehicle equipped with common automobile control interfaces, including a physical steering wheel, physical gas and brake pedals and an automatic gearbox, see Figure 7-3. Mirrors and a speed indicator were projected onto the outside screen. Instructions how to control the driving simulator was provided at the beginning of the experiment and included time to practice. Other vehicles drove in front, aside and behind the simulated vehicle. All vehicles drove with time headways between 1 and $1.5 \mathrm{~s}$ at about $50 \mathrm{~km} / \mathrm{h}$, as to simulate traffic congestion. The position of the neighbouring vehicles was identical within each trial of a specific scenario to ensure that every participant carried out the situations under the same circumstances. The controls allowed participants to intervene any time and to take back full control when necessary. A display behind the steering wheel showed the graphical interface for concept $D$. Furthermore, the edges of the windscreen and side windows were equipped with LED-strips to provide the illumination signals for concept $E$. The behaviour of the concepts was synchronized with the traffic behaviour by pre-defined scripts. The simulated environment allowed the experimenter to start the traffic scenarios and corresponding scripts simultaneously.

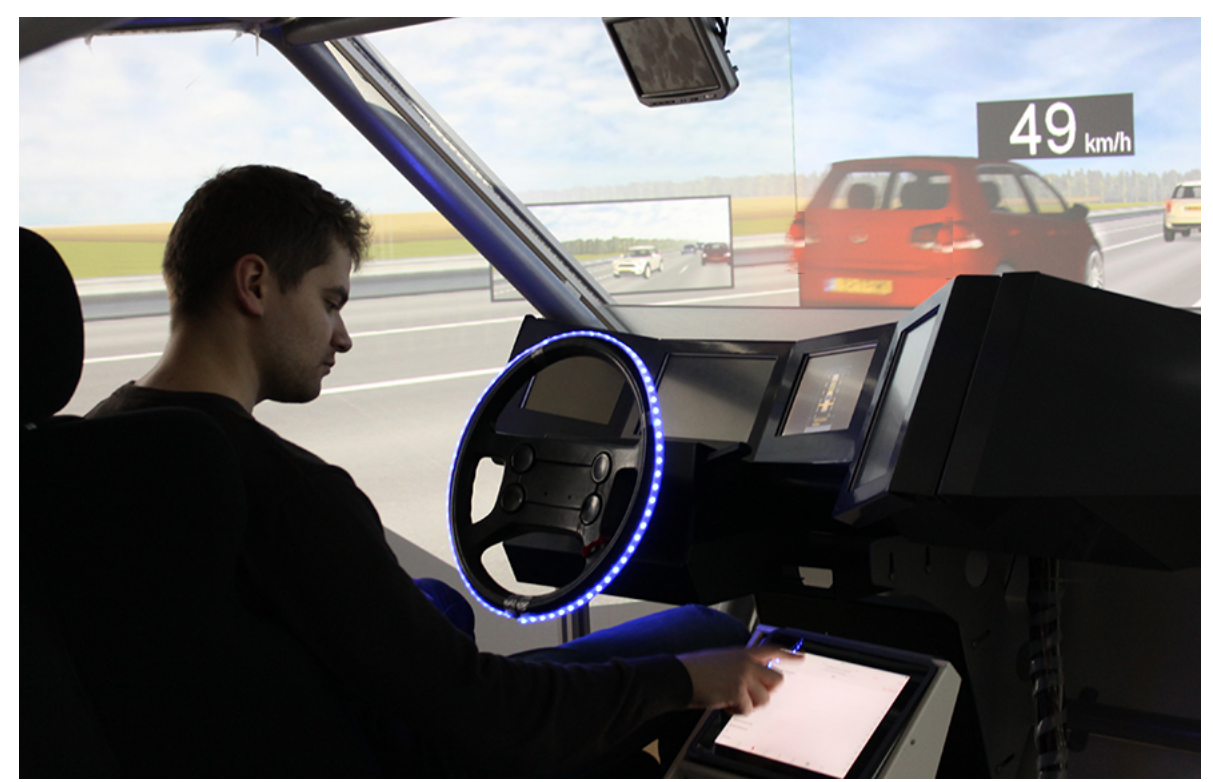

Figure 7-3 Mocked up vehicle interior used in driving simulator environment 


\subsubsection{Experimental design \& procedure}

A within-subject experimental design was implemented. All participants completed three sessions (one with each concept) and each session consisted of four different scenarios. The scenarios were selected from the six available scenarios (explained in Paragraph 7.2.2). The different scenarios were assigned to ensure that participants encountered in each session (i.e. with each concept) two scenarios which required intervention and two scenarios which required supervision. Furthermore, the scenarios were divided over the sessions per participant to ensure: (a) participants experienced each scenario twice but always with another concept, and (b) the combinations of a concept with a specific scenario, accounted for ordereffects. Each subject participated in 12 trials (3 concept-sessions * $(2$ intervention +2 supervision scenarios) $=12$ trials). The test set-up planned for at least 36 participants, providing data from $432(36 * 12)$ trials, and subsequently 24 ( 432 / ( 3 concepts * 6 scenarios $)=24)$ datasets were planned per concept tested within a specific scenario. A trial lasted between 2 and 3 minutes. Time between trials was needed for taking test queries. In total an experiment took per participant a maximum of one hour and fifteen minutes.

Participants were instructed that they were the responsible driver of a vehicle that was driving automatically within the following boundary conditions: Travelling on motorways with speed until $50 \mathrm{~km} / \mathrm{h}$, during which a target vehicle and road lines were recognised. The automation was introduced in terms of a Congestion Assistant system and it was explained that situations could happen which require extra attention (like approaching an interchange) or require the driver to take over control (e.g. when road lines are not being recognised). To help the driver with his/her responsibility, it was also explained that the system would give signals (i.e. stimuli provided by the concepts) to either ask for attention or urge for intervention. Participants were not familiarized with the signals before taking part in the trials. To add on realistic circumstances, a tablet mounted at the centre console enabled participants to view news from internet-sites or select music from a stored database (See Figure 7-3). Furthermore, participants received explanation that they retrieve full vehicle control as soon as they used any of the regular controls (i.e. steering wheel or pedals). A test run was performed by the participants to exercise on operating the simulator, including braking and lane-changing. The participants were encouraged to use the tablet as long as the driving situation allowed to do so, according to their own judgement. The instruction intended to provide trust in the automation and it was advised to only intervene when intervention seems indispensable to avoid an accident.

\subsubsection{Selected measurements}

The concepts were tested for intervention-support during the critical scenarios that required accident avoidance (i.e. " $1 b$ " and " $3 b$ "). Accident avoidance was measured with Time-toCollision (TTC) and Accident Avoidance Ranking (AAR). Similarly as described in Paragraph 5.3.2, AAR accounted for three-fold possibilities of intervention: (i) intervention failed and an 
accident occurred, (ii) intervention was successful and consisted of braking while staying within the original lane, or (iii) intervention was successful and based on swerving out without causing (as yet) an accident. One scenario (" $2 \mathrm{~b}$ : Merge-out") considered detection of changes in system state due to a failing target-vehicle (A previous target merged out leaving an empty lane in front). Subsequently, the participant was requested to take over driving. Within this scenario performance was evaluated by observing take-over behaviour and measuring reaction times until participants took over control. Supervision is considered successful if drivers remain situation aware. In our case, situational awareness refers to both traffic situation and automation state, for example system's recognition of a target vehicle. A wide-accepted definition of Situation Awareness (SA) is provided by Endsley (1995b) and describes SA in terms of three levels: "(1) the perception of elements in the environment within a volume of time and space, (2) the comprehension of their meaning, and (3) the projection of their status in the near future". Correct SA was measured for each concept in every scenario based on a specific probetaking technique, i.e.: SAGAT (Charlton, 2002; De Winter et al., 2014; Endsley et al., 1998). SAGAT is based on freezes in the driving simulation and then probes are taken that are assumed to be representative for SA as they resemble the three levels of SA. For example: After the simulation froze, it was asked: "What type of vehicle is aside you?" (perception), respectively; "What caused the system to request your attention?" (comprehension) and "if the simulation continues after the "freeze", what situation would most likely require your intervention?" (projection), see also section 5.3.1. We also examined Workload, Arousal, Spare Attention and Received Information, based on self-assessment. These four aspects represent mental efforts and were measured with queries ${ }^{12}$, like: "How much information have you gained about the situation? Have you received and understood a great deal of knowledge (High) or very little (Low)?" Participants were then asked for their self-assessment by answering on a 7-point scale ranging from 1 (low) to 7 (high). Furthermore, to gain insight in participants' subjective appreciation of the concepts, we measured concept acceptance after each session with a 'Van der Laan'-questionnaire (Van der Laan et al., 1997) that measures two factors: Perceived Usefulness and Satisfaction. (In comparison to the original 5-point scale, we adapted the Van der Laan scale to contain a scale with 7-points in order to provide consistency with afore explained 7-points scale for measuring mental efforts.) At the end - after the experiment was completed and participants had experienced all three concepts - participants were also asked for their preferred concept. Then, participants expressed their preference by assigning 15 points over all three concepts. This allowed participants to express a balanced opinion. They could for example express indifferent scores by assigning 5 points equally to each concept. Or, they could express scores to two almost equally superior concepts by a 0 / 8 / 7 divide. Any division of scores between concepts was allowed as long as they add on to a total of 15.

\footnotetext{
12 The queries were taken from a standardized SART questionnaire (Charlton, 2002), see Appendix C.
} 


\subsection{Results on support for intervention ${ }^{13}$}

\subsubsection{Accident avoidance}

In line with three-fold possibilities for intervention, Figure 7-4 shows three categories of accident avoidance per concept and per scenario. The bottom bars visualize the number of accidents, the bars in the middle represent successful avoidance when participants did not swerve-out but stayed within their lane and braked. The top bars show the number of successful swerve-outs. When, at first, ignoring differences between concepts, we see that sixteen (22.2\%) accidents happened within scenario 1b "Emergency Brake (EB)" and seven $(9.7 \%)$ in scenario 3b "Close Cut-in" (CI). Based on these numbers, scenario $1 \mathrm{~b}$ "Emergency Brake" was significantly more dangerous than $3 b(C l): \chi^{2}(1, N=144)=4.19, p=0.041$ (twotailed). Within the most dangerous scenario (1b "Emergency Brake") the concepts scored almost indifferent with respect to accident occurrence. Scenario 3b "Critical Cut-in" on the contrary, does show some differences between concepts: Here, most accidents occurred with concept $\mathrm{E}$ and least with $\mathrm{A}$. However, a Kruskal-Wallis test revealed no statistically significant effect of Concept on Accident Occurrence: $\chi^{2}(2, N=72)=1.97, p=0.374$.

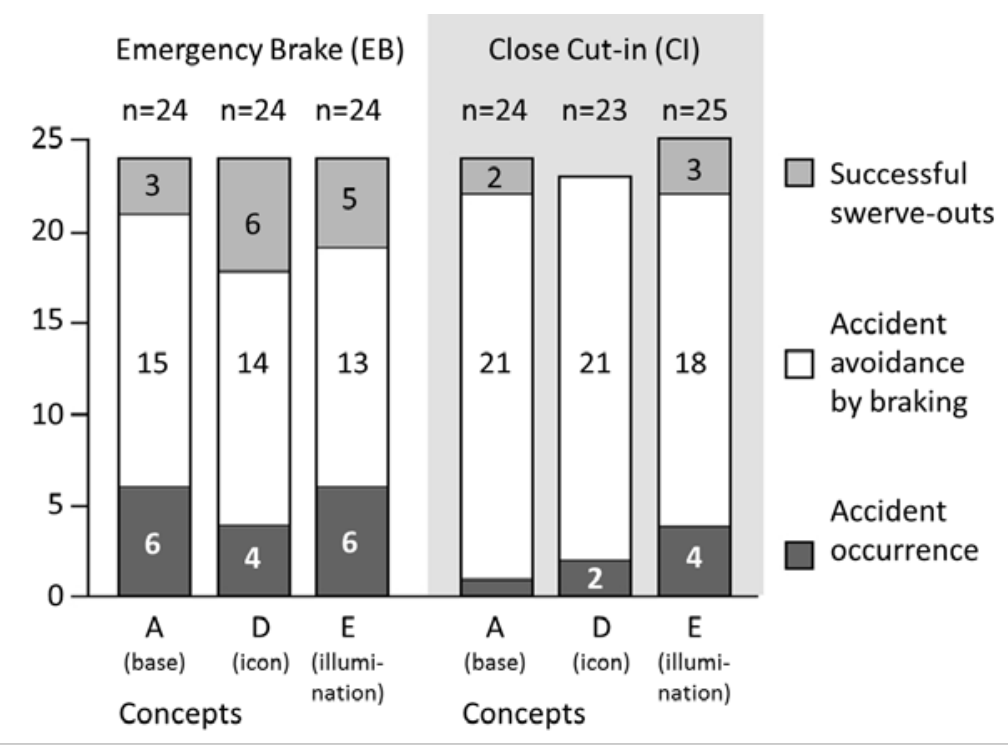

Figure 7-4 Numbers with failed intervention (i.e. accident occurrence, shown with the bottom bars) and successful intervention, either by braking (middle bars) or by swerving out (top bars).

With regard to successful swerve-outs, the results show that concept $E$ performed most successful swerving outs, i.e. eight (in both scenarios). Concept D denoted six and concept $A$

\footnotetext{
${ }^{13}$ The content of this section is based on: Beukel A.P. van den, Voort M.C. van der. (2016). Driving Automation \& Changed Driving Task - Effect of Driver-interfaces on Intervention. In: Intelligent Vehicles (IV), 2016 IEEE International Conference on. IEEE, Gothenburg, June 20-22, 2016.
} 
denoted a total of five successful swerve-outs. However, the differences between concepts $E$ and $A$ are not statistically significant. $\chi^{2}(1, N=48)=1.23, p=0.273$ (two-tailed). While scenario $1 \mathrm{~b}(\mathrm{~EB})$ related to significant more accidents than scenario $3 \mathrm{~b}(\mathrm{Cl})$, scenario $1 \mathrm{~b}(\mathrm{~EB})$ also denoted most successful swerve-outs (albeit without significant differences compared to scenario 3b "Critical Cut-in" (CI)). The observation that more critical situations result in more swerving out intervention-behaviour is in line with other research (Weber \& Farber, 2015). Despite the explainable differences between scenarios, the results with regard to accident avoidance and occurrence show that the additional features of concepts $D$ and $E$ do not provide the intended support for intervention. In fact, the results within scenario $3 \mathrm{~b}$ ("Close Cut-in") might indicate a deteriorating influence of concepts $D$ and $E$ on accident occurrence.

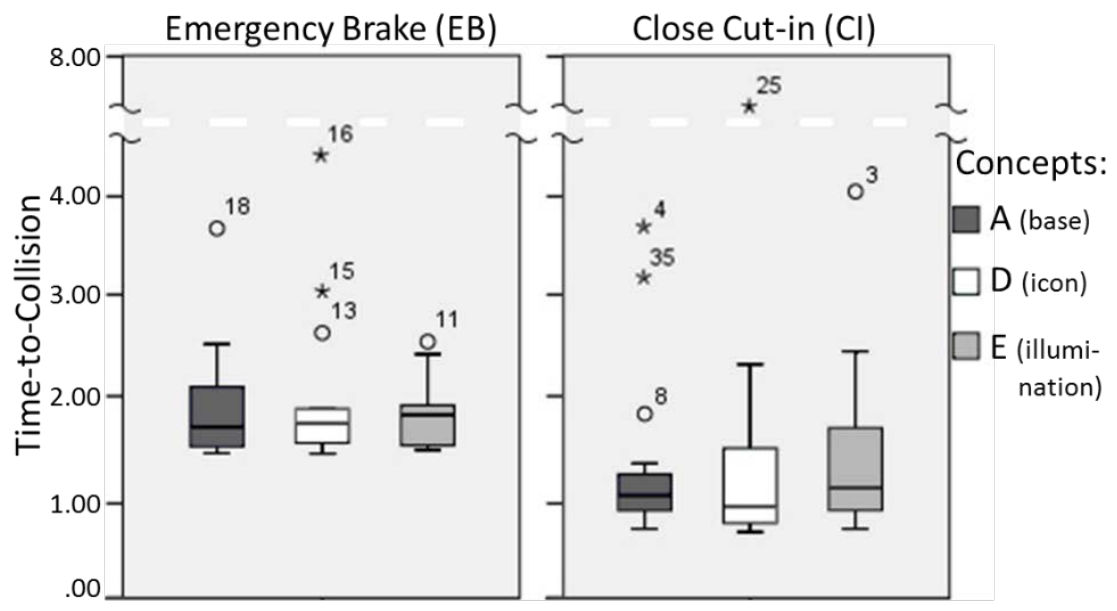

Figure 7-5 Boxplot with Time-to-Collision (TTC) per scenario $1 b(E B), 3 b(C I)$ and per Concept

\section{Time-to-Collision}

Figure 7-5 provides a boxplot with TTC-scores for scenarios $1 \mathrm{~b}$ and $3 \mathrm{~b}$. Within Scenario $1 \mathrm{~b}$ ("Emergency Brake") the concepts denoted better mean TTC-scores than within scenario 3b ("Critical Cut-in"), although (based on accident occurrence) scenario 1b ("Emergency Brake") was more dangerous. An explanation could be that scenario 3b ("Close Cut-in") provided more visual clues and the event occurred more gradually then scenario $1 \mathrm{~b}(\mathrm{~EB})$. Probably this has made participants more awaiting and restrained for intervention. It could also be that the more time-critical scenario $1 b$ ("Emergency Brake") caused stronger counter-reactions, i.e. stronger braking and subsequently better TTC. Apart from the differences between scenarios, we observe no statistical effect of Concept on Time-to-Collision. A Manova within scenario $1 \mathrm{~b}$ ("Emergency Brake") showed no interaction between Concept and TTC $(F(2,39)=0.29, p=$ 0.754 ), nor when scenario $1 \mathrm{~b}$ and $3 \mathrm{~b}$ ("Close Cut-in") were taken together: $F(2,100)=0.13, p$ $=0.876$. Mean scores are in both scenarios highest for concept $D$, which show some remarkable outliers.

\section{Accident Avoidance Ranking}

Afore section 7.2.5 'Independent variables' explained why we applied a combined measure: Accident Avoidance Ranking (AAR). This measure consists of an (non-discrete) interval-scale 
ranging from 1 to 5 , with the lower values expressing better accident avoidance. The value " 5 " was denoted to those occasions when an accident happened, the value " 1 " to occasions when participants successfully swerved out. Values between 1 and 5 were computed from transformed TTC-values, according to: $\mathrm{TTC}_{\text {Transformed }}=\operatorname{EXP}(1 / \mathrm{TTC})$. Due to this transformation the larger (better) TTC-values transformed close to " 1 " and the very short TTC-values (almost accident) transformed close to " 5 ". The AAR measure allowed to assess accident avoidance based on ranking. As it combines accident occurrence and different possibilities for accident avoidance it is theoretically the most complete objective measure to assess intervention performance within this experiment.

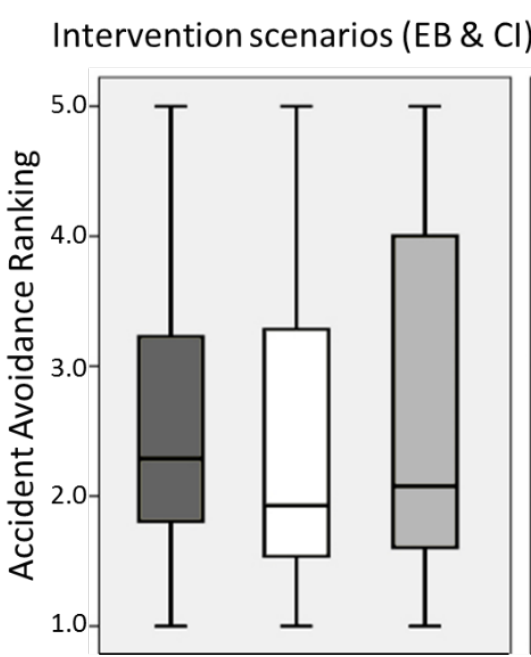

(a) Emergency Brake (EB)

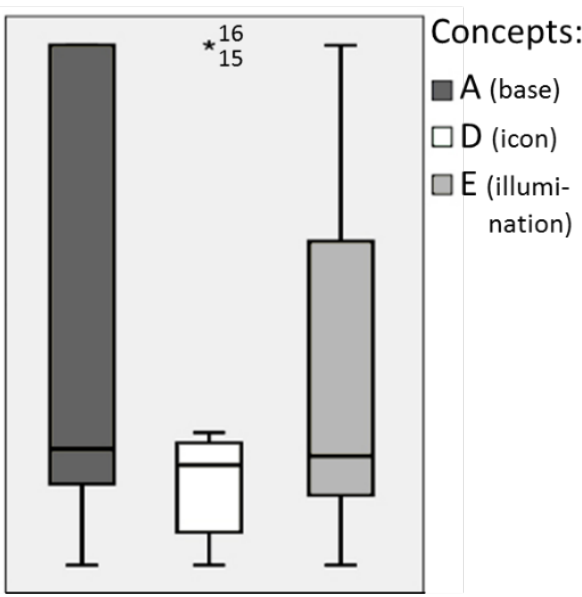

(b)

Figure 7-6 Boxplot Accident Avoidance Ranking, (a) independent of scenario, (b) in scenario $1 b$ "Emergency Brake" (EB). Value "1" denotes accident avoidance by means of successfully swerving out. Value " 5 " denotes accident occurrence. Note. The whiskers show minimum and maximum scores.

Figure 7-6a shows a boxplot of AAR independent of scenario. The results show that accident avoidance was best with concept $D$ and worst with concept $A$. However, there was no statistically significant effect of Concept on AAR. Within scenario 1b "Emergency Brake" (the most dangerous scenario) differences between concept-scores were largest, see Figure 7-6b. Based on a Kruskal-Wallis ranking test, Concept A scored a mean rank of 38.3, concept B 29.1 and concept C 34.6 within a total of 67 measuring points (ranks) for AAR in scenario 1b (EB). However, the relation between Concept and AAR was not statistically significant in this scenario: $\chi^{2}(2, N=67)=2.56, p=0.278$, neither in scenario $3 b(C l)$. When results from both scenarios are taken together, the AAR-test provided 138 possible ranks. Concept $D$ was best ranked with a mean rank of 63.0, concept E scored a mean rank of 70.3 and concept $A$ scored a mean rank of 75.4. Although these scores do not reveal statistically significant effects $\chi^{2}(2$, $N=138)=2.22, p$-value $=0.33)$, the pattern reveals similarities with accident occurrence: $D$ was ranked best, $E$ mediocre and concept $A$ worst. The observation that $D$ scores best and $E$ in some occasions worse (i.e. for accident occurrence) was against expectations. 
An assumption is that the additional features of concept $E$ might have caused a partially counter-productive effect due to the signals being jittery to some people. It is noteworthy that approximately seventeen (of 37) participants explicitly expressed after the test that they experienced the illumination to attract attention - though in a negative manner. Concept $E$ also covered a tactile stimulus. Although intended to provide a brake-action affordance, this additional stimulus might have degraded performance. Since Baldwin \& May (Baldwin \& May, 2011) found that collision avoidance was best with levels of perceived urgency which are not too low, but also not too high, our combination of illumination and a tactile signal within concept E could have caused inefficient high levels of perceived urgency. Seven participants explicitly mentioned the tactile feedback to be inappropriate, while uncomfortable or causing startle. Further assessment below with respect to gained Situation Awareness and cognitive performance might help to understand the influence of inappropriate levels of urgency (if any).

\subsubsection{Support for intervention: Situation Awareness (SA)}

Within the Emergency-brake (EB) scenario 1b, Situation Awareness was indifferent between concepts for all three levels of SA (i.e. Perception, Understanding and Projection of future state) and showed about 85\% correct SA. A probable explanation for the indifferent scores is that the event (emergency brake of target-vehicle) occurred very suddenly with a minimum of cues perceivable within the road-traffic environment. Therefore SAGAT-measurement might had not enough discriminating power in this situation to unveil differences between concepts. Besides, this finding is comparable with earlier findings with the same scenario (but different concepts) in Chapter 5.

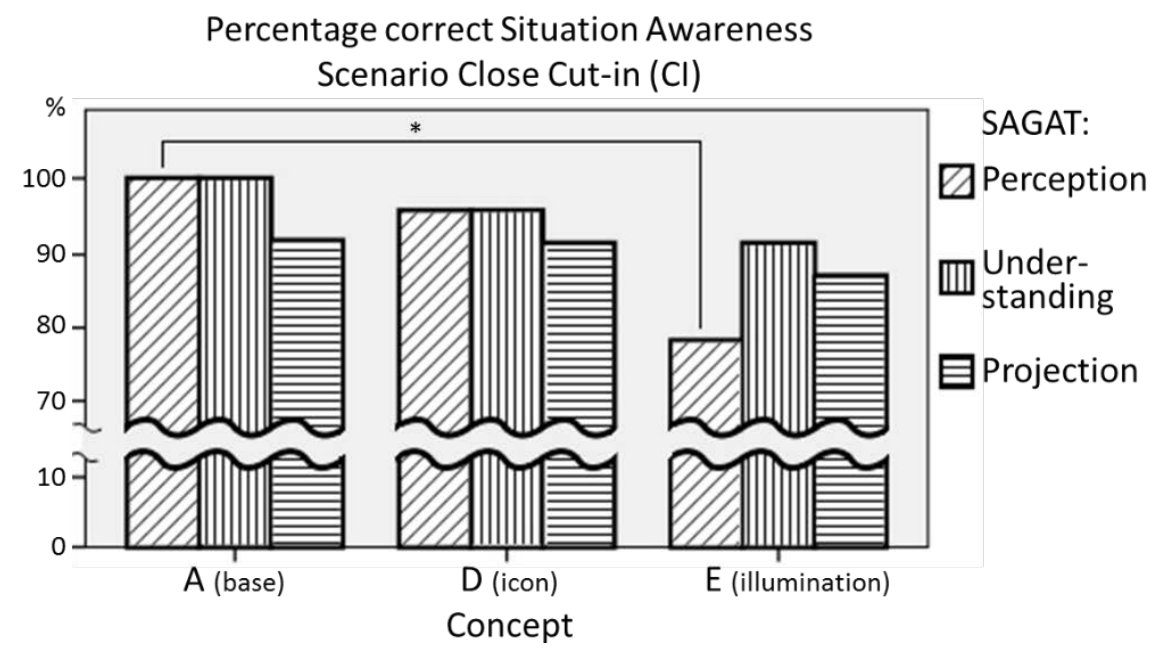

Figure 7-7 Percentages correct Situation Awareness (based on SAGAT) per SA-level and per Concept, within scenario $3 b$ Close Cut-in (CI).

Note. Statistically significant differences between scores $(p<0.05)$ are marked*.

In contrast to scenario $1 \mathrm{~b}(\mathrm{~EB}), \mathrm{SA}$-measurement within the cut-in scenario 3b ("Critical Cut$\left.i n^{\prime \prime}\right)$ (See Figure 7-7) shows a significant effect of Concept on SAGAT-perception: $\chi^{2}(2, N=72)=$ 7.53, $p=0.023$ (two-tailed), with concept A showing best perception and $E$ worst. The 
difference between $A$ and $E$ is significant: $\chi^{2}(1, N=48)=5.58, p=0.018$ (two-tailed). The difference between $D$ and $E$ shows a trend that $D$ is better than $E: \chi^{2}(1, N=48)=3.05, p=$ 0.080 (two-tailed). In scenario 3b ("Critical Cut-in"), SAGAT-understanding shows a comparable trend between concepts: with concept $A$ denoting best and concept $E$ worst understanding, however the differences are not significant. SAGAT-projection scored almost identical between concepts.

The SAGAT-scores in scenario $3 \mathrm{~b}(\mathrm{Cl})$ for the base concept $(\mathrm{A})$ are relatively high with $100 \%$ correct SA-perception and SA-Understanding. The significant lower SAGAT-Perception scores for concept $E$ combined with the high base-line scores of concept $A$, confirm that there is a negative trade-off from the additional stimuli (illumination and tactile) provided by concept $\mathrm{E}$. Maybe the additional stimuli have caused confusion and misunderstanding, resulting in lower Situation Awareness.

\subsubsection{Support for intervention: Cognitive performance}

With answering on a scale that ranges from low ("1") to high ("7") participants expressed their score (self-assessment) on each of following psychological aspects: arousal, demand and spare attention.

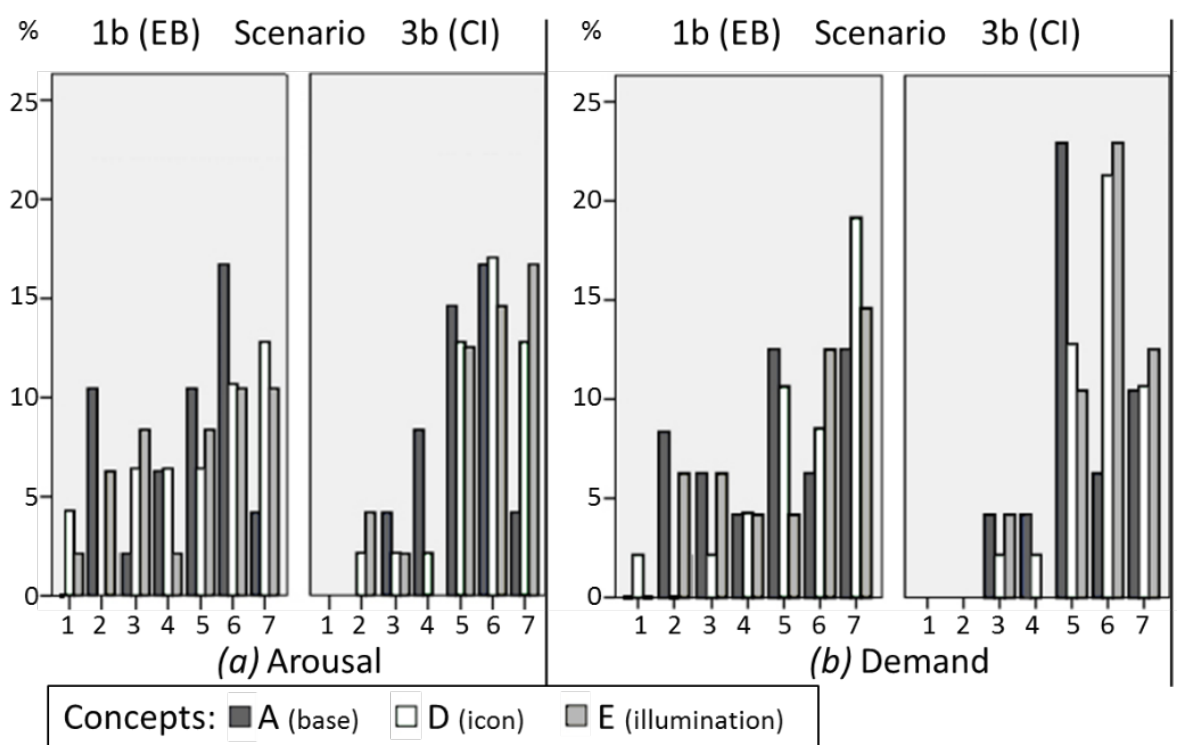

Figure 7-8 Percentages with subjective rating for (a) Arousal and (b) Demand
per concept and per scenario.

Note. " 1 " represents very low and "7"very high Arousal, respectively Demand

One-way ANOVAs revealed no significant effect of Concept on Arousal within scenario $1 b(E B)$, nor in scenario $3 \mathrm{~b}(\mathrm{Cl})$ (see Figure 7-8a). Nonetheless, some results are noteworthy. Concept $\mathrm{A}$ (Mean $=4.67, \mathrm{SD}=1.69$ ) shows ambivalent scores in the emergency-brake scenario $1 \mathrm{~b}(\mathrm{~EB})$, indicating that users perceive the base-line audible warnings either a rather high stimulus or a low stimulus. Users' perception of arousal was more coherently with concept D and indicated 
a rather high stimulus (Mean $=4.89, S D=1.93$ ). This is remarkable, because concept $D$ does in addition to A only add graphical feedback behind the steering wheel (which is in itself not a strong additional stimulus). Most spread (indifferent scores) showed concept E (Mean $=4.60$, $\mathrm{SD}=1.95$ ). Within scenario $3 \mathrm{~b}$ ("Close Cut-in") participants perceived themselves to be more alert with concept $E$ (Mean=5.63, SD=1.50) than with concept $A$ (Mean=5.06, SD=1.22). Therewith, Arousal in scenario $3 \mathrm{~b}(\mathrm{Cl})$ is more according to expectations and explainable by the provided stimuli. Differences between $A$ and $E$ are however not statistically significant ( $p$-value $=0.151$, two-tailed).

Demand-scores show a similar trend as observed for arousal (see Figure 7-8b). One-way ANOVAs did again not reveal a significant relation with Concept neither in scenario $1 \mathrm{~b}$ (EB), nor in scenario $3 \mathrm{~b}(\mathrm{Cl})$. The results show that users coherently indicate concept $\mathrm{D}$ to be quite demanding. The higher levels of demand for concept $D$ could be explained by the additional efforts needed in this concept to perceive the icon and read the associated text. However, within scenario $1 b(E B)$ the differences between highest (concept $D$ : mean $=5.50, S D=1.69$ ) and lowest scores (concept $A$ : mean $=4.79, S D=1.82$ ) are not statistically significant $(p=0.181$, two-tailed). In scenario 3b (CI) demand was again lowest for A (Mean=5.19, SD=1.29), but highest for $\mathrm{E}(\mathrm{Mean}=5.79, \mathrm{SD}=1.10)$. These differences reveal a trend difference $(p$-value $=$ 0.084 , two-tailed)

Although, scenario $1 \mathrm{~b}(\mathrm{~EB})$ was (based on its fast evolving critical event and associated number of accidents) most dangerous, demand in scenario $3 \mathrm{~b}(\mathrm{Cl})$ was perceived higher. These differences can be explained by findings from Chapter 5 assuming that drivers perceive dangerous but short situations less effort-taking compared to traffic situations which are less dangerous but more gradually evolving. This influence of gradually evolving stimuli on demand (or effort) could also be an explanation for the ambivalent scores with concept A: At the very moment a critical event happened, concept $A$ had other than an acoustical warning, no extra stimuli. The absence of a time-spread perceived stimulus neither provided by the concept, nor included in the traffic situation, probably explains why more people rated concept $A$ in that particular situation rather low on demandingness.

With regard to Spare-attention, differences between concepts are only observed in the cut-in (CI) scenario 3b. Then, participants perceived themselves to have most spare attention with $D$ (Mean=4.65, SD=1.42) and least with concept $E$ (Mean=3.96, SD=1.73). However, the differences are not significant ( $p$-value $=0.129$, two-tailed).

\subsubsection{Support for taking back control}

The necessity to retake control in scenario $2 \mathrm{~b}$ was influenced by system-design, i.e. the inability to drive automatically without a target-vehicle. Although participants had received explanation on the system's boundary conditions, this scenario was one of the most difficult to understand. Because there was no training on exploring system boundaries. Besides, it is always more 
difficult to deduct information based on something that is missing (i.e. a target-vehicle) compared to when elements are added in the traffic situation (e.g. a vehicle cutting in).

Table 7-2 Counts of successful performance to take back control

\begin{tabular}{|l|l|l|l|}
\hline \multicolumn{4}{|l|}{ Taking back control - scenario: Merge-out (2b) } \\
\hline Concepts & Successful & Failed & N \\
\hline A (base) & $9(39 \%)$ & 14 & 23 \\
D (icon) & $14(56 \%)$ & 11 & 25 \\
E (illumination) & $11(55 \%)$ & 9 & 20 \\
\hline total & $34(50 \%)$ & 34 & 68 \\
\hline
\end{tabular}

Regarding the understanding of the need to retrieve control: When using concept $A$ participants understood this in $39 \%$ of occasions, against $56 \%$ and $55 \%$ of occasions for respectively concepts $D$ and $E$. However these differences do not denote statistically significant differences and there was no effect of Concept on Taking back Control: $\chi^{2}(2, N=68)=1.62, p$ value $=0.44$. Although these results are in favour of concepts $D$ and $E$, review of Reaction Time (RT) provides a different picture. Then, concept A scores best, see Figure 7-9.

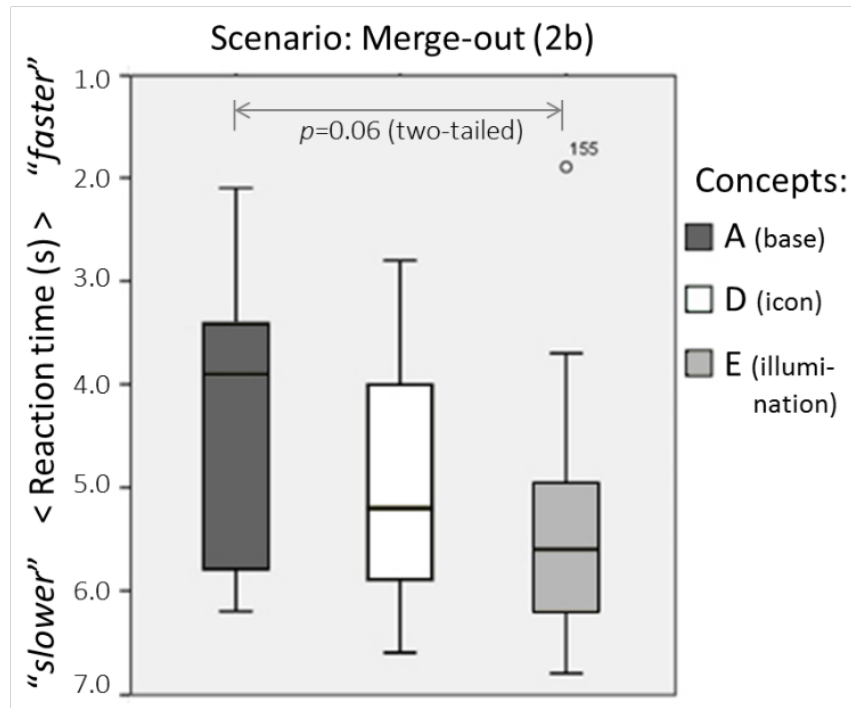

Figure 7-9 Boxplot Reaction time to retake control. Scenario: Merge-out target-vehicle (2b)

Reaction Time (RT) was calculated based on the differences in time between the moment a take-over-request was raised (both acoustically as visually) and the moment when the participant used the accelerator. This was done while after the ego-vehicle lost its target, longitudinal control (i.e. ACC) was terminated and using the accelerator was taken as indication for participants consciously noticing its termination and performed taking over of control. Again the effect of Concept on Reaction Time was not statistically significant: $F(2,31)=1.24$, $p$-value $=0.30$. However, reaction time was best (fastest) with concept $A$ (Mean=4.32; SD=1.43) and slowest with $E$ (mean=5.31; $S D=1.46)$. Concept $D$ scored mean=4.88 and $S D=1.33$. 
Interestingly, the concepts that related to most occasions with successful retrieving control (i.e. $\mathrm{D}$ and $\mathrm{E}$ ) denoted longer reaction times compared to $\mathrm{A}$. This can be explained by the additional information or cues which $D$ and $E$ provided, which needed time for interpretation and therefore denoted high RT. But this additional information could have helped more participants to understand (and subsequently decide) to take-over vehicle control. Results show a trend RT for $\mathrm{A}$ is better compared to $\mathrm{E}: p$-value $=0.059$ (two-tailed) (See Figure 7-9).

\subsubsection{Support for intervention: conclusion}

The observation that the icon-concept (D) scores best and the illumination-concept (E) worse in most occasions requiring support for intervention (i.e. accident avoidance) was against expectations and raised the concern that $\mathrm{E}$ might have been counter-productive. It was hypothesized that some characteristics of concept $E$ (i.e. attracting attention without a specific instruction) had made people more awaiting with regard to what happened and whether the system might intervene or take some sort of control by itself. This could explain why concept $E$ had higher (worse) Accident Avoidance Ranks than concept D even though concept D required reading of instructions (i.e. icon with text). In this respect the better performance (though without significant differences) for concept $D$ could be the result from concept $E$ being less supportive instead of $D$ being more supportive. Although this could have influenced concept scores, most likely the combination of stimuli provided with $E$ has negatively influenced performance, due to annoyance (Note: concept E did not only provide a visualacoustic stimulus but also a vibration at the front-end of the seat-pan at the moment intervention was required). This is a plausible explanation since mismatched perceived levels of urgency (too low, but certainly also too high) has shown in previous studies to influence performance negatively (Baldwin \& Lewis, 2014; Chapanis, 1994). Moreover, the combination of stimuli, including tactile feedback at the moment intervention was necessary, has probably caused a startle-response for some participants (Baldwin \& May, 2011). With respect to cognitive performance, the results seem to confirm that the additional stimuli provided by illumination and tactile feedback in concept $E$ do increase arousal and at the same time make the use-situation more demanding and reduce spare attention. With other words; the provided additional stimuli come across at the expenses of cognitive resources. Compared to the baseline concept $(A)$, concept $D$ provides a less strong additional stimulus than concept $E$, subsequently concept $D$ relates to a more moderate influence on arousal, demand and attention.

The illumination-concept (E) was composed to not include vibration during 'soft warnings' (i.e. for supervisory tasks). It could be that supervision and intervention benefit from different concept-compositions. Therefore this chapter continues to examine the defined concepts in additional scenarios, including those demanding supervisory task-performance. The results will be compared with above explained results for intervention and allow a more in-depth evaluation what concept types are beneficial for the driver's changing role, i.e. supervision with (occasionally) intervention. 


\subsection{Results on support for supervision}

\subsubsection{Hazard detection}

The detection task allows to compare only the additional visual stimuli provided by concepts D and $\mathrm{E}$. This is because in the situation where the detection task was being raised, only visual stimuli were being transgressed. The situation was the merge of two highway sections. At this occasion the sides of the windscreen lit op with concept $D$ and concept $E$ displayed a graph with side-warning, see Figure 7-10. Both concepts did not raise an acoustic alert in this situation, nor tactile feedback. Therefore comparison of detection in this situation allowed if any of the visual feedback alone (icon or illumination) intrinsically raised more attention.

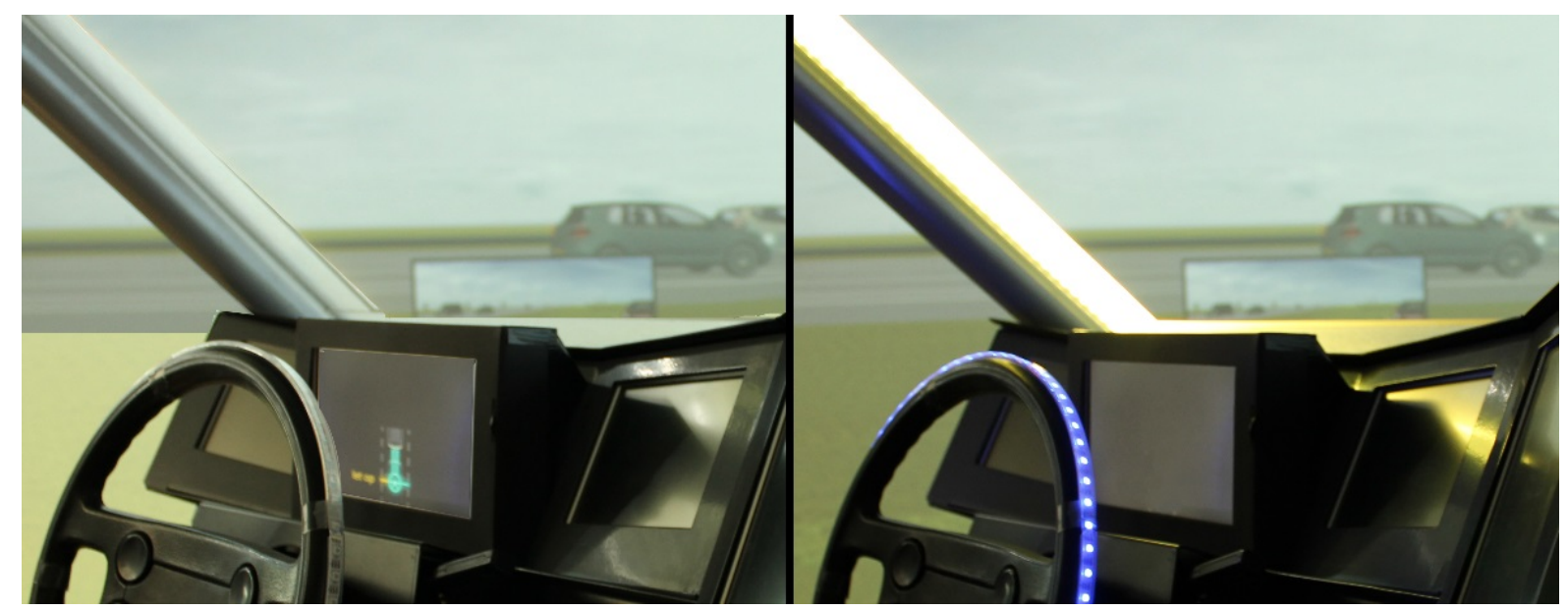

Figure 7-10 Pictures showing concept D (left) and concept $E$ (right) during the hazard alert for an approaching vehicle in a highway-merge situation. Concept $D$ depicts an icon behind the steering wheel, and concept $E$ uses illumination of the pillar aside the windscreen. Both alerts were only visual.

Table 7-3 shows that the statistically significant differences are in favour of illumination (concept $\mathrm{E}$ ): With the icon-feedback (concept $\mathrm{D}$ ) participants successfully detected the alert in $40.9 \%$ of occasions, and with illumination detection was significantly higher with $82.6 \%$ of occasions $\left(\chi^{2}(1, N=45)=8.32, p\right.$-value $=0.004$, two-tailed $)$.

Table 7-3 Number of successful hazard detection

\begin{tabular}{|l|l|l|l|}
\hline & \multicolumn{2}{|l|}{ Detection } & \\
\hline Concept & Successful & Failed & Total \\
\hline D (icon) & $9(41 \%)$ & 13 & 22 \\
E (illumination) & $19(83 \%)$ & 4 & 23 \\
\hline
\end{tabular}




\subsubsection{Support for supervision: Situation Awareness (SA)}

This section provides results of how situation aware participants were while being supported by a concept in each of the scenarios demanding a supervisory-role from the driver, i.e.: "1a: Complex Road"; "2a: Vehicle Passing" and "3a: Speed Oscillation".

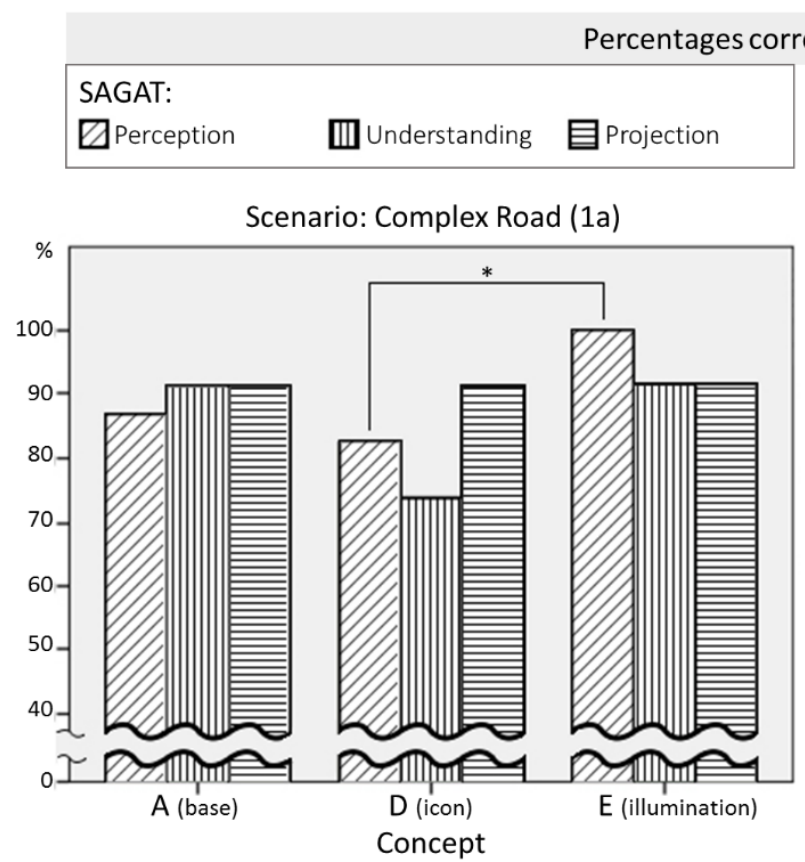

(a)

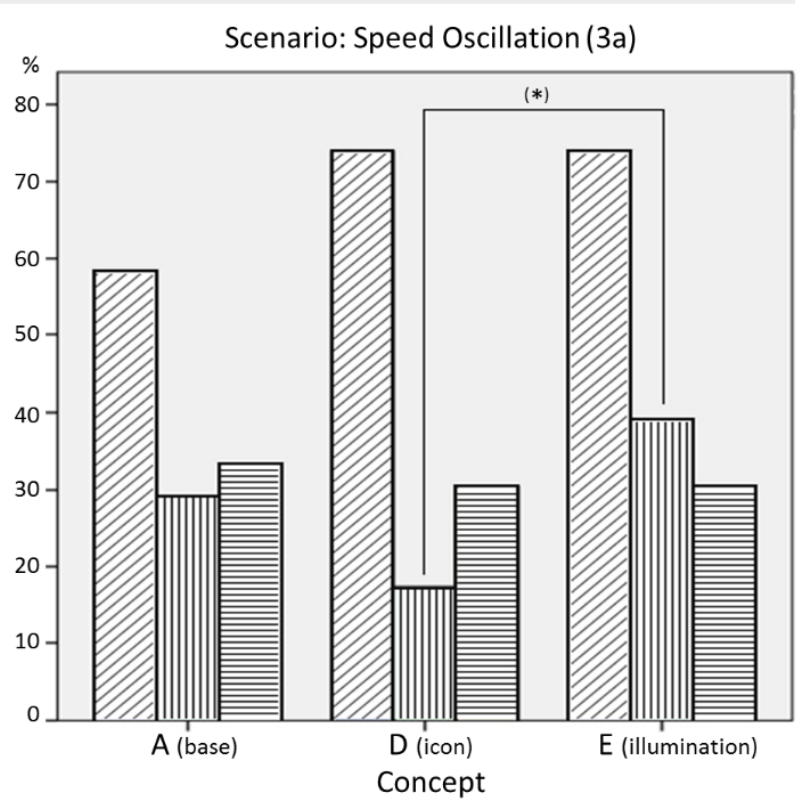

(b)

Figure 7-11 Percentages correct Situation Awareness (based on SAGAT) per SA-level (SAPerception, SA-Understanding and SA-Projection) and per concept. Note. Part (a) shows results within scenario Complex Road (1a) and part (b) within scenario Speed Oscillation (3a). Results marked with * denote statistically significant differences $(p<0.05)$. Differences indicating a trend $(0.05<p<0.10)$ are marked with $\left(^{*}\right)$.

Scenario 1a, approaching a combined on- and off-ramp. Within this scenario the attentionneed was induced by infrastructure, i.e.: an increasing road complexity with traffic from a combined on- and off-ramp dominated the situation. Kruskal-Wallis test showed no significant influence of Concept on SA-Perception $\left(\chi^{2}(2, N=72)=4.06, p\right.$-value $=0.132$, two-tailed), neither on SA-Understanding $\left(\chi^{2}(2, N=72)=3.67, p\right.$-value $=0.160$, two-tailed $)$. However, if we compare best and worst scores of concept pair-wise, it shows that SA-Perception is with concept $E$ significantly better than with $D: \chi^{2}(1, N=48)=4.36, p$-value $=0.038$ (two-tailed). SAGAT-perception was with concept $E$ also better than $A$, but without a statistically significant difference between the two: $\chi^{2}(1, N=48)=3.20, p$-value $=0.074$ (two-tailed). The results show that within this scenario requiring attention due to changes in road infrastructure, perception of elements important to gain Situation Awareness (SA), was best with the illuminationconcept (E) and worst with the icon-concept (D). Understanding of the elements important for Situation Awareness appears equally good with $A$ and $E$ and worse with concept D. See Figure 7-11a. However, no significant difference were found between concept $D$ and either concept A or E. It is likely that the visually dominated changes of road complexity seen in this scenario, 
comprise circumstances where the directional illumination (concept E) demonstrate its full potential.

Scenario $2 \mathrm{a}$, vehicle passing, offered a situation of a neighbouring vehicle at the right lane while overtaking and therewith created a potentially dangerous situation. The situation was designed to demonstrate a potential cut-in from the right. Hence, the attention-need was induced by the behaviour of other road users. The perception of a vehicle being in the blind spot was with all three concepts high: between $92 \%$ and $100 \%$. Between $90 \%$ and $100 \%$ of participants correctly understood the risk of a possible cut-in. However, only between $50 \%$ and $58 \%$ of participants also correctly anticipated future state that this could cause a necessity for taking-over. The scores between concepts were indifferent and therefore do not provide in this situation insight if one of the concepts provide more support for supervision than the other.

Scenario 3a, speed oscillation, comprised a difficult to understand situation. Complex system behaviour, i.e. traffic speed oscillating around a defined speed threshold, raised a soft warning to prepare drivers for potential take-over in case the system boundaries would be transgressed. The difficulty of this scenario is reflected on the relatively low scores for SAUnderstanding, see Figure 7-11b: It varies between $16 \%$ correct understanding with concept D and $39 \%$ correct understanding with concept $\mathrm{E}$. These difference reveal a trend that correct understanding in this scenario is higher with concept $E$ than concept $B: \chi^{2}(1, N=48)=2.64, p$ value $=0.052$ (one-tailed). Anticipation of the future-state (i.e. probability to take-over control) was low (about 30\% correct anticipation) and did not demonstrate differences between concepts.

\subsubsection{Support for supervision: Cognitive performance}

Cognitive performance was measured in the same scenarios reviewed in the previous section. The assessment comprised the following: Workload, Arousal, Spare Attention and Received Information - all based on self-assessment using questionnaires adapted from SART (Endsley et al., 1998). One-way ANOVAs showed that there were no significant effects of Concept on any of the cognitive aspects within the scenarios. Nonetheless, some results are noteworthy.

In scenario 1a ("Complex Road"), only a mediocre influence of Concept on Received Information was found: $F(2,69)=1.38, p$-value $=0.26$. Results with regard to Received Information denote largest differences between Concept $A$ (Mean=4.75, SD=1.39) and Concept $\mathrm{E}$ (Mean=5.40, $\mathrm{SD}=1.28$ ), indicating a trend on participants' perception to receive more information in scenario $1 \mathrm{a}$ with concept $\mathrm{E}$ than with $\mathrm{A}$ : $p$-value $=0.051$ (one-tailed) Scenario 2 a did not denote any notable differences.

Within scenario 3a ("Speed oscillation") we observe some differences between received information and arousal. Participants perceived to receive more information with concept $D$ (Mean=5.06, SD=1.43) compared to $A$ (Mean=4.40, SD=1.70) or $E(M e a n=4.42, S D=1.18)$. 
Probably this is due to concept B being most specific within this scenario. However, Perceived Information does not show significant differences between the concepts: Between A and D pvalue $=0.12$ and between $E$ and $D p$-value $=0.13$. Furthermore, in this scenario participants perceived themselves less alert with concept $A$ (Mean=4.23, SD=1.56) than with $D$ (Mean=5.06, $S D=1.55$ ) or $E$ (Mean=4.75, SD=1.73). The situation was difficult to understand without interface support. Presumably, most participants perceived it as "not much going on" (as some participants also stated) and maybe this has caused ignorance.

\subsection{Concept acceptance}

\subsubsection{Perceived usefulness and satisfaction}

Table 7-4 Mean scores for Perceived Usefulness and Satisfaction (VanderLaan)

\begin{tabular}{|l|l|l|l|l|l|l|}
\hline \multicolumn{4}{|l|}{ Concept-scores for concept acceptance } \\
\hline \multirow{4}{*}{ Concepts } & Perceived Usefulness (VanderLaan) & \multicolumn{4}{l|}{ Satisfaction (VanderLaan) } \\
\cline { 2 - 7 } & $\mathrm{N}$ & Mean & Std. Dev. & N & Mean & Std. Dev. \\
\hline A (base) & 36 & 5.70 & 1.14 & 36 & 4.84 & 1.24 \\
D (icon) & 36 & 5.77 & 1.23 & 36 & 4.96 & 1.32 \\
E (illumination) & 37 & 5.92 & 1.05 & 37 & 4.99 & 1.32 \\
\hline Total & 109 & 5.79 & 1.14 & 109 & 4.93 & 1.28 \\
\hline
\end{tabular}

Note. Scores range from 1=absolutely not useful, not satisfying; to $7=e x t r e m e l y ~ u s e f u l$, satisfying

Table 7-5 Relative concept-scores, compared to baseline-concept (A)

\begin{tabular}{|l|l|l|l|l|l|l|l|}
\hline \multirow{2}{*}{ Concepts } & \multirow{2}{*}{$\mathrm{N}$} & \multicolumn{3}{|l|}{ Perceived Usefulness (VanderLaan) } & \multicolumn{2}{l|}{ Satisfaction (VanderLaan) } \\
\cline { 3 - 8 } & Mean & Std. Dev. & $\begin{array}{l}p \text {-value } \\
\text { cf. A }\end{array}$ & Mean & Std. Dev. & $\begin{array}{l}p \text {-value } \\
\text { cf. A }\end{array}$ \\
\hline D (icon) & 35 & 0.059 & 1.447 & $p=0.81$ & 0.093 & 1.301 & $p=0.68$ \\
E (illumination) & 36 & 0.194 & 0.994 & $p=0.25$ & 0.097 & 1.458 & $p=0.69$ \\
\hline
\end{tabular}

Note. Scores are within-subject comparisons with scores for Perceived Usefulness and Satisfaction for concept $\mathrm{D}$, and concept $\mathrm{E}$, compared to concept $\mathrm{A}$. For example, the mean Perceived Usefulness score for $D(0.059)$ is the average difference of all participants between scores for concepts $D$ and $A$ on Perceived Usefulness.

Table 7-4 shows the mean scores of subjective rating for Perceived Usefulness and Satisfaction (Van der Laan et al., 1997) based on scores ranging ${ }^{14}$ from: 1=absolutely not useful, not satisfying, to; 7=extremely useful, satisfying. Based on one-way ANOVAs, no significant effect was found of Concept on Perceived Usefulness $(F(2,106)=0.37, p=0.69)$ and neither on Satisfaction $(F(2,106)=0.13, p=0.88)$. Of course, baseline subjective ratings differ per person. Therefore a within subject comparison of differences in ratings is provided in Table 7-5. The

\footnotetext{
${ }^{14}$ Due to reasons explained in section 7.2.5 the original 5-points scale was adapted to a 7-points scale.
} 
table compares scores for concept $D$ and $E$ to concept $A$ - which scores were, as a base-line concept, set to zero. In other words: Scores for D and E in Table 7-5 are taken within subject relative to concept $A$. Then, the largest difference between $A$ (base) and $C$ (illumination) show results in favour of $E$ with respect to perceived usefulness: $t(35)=1.174, p=0.249$ (two-tailed). However, again the results do not denote significant effects of Concept ( $D$ or $E$ ) on Perceived Usefulness, neither on Satisfaction.

Table 7-6 shows participants' subjective concept rating. This ratings was expressed with (a) participants' selection of their preferred concept, and (b) the participants were asked to divide 15 points over the three concepts. The results show that a majority (56\% of respondents) preferred Concept $C$ and concept $A$ was most rejected (by $70 \%$ of respondents). The low scores of concept $A$ are according to expectations as it was selected to only provide audible signals, i.e. least support. With regard to the assigned points, see (b) in Table 7-6, the differences between $A$ and $E$ are (very) significant: $t(70)=3.068, p<0.025$. Differences between $A$ and $D$ are significant: $t(70)=2.455, p<0.025$. Differences between $D$ and $E$ are not statistically significant $(p=0.610)$. Basically, the subjective ratings shows scores in favour of concept $\mathrm{E}$ but the differences with $D$ are small. Based on participants' subjective opinion concept $D$ and $E$ are both accepted and concept $A$ is rejected.

Table 7-6 Participants' subjective concept rating

\begin{tabular}{|l|l|l|l|l|l|}
\hline \multirow{2}{*}{ Concepts } & \multicolumn{3}{|c|}{\begin{tabular}{l}
\multicolumn{3}{c|}{ (b) } \\
Preference: Numbers of \\
\end{tabular}} & $\begin{array}{l}\text { Points (SUM of } 15 \text { available) assigned to } \\
\text { participants' selected concept as }\end{array}$ & $\begin{array}{l}\text { lancepts } \\
\text { conced }\end{array}$ \\
\cline { 2 - 6 } & "preferred" & "poorest" & Mean & Std. Dev. & $\%$ of 15 points \\
\hline A (base) & $6(18 \%)$ & $24(70 \%)$ & $3.47^{*, \#}$ & 3.79 & $23 \%$ \\
D (icon) & $9(26 \%)$ & $7(21 \%)$ & $5.56^{\#}$ & 3.46 & $37 \%$ \\
E (illumination) & $19(56 \%)$ & $3(9 \%)$ & $5.97^{*}$ & 3.09 & $40 \%$ \\
\hline
\end{tabular}

Note. Participants' subjective concept rating expressed with (a) concept-preference and (b) assigned points, i.e.: Participants were asked to divide a total of 15 points over the three concepts.

Statistically significant differences are typed in italic font. ${ }^{*}$ indicates significant difference between concept $\mathrm{A}$ and $\mathrm{E}$. " indicates significant difference between concept A and D.

\subsubsection{Participants' perception of concepts}

At the end of the test each participant was conducted to an open interview. During this interview the experimenter first asked what different stimuli they could recite. This was to activate participant's memory of the concepts he/she encountered during the trials. Then the experimenter summarized shortly in what order the participant had experienced which concept and asked for their spontaneous opinions, e.g. likes and dislikes, irritations and surprises or any other opinions about the concepts. The interview was closed with asking: (a) participant's preference, and (b); to divide 15 points over the three concepts - as explained in the previous section. This section presents an overview with the participants' spontaneous opinions expressed during the interviews. 
Table 7-7 summarizes the main findings from the interviews. Concept $E$ evoked the most ambivalent opinions. On the one hand a vast majority (28 participants) considered concept $E$ to be attracting attention (considered a positive asset) and at the same time 21 participants explicitly mentioned that they perceived some aspects how concept $\mathrm{E}$ attracts attention unpleasant. Moreover, in five occasions (when experiencing concept E's hard warning) participants reported during the experiment that they had a fright. We observed different aspects causing participants' negative opinion: 6 participants mentioned explicitly that they found the vibrotactile stimulus in the seat-pan to be irritating. 7 persons found the illumination - especially the red illumination - annoying. Two people perceived the illumination to be unnecessary and only providing a distraction. Furthermore, 3 participants rejected concept $E$ due to lack of explanation why an alert was raised. Seventeen participants found concept $E$ to be both attention attracting and annoying at the same time. Most people recognized that the stimuli differed between soft and hard-warnings and that their rejection how attention was attracted especially considered the hard warnings. This could explain why concept E was preferred and at the same time conceived to attract attention in a negative manner. Although the vibrotactile stimulus of concept $E$ mostly received rejection, 3 participants explicitly mentioned the haptic feedback to be positive. They made remarks like: "It makes you alert right away". "Building up trust" (in automation - induced by concept E's feedback) was also mentioned three times.

Table 7-7 Number of some specific opinions on concepts A, D and E.

\begin{tabular}{|l|c|c|c|l|}
\hline Opinion & A & D & E & Example \\
\hline $\begin{array}{l}\text { Concept attracts attention in a positive } \\
\text { manner }\end{array}$ & 11 & 2 & 28 & $\begin{array}{l}\text { "Signals explains what needs } \\
\text { attention." }\end{array}$ \\
$\begin{array}{l}\text { Concept attracts attention in a } \\
\text { negative manner } \\
\text { Concept is informative }\end{array}$ & 1 & 3 & 21 & "Signals are too harsh." \\
Concept is not informative & - & 15 & 6 & $\begin{array}{l}\text { "Signals confirm correct system } \\
\text { function." } \\
\text { "Information was difficult to }\end{array}$ \\
\hline
\end{tabular}

Note. Measurements are based on spontaneous answers during an open interview at the end of each experiment. $(n=37)$

The illumination around the steering wheel received ambivalent reactions as well. 5 people generally appreciated the illumination and 9 people rejected it. Some people recognized the steering wheel illumination as confirmation of system activity, 1 person perceived the wheel illumination more quietly than windshield-illumination. However, 2 persons perceived it an unpleasant feature or a distraction. According to 2 people it does not offer added value and 1 person mentioned that it brings you in a position to look away from the road. When reviewing these results, we need to keep in mind the limitation that participants did not operate the automation themselves. With all trials participants drove directly automatically which was also 
explained beforehand. There was no need to activate or deactivate the automation during the trials. Therefore the need to check system activity during the trials was relatively low and possible added value to verify with the steering wheel illumination whether the system is active, could not be experienced.

For being informative, especially concept $D$ was favoured (15 times). The dominating reason was that concept $D$ provided explanation on cause for system-status and -change. Despite the reduced need to check system activity, 6 participants explicitly mentioned that concept D allowed anytime a short check on system status. Some people also valued that the concept provided an explicit instruction to the driver, like "Take over now" or "Attention complex road". Only 2 participants mentioned their appreciation for the way $D$ attracted attention, explaining that it was the location they were familiar with. In contrast, 17 participants rejected the way concept $D$ attracted attention or considered the information not informative. The main reasons were: Necessity to look away from road (2); Information was unclear (1); Information was not being noticed (6) or obstructed by steering wheel (13 times). Here, it needs to be mentioned that the instrument cluster behind the steering wheel only depicted information on automation status. With a more commonly applied set of information, the demand to review information in the cluster would be higher and this might raise appreciation about concept D's location at the same place of other instruments.

Eleven people were positive about the attention attracting feature of concept $A$. This confirms that sound is an important base feature to attract attention. The remarks of some participants seem to reflect that they found the additional features of $D$ or $E$ not productive and they had the opinion that a sound alert would be enough. Even more, some people expressed that the additional features would only be a distraction and for that reason favoured the baseline concept (A). Others (5) were critical against A: "The sound causes a fright" (1), and "The sound does not explain why an alert is raised" (2) were mentioned.

Independent of the concepts, seventeen people mentioned explicitly that they considered usage of a tablet to be too distracting and dangerous. (During our test participants were asked to browse the internet and select sound tracks from a stored data-base.) People remarked that they only performed this secondary task because they were asked to do so. Observation of the task showed that it was not performed in an effective way: Most people browsed a bit on newssites, without actually reading.

Five participants were afraid that the illumination provided with concept E would cause glare for themselves or other road users. Influences of weather and light conditions on the 'readability' of concept E's illumination signals are an important topic for further research. One participant named the yellow illumination field with the wrong colour, i.e. "green". This person denied to have dichromatism. An explanation could be that the yellow illumination against the blue coloured sky in the simulator made the illumination appear green. Of course, it is 
important that the level of urgency conveyed with the illumination-signals is not being influenced by light conditions.

\subsection{Discussion}

We tested three concepts: Concept A which provided only acoustic warning and served as baseline; Concept $D$ which required interpretation of graphical information on system status, displayed as icons behind the steering wheel; and Concept E which combined an acoustictactile stimulus with 'directional' illumination. See section 7.1.4 for a detailed description of the concepts. The aim of the test was to explore what interface-aspects provide on the one hand support for supervision and on the other hand support for intervention. The concepts provided stimuli which are differentiated between soft and hard warnings. The soft-warnings demanded attention for potential hazardous situations. The hard-warnings required intervention to take over control. Concept E was designed with a large difference between both warning types: Its hard-warning offered not only colour coding (consisting of red illumination of complete lower windscreen-band), but also included an additional tactile stimulus (vibration of the front seat pan). During concept creation important considerations were to inform drivers about system-status and to support them in returning back in the control-loop, in order to reduce automation-induced OOTL-performance problems - as explained in the introduction.

\subsubsection{Performance expectations and main results}

The expectation was that especially the acoustic-tactile concept with 'directional' illumination (concept E) would provide best support for drivers in their changed role. This expectation was based on the concept's ability to attract and direct attention towards the locus outside the vehicle that needs attention. It was also hypothesized that concept $\mathrm{E}$ - in contrast to D - would urge the driver to notice why attention was needed within the traffic scenery itself. Therewith, E was expected to induce stronger driver-involvement and made him/her take part in the control-loop, whereas concept $D$ was expected to require reasoning-time until the driver had understood where attention is needed. Therefore, faster reaction times were expected with concept E compared to D. Main findings are summarized in Figure 7-9. In short, during two (out of three) scenarios which require supervisory support, the illumination-concept (E) showed significant or close to significant better Situational Awareness (SA) than the iconconcept (D). Moreover, with the illumination-concept (E) the detection-task was performed significantly better than with the icon-concept (D). Against expectations however, neither the illumination-concept (E) nor the icon-concept (D) demonstrated support for intervention. Presumably, support for supervision and intervention benefits from different interfacefeatures.

We will now discuss what these results mean for recommending interface-features to provide the desired support for both supervision and intervention 


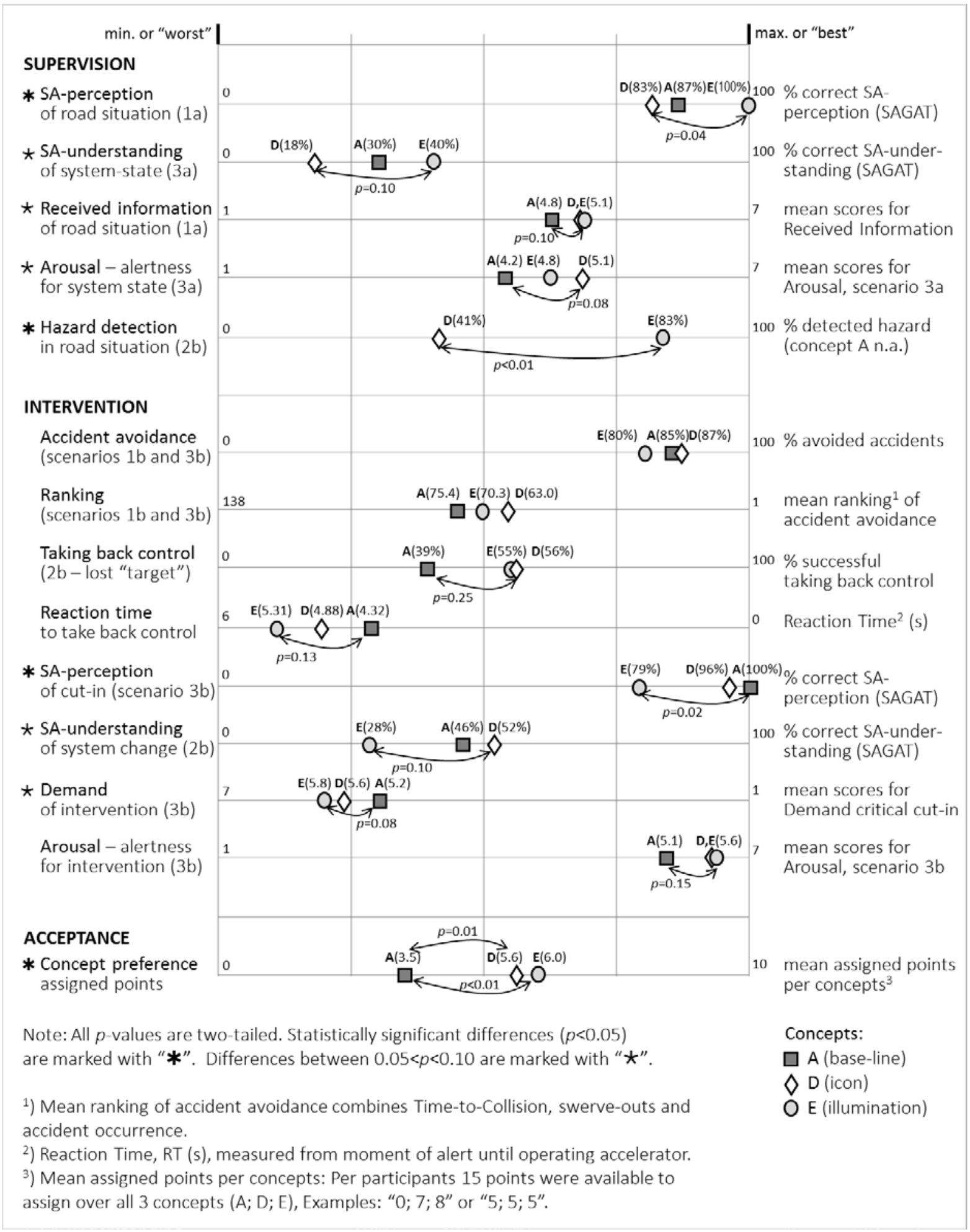

Figure 7-9 Overview with concepts' main results of their support offered for supervision and intervention, including results for acceptance.

The results indicate that the illumination-concept (E) offers support for supervision, but compared to the baseline (A) neither the icon-concept (D), nor the illumination-concept (E) offers substantial support for intervention. 


\subsubsection{Driver-interface support for supervision}

The results suggest that guiding attention outside the vehicle with the illumination-concept (E) helped drivers more to gain SA than displaying information in the vehicle with the icon-concept (D). The latter required interpretation what outside traffic-aspects the displayed information should be connected with. The presumption is that icons used for feedback on system-state leave the driver to remain a rather passive 'observer', whereas the directional illumination provides a stronger cue to return in the control-loop. We also expected that the required interpretation why an alert was raised with the illumination-concept (E) would be a disadvantage. The icon-feedback on the other hand, required interpretation where traffic situations outside the vehicle needed attention, but was expected to convey more easily complex matters (for instance: changes in system-state induced by system-design). Nonetheless, within the speed oscillation scenario (" $3 a$ ": a scenario in which an alert was raised because of potentially changing system-state due to system's speed-threshold) the iconconcept (D) did not demonstrate raised performance. Maybe this is due to the icon-feedback not being observed behind the steering wheel, or due to misunderstanding of the provided icon-feedback. It could also be that support where attention is needed, compensates for reduced support explaining why attention is needed. These speculations leave unimpeded, that the illumination-concept (E) showed in the scenarios requesting supervision, superior levels of SA. Moreover, the illumination-concept (E) showed to be also superior with respect to the detection-task. Indeed, several studies confirm that driver's performance improves (e.g. better reaction times and accuracy) if attention is guided towards relevant locations, because operator's control improves by the information and direction of danger provided (F. C. H. Lee \& Chan, 2007; Liu \& Jhuang, 2012). Furthermore, the illumination-concept (E) received higher acceptance than the icon-concept (D). Overall, the results within this study showed a favourable relation between the illumination-concept (E) and support for supervision.

\subsubsection{Driver-interface support for intervention}

Despite the promising results of the illumination-concept (E) for supervisory support, neither the illumination-concept (E), nor the icon-concept (D) revealed to be of distinctive support for intervention. On the contrary - though without statistically significance -, the illuminationconcept (E) showed intervention-performance poorer than the baseline concept. Therefore the assumption was that the illumination-concept (E) had some counter-productive effects. Cause for counter-productive effects on intervention-support could be inappropriate levels of urgency, while too high levels of perceived urgency cause annoyance (Chapanis, 1994; Marshall et al., 2007) and have a counter-productive influence on task-performance (Baldwin \& May, 2011). Remarks made by participants actually confirm annoyance of concept $E$, like: "E attracts attention - to the point of being irritating". Using different terms, seventeen out of thirty-seven participants made remarks with the same tenor. In addition to the consideration that the combination of three stimuli with concept E's hard-warning could have caused 
irritation, we discuss below whether a specific compilation of stimuli might have caused annoyance.

\section{Possible influence of modality on annoyance}

While the differences in offered stimuli between hard- and soft-warnings were largest with the illumination-concept (E) due to the additional tactile feedback (during hard-warnings) and because the hard-warnings of concept $\mathrm{E}$ are associated with annoyance, one might consider that specifically the tactile feedback caused annoyance. However, an earlier study (Van den Beukel \& Van der Voort, 2016) showed that people conceived the situation with illumination to be more hazardous than without illumination in identical scenarios. These differences were based on visual aspects alone (i.e. without any tactile feedback) and the illumination areas were identical to concept $E$ in our current study (i.e. colour, position and size of the illumination). Nonetheless, the differences were not statistically significant. With respect to possible modality-induced raised levels of annoyance, Baldwin and Lewis (2014) suggest that especially auditory signals cause deteriorating effects. However, based on Marshall et al. (2007), our particular characteristics of the audible signal are considered mediocre on both urgency and annoyance. Moreover, the sound-alert of concept E's hard-warning was identical to the one used in baseline concept $(A)$, where it did not cause annoyance. These results suggest that within our study the sound-alert in itself did not cause negative side-effects. Although both existing research and our study do not provide strong suggestions for a causal relationship of any of these features individually, the appearance of annoyance in combination with the additional stimuli offered in concept $E$ makes us conspicuous of some deteriorating influence of either illumination or tactile feedback.

\section{Possible performance deficits due to combination of modalities}

Besides presumable deteriorating influence of either illumination or tactile feedback, it could also be that the combination of different modalities (i.e. acoustic, visual and haptic within concept E) caused an interrelated conflict. Ferris, Penfold, Hameed, and Sarter (2006) revealed that invalid cross-modal cues (e.g. a driver perceives an auditory cue to come from a different location than a visual cue although both are meant to indicate the same target) lead to longer response times and reduce response accuracy. In our research the visual stimulus holds a strong spatial cue, but the tactile cue (vibration in the front end of the seat pan) was loosely linked with the direction of danger. It did not differentiate between front-left and front-right. The acoustic warning did not provide spatial cues either. According to Ferris et al. (2006) weak cross-modal links could already negatively influence performance. Therefore, weak crossmodal links of concept $E$ could be an explanation for reduced reaction times. However, the illumination-feature of the concept holds a strong spatial link and one might argue that this would have compensated the weak cross-modal links. Furthermore, the icon-concept (D) provides even weaker cross-modal and spatial links, but is not associated with longer reaction times than the illumination-concept $(E)$. Overall, findings from previous research on the influence from cross-modal links do not provide evidence for a specific combination of modalities within our concepts that has caused reduced intervention-performance. 
Nonetheless, stronger cross-modal links are important to consider for further development of desirable interface-support.

\section{Possible performance deficits due to unexpectedness of stimulus}

Ferris et al. (2006) discovered that response times increase due to cues in an unexpected modality. Therefore, the unexpectedness of our tactile cue within a dominantly visual task could be an explanation for the low scores on intervention-support with concept $\mathrm{E}$. An extreme manifestation when a stimulus appears unexpectedly is when it causes a startle response. Measurement of startle was not foreseen within our assessment framework. However, 8 (out of 37) participants reported during the experiment that they had a fright. In five occasions this was due to the stimuli from a hard warning raised by concept $E$ (cf. 2 times with concept $D$ and 1 occasion with concept A). With regard to the effect of warning stimulus modality on startle, some studies suggest that startle will inhibit if the stimuli are presented in different modalities than the modality that requires attention within a specific task (Cristy Ho, Reed, \& Spence, 2007). However, other studies found that selective attention allocated to a foreground stimulus facilitates startle regardless of stimulus modality (Lipp, Siddle, \& Dall, 2000). This effect of selective attention on startle may not be found, if task demands are small. According to these studies, stimulus change - regardless of stimulus modality - enhances startle. Based on these findings, we suggest that the unexpectedness of the stimulus (in our case concept E's haptic cue) may have caused startle-responses, not necessarily the specific type of stimulus.

\subsubsection{Limitations and long-term implications}

Partially automated driving shifts the driver into a complicated role of full responsibility for driving safely without being in permanent control. The aim of this research was to propose interface-solutions, which support drivers with their changing role to supervise the automation and to intervene if required. The results show that visual illumination of relevant traffic events is especially beneficial for support of supervision. Unfortunately, the results do not allow specific recommendations on interface-aspects beneficial for intervention. During our test, the majority of participants expressed on the one hand to be positive towards the raised level of comfort induced by automation ("I like to listen to the music and relax") and at the same time rejected engagement in distracting tasks like Web browsing. On the one hand this is a positive outcome: the drivers showed to be serious about their supervisory task and are at the same time prepared to take advantage from automated driving and accept more homogenous driving (i.e. driving in follow-mode). On the other hand, this outcome is limited by testbehaviour and potential long-term implications. First of all, the participants used the system for ca. 45 minutes. During this time they encountered 12 trails and experienced 6 times a situation which required intervention. Therefore the test placed participants in situations where much more attention from the driver was needed than would be in real-life circumstances. Moreover, the participants took part voluntarily out of general interest or because they considered the topic important to society. Therefore the respondents could be characterized by their consciousness of responsibility. It is unlikely that this attitude is 
representative for the characteristics of future generations of 'drivers' who are increasingly using automation and attention-seeking devices like smartphones. Further research is needed on long-term implications, such as habituation, behavioural adaptation and skill degradation.

\section{Habituation}

Habituation to a stimulus might eventually lead to a terminated response. Especially soft warnings are in danger to be conceived as false alarms. Then, their perceived irrelevance is likely to elicit habituation. It goes without saying that ignorance of the provided signals could be dangerous, but could also cause indirect side effects like the adoption of inappropriate levels of trust and subsequent behavioural adaptation. Nonetheless, when anticipating habituation it might also be necessary that important hard-warnings are introduced with a high urgency-level (for example our acoustic-tactile interface with illumination). Otherwise, habituation might weaken these signals over time to levels perceived as non-urgent. However, long-term investigations of these considerations are necessary to achieve more insight in this matter.

\section{Behavioural adaptation}

Our concepts provide continuous feedback on system-state and system changes. Drivers could easily perceive this information as confirmation of automation-activity and therewith degrade their barrier to perform secondary tasks and subsequently reduce their responsibility in supervision. Therefore, it is very important to bring across an appropriate level of trust in automation (J. D. Lee \& See, 2004). Conveying information on system state is a strong advantage of the icon-concept (D), which displays the ego-vehicle and its surrounding situational features in a picture behind the steering wheel. Nonetheless, such advantages were not demonstrated during our short time-span tests. Further research is needed of how behavioural adaptation in the long-term is influenced by the particular features of the illumination-concept (E) as well as the icon-concept (D). Other important aspects that might influence behavioural adaptation are driver's attitude towards technology, willingness to take risks and driving experience.

\section{Driving experience and training}

Although the illumination-concept (E) helps to raise SA and showed superior performance in task-detection, none of the concepts improved intervention-support and the raised levels of SA are rather small. In other words, the offered support only has a small share in improving the renewed driving task, i.e. supervision with now and then intervention. Considering that usability is not an intrinsic product characteristic, but resulting from the combination of circumstances, product-interface and user-experience, it is advisable to review potential benefits of additional training to operate systems for automated driving. The potential benefits to offer intrinsic training, i.e. while using the concepts, are important areas for further research. Based on previous research, we expect that the mechanisms to raise performance from knowledge-based level to skill-based levels might offer valuable insights to comprise intrinsic training (Van den Beukel \& Van der Voort, 2012). 


\subsection{Concluding remarks}

This research tested three interface-concepts intended to support drivers with their changing role when driving partially automated (i.e. supervision with now-and-then intervention). Concept A provided only acoustic warnings and served as a baseline. Concept D presented status-information and take-over requests in a conventional manner: It displayed icons behind the steering wheel. Concept E was more advanced, using illumination in the windscreen and haptic feedback in the seat-pan to direct attention towards the locus of a potential hazard and to create an affordance for intervention when required. Concept E only combined illumination with vibrotactile feedback when intervention was needed. The illumination-concept (E) showed superior support for supervision: It showed significant better hazard-detection then the icon-concept (D) and hazard-detection is an important aspect for supervisory control. Moreover, measurement of Situation Awareness (another important aspect for supervisory control) denoted significant differences in favour of the illumination-concept (E) within two scenarios requiring supervision. Knowing that supervision will be the dominating driver's responsibility when utilizing partially automated driving, we conclude that the illuminationconcept $(E)$ is a recommendable solution for support of the driver's changing role. Furthermore, it was considered that the illumination helps drivers to return more easily in the control-loop and to switch attention more easily between in-vehicle tasks and traffic-related circumstances. Nonetheless, neither the illumination-concept (E), nor the icon-concept (D) showed support for intervention. During intervention the illumination-concept (E) scored comparable or worse than the baseline-concept (A). Although these differences were not statistically significant, the scores are remarkable and against expectations. It was hypothesized that the combination of concept E's intervention-warning, especially the unexpectedness of the vibro-tactile stimulus in addition to the acoustic and visual stimuli, caused counter-productive levels of annoyance and sometimes startle. With regard to overall support for the changing driver's role (including supervision and intervention) participants' subjective preferences are nonetheless in favour of the illumination-concept (E). This seems to confirm participants' recognition of the features that are intended to raise support. Furthermore, it is concluded that intervention and supervision benefit from different interfacefeatures. Adding to this conclusion, we discussed possibly underlying causes for the ambiguity shown with concept E. For instance, how modality and the applied combination of stimuli might have affected annoyance or startle. The considerations provided in this chapter contribute to further development of - and knowledge about -, appropriate driver-vehicle interaction while vehicle-operation advances into operating partially automated driving systems, requiring supervisory-control and interventions. 

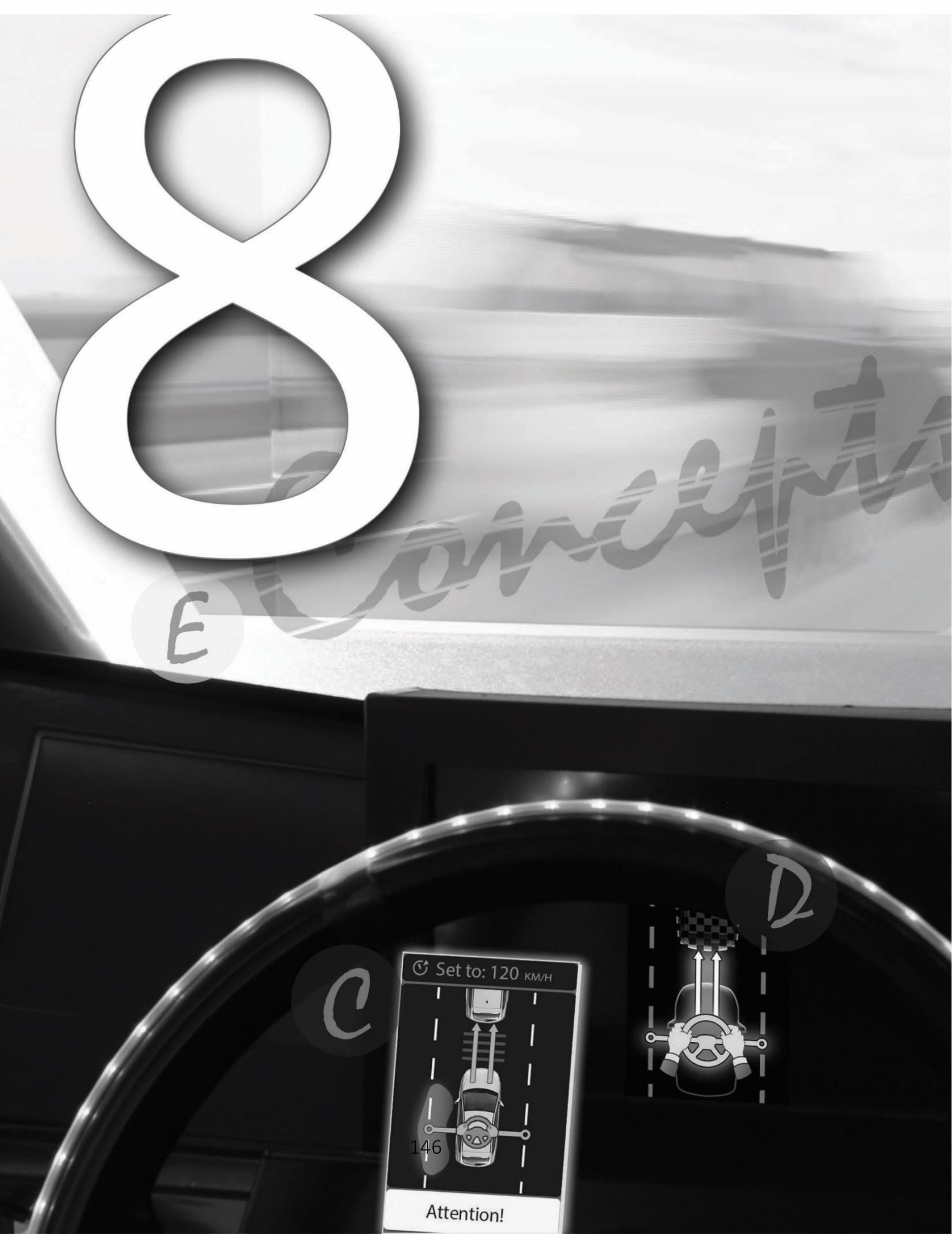


\section{Chapter 8. Comparison of interface-types}

This chapter is based on the following publication:

Van den Beukel, A.P. (2016). Comparing driver's support for supervision and intervention during partially automated driving. In: Proceedings of the Fifth European Conference on Human Centred Design for Intelligent Transport Systems. HUMANIST, Loughborough, UK. June $30^{\text {th }}+$ July $1^{\text {st }}, 2016$.

\subsection{Introduction}

With two driving simulator studies and an internet-survey, five different interface-concepts have been developed and evaluated. The concepts were tested within identical scenarios representative for partially automated driving. Therefore the test-data from the two driving simulator experiments allow comparison and this chapter compares findings from both studies. The aim is to collect recommendations for further directions for the development of appropriate support.

To attain this objective, section 8.2 will first explain the applied method to assess and compare concepts' test-results from both studies. Then, section 8.3 explains the concepts, before section 8.4 presents the results of collected data to compare the concepts. Finally, section 8.5 concludes with recommendations for further development.

\subsection{Method}

This chapter compares performance to support drivers in supervision and intervention. This support is offered by five interface-concepts and is tested in two previous driving simulator studies, covered in Chapter 5 and 7. It also compares participants' acceptance of the concepts.

\subsubsection{Scenarios}

The set with six scenarios consisted of three so called hazardous scenarios and three critical scenarios. As explained in Chapter 5, the scenarios have been validated and found representable for real-road circumstances when driving partially automated (Van den Beukel et al., 2015). The hazardous scenarios requested attention from the driver because of a difficult or potentially dangerous situation, like approaching a combined on/off ramp. The critical scenarios required intervention to avoid an accident, for example when a neighbouring vehicle cuts in too close and violates minimum required follow-distances. 


\subsubsection{Measurement data}

Supervisory control is strongly related to driver's understanding how the system reacts to difficult situations in combination with knowledge and understanding of required human (re)actions (Jamson et al., 2013). Cognitive performance is well covered by the psychological construct Situation Awareness (Endsley, 1995c). Intervention tasks, on the other hand, are strongly related to operational capabilities to perform fast and accurate counter-measures and undertaking actions timely and adequately to solve a critical situation (Merat et al., 2014). Consequently, the assessment of intervention should especially address task-performance. In a previous study (Van den Beukel \& Van der Voort, 2016b) that has been explained in Chapter 5, we introduced 'Accident Avoidance' to assess this task-performance. Accident Avoidance is a combined assessment of accident avoidance by either swerving out or by braking - the latter based on Time-To-Collision (TTC) data. In addition to cognitive performance and taskperformance, our framework should also assess perceived comfort, because raising comfort is in general an important goal for the development of driving-assistance (Bengler et al., 2014). To summarize, our concept evaluation will be based on comparison of scores between concepts with regard to: Accident Avoidance, gained Situation Awareness (SA) and Concept Acceptance.

\subsubsection{Material \& Procedure}

Both studies took place in the same (mid-fidelity) driving simulator from University of Twente, see Chapter 3. Within both studies a trial consisted of experiencing a concept within a specific scenario. Test trails were relatively short and took between 4 to 6 minutes. After each trial the simulation was frozen to allow probe-taking to measure Situation Awareness and to take additional questionnaires. Also driving-data were collected, like Reaction Time and Time-toCollision to measure driving performance. Within each trial participants drove directly automatically and the surrounding traffic was programmed so that participants had exactly the same chance of resolving the situation. The applied concepts will be explained in section 8.3.

\subsubsection{Analysis}

We collected data measured within both studies that allow assessment of concepts' support in supervision and intervention, i.e.: measurement of Situation Awareness, measurement of Accident Avoidance and measurement of Concept Acceptance. In both studies, measurement of SA was based on probe-taking and used so called SAGAT-technique (Endsley \& Kiris, 1995). Measurement of Concept Acceptance was based on a VanderLaan-questionnaire - of which the subscale Perceived Usefulness was most applicable. Because the data were collected from different studies, independent sample test are needed to compare results between concepts. 


\subsection{Concepts}

The concepts were designed to explore different kind of support for supervision and intervention. Because the driver's changing role is dominated by a demand for supervision (as explained in the introduction), most emphasis is on support in directing attention. Conventional interfaces either use single modal (audible or visual) means to direct attention, or multimodal means, like combinations of audible and visual signals. Introduction of multimodal interfaces has advantage that a signal might be picked up more effectively when there is competition from other signals using the same sensorial modus. However, multimodal interface might introduce new problems, like: distraction, spatial mismatch, raised annoyance, confusion and misinterpretation (Van den Beukel et al., 2016). Recently, engineers and scientists have levered their attention to advanced interfaces, like using force-feedback and illumination to direct attention. Knowing that our concepts represents only a modest range of possible concepts, they do represent a relatively large spectrum of potential solutions, see Table 8-1. See for a more extensive review of design considerations previous chapter 7.

Table 8-1 Concepts and their signals to convey 'soft' warnings (for supervision) and 'hard' warnings (for intervention)

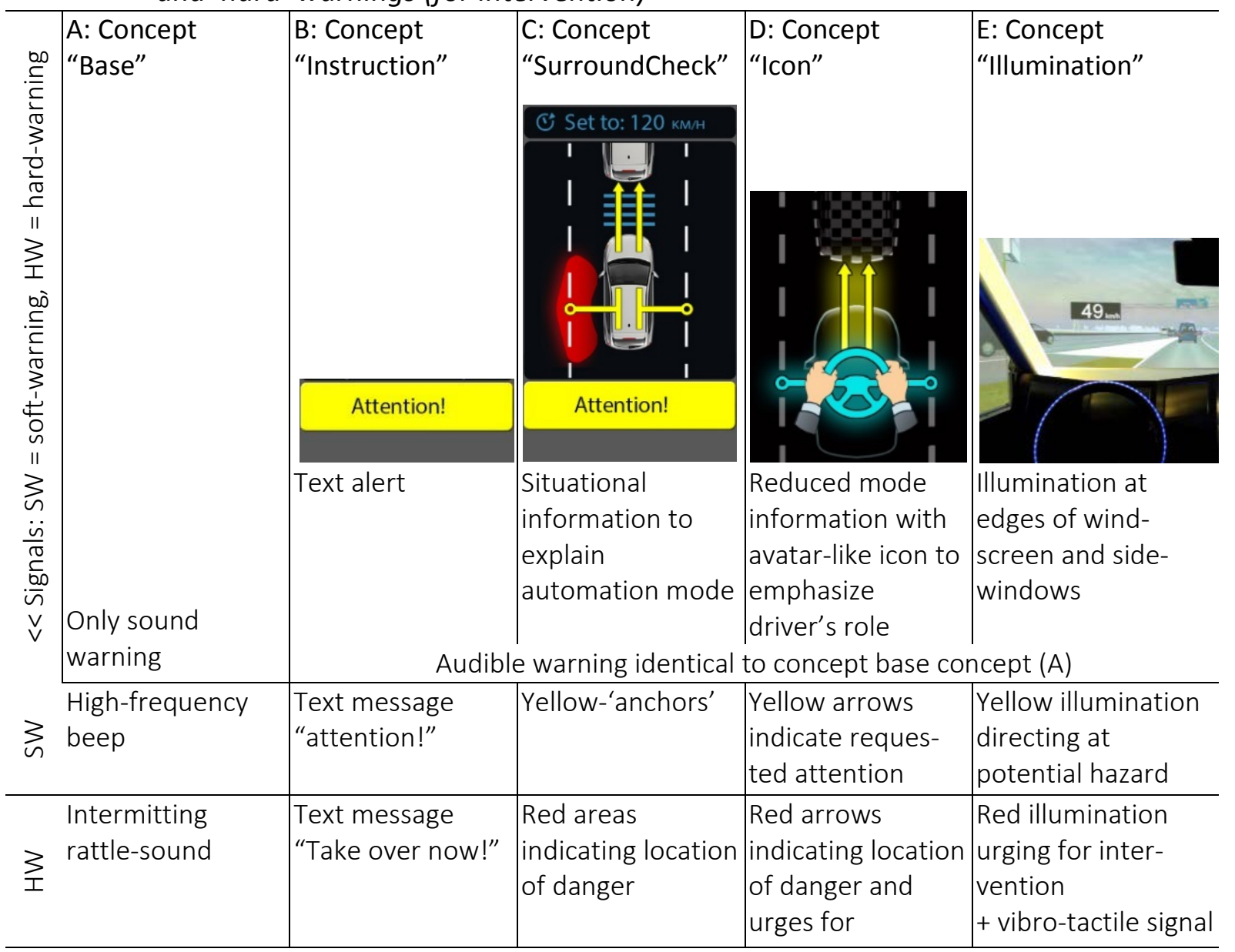

Note. The graphical displays of concepts B, C and D are positioned behind the steering wheel. 
Due to the demand for supervision and occasional intervention, all concepts were designed to provide signals of two kinds: (1) 'soft' warnings asking for attention, and (2) 'hard' warnings urging for intervention. The signals of a soft-warning are intended to ask for attention, because of a potentially difficult or maybe dangerous situation. An example is when the vehicle approaches a combined on/off-ramp where vehicles may enter and exit the lane at the same time. The signals of a hard-warning are intended to urge for intervention, because of direct danger. An example is when a vehicle is cutting in too close, violating minimally required followdistances.

Concept $A$ is intended as a reference and includes only audible soft and hard warnings. All other concepts include the same audible warnings with other added features. Concept B, 'Instruction-concept', enhances hard warnings by instructing the driver upon required intervention. Concept C (called 'SurroundCheck') enhances soft warnings by graphically explaining why automation mode changes. Besides the audible signals it provides detailed mode information with a graphical representation of the own vehicle, a target-vehicle, front and side distances and recognition of target and road lines. A fourth concept (D) is called 'Icon'concept. Because the detailed information of the 'SurroundCheck'-concept might work as a distraction, the 'Icon'-concept is intended as a refined version: This concept enhances both soft and hard warnings by providing reduced mode information in combination with instruction on the driver's role with depiction of an avatar-like icon. This icon is intended to emphasize the driver's role. The fifth and last concept $E$ is called 'Illumination'-concept. This concept is intended to steer driver's focus towards the location outside the vehicle where attention is needed. Within critical situations this concept also had a vibro-tactile signal in the front end of the seat-pan, intended as a cue for action.

\subsection{Results}

The results in table 8-2 show that none of the concepts show a dominating superior performance over all assessment aspects and neither within both scenario-types taken together (critical and hazardous). Moreover, the differences are often small. Hence, only in some occasions concepts show significant differences among one another.

The results identify the 'SurroundCheck'-concept (C) to be ambivalent: In hazardous situations it shows best SA-comprehension, however in critical situations (i.e. requiring intervention) this concept performs worst on both SA-comprehension and Accident Avoidance. For illustration: Based on SA-Comprehension (SAGAT-Level2) Concept C scores within the hazardous scenarios significantly better than base concept $A 1$ : $t(46)=3.36, p<0.01$. But concept (C) performed significantly worse than the 'Instruction'-concept (B) within the critical scenarios, i.e. $t(46)=$ 2.20, $p=0.033$. The 'SurroundCheck'-concept (C) was designed to provide most detailed mode information (for example road lines and relative position to surrounding traffic). Probably this information was advantageous during hazardous (i.e. non-critical) situations - requesting supervision, but worked at the same time as a distraction during critical situations. 
Table 8-2 Concept comparison for Situation Awareness, Accident Avoidance and Perceived Usefulness per scenario-type (critical or hazardous)

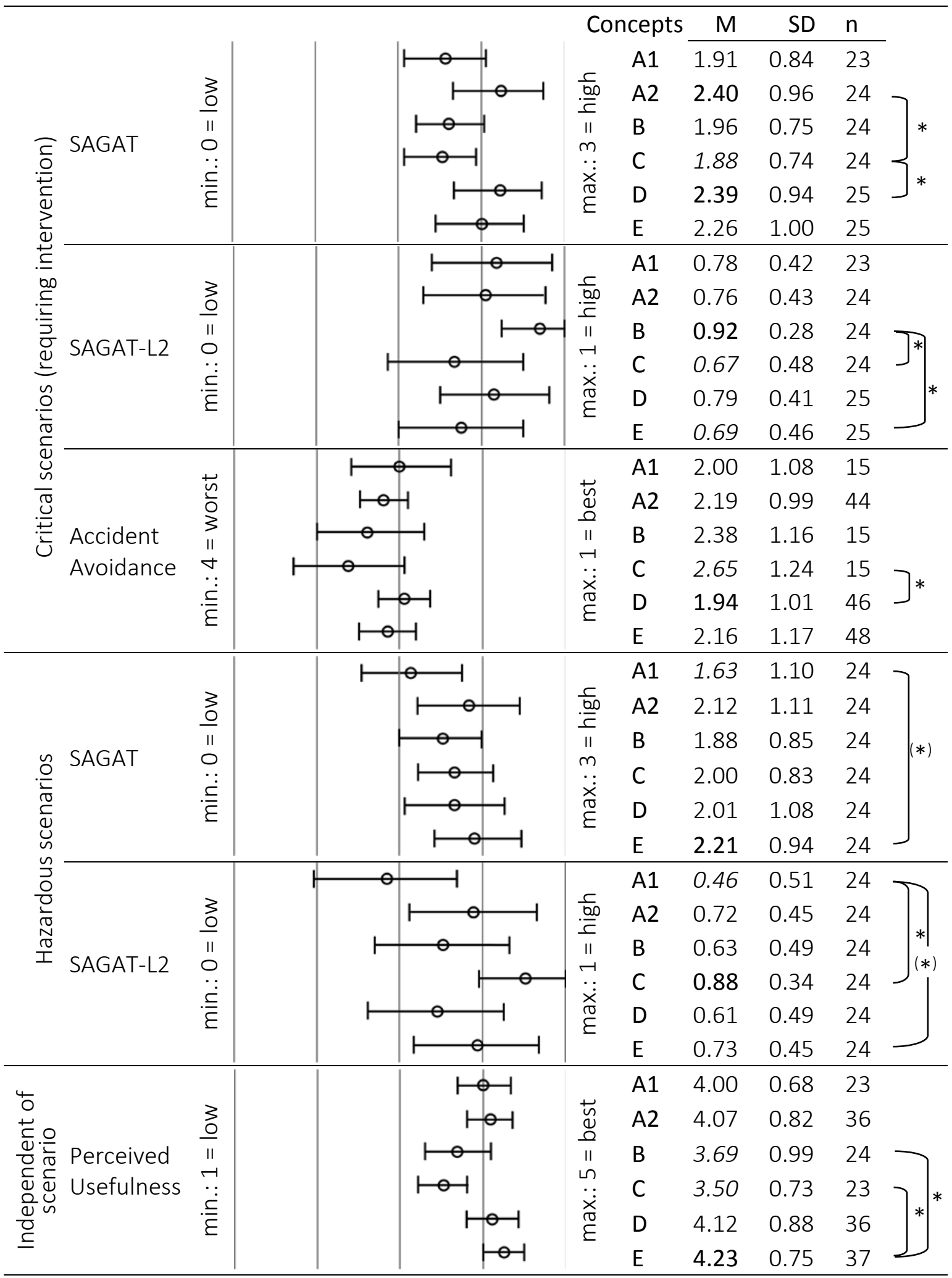

$* p<0.05 \quad(*) 0.05<p<0.10 \quad$ Error bars show 95\% Confidence Intervals.

Note. $\mathrm{M}=$ Mean, $\mathrm{SD}=$ Standard Deviation. $\mathrm{SAGAT}=\mathrm{SA}$-measurement based on probe-taking. SAGAT-L2 refers to SA-Comprehension. A1 refers to the base concept tested during the framework-study (Chapter 5 ) and A2 refers to the same base concept tested in Chapter 7. 
Furthermore, the 'illumination'-concept (E) was intended to support especially intervention. This expectation was based on its directional cue to guide focus outside the vehicle where attention was needed and at the same time conveying urgency through colour coding. Nonetheless, results do not demonstrate any advantages of this concept during scenarios which required intervention. On the contrary, it seems that the 'illumination'-concept had a counter-productive effect on intervention-support. Possible causes of this effect are discussed in the previous Chapter. Most likely this is due to the unexpectedness of the additional vibrotactile cue that concept $\mathrm{C}$ applied as additional stimulus for intervention. Probably this additional cue caused too much annoyance and then reduced performance.

Scores for Accident Avoidance in table 8-2 also reveals that the 'Icon'-concept (D) is an improvement in comparison to the 'SurroundCheck'-concept $(C): t(59)=2.23, p=0.029$. This is especially important because the 'Icon'-concept was intended as a refinement of the 'SurroundCheck'-concept (C).

Perceived Usefulness shows highest scores for the 'illumination'-concept (E), but the base-line concept performs almost identical. Here we need to remember that the data in this chapter are not based on within subject comparison. It could be that participants' overall appraisal is dominated by experiences during hazardous scenarios because concept preference is more in line with performance measured during hazardous scenarios than with scores from critical scenarios.

\subsection{Conclusions}

This research evaluated five interface-concepts intended to support drivers with their changing role when driving partially automated (i.e. supervision with now-and-then intervention). Concept A provided only acoustic warnings and served as a baseline. Concept B presented textbased instructions in a conventional manner. Concept $C$ was more detailed, providing situational information with regard to the road-situation and surrounding traffic on a display behind the wheel. Concept $D$ had similarities with $C$, but provided the situational information more reduced and emphasized driver's role. Concept $\mathrm{E}$ was most advanced using illumination in the windscreen and haptic feedback in the seat-pan to direct attention towards the locus of a potential hazard and to create an affordance for intervention when required.

Based on measurement of Situation Awareness, the 'illumination'-concept (E) shows superior support for supervision. (That is: within hazardous scenarios.) Knowing that supervision will be the dominating driver's responsibility when utilizing partially automated driving, we consider the illumination-concept (E) a recommendable development-direction for support of the driver's changing role. Nevertheless - based on Accident Avoidance scores, none of the concepts show raised levels of support for intervention in comparison with the base-concept. Against expectation, the 'illumination'-concept (E) scores comparable or worse than the baseline-concept (A). Probably, the combination of concept E's intervention-warning, 
especially the unexpectedness of the vibro-tactile stimulus in addition to the acoustic and visual stimuli, caused counter-productive levels of annoyance. Moreover, the more graphically advanced the concepts are, i.e. 'SurroundCheck'-concept (C) and 'Icon'-concept (D), the more it confirms that graphical information acts as a distraction during intervention. An observation that is illustrate by those concepts' lower scores on Accident Avoidance compared to the base line. Therefore, we recommend to use graphical mode information in a reduced manner.

Based on previous considerations we conclude that intervention and supervision benefit from different interface-features. The evaluation presented in this paper contribute to further development of - and knowledge about, appropriate driver-vehicle interfaces while operating vehicles advances into managing partially automated driving systems. 


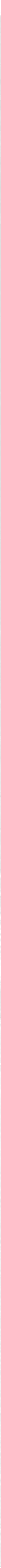




\section{Chapter 9. Conclusions and recommendations}

Driving automation changes the driver's role from actively operating the vehicle to supervising the system with occasionally a necessity to intervene. Driving automation requires drivers to act as a backup in case automation fails or reaches its boundary limits. As a result, the driver's responsibility to supervise the automation is a demanding task. Carefully designed driverinterfaces are therefore needed to support drivers with supervision and intervention. To help the development of such interfaces, this thesis has two objectives: (a) to design efficient means to evaluate potential improvements in driver support, and (b) to recommend interfacefeatures that support drivers in performing their changing task. With the validation of a designed assessment framework which is representative for partially automated driving, the first objective is achieved. Thereafter, insight in improved interface-solutions is collected through the design and evaluation of several potential interface-solutions within this framework. In line with this approach the thesis concludes with:

\footnotetext{
* Recommendations for the evaluation of potential interface solutions (section 9.1)

* Design recommendations for interface-features to provide the desired support for both supervision and intervention (section 9.2)

* General considerations with respect to support for the driver's changing role, including considerations how the changing driver-vehicle interaction influences future implementation of automated driving (section 9.3)

* Final conclusion (section 9.4)
}

Recommendations for further research are included in sections 9.1 throughout 9.3.

\subsection{Recommendations for evaluation of potential solutions}

The first objective of this research is to determine efficient ways to evaluate potential solutions for the driver's interaction related to partially automated driving. In parallel with the dual characteristic of the driver's changing task, two distinctive types of support need to be evaluated: Supervision and Intervention. Because an assessment framework to evaluate this combination of support does not exist, a framework as such is designed.

\section{Assessment aspects}

Assessment of supervision asks for evaluating the driver's cognitive understanding of how a system reacts to different situations (Jamson et al., 2013). Intervention requires taskperformance in situations which need a safe way of regaining control over the vehicle (Martens et al., 2008). It is also important that the driver appreciates the interface features which are intended to support them with supervision and intervention. Therefore, the assessment framework includes the following three assessment aspects: (1) Situation Awareness (SA) to evaluate the driver's understanding of traffic situations and how automation reacts, (2) 
Accident Avoidance (AA) to evaluate operational capabilities to solve a critical situation, and (3) Concept Acceptance (CA) to evaluate drivers' appraisal of the interface features intended to support them.

\section{Measurement techniques}

An objective and subjective measurement technique is selected for the SA-assessment: Objective SA-measurement is based on probe-taking according to the Situation Awareness Global Assessment Technique (SAGAT) and self-assessment allows assessment of how situation aware drivers perceive themselves/ Self-assessment is based on the Situation Awareness Rating Technique (SART). Combining both techniques is especially relevant as drivers have a concerning lack in awareness of their cognitive performance and any shortfall in it (Walker, Stanton \& Young, 2008). For assessment of AA, measuring reaction time to retrieve control lacks clarity about what such time-span represents. Some researchers refer to elapsed time until the driver is in the loop, others measure time until the vehicle has come to a safe standstill. The retrospective point in time to start measurement is also ill-defined. Therefore, the assessment of AA is operationalized through measurement of Time-to-Collision (TTC) and counting accident occurrence. Assessment of CA is operationalized through measurement of Perceived Usefulness (Van der Laan et al., 1997). Furthermore, insight in the driver's SA and performance in $\mathrm{AA}$ is complementary to one another: despite correct understanding, adequate control could fail.

\section{Driving simulator scenarios}

The framework is designed for application within a driving simulator. Because assessment of $S A, A A$ and $C A$ require relevant testing situations, driving scenarios representative for automated driving are inseparable from the framework. Therefore the framework includes a total of 6 scenarios. In line with the driver's changing demand to supervise the automation and occasionally intervene, these driving scenarios were divided in two categories: (1) 'Hazardous' scenarios with a need for driver's attention (but without an immediate necessity for intervention), (2) 'Critical' scenarios requiring driver's intervention in order to avoid an accident. The framework and driving scenarios have been validated within a preliminary test using pre-defined interface-concepts. Analysis of this test's results for driving performance and participants' mental effort, show differences in the required scope, urgency and difficulty of the driver's role. These differences confirm that the driving scenarios conceive the two intended categories. It is therefore concluded that the driving scenarios are representative for supervision and intervention tasks as a result of automated driving. Furthermore, the driving simulator provide scenarios within a controlled environment allowing reproducibly situations without jeopardizing road safety when tested in real life circumstances.

\section{Validation of assessment framework}

The predefined interface-concepts are purposely designed to offer different levels of support ranging from: (A) audible alerts only, (B) alerts including a textual instruction to the driver (e.g. words displaying "attention" or "take over"), to (C) alerts in combination with graphical 
explanation of automation mode. Comparison of objective measurements (i.e. accident avoidance and probe-taking for measuring SA) shows congruency in identification which concepts scores best and worst for supervision or intervention support. Furthermore, the conformity between the concepts' performance (i.e. AA- and SA-scores) and their purposely designed differences in level of support, demonstrates the framework's predictive power to identify meaningful differences between potential interface-solutions.

\section{Contribution to the development of automated driving}

The results explained above demonstrate the framework's quality to reliably evaluate potential interface solutions. Nonetheless, it is noticed that the framework has a reduced sensitivity to identify small differences in effectiveness of offered support. With regard to support for intervention, the majority of measures is successful in identifying 'worst' performance but less discriminative in identifying the 'best' concept. Although, the relatively small conceptual differences between the concepts in the higher score-range explain this observation, it is somewhat dissatisfying as optimisation of solutions always comes with gradual refinements. Therefore, this study recommends to use the framework's results for expert judgement. As it provides a supportive combination of objective and subjective assessment aspects, the framework enables designers to put data in perspective and resolve conclusions. This is with respect to desirableness and effectiveness of the evaluated interface-support and thereby helps to make further decisions on what solutions or interface directions are considered appropriate. Based on these results, it is also concluded that the framework successfully shows predictive power to fast fail inadequate interface-support early in the design process. Since necessary changes to solve design failures are more expensive when made at later stages of the development, this is an important contribution to the development and application of automated driving.

\section{Concern on user preferences}

Furthermore, the framework's test reveals that drivers have difficulty with correct assessment of potential danger that occur during supervision. In the study, it turned out that drivers perceive gradually evolving but not so dangerous situations more hazardous than a sudden but (far more) critical situation. This has a negative influence on users' ability to correctly assess required support. Within the study it is also observed that users' judgement of desired support contradicts with results for most optimal support according to objective performance measures. Both observations are in line with other studies which emphasize that necessarily care is to be taken when making decisions based on user preferences (Andre \& Wickens, 1995). This also underlines the importance to use the data generated with the framework as part of expert judgement.

\section{Concern on demandingness of the driver's changing role}

Moreover, the framework's validation shows that the complexity of the simulated situations has a large influence on supervision and intervention performance. Statistical analysis revealed that the scenarios have a larger influence on task-performance than the interface-concepts. 
This raises the question whether additional interface support is actually able to compensate for the raising demands due to the driver's changing role - a concern that we will reflect upon in more detail in section 9.3.1.

\subsection{Design recommendations to support supervision and intervention}

Within three studies ${ }^{15}$, the designed assessment framework has been used to evaluate a total of five potential interface solutions. These studies are intended to create insight in interface features that benefit the driver's changing role. Therewith this thesis obtains its second objective: to recommend interface features that support drivers in performing their changing task.

\section{Disadvantages of existing interfaces}

The majority of existing interfaces on the market provide icon-based mode information with or without a combined text message, which is graphically displayed at a conventional location near the steering wheel or combined with the existing instrumentations. This way of displaying information allows the driver to ascertain oneself at any time about the system state. For the majority of cases involving only one function, this is often sufficient. With automated driving however, changes in automation mode dominantly originate from changes in the external traffic environment. Examples are failures to detect lane markings or the inability to locate a target-vehicle. To support supervision of the driving automation, warnings are therefore needed that convey information about the location of an event including its criticality. Existing interface solutions do not connect the mode information to the relevant location outside the vehicle. Moreover, the provided mode information has more than once shown to be a distraction at the very moment an intervention is required (Hurts, Angell, \& Perez, 2011; J. D. Lee et al., 2004; Rogers et al., 2011; Stanton et al., 2011). As a consequence the required cognitive attention to understand on-screen mode information could make the information a distraction in itself.

\section{Tested interface features to support supervision and intervention}

Supervision and intervention do not necessarily benefit from the same interface features. To research how interface features possibly improve supervision or intervention, a total of five potential interface concepts are tested. All concepts provide signals of two kinds: (1) 'soft' warnings asking for attention, and (2) 'hard' warnings urging for intervention. Concept $A$ is intended as a reference and includes only audible soft and hard warnings. All other concepts include the same audible warnings. Concept B enhances hard warnings by instructing the driver upon required intervention (e.g. Words displaying "attention" or "take over"). Concept C enhances soft warnings by graphically explaining why automation mode changes. A fourth concept (D) enhances both soft and hard warnings by providing mode information in

\footnotetext{
${ }^{15}$ Including the framework's test used to validate the framework itself.
} 
combination with instruction on the driver's role with depiction of an avatar-like icon. The fifth concept $(\mathrm{E})$ is called Illumination.

\section{Illumination concept $(E)$}

Like traditional interfaces, the graphical information of concepts $B, C$ and $D$ is presented inside the vehicle (behind the steering wheel). Previously listed disadvantages of such presentation of information encouraged us to experiment with a fifth and advanced interface (E) that is able to illuminate edges of the windscreen and side windows. Through variation of location, length and colour of the illumination, concept E differentiates between soft and hard warnings and, more importantly, tries to steer the driver's notice to the location outside the vehicle that requires attention.

\section{Awareness of automation mode}

Since the Illumination concept (E) is expected to support especially intervention but not necessarily supervision, we tested illumination first on support for supervision. Based on an internet-survey with 100 participants we measured the understanding of automation mode while participants watched video-clips with driving scenarios. This was either through support from illumination or audible support being the base reference concept. The driving scenarios are the same as in afore designed assessment framework. The results reveal that illumination in the windscreen raises driver's awareness of the automation mode and therewith contributes to support for supervision.

\section{Support for supervision}

In addition to the internet-survey, the concepts are tested in two series of driving simulator experiments with twenty-four and thirty-seven participants respectively. Based on these tests it is concluded that illumination in the windscreen in case of potentially hazardous traffic situations raises the driver's Situation Awareness compared to the traditional icon-based (onscreen) interface (D). This positive effect on situational understanding is revealed along with advantages in supervisory performance. Illumination in the windscreen also reveals to significantly improve detection of potentially hazardous traffic situations within the driver's peripheral field of view. Both outcomes confirm that there is in general a favourable relation between illumination and support for supervision.

\section{Support for intervention}

Several studies demonstrate a positive relationship between raised levels of SA and raised performance in intervention (De Winter et al., 2014; Jamson et al., 2013; Kass, Cole, \& Legan, 2008). Unfortunately, results in this thesis for intervention are controversially: Illumination raises driver's SA, but did not show improvements in intervention compared to the baseline concept (A). For explanation of this unexpected result a closer look is needed at the design of concept $E$, i.e. the Illumination concept. 


\section{Multisensorial interface features of concept $E$}

Concept $\mathrm{E}$ was expanded with a vibro-tactile stimulus in case intervention was needed, i.e. vibro-tactile pots in the front-end of the seat cushion created a stimulus to react (i.e. braking). Although this concept was designed with a combination of illumination and stronger stimulus to enhance intervention compared to icon-based warnings, no additional benefits for intervention are shown.

\section{Concerns on the combination of illumination with a vibro-tactile cue}

Looking at possible deficits due to combination of modalities, annoyance and unexpectedness of stimuli, we found the following explanations why illumination in connection with the vibrotactile cue is counter-productive to intervention:

* Illumination fundamentally attracts attention without a specific instruction, whereas the vibro-tactile cue could be interpreted as system-activity. Based on observation of required interventions, this combination seems to have made drivers more hesitant and doubtful whether the automation might take corrective actions by itself, resulting in delayed reactions.

* The combination of illumination and a vibro-tactile cue made situations appear more dangerous. Although drivers might react stronger due to increased urgency, too high levels of perceived urgency deteriorates performance. Based on evidence provided by participants' verbal reactions, rising levels of too strong urgency could be another explanation for impaired intervention-support.

* Moreover, participants' responses confirm that the combination of the vibro-tactile cue and illumination caused tension and made the user situation more demanding. This may have reduced the available attention for the road situation and provides again explanation for impaired performance.

* Furthermore, the unexpected appearance of the vibro-tactile stimulus (and not necessarily the type of modality) is considered to have caused a startled response which has a deteriorating effect on performance. Remarks made by participants confirm this consideration. Subsequently, it was concluded that this unexpected introduction of the stimulus has been the major cause for impaired interventionsupport.

\section{Importance to test intermediate interface prototypes}

Multisensorial cues are often advocated because of their sensorial redundancy. If one sensorial channel is occupied (e.g. by reviewing an on-screen map), a stimulus based on another sensorial channel is more likely to interrupt and get attention, e.g. an acoustic alarm. The above listed concerns of a counterproductive influence on intervention due to the combination of a visual and vibro-tactile cue, illustrate the difficulty finding the right balance in a multimodal constitution of warning signals - for which we have not found specific recommendations that justify immediate application. It shows however that it was particularly the unexpectedness of an additional stimulus (not necessarily the stimulus' modality) that causes annoyance. Hence, 
care should be taken with implementation of unexpected stimuli. Furthermore, these findings underline the importance to apply testing of intermediate prototypes with a predefined assessment framework to identify counterproductive effects on operator-performance when experimenting with multimodal interfaces.

\section{Broader benefits of illumination}

The conclusion is that there is in general a favourable relation between illumination and support for supervision. This conclusion is specifically based on the Illumination's quality to raise driver's Situation Awareness (SA) compared to traditional icon-based (on-screen) interfaces. This quality is demonstrated despite Illumination's lacking explanatory information with regard to automation mode. A plausible and favourable explanation is that providing information where attention is needed, compensates for reduced information why attention is needed. Furthermore, the interruptive character of illumination, could have helped to return faster in the control-loop and that, in turn, might have increased SA. Other means to provide directional cues, like force feedback on the steering wheel or audible cues are more appropriate when a specific intervention is foreseen, for example emergency braking (Isermann, Schorn, \& Stählin, 2008; Schieben, Griesche, Hesse, Fricke, \& Baumann, 2014). Based on the previously explained concerns for intervention, such cues are however in danger to become counter-productive, if they occur too unexpectedly. Illumination, on the contrary, provides a relatively generic and regular means to guide attention. Since the driver's changing task is being dominated by a rather unremitting demand for supervision, this is an important benefit.

\section{Recommended design direction}

Although illumination does in this research not demonstrate advantages for intervention, it neither holds the disadvantages of causing distraction as is the case with icon-based explanatory information, like concepts $C$ and $D$. Illumination is therefore considered a generally recommended design-direction to base support on both for supervision and intervention. Moreover, the driver's task is increasingly combined with secondary tasks due to expanding integration of In-Vehicle Information Systems (IVIS). Therefore, illumination as a means to attract driver's attention away from IVIS and direct it to the road situation is beneficial even when not driving automatically.

\section{Design guidelines for supervision}

In summary, the following design guidelines are developed in relation to desired support for supervision:

* The driver's changing task is dominated by a steady demand for supervision. Because unexpected stimuli cause counter-productive effects on intervention, cues for supervision are best when based on stimuli that gradually attract attention. For example, their presence manifest itself when supervision is requested. 
* Support for supervision should entail qualities to prepare drivers for fast return in the control-loop by providing cues that convey where pertinent attention is needed. Explanation why attention is needed, should be carefully considered. This is because explanatory information works as a distraction and then slows down the return in the control-loop.

* Interfaces to support supervision should include urgency of required attention, without causing discontent. In this respect visual colour modality is generally preferable, as its characteristics can be changed to manipulate urgency, with a minimum effect towards annoyance.

* As observation and detection is key to supervision, stimuli should improve detection of hazardous traffic situations within the driver's peripheral view.

The above mentioned aspects are facilitated via the application of 'directional illumination' as explained in this thesis, i.e. spatial cues based on illumination of edges around the windscreen and side-windows. This type of illumination is therefore a strongly recommended solution to provide support for supervision.

\section{Design guidelines for intervention}

With regard to support for intervention, this thesis provides the following guidelines:

* Use sensorial cues that users are familiar with. This is important because unexpected appearance of a stimulus may cause inappropriate levels of perceived urgency and this in turn deteriorates intervention.

* Special attention should be given to avoid a startled effect due to a stimulus being too intense. (Besides, startle could also be the result from unexpectedness of a stimulus).

* Be careful with sensorial redundancy to avoid that the combination of sensorial stimuli convey inappropriate levels of urgency or mismatched levels of perceived danger.

* Provide cues that convey correctly perceivable information on task-allocation, because confusion between required human action and automation-activity deteriorates intervention.

\section{Further research on support for supervision and intervention}

Difficulties to provide precise recommendations for multimodal cues that deliver desired support for intervention underline the importance to conduct experiments early in the design process including evaluation of intermediate prototypes. With regard to further development of design-directions to support supervision and intervention, the following recommendations for future research are made:

* Further research is to (a) improve visibility of the illumination under different light conditions, and to (b) explore how different light conditions influence perception of the visual cue, i.e. level of urgency. Although visibility of the illumination can most likely be made (automatically) adaptive to light conditions, research into the effectiveness, 
adaption and avoidance of counter-productive effects with regard to its perceived urgency remains relevant. Further research is also needed regarding the relationship between illumination and perception of the intended direction of the cue.

* A comparison between intervention-performance for illumination with or without vibro-tactile cues, is needed to discover the extent to which the vibro-tactile stimulus is related to inappropriate levels of perceived urgency and annoyance.

* Furthermore, research on appropriate controls to activate and operate the automation, including setting system's preferences, is needed. It is especially important to research how active involvement in system operations could raise mode awareness and understanding of automation-state.

\subsection{Discussion: influence of the driver's changing role on mobility}

The previous section described the recommendations for interface directions that provide support for the driver's changing role. This driver's changing role marks a fundamental change in car driving; from mastering a vehicle in a variety of circumstances to monitoring the automation. Because automated driving is intended to improve safety and raise comfort, we will discuss in this chapter how this changing role influences respectively (1) safety, and (2) comfort. To discuss the extent in which the intended improvements are attainable, we will also discuss this relationship in a broader scope, i.e. (3) the context regarding car-mobility.

\subsubsection{Safety}

Safety of car mobility has steadily grown and since the nineteen seventies this enduring trend is considered a tribute to driving assistance systems. As automated driving is an advanced step in the evolution of such systems, the general opinion is that this next step will benefit safety as well. Nonetheless, this thesis highlights considerable safety concerns with the implementation of partially automated driving. Without precaution, the introduction of automated driving is likely to evoke a new situation wherein the enhancement of one safety-aspect starts to contradict another. That is; human skills for good driving performance will decline due to assistance based on automation. This thesis reveals successful efforts in creating interface solutions to enhance the driver's supervisory task. Despite required further efforts to create more adequate support for intervention, it is disputable whether these additional improvements will suffice to level out the increased demands on the driver for supervision and intervention. Interface support focusses on improving a single measure, i.e. driver assistance, whereas traffic safety originates from a multi-dimensional interplay of aspects; including for instance driver's skills and traffic conditions. The observation in this research is that traffic circumstances (i.e. the defined scenarios) have a larger influence on drivers' performance than interface-support. This is a confirmation that additional measures are required in order to help automated driving raise safety. 


\section{Cooperative interaction}

A first measure dawns when we are aware of the irony between driving automation and the required human fall-back solution. Within the technology-minded approach for development of automated driving, drivers are considered unreliable, for example due to fatigue and being susceptible to distraction. However the main problem we are trying to solve in this thesis is to meet the raised demands placed on drivers, because in critical situations drivers need to compensate for automation-deficits. This illustrates that development of solutions in which the driver capabilities are being undervalued, is a counterproductive approach. Hence, several authors have conversely advocated an approach to actually support those aspects which humans are good at, instead of solely focusing on tasks human operators have trouble with (Hollnagel, 2011; Kaber \& Endsley, 1997; Woods, Dekker, Cook, Johannesen, \& Sarter, 2010). In critical situations humans are for instance better at interpreting and taking action following incomplete or new information, whereas during calm situations the technology performs better than humans in consistently and simultaneously perceiving all traffic parameters. Consequently, we recommend that information about the system's reliability is presented to the driver. This allows the driver to have a better notion of the situations the technology is unprepared for. Beller, Heesen, and Vollrath (2013) showed that the presentation of automation uncertainty improves driver-automation cooperation. In this respect it should also be noted that many accidents are being avoided by careful and successful anticipation of attentive traffic participants. In general, we advise a stronger focus on a rather cooperative interaction between driver and automation to complement each other's capabilities (Evers, Winterboer, Pavlin, \& Groen, 2010; Hollnagel, 2006). Section 9.3.2 will elaborate on possible solutions for joint driver-vehicle control.

\section{Training for supervision}

Another measure to meet the increased demands for supervision and intervention is through training. Advanced Driver Assistance Systems (ADAS) are often poorly understood by users (Bengler et al., 2014; Jin \& Kaber, 2009; Nirschl, 2007). Since existing driving training is still focused on the driver's traditional role, a change of the driver's understanding and skills to interact with the new technology is necessary. Next to a raised mode awareness (see previous section), enhanced prior knowledge and information will improve supervision-support. Indeed, correct mental models have proven to raise drivers' ability to cope with mode errors (Sarter \& Woods, 1995). Therefore, upfront training to raise driver's understanding of system's limitations is expected to raise Situation Awareness and subsequently driver's performance. Furthermore, training and support for supervision (i.e. illumination) both will help to raise Situational Awareness, but in different ways. That is, illumination especially enhances perception whereas training especially improves understanding and (re)acting. This raises the expectation that tailored training of support for supervision could strengthen the driver's role during automation. As a result, research how to attune training-solutions and interfacesolutions is strongly recommended. Specific training is expected to reduce the cognitive load required to understand explanatory information and at the same time improves required 
reactions. It is in particular recommended to research how to present system's limits coherently with training purposes and on how to recognize system's limits and to react on them.

\section{Training for intervention}

The approach to enhance perception and reaction through a combination of training and interface presentation, would especially be beneficial for frequently performed tasks, like supervisory tasks. However, situations when intervention is needed are often too infrequent for this approach. Moreover, these situations are often too critical to be exercised in real traffic. Therefore, specific training for drivers would allow introduction of system limitations in a controlled and safe setting, perhaps in driving simulators or on testing grounds. In that case, users would be able to build up an adequate mental model before encountering system's limits in real traffic. The importance of training is underlined by the fact that although technical advances are likely to reduce the frequency for humans to act as a fall-back solution, the ability to intervene reduces even further due to reduced exercise. Furthermore, operators of complex systems, like air-traffic control or rail transport, need to intensively train and preserve required skills in order to meet safety concerns. As automated driving brings expanding complexity to operate the vehicle to a comparable level of afore mentioned examples, it is necessary to research whether today's drivers meet the required skills.

\section{Recommendations for further research}

To summarize our consideration how the change of the driver's role influences the safety aspects of automated driving, the following recommendations for further research are made:

* Further research is urgently needed around efficient and adequate concepts for training. Specific training goals need to be identified, for example required levels of intervention-skills. Research is also required towards an effective approach to implement training. It is recommended to research the possibilities of how training solutions and interface solutions could be adapted to create a coherent support for supervision. To minimize cognitive load required to understand automation state and state changes, special attention is needed for the presentation of system's limits and easily training of how to recognize system's limits.

* Furthermore, research is needed into the design of controls that allow improved drivervehicle cooperation. Along with consideration how to improve the cooperation between driver and technology, this research should include desirable allocation of functions between human and machine operation in order to take advantage of the capabilities of both. Because traffic circumstances revealed having more influence on driving performance than interface solutions, we recommend to research solutions for the dynamic allocation of functions dependent on situation. Research how to convey information about technology's reliability is also recommended, because this information allows the driver to have a better notion of the situations the technology is unprepared for. 


\subsubsection{Comfort}

From a consumer's perspective, increased safety and improved traffic efficiency due to driving automation incorporate profound but indirect benefits. Whereas comfort-enhancement is a tangible asset consumers pursue when buying a new vehicle. Realizing that vehicles introduced with means for driving automation represent high-end luxury goods, raised comfort is an important and indisputable quality for a successful implementation of automated driving. Despite this demand for comfort, it is questionable whether supervisory control with occasionally intervention will take less effort than drivers operating the car themselves. Acceptance of automated driving is therefore expected to be strongly influenced by the appraisal of gained benefits in contrast to required supervision efforts. This section reviews how the driver's changing role influences this appraisal. Furthermore, possible solutions to reduce required efforts are identified along with a discussion whether such solutions will meet the demand for raised comfort when driving automatically.

\section{Possible comfort enhancement}

First of all, we observed during our tests that participants hold a positive attitude towards the provided comfort of automated driving: Despite low speeds, a majority of people valued the opportunity to drive steadily and more relaxed in traffic congestions. This observation is made although participants experienced a frequent necessity for intervention during the tests. Hence, participants seem to recognise the potential benefits that automation could bring. However, the circumstances (like traffic congestion) in where benefits gained seem to balance out required efforts (i.e. supervision) represent a limited sample of all traffic conditions drivers are confronted with. As it varies strongly between drivers, lifestyle and countries what situations dominate car-usage, these benefits might only apply to a minority of potential customers. It is also disputable whether automated driving offers a major contribution to raised comfort in these situations as long as drivers are not essentially exempted from vehicle control. Moreover, additionally required safety measures (for instance training, as explained in the previous section), place new demands on the driver. In order to raise comfort more fundamentally, it is therefore necessary to reconsider definition of the driving task along with redefining driving controls. Could for example the driver-interface be reinvented to pursue non-driving tasks in an acceptable way?

\section{Improvement of driver-vehicle interaction}

Experiments with new controls that are better tailored to the driver's changing role are relatively scarce. Noteworthy are the theoretically considerations on joint driver-vehicle interaction by Erik Hollnagel (Hollnagel, 2006) and the H-mode projects by Frank Flemisch and Johann Kelsch (Flemisch et al., 2014). The latter consist of a horse (i.e. " $\mathrm{H}^{\prime \prime}$ ) metaphor with force feedback in a joystick-like control. Analogue to holding reins when horse riding, the control-device allows to tighten up or let go control and therefor choses the level of authority given to the vehicle. While levering the authority given to the vehicle, joystick-like controls could also be a solution to shift easier between being engaged in either driving or non-driving 
tasks. Experiments have also demonstrated that these joystick-like controls enable integration of longitudinal and lateral control in one device. Therefore, application of an additional and dedicated control to perform secondary tasks might become more feasible. Furthermore, studies have shown that joystick-like interfaces are more intuitive for untrained drivers (Flemisch et al., 2014). This could be an indication that such interfaces are less effort-taking. This is not only an advantage to raise performance in unexpected situations requiring fast responses. The operation of different controls expands the (cognitive) demands placed on the driver. Therefore the reduced control effort would be an additional advantage to enhance the primary driving task. The ease to efficiently shift between being engaged in either driving or non-driving tasks is also facilitated by control placement and cockpit design. If, for example, the steering control is replaced by a joystick and the freed-up space would allow for an information panel which could create further advantages. Then, non-driving information could be provided in a mediated way on the information panel and would be accessible when circumstances allow and should be interrupted when the joint driver-vehicle system requires full human attention. Furthermore, there is not only a growing demand to facilitate shifting between driving controls and non-driving controls, but also for shifting between controls for different kind of assistance functions. For instance, Traffic Jam assist, Adaptive Cruise Control and automated parking. To conclude: it is strongly recommended to research how new controlsolutions, along with research on a renewed cockpit and interior design, would comply better with the need to easily shift between being engaged in a variety of manually driving, supervision and non-driving tasks. This could help to gain more comfort-benefits from utilization of automated driving.

\section{Perceived comfort}

Apart from physical means specifically designed to comfortably operate driving and nondriving tasks, the appraisal of automated driving will also depend on perceived comfort. This is because comfort is directly related to people's mind-set, i.e. to the degree of technologyacceptance and willingness to hand over authority to the system. From other areas of transport which incorporate a high degree of automation, we observe that the probability of being involved in an accident is very low, but the consequences generally high. An example is when trucks are driving in a platoon, if then a truck in front brakes and the next truck has lost the data-connection, the consequences are severe and might be fatal. In general, the ease of acceptance seems inversely proportional to the level of automation unless automation is applied in a completely controlled environment. It is disputable whether people value reduced effort when this involves a loss of authority with considerably perceived risks. It is most likely that people favour extra comfort in moderate and not too risky situations only and prefer to keep authority in all other situations. This presumption is in line with existing research on user preferences of ADAS (Brookhuis et al., 2009; Hoedemaeker, 2000; Trösterer, Wurhofer, Rödel, \& Tscheligi, 2014; Van Driel, 2007) and cause restraints with regard to the scale of expected comfort-benefits gained from automated driving. 


\section{Conclusion and recommendations for further research}

The conclusions from this section, on the appraisal between required efforts and gained benefits, are that: (1) Raised comfort is not intrinsic to application of automated driving; (2) Additional measures are required in order to gain comfort advantages from utilization of automated driving. Based on discussion described above the following recommendations for further research are made:

* Prolonged field operational tests are needed to compare vehicles with and without driving automation in a variety of circumstances. This approach is important to gain detailed answers on the appraisal between required efforts and gained comfort. Field operational tests are also important to reveal long term implications like behavioural adaptation (as referred to in the introduction) and to check for counter-productive effects that are not anticipated.

* Further research is needed on control-solutions for the driver's changing role towards the supervision of the automation that respect demand from additional assistance systems. For example; research how controls for supervision and intervention are applicable for other ADAS, like automated parking or adaptive cruise control.

* In addition, research is recommended arond the design and development of controls that allow a more combined approach to operate driving and non-driving related tasks and subsequently shift more efficiently between operating the two. This is important because controls that offer such quality of function operability are expected to enable more comfort advantages from application of automated driving.

\subsubsection{Context regarding car mobility}

It is unlikely that the ultimate responsibility for driving will be removed from the human driver within the next decades (Etemad, 2015; Van Witsen, 2016). Revised legislation might broaden legal possibilities for prolonged automated driving (for example on highways) (Nowakowski, Shladover, \& Chan, 2016). However, prolonged times of being detached from the driving task will actually increase the risk of performance problems introduced in Chapter 2, like reduced situation awareness, slower reaction times and skill degradation. As a consequence, the driver's changing role places considerable pressure upon the driver's ability to take responsibility. Hence, the liability of automated driving also remains a difficult case for insurers. That is, drivers remain from a legislative point of view responsible, but who is liable when shortcomings in system-design actually cause an accident? The difficulties of liability, underline that solutions to support drivers in coping with the changing demands for supervision and intervention, aren't only desired but also required in order to successfully introduce automated driving.

Moreover, we anticipate a remarkable change in level of responsibility, as driving automation actually transfers mobility to a service rather than a personal means for travelling. The extent to which automated driving will be established as a service is difficult to predict (Infra \& Milieu, 
2015). It is however important to consider the consequences from becoming a service: People who use car service on demand or participate in car sharing are less likely to build up experience with a particular car brand. Some training or instructions from the service provider might become mandatory, but more likely, users will become more demanding. With private ownership people generally feel responsible for their vehicle and show some forgivingness to suboptimal performance (for instance because the car has known shortcomings due to age). However, customers will require more reliability and are likely to feel less responsible when car mobility becomes a service. When faced with different service providers, the need for standardization grows. Hence, research is needed towards the development of new standards for vehicle-control.

In general, the recommendation from this discussion on legislation, liability and responsibility is that research is needed on how these aspects will change the demands on the driver-vehicle interface for cars equipped with driving automation. This should include investigating the acceptability of possible interface solutions for all parties, like government, insurers, manufacturers, customers and drivers.

\subsection{Final conclusion}

This thesis addresses interface design for automated driving and specifically focuses on the means to support the driver in his changing role from actively operating the vehicle to supervising the automation. This support is needed because supervision (with occasionally a necessity for intervention) is considered a more difficult task for the driver than manual control. This thesis firstly proposes an assessment framework to evaluate interface performance with regard to desired support and discloses its first contribution aiming at efficient development of comfortable, yet in-control and safe means of operating automated vehicles. Secondly, a series of three experiments with five interface-concepts provided insight in interface-features that benefit the creation of desired support for supervision and intervention. It is demonstrated that supervision and intervention benefit from different support features. Application of 'directional illumination', i.e. a spatial cue based on illumination around the windscreen and side-windows, reveals strong indications to provide support for supervision. With regard to support for intervention, this thesis provides several design guidelines.

Because automated driving is intended to improve safety and raise comfort, we also discussed how the driver's changing role influences the practicality of these advantages. This discussion reveals that considerable further improvements are required in order for the automation to become beneficial. Additional improvements are proposed, like training for supervision and intervention, solutions for joint driver-vehicle control and cockpit design that mediates access to non-driving functions. Without these improvements the change in driver's role will reduce the advantages of automated driving. This leaves the benefits of driving automation to be deceptive. Despite expected future technological advances, driving automation of passenger 
vehicles within existing infrastructure will demand a changing role from the driver. Therefore, cooperation between driver and vehicle remains imperative to safe and comfortable vehiclecontrol and so does the means for this cooperation, i.e. the driver-vehicle interface.

This thesis addresses the persisting need to support the change in role of the driver from just driving to supervising and intervening. Along with the proposed assessment framework and identified design recommendations, the thesis herewith delivers a major contribution to a more prevalent human-centred development for a future range of automated vehicles intended to take benefits from raised comfort and safety. 


\section{References}

2getthere. (2016). Automated Transit Networks. Company Brochure.

Abbink, D. A., \& Mulder, M. (2010). Motivation for a neuromuscular basis for haptic shared control. Paper presented at the Analysis, Design, and Evaluation of Human-Machine Systems Conference.

Abbink, D. A., Mulder, M., \& Boer, E. R. (2012). Haptic shared control: smoothly shifting control authority? Cognition, Technology \& Work, 14(1), 19-28.

adaptIVe. (2016). Automated Driving Applications and Technologies for intelligent vehicles. EU-FP7 project: adaptIVe.

Andre, A. D., \& Wickens, C. D. (1995). When users want what's not best for them. Ergonomics in Design: The Quarterly of Human Factors Applications, 3(4), 10-14.

Audi. (2016). Audi Traffic Jam Assist [online].

Bainbridge, L. (1983). Ironies of automation. Automatica, 19(6), 775-779. doi:10.1016/0005-1098(83) 90046-8

Baldwin, C. L., \& Lewis, B. A. (2014). Perceived urgency mapping across modalities within a driving context. Applied Ergonomics, 45(5), 1270-1277. doi:10.1016/j.apergo.2013.05.002

Baldwin, C. L., \& May, J. F. (2011). Loudness interacts with semantics in auditory warnings to impact rear-end collisions. Transportation Research Part F-Traffic Psychology and Behaviour, 14(1), 3642. doi:10.1016/j.trf.2010.09.004

Becker, S., Hanna, P., \& Wagner, V. (2014). Human Machine Interface Design in Modern Vehicles. Encyclopedia of Automotive Engineering.

Beller, J., Heesen, M., \& Vollrath, M. (2013). Improving the driver-automation interaction an approach using automation uncertainty. Human Factors: The Journal of the Human Factors and Ergonomics Society, 55(6), 1130-1141.

Bengler, K., Dietmayer, K., Farber, B., Maurer, M., Stiller, C., \& Winner, H. (2014). Three decades of driver assistance systems: Review and future perspectives. Intelligent Transportation Systems Magazine, IEEE, 6(4), 6-22.

Benyon, D. (2010). Designing Interactive Systems - A comprehensive guide to $\mathrm{HCl}$ and interaction design. Harlow, UK: Pearson.

Bergenhem, C., Shladover, S., Coelingh, E., Englund, C., \& Tsugawa, S. (2012). Overview of platooning systems. Paper presented at the Proceedings of the 19th ITS World Congress, Oct 22-26, Vienna, Austria (2012).

Bishop, R. (2005). Intelligent vehicle technology and trends. Norwood, MA Artech House Publishers.

Blumenthal, T. D. (1996). Inhibition of the human startle response is affected by both prepulse intensity and eliciting stimulus intensity. Biological psychology, 44(2), 85-104. 
Bolovinou, A., Kotsiourou, C., \& Amditis, A. (2013). Dynamic road scene classification: Combining motion with a visual vocabulary model. Paper presented at the 16th International Conference on Information Fusion (FUSION), 2013.

Bradley, R. (2016). The electric-vehicle maker sent its cars a software update that suddenly made autonomous driving a reality. MIT Technology Review.

Braun, C. C., Sansing, L., Kennedy, R. S., \& Silver, N. C. (1994). Signal word and color specifications for product warnings: an isoperformance application. Paper presented at the Proceedings of the Human Factors and Ergonomics Society Annual Meeting.

Braun, C. C., Sansing, L., \& Silver, N. C. (1994). The interaction of signal word and color on warning labels: Differences in perceived hazard. Paper presented at the Proceedings of the Human Factors and Ergonomics Society Annual Meeting.

Brookhuis, K. A., De Waard, D., \& Janssen, W. H. (2001). Behavioural impacts of advanced driver assistance systems-an overview. European Journal of Transport and Infrastructure Research, 1(3), 245-253.

Brookhuis, K. A., van Driel, C. J., Hof, T., van Arem, B., \& Hoedemaeker, M. (2009). Driving with a congestion assistant; mental workload and acceptance. Applied Ergonomics, 40(6), 1019-1025.

Broström, R., Engström, J., Agnvall, A., \& Markkula, G. (2006). Towards the next generation intelligent driver information system (IDIS): The Volvo car interaction manager concept. Paper presented at the Proceedings of the 2006 ITS World Congress.

Campbell, M., Egerstedt, M., How, J. P., \& Murray, R. M. (2010). Autonomous driving in urban environments: approaches, lessons and challenges. Philosophical Transactions of the Royal Society of London A: Mathematical, Physical and Engineering Sciences, 368(1928), 4649-4672.

Carsten, O., Lai, F. C., Barnard, Y., Jamson, A. H., \& Merat, N. (2012). Control Task Substitution in Semiautomated Driving Does It Matter What Aspects Are Automated? Human Factors: The Journal of the Human Factors and Ergonomics Society, 54(5), 747-761.

Chapanis, A. (1994). Hazards associated with three signal words and four colours on warning signs. Ergonomics, 37(2), 265-275. doi:10.1080/00140139408963644

Charlton, S. G. (2002). Measurement of cognitive states in test and evaluation. In S. G. Charlton \& T. G. O'Brien (Eds.), Handbook of Human Factors Testing and Evaluation (pp. 97-125). Mahwah, NJ: Lawrence Erlbaum Associates.

Continental (Producer). (2013). Continental counts on LEDs as co-pilot [online].

Creswell, J. W., \& Clark, V. L. P. (2007). Designing and conducting mixed methods research. Thousand Oaks, CA: Sage.

Daimler. (2015). Active Lane Keeping Assist for Mercedes-Benz passenger cars [online]. Retrieved from www.daimler.com/ Technology \& Innovation > Safety

Damiani, S., Deregibus, E., \& Andreone, L. (2009). Driver-vehicle interfaces and interaction: Where are they going? European Transport Research Review, 1(2), 87-96. doi:10.1007/s12544-009-00092 
De Winter, J. C. F., Happee, R., Martens, M. H., \& Stanton, N. A. (2014). Effects of adaptive cruise control and highly automated driving on workload and situation awareness: A review of the empirical evidence. Transportation Research Part F: Traffic Psychology and Behaviour, 27, Part B, 196217. doi:10.1016/j.trf.2014.06.016

Dirken, H. (1997). Product-ergonomie: Delft University Press, Delft,(in Dutch).

Donges, E. (1999). A Conceptual Framework for Active Safety in Road Traffic. Vehicle System Dynamics, 32(2-3), 113-128. doi:10.1076/vesd.32.2.113.2089

Dziennus, M., Kelsch, J., \& Schieben, A. (2015). Ambient light based interaction concept for an integrative driver assistance system-a driving simulator study. Paper presented at the HFES 2015, Groningen.

Edworthy, J., Hellier, E., Walters, K., Clift-Mathews, W., \& Crowther, M. (2003). Acoustic, semantic and phonetic influences in spoken warning signal words. Applied Cognitive Psychology, 17(8), 915933. doi:10.1002/acp.927

Edworthy, J., Loxley, S., \& Dennis, I. (1991). Improving auditory warning design: Relationship between warning sound parameters and perceived urgency. Human Factors, 33(2), 205-231.

Endsley, M. R. (1995a). Measurement of Situation Awareness in Dynamic-Systems. Human Factors, 37(1), 65-84. doi:10.1518/001872095779049499

Endsley, M. R. (1995b). Toward a Theory of Situation Awareness in Dynamic-Systems. Human Factors. The Journal of the Human Factors and Ergonomics Society, 37(1), 32-64. doi:10.1518/ 001872095779049543

Endsley, M. R. (1995c). Towards a new paradigm for automation: Designing for situation awareness. Analysis, Design and Evaluation of Man-Machine Systems 1995, Vols 1 and 2, 365-370.

Endsley, M. R. (1996). Automation and situation awareness. In R. Parasuraman \& M. Mouloua (Eds.), Automation and human performance: Theory and applications (pp. 163-181). Mahwah, NJ: Lawrence Erlbaum.

Endsley, M. R., \& Connors, E. S. (2008). Situation Awareness: State of the Art. 2008 leee Power \& Energy Society General Meeting, Vols 1-11, 945-948.

Endsley, M. R., \& Garland, D. J. (2000). Pilot situation awareness training in general aviation. Paper presented at the Proceedings of the Human Factors and Ergonomics Society Annual Meeting.

Endsley, M. R., \& Kaber, D. B. (1999). Level of automation effects on performance, situation awareness and workload in a dynamic control task. Ergonomics, 42(3), 462-492. doi:10.1080/ 001401399185595

Endsley, M. R., \& Kiris, E. O. (1995). The out-of-the-loop performance problem and level of control in automation. Human Factors: The Journal of the Human Factors and Ergonomics Society, 37(2), 381-394.

Endsley, M. R., Selcon, S. J., Hardiman, T. D., \& Croft, D. G. (1998). A comparative analysis of SAGAT and SART for evaluations of situation awareness. Proceedings of the Human Factors and Ergonomics Society 42nd Annual Meeting, Vols 1 and 2, 82-86.

Engström, J., \& Hollnagel, E. (2007). A general conceptual framework for modelling behavioural effects of driver support functions. In P. C. Cacciabue (Ed.), Modelling Driver Behaviour in Automotive Environments (pp. 61-84). London: Springer. 
Etemad, A. (2015). Automated Driving - What is possible today? (www.adaptive-ip.eu). from EU FP7project adaptIVe

EU. (2011). White paper: Roadmap to a Single European Transport Area-Towards a competitive and resource efficient transport system.: European Commission Retrieved from http://eurlex.europa.eu/.

Evers, V., Winterboer, A., Pavlin, G., \& Groen, F. (2010). The evaluation of empathy, autonomy and touch to inform the design of an environmental monitoring robot. Paper presented at the International Conference on Social Robotics.

Fagerlonn, J. (2011). Urgent alarms in trucks: effects on annoyance and subsequent driving performance. IET Intelligent Transport Systems, 5(4), 252-258. doi:10.1049/iet-its.2010.0165

Fahlquist, J. N. (2006). Responsibility ascriptions and vision zero. Accident analysis \& prevention, 38(6), 1113-1118.

Farrell, S., \& Lewandowsky, S. (2000). A connectionist model of complacency and adaptive recovery under automation. Journal of Experimental Psychology: Learning, Memory, and Cognition, 26(2), 395.

Ferris, T., Penfold, R., Hameed, S., \& Sarter, N. (2006). The implications of crossmodal links in attention for the design of multimodal interfaces: A driving simulation study. Paper presented the Proceedings of the Human Factors and Ergonomics Society Annual Meeting.

Fitch, G. M., Hankey, J. M., Kleiner, B. M., \& Dingus, T. A. (2011). Driver comprehension of multiple haptic seat alerts intended for use in an integrated collision avoidance system. Transportation Research Part F: Traffic Psychology and Behaviour, 14(4), 278-290. doi:10.1016/j.trf. 2011.02.001

Flemisch, F., Bengler, K., Bubb, H., Winner, H., \& Bruder, R. (2014). Towards cooperative guidance and control of highly automated vehicles: H-Mode and Conduct-by-Wire. Ergonomics, 57(3), 343360. doi:10.1080/00140139.2013.869355

Flemisch, F., Heesen, M., Hesse, T., Kelsch, J., Schieben, A., \& Beller, J. (2012). Towards a dynamic balance between humans and automation: authority, ability, responsibility and control in shared and cooperative control situations. Cognition, Technology \& Work, 14(1), 3-18.

Flemisch, F., Kelsch, J., Löper, C., Schieben, A., Schindler, J., \& Heesen, M. (2008). Cooperative Control and Active Interfaces for Vehicle Assistance and Automation. Paper presented at the FISITA World Automotive Congress, Münich.

Fornasiero, E. (2011). Evaluation of the effectiveness of "innovative" and "unconventional" systems in urban areas. IUAV University of Venice, Venice, Italy.

Fracker, M. L. (1991). Measures of situation awareness: Review and future directions. Retrieved from Springfield, VA: Defense Technical Information Center

Gartenberg, D., McCurry, M., \& Trafton, G. (2011). Situation Awareness Reacquisition in a Supervisory Control Task. Paper presented at the Proceedings of the Human Factors and Ergonomics Society Annual Meeting.

Gasser, T. M., \& Westhoff, D. (2012). BASt-study: Definitions of automation and legal issues in Germany. Paper presented at the Road Vehicle Automation Workshop. 
General_Motors. (1956, Last visited April 24th, 2016). Progress Possibility - The Electronically Controlled Car on the Safety Autoway of Tomorrow. Oldcarbrochures.com.

Geyer, S., Baltzer, M., Franz, B., Hakuli, S., Kauer, M., Kienle, M., . . W Winner, H. (2014). Concept and development of a unified ontology for generating test and use-case catalogues for assisted and automated vehicle guidance. IET Intelligent Transport Systems, 8(3), 183-189. doi:10.1049/ietits. 2012.0188

Gold, C., Damböck, D., Lorenz, L., \& Bengler, K. (2013). "Take over!" How long does it take to get the driver back into the loop? Paper presented at the Proceedings of the Human Factors and Ergonomics Society Annual Meeting.

Google. (2016). Google Self Driving Car - Company Website.

Götze, M., \& Bengler, K. (2015). Urban Driving: Where to Present What Types of InformationComparison of Head-Down and Head-Up Displays Human Interface and the Management of Information. Information and Knowledge in Context (pp. 190-200): Springer.

Green, P., Sullivan, J., Tsimhoni, O., Oberholtzer, J., Buonarosa, M. L., Devonshire, J., ... Sayer, J. (2008). Integrated vehicle-based safety systems (IVBSS): Human factors and driver-vehicle interface (DVI) summary report. Retrieved from

Guizzo, E. (2011). How Google's Self-Driving Car Works.

Gunia, D., Kashi, A., Merz, M., Roeber, M., Wegner, G., \& Paffrath, S. (2011). Traffic Jam Assist Scenarios \& Requirements. Retrieved from Köln, Germany:

Hale, A. R., Stoop, J., \& Hommels, J. (1990). Human error models as predictors of accident scenarios for designers in road transport systems. Ergonomics, 33(10-11), 1377-1387.

Harris, D. H. (2002). Human Performance Testing. In S. G. Charlton \& T. G. O'Brien (Eds.), Handbook of Human Factors Testing and Evaluation (pp. 79-95). Mahwah, NJ: Lawrence Erlbaum Associates.

Harvey, C., Stanton, N. A., Pickering, C. A., McDonald, M., \& Zheng, P. (2011). A usability evaluation toolkit for In-Vehicle Information Systems (IVISs). Applied Ergonomics, 42(4), 563-574. doi:10.1016/j.apergo.2010.09.013

Hellier, E., \& Edworthy, J. (1999). On using psychophysical techniques to achieve urgency mapping in auditory warnings. Applied Ergonomics, 30(2), 167-171. doi:10.1016/S0003-6870(97)00013-6

Hesse, T., Engström, J., Johansson, E., Varalda, G., Brockmann, M., Rambaldini, A., . . Kanstrup, L. (2011). Towards user-centred development of integrated information, warning, and intervention strategies for multiple ADAS in the EU project interactive Universal Access in Human-Computer Interaction. Context Diversity (pp. 280-289): Springer.

Hesse, T., Johansson, E., Brockmann, M., Rambaldini, A., Kelsch, J., Fricke, N., \& Etemad, A. (2012). Information, Warning \& Intervention (IWI) Strategies. Retrieved from www.interactive-ip.eu

Ho, C., Reed, N., \& Spence, C. (2007). Multisensory in-car warning signals for collision avoidance. Human Factors: The Journal of the Human Factors and Ergonomics Society, 49(6), 1107-1114.

Ho, C., Tang, H. Z., \& Spence, C. (2005). Using spatial vibrotactile cues to direct visual attention in driving scenes. Transportation Research Part F-Traffic Psychology and Behaviour, 8(6), 397-412. doi:10.1016/j.trf.2005.05.002 
Hoc, J.-M., Young, M. S., \& Blosseville, J.-M. (2009). Cooperation between drivers and automation: implications for safety. Theoretical Issues in Ergonomics Science, 10(2), 135-160.

Hoedemaeker, M. (2000). Driving with intelligent vehicles: Driving behavior with ACC and the acceptance by individual drivers. Proceeding of the IEEE Intelligent Transportation Systems, Dearborn, MI.

Hoedemaker, M., \& Kopf, M. (2001). Visual sampling behaviour when driving with adaptive cruise control. Paper presented at the Proceedings of the Ninth International Conference on Vision in Vehicles. Australia.

Hoffman, J., Lee, J. D., \& Hayes, E. M. (2003). Driver preference of collision warning strategy and modality. Paper presented at the Proceedings of the Second International Driving Symposium on Human Factors in Driver Assessment, Training and Vehicle Design.

Hollnagel, E. (2006). A function-centred approach to joint driver-vehicle system design. Cognition, Technology \& Work, 8(3), 169-173.

Hollnagel, E. (2011). The human in control: Modelling what goes right versus what goes wrong. Paper presented at the Human modelling in assisted transportation: models, tools and risk methods, Milan.

Hurts, K., Angell, L. S., \& Perez, M. A. (2011). The Distracted Driver: Mechanisms, Models, and Measurement. Reviews of Human Factors and Ergonomics, 7(1), 3-57. doi:10.1177/ $1557234 \times 11410387$

Infra, \& Milieu. (2015). Chauffeur aan het stuur? Ministerie van Infrastructuur en Milieu. Retrieved from http://www.kimnet.nl/sites/kimnet.nl/files/chauffer-aan-het-stuur.pdf

Isermann, R., Schorn, M., \& Stählin, U. (2008). Anticollision system PRORETA with automatic braking and steering. Vehicle System Dynamics, 46(sup1), 683-694. doi:10.1080/00423110802036968

Jamson, A. H., Merat, N., Carsten, O. M. J., \& Lai, F. C. H. (2013). Behavioural changes in drivers experiencing highly-automated vehicle control in varying traffic conditions. Transportation Research Part C: Emerging Technologies, 30, 116-125. doi:10.1016/j.trc.2013.02.008

Jin, S., \& Kaber, D. B. (2009). The role of driver cognitive abilities and distractions in situation awareness and performance under hazard conditions. Paper presented at the proceedings of the IEA 2009 17th World Congress on Ergonomics, Beijing, China.

Johnson, R. B., \& Onwuegbuzie, A. J. (2004). Mixed methods research: A research paradigm whose time has come. Educational researcher, 33(7), 14-26.

Kaber, D. B., \& Endsley, M. R. (1997). Out-of-the-loop performance problems and the use of intermediate levels of automation for improved control system functioning and safety. Process Safety Progress, 16(3), 126-131.

Kaber, D. B., \& Endsley, M. R. (2004). The effects of level of automation and adaptive automation on human performance, situation awareness and workload in a dynamic control task. Theoretical Issues in Ergonomics Science, 5(2), 113-153.

Kammel, S., Ziegler, J., Pitzer, B., Werling, M., Gindele, T., Jagzent, D., ... Hundelshausen, F. v. (2008). Team AnnieWAY's autonomous system for the 2007 DARPA Urban Challenge. Journal of Field Robotics, 25(9), 615-639. 
Kass, S. J., Cole, K., \& Legan, S. (2008). The role of situation awareness in accident prevention. In A. De Smet (Ed.), Transportation Accident Analysis and Prevention (pp. 107-122): Nova Science Publishers, Inc.

Kazi, T. A., Stanton, N. A., Young, M. S., \& Harrison, D. (2005). Assessing drivers' level of trust in Adaptive Cruise Control and their conceptual models of the system: implications for system design. Driver behaviour and training, 2, 133.

Kelsch, J., \& Dziennus, M. (2015). Joint driver-automation system design: Gradual action-oriented ambient stimuli. Paper presented at the HFES EUROPE 2015, Groningen, The Netherlands.

Key, C. E. J., Morris, A. P., \& Mansfield, N. J. (2016). Situation Awareness: Its proficiency amongst older and younger drivers, and its usefulness for perceiving hazards. Transportation Research Part F: Traffic Psychology and Behaviour, 40, 156-168.

Kiefer, D., LeBlanc, D., Palmer, M., Salinger, J., Deering, R., \& Shulman, M. (1999). Development and validation of functional definitions and evaluation procedures for collision warning/avoidance systems. Retrieved from http://ntl.bts.gov/lib/jpodocs/repts_te/87101!.pdf.

Kokar, M. M., \& Endsley, M. R. (2012). Situation Awareness and Cognitive Modeling. leee Intelligent Systems, 27(3), 91-96.

Lagervik, C., \& Gustavsson, P. M. (2006). A System Theoretical Approach to Situation Awareness and its Application, A Holistic View of Purposeful Elements. Paper presented at the 11th International Command and Control Research Symposium.

Landau, K. (2002). Usability criteria for intelligent driver assistance systems. Theoretical Issues in Ergonomics Science, 3(4), 330-345. doi:10.1080/14639220210137748

Lansdown, T. C., Brook-Carter, N., \& Kersloot, T. (2004). Distraction from multiple in-vehicle secondary tasks: Vehicle performance and mental workload implications. Ergonomics, 47(1), 91-104. doi:10.1080/00140130310001629775

Larsson, A. F. L., Kircher, K., \& Andersson Hultgren, J. (2014). Learning from experience: Familiarity with ACC and responding to a cut-in situation in automated driving. Transportation Research Part F: Traffic Psychology and Behaviour, 27, Part B, 229-237. doi:10.1016/j.trf.2014.05.008

Lee, F. C. H., \& Chan, A. H. S. (2007). Attending visual and auditory signals: Ergonomics recommendations with consideration of signal modality and spatial stimulus-response (S-R) compatibility. International Journal of Industrial Ergonomics, 37(3), 197-206. doi:10.1016/ j.ergon.2006.10.017

Lee, H. K., Suh, K. S., \& Benbasat, I. (2001). Effects of task-modality fit on user performance. Decision Support Systems, 32(1), 27-40. doi:10.1016/S0167-9236(01)00098-7

Lee, J. D., Hoffman, J. D., \& Hayes, E. (2004). Collision warning design to mitigate driver distraction.

Lee, J. D., \& See, K. A. (2004). Trust in automation: Designing for appropriate reliance. Human Factors: The Journal of the Human Factors and Ergonomics Society, 46(1), 50-80.

Lee, J. D., Ward, N., Boer, E. R., Brown, T., Balk, S., \& Ahmed, O. (2013). Making driving simulators more useful for behavioral research - Simulator characteristics comparison and model-based transformation. lowa City, IA: University of lowa - National Advanced Driving Simulator.

Lipp, O. V., Siddle, D. A., \& Dall, P. J. (2000). The effect of warning stimulus modality on blink startle modification in reaction time tasks. Psychophysiology, 37(01), 55-64. 
Lippert, J., \& Clark, J. (2016). Google to Make Driverless Cars in 2016. from Bloomberg

Liu, Y.-C., \& Jhuang, J.-W. (2012). Effects of in-vehicle warning information displays with or without spatial compatibility on driving behaviors and response performance. Applied Ergonomics, 43(4), 679-686. doi:http://dx.doi.org/10.1016/j.apergo.2011.10.005

Locken, A., Muller, H., Heuten, W., \& Boll, S. (2015, June 28 2015-July 1 2015). An experiment on ambient light patterns to support lane change decisions. Paper presented at the Intelligent Vehicles Symposium (IV), 2015 IEEE.

Ma, R. Q. (2006). The Effects of In-vehicle Automation and Reliability on Driver Situation Awareness and Trust. North Carolina State University, Raleigh, NC.

Ma, R. Q., \& Kaber, D. B. (2005). Situation awareness and workload in driving while using adaptive cruise control and a cell phone. International Journal of Industrial Ergonomics, 35(10), 939-953. doi:DOI 10.1016/j.ergon.2005.04.002

Mäkinen, T., Sjögren, A., Hesse, T., Suermann, M., Engström, J., \& Etemad, A. (2010). Use Cases and Requirements of Accident Avoidance by Active Intervention for Intelligent Vehicles. Retrieved from interactIVe European Project 7th Framework Programme:

Marshall, D. C., Lee, J. D., \& Austria, P. A. (2007). Alerts for in-vehicle information systems: Annoyance, urgency, and appropriateness. Human Factors, 49(1), 145-157. doi:10.1518/ 001872007779598145

Martens, M. H. (2007). The failure to act upon important information: where do things go wrong. (PhDthesis), Vrije Universiteit, Amsterdam, The Netherlands.

Martens, M. H., Pauwelussen, Schieben, Flemisch, F., Merat, Jamson, \& Caci. (2008). Human Factors' aspects in automated and semi-automatic transport systems: State of the art. Retrieved from http://www.citymobil-project.eu/

Martens, M. H., \& Van den Beukel, A. P. (2013). The road to automated driving: Dual mode and human factors considerations. Paper presented at the 16th International IEEE Conference on Intelligent Transportation Systems-(ITSC), 2013.

Matthews, M., Bryant, D., Webb, R., \& Harbluk, J. (2001). Model for situation awareness and driving: Application to analysis and research for intelligent transportation systems. Transportation Research Record(1779), 26-32.

MB-world. (2015). MBWorld.org Forums - Active Lane Keeping Assist.

McRuer, D. T., Allen, R. W., Weir, D. H., \& Klein, R. H. (1977). New results in driver steering control models. Human Factors: The Journal of the Human Factors and Ergonomics Society, 19(4), 381397.

Merat, N., Jamson, A. H., Lai, F. C., \& Carsten, O. (2012). Highly automated driving, secondary task performance, and driver state. Human Factors: The Journal of the Human Factors and Ergonomics Society, 54(5), 762-771.

Merat, N., Jamson, A. H., Lai, F. C. H., Daly, M., \& Carsten, O. M. J. (2014). Transition to manual: Driver behaviour when resuming control from a highly automated vehicle. Transportation Research Part F: Traffic Psychology and Behaviour, 27, 274-282. doi:10.1016/j.trf.2014.09.005 
Merat, N., \& Lee, J. D. (2012). Preface to the special section on human factors and automation in vehicles designing highly automated vehicles with the driver in mind. Human Factors: The Journal of the Human Factors and Ergonomics Society, 54(5), 681-686.

Michon, J. A. (1985). A critical view of driver behavior models: what do we know, what should we do? In L. Evans \& R. C. Schwing (Eds.), Human behavior and traffic safety (pp. 485-524). New York: Springer.

Miller, C. A., Funk, H., Goldman, R., Meisner, J., \& Wu, P. (2005). Implications of adaptive vs. adaptable Uls on decision making: Why "automated adaptiveness" is not always the right answer. Paper presented at 1st international conference on augmented cognition.

Miller, C. A., \& Parasuraman, R. (2007). Designing for flexible interaction between humans and automation: Delegation interfaces for supervisory control. Human Factors: The Journal of the Human Factors and Ergonomics Society, 49(1), 57-75.

Morris, A. P., Reed, S., Welsh, R., Brown, L., \& Birrell, S. (2015). Distraction effects of navigation and green-driving systems-results from field operational tests (FOTs) in the UK. European Transport Research Review, 7(3), 1-9.

Mulder, M., Abbink, D. A., \& Boer, E. R. (2012). Sharing Control With Haptics Seamless Driver Support From Manual to Automatic Control. Human Factors: The Journal of the Human Factors and Ergonomics Society, 54(5), 786-798.

Mulder, M., Van Paassen, M. M., \& Abbink, D. A. (2008). Haptic gas pedal feedback. Ergonomics, 51(11), 1710-1720. doi:10.1080/00140130802331583

Naujoks, F., Purucker, C., Neukum, A., Wolter, S., \& Steiger, R. (2015). Controllability of Partially Automated Driving functions - Does it matter whether drivers are allowed to take their hands off the steering wheel? Transportation Research Part F: Traffic Psychology and Behaviour, 35, 185-198. doi:10.1016/j.trf.2015.10.022

Nielsen, J. (1992). Finding usability problems through heuristic evaluation. Paper presented at the Proceedings of the SIGCHI conference on Human factors in computing systems.

Nielsen, J. (2005). Ten usability heuristics. www.nngroup.com.

Nieto, M., Otaegui, O., Vélez, G., Ortega, J. D., \& Cortés, A. (2015). On creating vision-based advanced driver assistance systems. IET Intelligent Transport Systems, 9(1), 59-66. doi:10.1049/ietits.2013.0167

Nieuwenhuijsen, J. (2015). Diffusion of Automated Vehicles: A quantitative method to model the diffusion of automated vehicles with system dynamics. TU Delft, Delft University of Technology.

Nirschl, G. (2007). Human-centered development of advanced driver assistance systems Human Interface and the Management of Information. Interacting in Information Environments (pp. 1088-1097): Springer.

Norman, D. A. (1983). Some observations on mental models. Mental models, 7(112), 7-14.

Norman, D. A. (1990). The'problem'with automation: inappropriate feedback and interaction, not'overautomation'. Philosophical Transactions of the Royal Society B: Biological Sciences, 327(1241), 585-593. 
Nowakowski, C., Shladover, S. E., \& Chan, C.-Y. (2016). Development of Behavioral Competency Requirements to Determine the Readiness of Automated Driving Systems for Public Operations. Paper presented at the Transportation Research Board 95th Annual Meeting.

Oppermann, R. (1994). Adaptive user support: ergonomic design of manually and automatically adaptable software. Hillsdale, NJ: Erlbaum.

Parasuraman, R., Galster, S., Squire, P., Furukawa, H., \& Miller, C. (2005). A flexible delegation-type interface enhances system performance in human supervision of multiple robots: Empirical studies with RoboFlag. Systems, Man and Cybernetics, Part A: Systems and Humans, IEEE Transactions on, 35(4), 481-493.

Patten, C. J., Kircher, A., Östlund, J., \& Nilsson, L. (2004). Using mobile telephones: cognitive workload and attention resource allocation. Accident analysis \& prevention, 36(3), 341-350.

Payre, W., Cestac, J., \& Delhomme, P. (2014). Intention to use a fully automated car: Attitudes and a priori acceptability. Transportation Research Part F: Traffic Psychology and Behaviour, 27, Part B, 252-263. doi:http://dx.doi.org/10.1016/j.trf.2014.04.009

Petermeijer, S. M., de Winter, J. C., \& Bengler, K. J. (2016). Vibrotactile displays: A survey with a view on highly automated driving. leee Transactions on Intelligent Transportation Systems, 17(4), 897-907.

Pfromm, M., Cieler, S., \& Bruder, R. (2013). Driver assistance via optical information with spatial reference. Paper presented at the IEEE Conference on Intelligent Transportation Systems, ITSC, The Hague, Netherlands.

Pohl, J., Sethsson, M., Degerman, P., \& Larsson, J. (2006). A semi-automated parallel parking system for passenger cars. Proceedings of the Institution of Mechanical Engineers, Part D: Journal of Automobile Engineering, 220(1), 53-65.

PReVENT. (2009). Response 3 - Code of Practice for the Design and Evaluation of ADAS. Retrieved from http://www.acea.be/ images/uploads/files/20090831 Code_of_Practice_ADAS.pdf

Radlmayr, J., Gold, C., Lorenz, L., Farid, M., \& Bengler, K. (2014). How traffic situations and non-driving related tasks affect the take-over quality in highly automated driving. Paper presented at the Proceedings of the Human Factors and Ergonomics Society Annual Meeting.

Rajamani, R., Tan, H.-S., Law, B. K., \& Zhang, W.-B. (2000). Demonstration of integrated longitudinal and lateral control for the operation of automated vehicles in platoons. Control Systems Technology, IEEE Transactions on, 8(4), 695-708.

Rasmussen, J. (1982). Human errors. A taxonomy for describing human malfunction in industrial installations. Journal of occupational accidents, 4(2), 311-333.

Rasmussen, J. (1983). Skills, rules, and knowledge; signals, signs, and symbols, and other distinctions in human performance models. IEEE Transactions on Systems, Man and Cybernetics, 13(3), 257266.

Risto, M. (2014). Cooperative in-vehicle advice: a study into drivers' ability and willingness to follow tactical driver advice. (PhD-thesis), University of Twente, Enschede.

Rogers, M., Zhang, Y., Kaber, D., Liang, Y. L., \& Gangakhedkar, S. (2011). The Effects of Visual and Cognitive Distraction on Driver Situation Awareness. Engineering Psychology and Cognitive Ergonomics, 6781, 186-195. 
Rose, A. M. (1989). Acquisition and retention of skills Applications of human performance models to system design (pp. 419-426): Springer.

Rosencrantz, H., Edvardsson, K., \& Hansson, S. O. (2007). Vision zero-Is it irrational? Transportation research part A: Policy and practice, 41(6), 559-567.

Rudin-Brown, C. M., \& Parker, H. A. (2004). Behavioural adaptation to adaptive cruise control (ACC): implications for preventive strategies. Transportation Research Part F: Traffic Psychology and Behaviour, 7(2), 59-76.

Saad, F. (2004). Behavioural adaptations to new driver support systems: Some critical issues. Paper presented at the Systems, Man and Cybernetics, 2004 IEEE International Conference on.

SAE International. Operational Definitions of Driving Performance Measures and Statistics J2944_201506: Society of Automotive Engineers.

SAE International. (2005). Interior Measurement Index J1100: Society of Automotive Engineers.

SAE International. (2013). SAE Levels of driving automation. http://cyberlaw.stanford.edu/loda.

Saffarian, M., De Winter, J., \& Happee, R. (2012). Automated driving: human-factors issues and design solutions. Paper presented at the Proceedings of the Human Factors and Ergonomics Society Annual Meeting.

Salmon, P. M., Stanton, N., Walker, G., \& Green, D. (2006). Situation awareness measurement: A review of applicability for C4i environments. Applied Ergonomics, 37(2), 225-238. doi:DOI 10.1016/ j.apergo.2005.02.001

Salmon, P. M., Stanton, N. A., Walker, G. H., Jenkins, D., Ladva, D., Rafferty, L., \& Young, M. (2009). Measuring Situation Awareness in complex systems: Comparison of measures study. International Journal of Industrial Ergonomics, 39(3), 490-500. doi:10.1016/ j.ergon.2008.10.010

Sarter, N. B., \& Woods, D. D. (1995). How in the world did we ever get into that mode? Mode error and awareness in supervisory control. Human Factors: The Journal of the Human Factors and Ergonomics Society, 37(1), 5-19.

Saust, F., Wille, J. M., Lichte, B., \& Maurer, M. (2011, 5-9 June 2011). Autonomous Vehicle Guidance on Braunschweig's inner ring road within the Stadtpilot Project. Paper presented at the Intelligent Vehicles Symposium (IV), 2011 IEEE.

Schaller, T. (2009). Stauassistenz-Längs-und Querführung im Bereich niedriger Geschwindigkeit. Technische Universität München.

Schaller, T., Schiehlen, J., \& Gradenegger, B. (2008). Congestion Assistance-Supporting the driver in lateral and longitudinal guidance. System development and customer acceptance. Aktive Sicherheit durch Fahrerassistenz, 3(10).

Schieben, A., Griesche, S., Hesse, T., Fricke, N., \& Baumann, M. (2014). Evaluation of three different interaction designs for an automatic steering intervention. Transportation Research Part F: Traffic Psychology and Behaviour, 27, Part B, 238-251. doi:10.1016/j.trf.2014.06.002

Schutte, P. (1999). Complemation: An alternative to automation. Journal of Information Technology Impact, 1(3), 113-118. 
Selcon, S. J. (1990). Decision support in the cockpit: Probably a good thing? Paper presented at the Proceedings of the Human Factors and Ergonomics Society Annual Meeting.

Seppelt, B. D., \& Lee, J. D. (2007). Making adaptive cruise control (ACC) limits visible. International Journal of Human-Computer Studies, 65(3), 192-205. doi:10.1016/j.ijhcs.2006.10.001

Shladover, S. E. (2007). Lane assist systems for bus rapid transit, Volume I: Technology Assessment. Publication RTA 65A0160, US Department of Transportation, Washington, DC.

Smisek, J., Van Paassen, M. M., Mulder, M., \& Abbink, D. A. (2013). Neuromuscular analysis based tuning of haptic shared control assistance for UAV collision avoidance. Paper presented at the World Haptics Conference (WHC), 2013.

Stanton, N. A., Dunoyer, A., \& Leatherland, A. (2011). Detection of new in-path targets by drivers using Stop\&Go Adaptive Cruise Control. Applied Ergonomics, 42(4), 592-601. doi:10.1016/ j.apergo.2010.08.016

Stanton, N. A., \& Young, M. S. (2005). Driver behaviour with adaptive cruise control. Ergonomics, 48(10), 1294-1313.

Strand, N., Nilsson, J., Karlsson, I. C. M., \& Nilsson, L. (2014). Semi-automated versus highly automated driving in critical situations caused by automation failures. Transportation Research Part F: Traffic Psychology and Behaviour, 27(PB), 218-228. doi:10.1016/j.trf.2014.04.005

Summala, H. (2005). Traffic Psychology Theories: Towards Understanding Driving Behaviour and Safety Factors. Paper presented at the International Conference of Traffic and Transport Psychology.

Tan, A., \& Lerner, N. D. (1995). Multiple attribute evaluation of auditory warning signals for in-vehicle crash avoidance warning systems. Retrieved from

Thomas, P., Morris, A. P., Talbot, R., \& Fagerlind, H. (2013). Identifying the causes of road crashes in Europe. Annals of advances in automotive medicine, 57, 13.

Thrun, S. (2010). Toward robotic cars. Communications of the ACM, 53(4), 99-106.

Tideman, M., Van der Voort, M. C., \& Van Arem, B. (2010). A new scenario based approach for designing driver support systems applied to the design of a lane change support system. Transportation Research Part C: Emerging Technologies, 18(2), 247-258.

Toffetti, A., Wilschut, E. S., Martens, M. H., Schieben, A., Rambaldini, A., Merat, N., \& Flemisch, F. (2009) CityMobil: Human factor issues regarding highly automated vehicles on eLane. Transportation Research Record (pp. 1-9).

Trösterer, S., Wurhofer, D., Rödel, C., \& Tscheligi, M. (2014). Using a Parking Assist System Over Time: Insights on Acceptance and Experiences. Paper presented at the Proceedings of the 6th International Conference on Automotive User Interfaces and Interactive Vehicular Applications, Seattle, WA, USA.

UN-ECE. (1968). Convention on Road Traffic. Inland Transport Commitee. Vienna, Austria: United Nations Economic Commission for Europe.

Urhahne, J. A. (2016). Who is driving my car? Development and Analysis of a Control Transition Startegy for Collaborative Automated Congestion Driving. (PhD-thesis), University of Twente, Enschede. 
Urhahne, J. A., Piastowski, P., \& Van der Voort, M. C. (2015). Modelling and Experimental Study for Automated Congestion Driving. Paper presented at the International Symposium on Visual Computing.

Van Arem, B., Van Driel, C. J. G., \& Visser, R. (2006). The impact of cooperative adaptive cruise control on traffic-flow characteristics. leee Transactions on Intelligent Transportation Systems, 7(4), 429-436. doi:10.1109/tits.2006.884615

Van den Beukel, A. P., \& Van der Voort, M. C. (2009). Evaluation of ADAS with a supported-Driver Model for desired Allocation of Tasks between Human and Technology Performance. Berlin: Springer.

Van den Beukel, A. P., \& Van der Voort, M. C. (2011). Human-Centered Challenges and Contribution for the Implementation of Automated Driving Advanced Microsystems for Automotive Applications 2011 (pp. 225-235): Springer.

Van den Beukel, A. P., \& Van der Voort, M. C. (2012). Making automated driving support-Method for Driver-Vehicle task allocation.

Van den Beukel, A. P., \& Van der Voort, M. C. (2013). The influence of time-criticality on Situation Awareness when retrieving human control after automated driving. Paper presented the Intelligent Transportation Systems-(ITSC), 2013 16th International IEEE Conference on.

Van den Beukel, A. P., \& Van der Voort, M. C. (2016a). Does directional illumination support mode awareness and understanding of driver's role? IET Intelligent Transport Systems. [Paper conditionally accepted on 25th September 2016.].

Van den Beukel, A. P., \& Van der Voort, M. C. (2016b). How to Assess Driver's Interaction with Partially Automated Driving - a Framework for Early Concept Assessment. Applied Ergonomics. doi: 10.1016/j.apergo.2016.09.005

Van den Beukel, A. P., Van der Voort, M. C., \& Eger, A. O. (2015). Towards a Framework for Testing Drivers' Interaction with Partially Automated Driving. Paper presented at the IEEE 18th International Conference on Intelligent Transportation Systems (ITSC), Las Palmas.

Van den Beukel, A. P., Van der Voort, M. C., \& Eger, A. O. (2016). Supporting the changing driver's task: Exploration of interface designs for supervision and intervention in automated driving. Transportation Research Part F-Traffic Psychology and Behaviour. doi: 10.1016/j.trf. 2016.09.009

Van der Laan, J. D., Heino, A., \& De Waard, D. (1997). A simple procedure for the assessment of acceptance of advanced transport telematics. Transportation Research Part C: Emerging Technologies, 5(1), 1-10.

Van Driel, C. J. G. (2007). Driver Support in Congestion - An assessment of user needs and impacts on driver and traffic flow. (PhD-thesis), University of Twente, Enschede, The Netherlands.

Van Nunen, E., Kwakkernaat, R., Ploeg, J., \& Netten, B. D. (2012). Cooperative competition for future mobility. Intelligent Transportation Systems, IEEE Transactions on, 13(3), 1018-1025.

Van Waterschoot, B. M., \& Van der Voort, M. C. (2009). Implementing human factors within the design process of advanced driver assistance systems (ADAS) Engineering Psychology and Cognitive Ergonomics (pp. 461-470): Springer.

Van Witsen, M. (2016, march 2016). Zelfrijdende auto's te ambitieus - Automatisch wegverkeer alleen in afgeschermd gebied. De Ingenieur, [in Dutch], 52-53. 
Venkatesh, V. (2000). Determinants of perceived ease of use: Integrating control, intrinsic motivation, and emotion into the technology acceptance model. Information systems research, 11(4), 342365 .

Vis, I. F., \& Harika, I. (2004). Comparison of vehicle types at an automated container terminal. OR Spectrum, 26(1), 117-143.

Vogel, K. (2003). A comparison of headway and time to collision as safety indicators. Accident analysis \& prevention, 35(3), 427-433.

Walker, G. H., Stanton, N. A., \& Young, M. S. (2008). Feedback and driver situation awareness (SA): A comparison of SA measures and contexts. Transportation Research Part F: Traffic Psychology and Behaviour, 11(4), 282-299.

Weber, S., \& Farber, B. (2015). Driver reactions in critical crossing situations. Paper presented at the IEEE 18th International Conference on Intelligent Transportation Systems (ITSC), 2015.

Wiese, E. E., \& Lee, J. D. (2004). Auditory alerts for in-vehicle information systems: The effects of temporal conflict and sound parameters on driver attitudes and performance. Ergonomics, 47(9), 965-986. doi:10.1080/00140130410001686294

Wogalter, M. S., Conzola, V. C., \& Smith-Jackson, T. L. (2002). Research-based guidelines for warning design and evaluation. Applied Ergonomics, 33(3), 219-230. doi:10.1016/S0003-6870(02) 00009-1

Wogalter, M. S., Kalsher, M. J., Frederick, L. J., \& Magurno, A. B. (1998). Hazard Level Perceptions of Warning Components and Configurations. International Journal of Cognitive Ergonomics, 2(12), 123-143.

Woods, D. D., Dekker, S., Cook, R. I., Johannesen, L. J., \& Sarter, N. B. (2010). Behind human error. Farnham: Ashgate Publishing, Ltd.

Young, M. S., Stanton, N. A., \& Harris, D. (2007). Driving automation: learning from aviation about design philosophies. International Journal of Vehicle Design, 45(3), 323-338.

Zijlstra, F. R. H. (1993). Efficiency in work behaviour: A design approach for modern tools. Delft: Delft University Press. 
Appendices 
Appendix A Rating Scale Mental Effort (RSME)

Please indicate, by marking the axis below, how much effort it took for you to complete the task you've just finished.

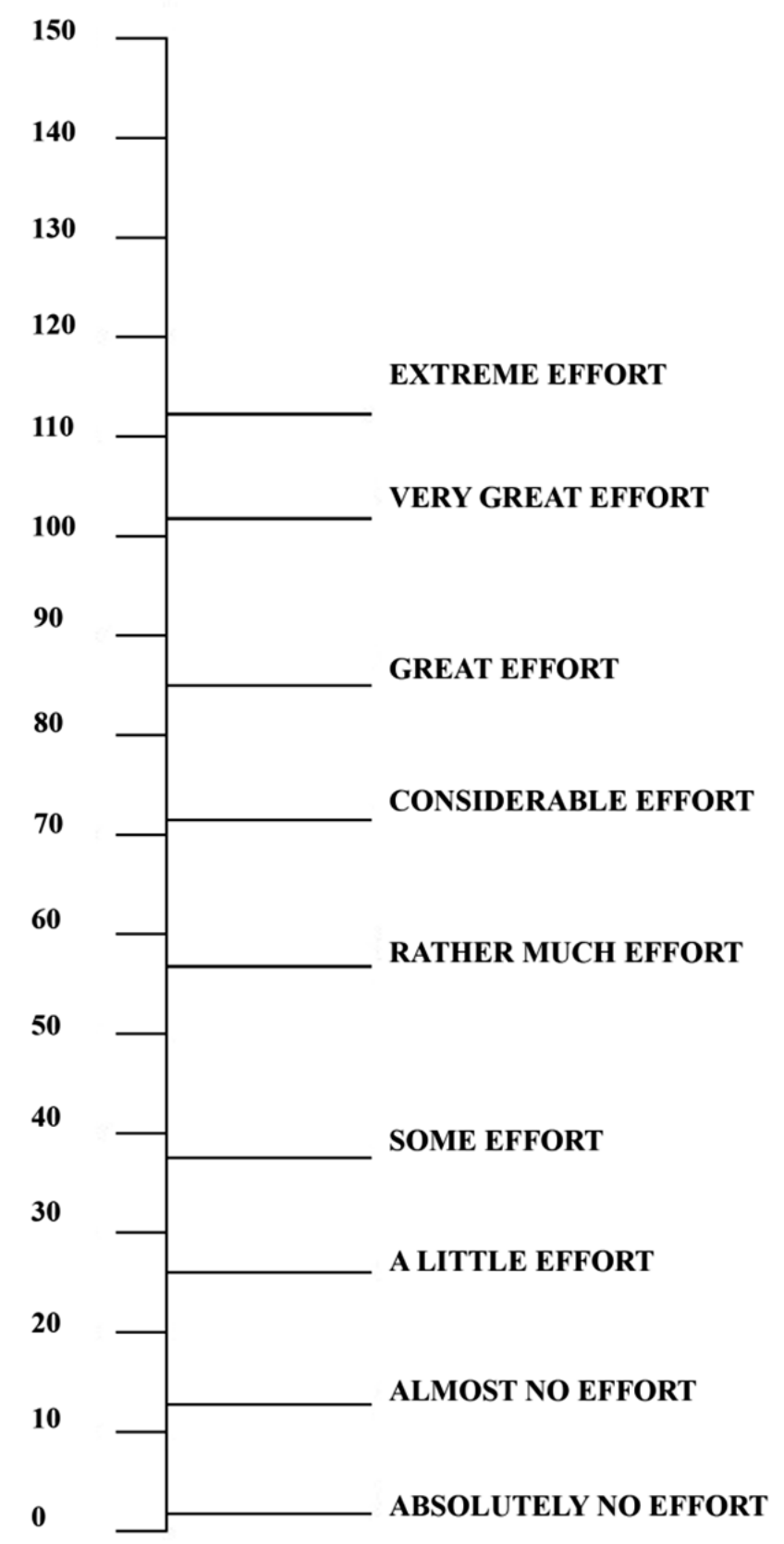




\section{Appendix B Questionnaire internet survey}

Produced with www.qualtrics.com

Note. Order of all video-clips with questions was randomized

Q1. [UK] Welcome. The following questions will tell us more about your opinion with regard to automated driving. Vehicles are being developed which are able to drive automatically in some specific situations. Such situations will be shown to you with a few videoclips. The first video will give explanation and instructions. The questionnaire will take about 10 minutes. Before we start I like to ask a few questions about your experience with car driving. Your opinion will be highly appreciated.

[NL] Welkom. De vragen in deze enquete geven ons inzicht in uw mening over automatisch rijden. Er worden auto's ontwikkeld die in sommige omstandigheden automatisch kunnen rijden. Enkele korte videos tonen u dergelijke omstandigheden. De eerste video geeft uitleg en een korte instructie. Het beantwoorden duurt ongeveer 10 minuten in totaal. Voordat we starten wil ik u graag enkele vragen stellen over uw rij-ervaring. Uw mening wordt erg gewaardeerd.

Q2. Do you possess a driving licence?

Bezit u een rijbewijs?

Q3. Do you have a car?

Beschikt u over een auto?

- Yes, I privately own a car. Ja, ik bezit zelf een auto

- Yes, I have a car from my employer. Ja, ik heb een auto via mijn werkgever

o No. Nee

o Something different (please explain). lets anders (geef graag uitleg).

Q4. For what purpose do you drive dominantly? Voor welk doel gebruikt u overwegend de auto?

o For work (like commuting, business trips, customer visits, delivery, etc.). Voor het werk (woon-werk verkeer, zakenreizen, klant bezoeken, goederen vervoer, etc.).

o For private purposes (shopping, visiting family and friends, holidays, etc.) Voor privé doeleinden (boodschappen, familie en vrienden bezoeken, vakantie, etc.)

Q5. How old (in years) is the vehicle you drive most often?

Hoe oud (aantal jaar) is de auto die $u$ het meest gebruikt? 
Q6. How is the vehicle (which you most often drive) equipped? (multiple answers are possible). Waarover beschikt de auto waarin $u$ het meeste rijdt? (meerdere antwoorden mogelijk).

o Automatic gear box Automatische versnelling

o Build-in navigation. Geïntegreerd navigatie systeem

o Cruise Control. Cruise control (ook wel tempomaat genoemd)

o Adaptive Cruise Control. Adaptieve cruise control (houdt ook afstand automatisch)

o Lane change assistant. Rij-strook wissel assistant

o Traffic sign recognition. Verkeersbord herkenning

o Heads-up display (projectie in voorruit)

o Parking sensors. Parkeersensoren

o Automated parallel parking. Automatisch parallel inparkeren

o Additional driving-related equipment. Nog ander uitrusting (t.b.v. rijden)

Q7. What is your age? Hoe oud bent $U$ ?

\section{Introduction (video-clip)}

Q9. Watch the video above (it includes sound) to receive a short explanation about automated driving. It also introduces the questions which come next.

Bekijk bovenstaande video (inclusief geluid) voor een uitleg over automatisch rijden. Het geeft ook een toelichting op de vragen die erna komen.

>> video-clip with explanation. Spoken introduction with Dutch subtitles<<

"Thank you for participating. Imagine that you are the driver of a car that drives automatically. That means that the car keeps distance and keeps you on the lane. This automation requires a car in front to follow and is available at low speeds. Nonetheless, you remain responsible for safe driving. Situations could happen which are difficult for driving automatically, or situations in which the car is not able to drive automatically. Then you, as a responsible driver, should pay extra attention, or you should take over the driving task. To help you, the vehicle will give signals to indicate if your attention or intervention is needed. These signals are based on sound, illumination or both. With the next questions, I ask you to watch videos and I am curious what you think the signals mean to you. This will help me to research how such vehicles should communicate with their drivers. Thanks again and regards from Arie Paul van den Beukel."

\section{A01p (video-clip) scenario: Approaching complex road (1a)}

Q11. 1A01

Watch the video above (it includes sound) and click ">>" when you are finished.

Bekijk bovenstaande video (inclusief geluid) en klik wanneer u klaar bent op ">>". 


\section{Q13. When the video stopped, what describes your required role the best?}

\section{Wat omschrijft de voor u vereiste rol het beste toen de video stopte?}

o I have no necessity to do something. Ik heb geen noodzaak om iets te doen.

o I should watch traffic carefully. Ik moet zorgvuldig opletten op het verkeer

o I should take over driving. Ik moet de rijtaak overnemen.

o I don't know. Ik weet het niet.

o None of the above (please explain). Géén van bovenstaande (geef graag uitleg).

Q14. How hazardous was previous situation in your opinion? Please use the slider ranging from 1 "not at all hazardous" to 9 "extremely hazardous".

Hoe gevaarlijk vond u voorgaande situatie? Gebruik s.v.p. onderstaande schuifknop variërend van 1 "helemaal niet gevaarlijk" tot 9 "extreem gevaarlijk".

>>slider bar $<<<<$

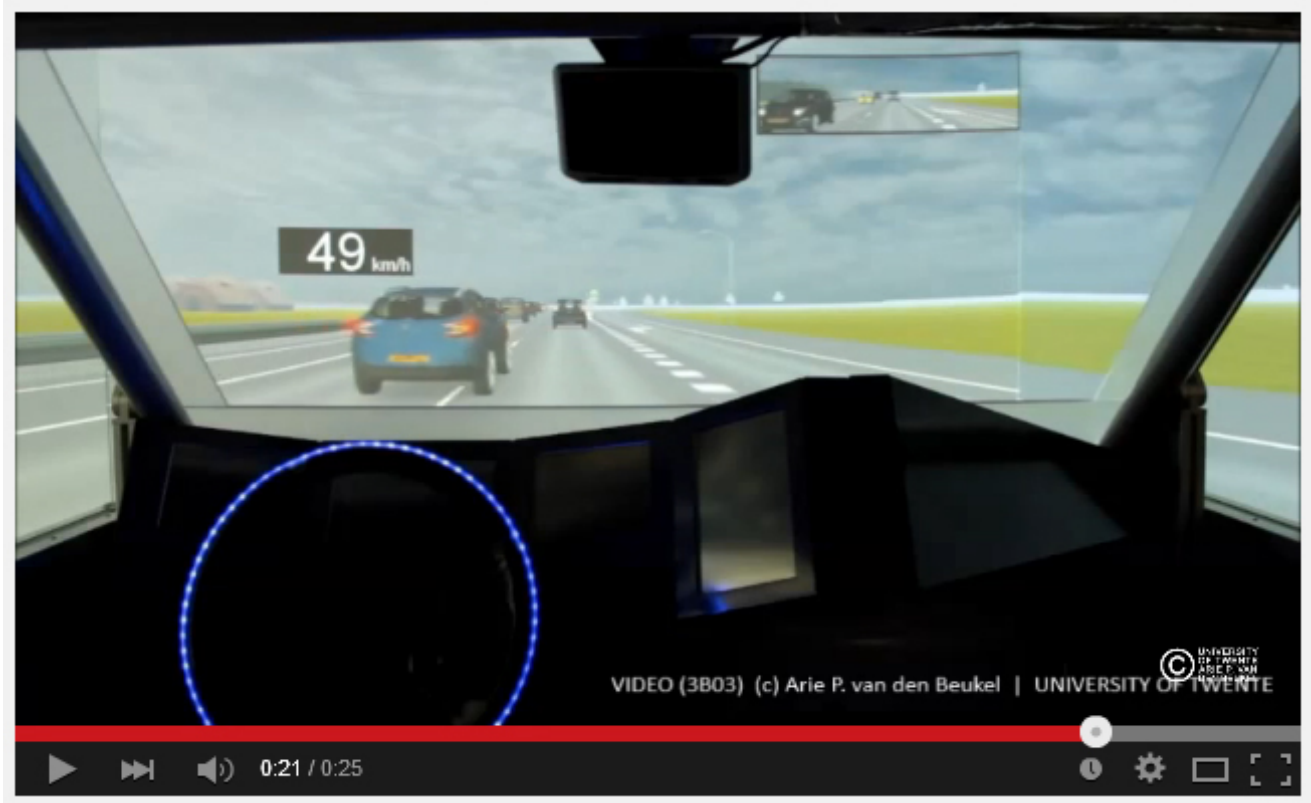

3B03p (video-clip) Scenario: Close cut-in (3b)

Q15. 3B03

Watch the video above (it includes sound) and click ">>" when you are finished.

Bekijk bovenstaande video (inclusief geluid) en klik wanneer u klaar bent op ">>".

\section{Q17. What changed shortly before the video stopped?}

\section{Wat veranderde er kort voordat de video stopte?}

o The system became available. Het systeem werd beschikbaar

0 The system became active. Het systeem werd actief.

o The system became unavailable. Het system was niet meer beschikbaar.

o The system stopped. Het systeem stopte.

o I don't know. Ik weet het niet.

o Something else (please explain). lets anders (geef graag uitleg).

2A03p (video-clip) Scenario: Vehicle passing illegally (2a) 
Q18. 2A03

Watch the video above (it includes sound) and click ">>" when you are finished.

Bekijk bovenstaande video (inclusief geluid) en klik wanneer u klaar bent op ">>".

Q20. What changed shortly before the video stopped?

Wat veranderde er kort voordat de video stopte?

o The system became available. Het systeem werd beschikbaar

0 The system became active. Het systeem werd actief.

o The system became unavailable. Het system was niet meer beschikbaar.

o The system stopped. Het systeem stopte.

o I don't know. Ik weet het niet.

o Something else (please explain). lets anders (geef graag uitleg).

Q21. What was in previous situation the reason why the system gave a signal (or signals)? Wat was in de voorgaande situatie de reden waarom het systeem een signaal (of signalen) gaf?

2B01p (video-clip) Scenario: Merge-out target-vehicle

Q22. 2B01

Watch the video above (it includes sound) and click ">>" when you are finished.

Bekijk bovenstaande video (inclusief geluid) en klik wanneer u klaar bent op ">>".

Q24. When the video stopped, what describes your required role the best?

Wat omschrijft de voor u vereiste rol het beste toen de video stopte?

o I have no necessity to do something. Ik heb geen noodzaak om iets te doen.

o I should watch traffic carefully. Ik moet zorgvuldig opletten op het verkeer

o I should take over driving. Ik moet de rijtaak overnemen.

o I don't know. Ik weet het niet.

o None of the above (please explain). Géén van bovenstaande (geef graag uitleg).

Q25. How hazardous was previous situation in your opinion? Please use the slider ranging from 1 "not at all hazardous" to 9 "extremely hazardous".

Hoe gevaarlijk vond u voorgaande situatie? Gebruik s.v.p. onderstaande schuifknop variërend van 1 "helemaal niet gevaarlijk" tot 9 "extreem gevaarlijk".

>>slider bar $<<<<$

\section{H2B3p (video-clip) Scenario: Approaching main road}

Q26. H2B3

Watch the video above (it includes sound) and click ">>" when you are finished.

Bekijk bovenstaande video (inclusief geluid) en klik wanneer u klaar bent op ">>". 
Q28. When the video stopped, what describes your required role the best?

Wat omschrijft de voor u vereiste rol het beste toen de video stopte?

o I have no necessity to do something. Ik heb geen noodzaak om iets te doen.

o I should watch traffic carefully. Ik moet zorgvuldig opletten op het verkeer

o I should take over driving. Ik moet de rijtaak overnemen.

o I don't know. Ik weet het niet.

o None of the above (please explain). Géén van bovenstaande (geef graag uitleg).

Q29. What was in previous situation the reason why the system gave a signal (or signals)? Wat was in de voorgaande situatie de reden waarom het systeem een signaal (of signalen) gaf?

AV01 (video-clip) Scenario: System becomes available Q30. AV01

Watch the video above (it includes sound) and click ">>" when you are finished.

Bekijk bovenstaande video (inclusief geluid) en klik wanneer u klaar bent op ">>".

Q32. What changed shortly before the video stopped?

Wat veranderde er kort voordat de video stopte?

o The system became available. Het systeem werd beschikbaar

o The system became active. Het systeem werd actief.

o The system became unavailable. Het system was niet meer beschikbaar.

o The system stopped. Het systeem stopte.

o I don't know. Ik weet het niet.

o Something else (please explain). lets anders (geef graag uitleg).

Q29. What was in previous situation the reason why the system gave a signal (or signals)? Wat was in de voorgaande situatie de reden waarom het systeem een signaal (of signalen) gaf?

1A01s (video-clip) scenario: Approaching complex road (1a)

Q34. 1A01

Watch the video above (it includes sound) and click ">>" when you are finished.

Bekijk bovenstaande video (inclusief geluid) en klik wanneer u klaar bent op ">>". 


\section{Q36. What changed shortly before the video stopped?}

Wat veranderde er kort voordat de video stopte?

o The system became available. Het systeem werd beschikbaar

0 The system became active. Het systeem werd actief.

o The system became unavailable. Het system was niet meer beschikbaar.

o The system stopped. Het systeem stopte.

o I don't know. Ik weet het niet.

o Something else (please explain). lets anders (geef graag uitleg).

Q37. What was in previous situation the reason why the system gave a signal (or signals)? Wat was in de voorgaande situatie de reden waarom het systeem een signaal (of signalen) gaf?

3B03s (video-clip) scenario: Close cut-in

Q38. 3B03

Watch the video above (it includes sound) and click ">>" when you are finished.

Bekijk bovenstaande video (inclusief geluid) en klik wanneer u klaar bent op ">>".

Q40. When the video stopped, what describes your required role the best?

Wat omschrijft de voor u vereiste rol het beste toen de video stopte?

o I have no necessity to do something. Ik heb geen noodzaak om iets te doen.

o I should watch traffic carefully. Ik moet zorgvuldig opletten op het verkeer

o I should take over driving. Ik moet de rijtaak overnemen.

o I don't know. Ik weet het niet.

o None of the above (please explain). Géén van bovenstaande (geef graag uitleg).

2A03s (video-clip) Scenario: Vehicle passing illegally

Q41. 2A03

Watch the video above (it includes sound) and click ">>" when you are finished.

Bekijk bovenstaande video (inclusief geluid) en klik wanneer u klaar bent op ">>".

Q43. When the video stopped, what describes your required role the best?

Wat omschrijft de voor u vereiste rol het beste toen de video stopte?

o I have no necessity to do something. Ik heb geen noodzaak om iets te doen.

o I should watch traffic carefully. Ik moet zorgvuldig opletten op het verkeer

o I should take over driving. Ik moet de rijtaak overnemen.

o I don't know. Ik weet het niet.

o None of the above (please explain). Géén van bovenstaande (geef graag uitleg). 
Q44. How hazardous was previous situation in your opinion? Please use the slider ranging from 1 "not at all hazardous" to 9 "extremely hazardous".

Hoe gevaarlijk vond u voorgaande situatie? Gebruik s.v.p. onderstaande schuifknop variërend van 1 "helemaal niet gevaarlijk" tot 9 "extreem gevaarlijk".

>>slider bar $<<<<$

2B01s (video-clip) scenario: Merge-out target vehicle

Q45. 2B01

Watch the video above (it includes sound) and click ">>" when you are finished.

Bekijk bovenstaande video (inclusief geluid) en klik wanneer u klaar bent op ">>".

Q47. What changed shortly before the video stopped?

Wat veranderde er kort voordat de video stopte?

o The system became available. Het systeem werd beschikbaar

0 The system became active. Het systeem werd actief.

o The system became unavailable. Het system was niet meer beschikbaar.

o The system stopped. Het systeem stopte.

o I don't know. Ik weet het niet.

o Something else (please explain). lets anders (geef graag uitleg).

Q48. What was in previous situation the reason why the system gave a signal (or signals)? Wat was in de voorgaande situatie de reden waarom het systeem een signaal (of signalen) gaf?

Q49. You answered the last question. Your opinion is highly appreciated and will be used to develop driver-support that fit to drivers. If you have any ideas, comments or suggestions please enter them below.

$U$ heeft de laatste vraag beantwoord. Wij waarderen uw mening en gebruiken de antwoorden om rij-ondersteuning te ontwikkelen die aans/uit op de wensen van bestuurders. Indien u ideeën, reacties of suggesties heeft, kunt u die graag hieronder invullen. 
Appendix C Questionnaire: Situation Awareness Global Assessment Technique (SAGAT)

Questions refer to probes in the simulated driving environment (Questions in Dutch)

Example taken from framework-study (Chapter 5)

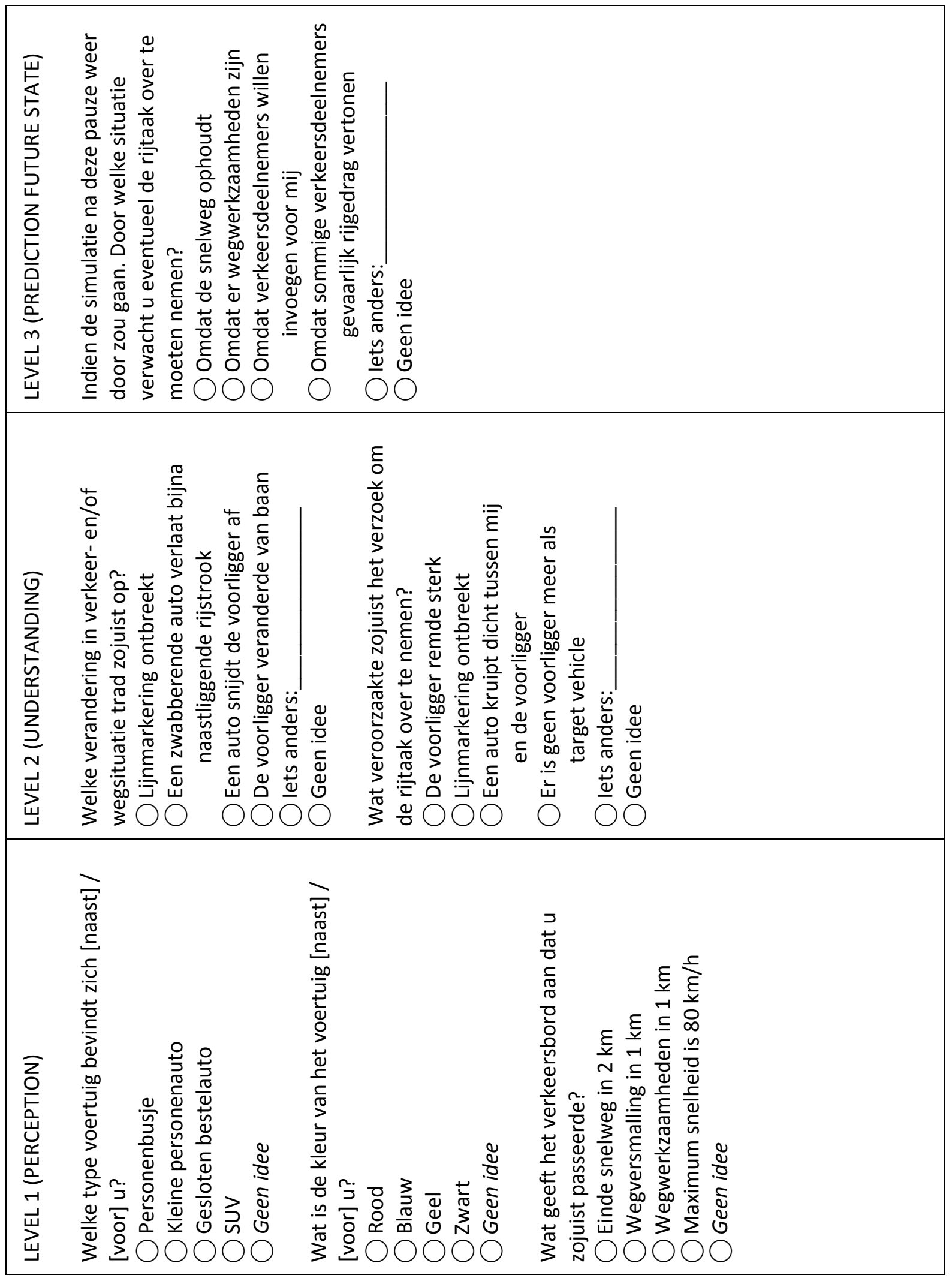




\section{Appendix D Questionnaire: Situation Awareness Rating Technique (SART)}

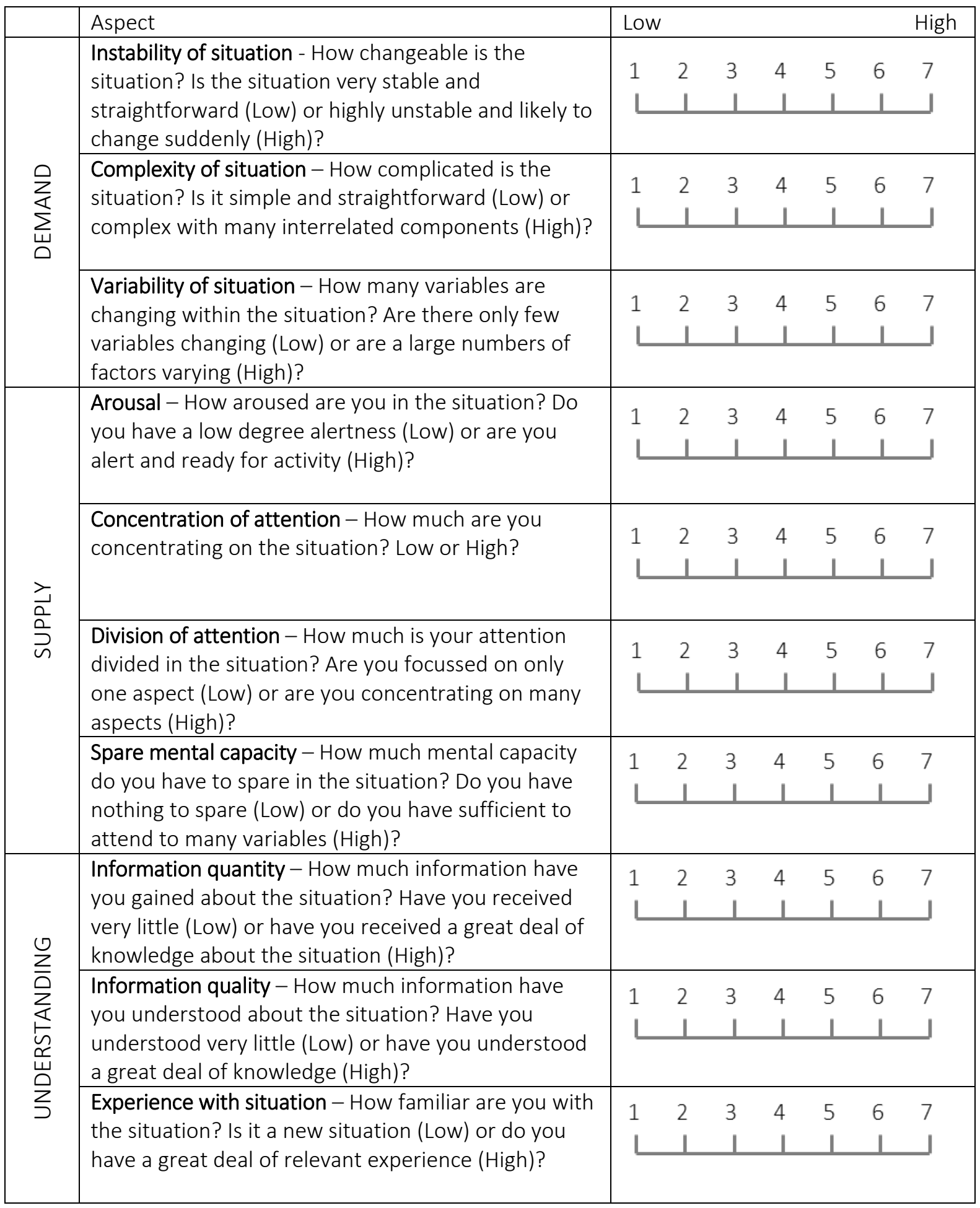

